\title{
Spatial and Temporal Analysis of Hydraulic Conductivity, Snow Depth and Soil Properties of a Bioretention System
}

by

\author{
Alwish Ranjith John Gnanaraj
}

A thesis submitted in conformity with the requirements

for the degree of Master of Applied Science

Department of Civil and Mineral Engineering University of Toronto

(C) Copyright by Alwish Ranjith John Gnanaraj 2018 


\title{
Spatial and Temporal Analysis of Hydraulic Conductivity, Snow Depth and Soil Properties of a Bioretention System.
}

\author{
Alwish Ranjith John Gnanaraj \\ Master of Applied Science \\ Department of Civil and Mineral Engineering \\ University of Toronto
}

2018

\begin{abstract}
Bioretention Cells (BC) are a Low Impact Development technology that provide distributed storm water management near to its source. Most research envisages BC as a black box with ambiguous processes between the input and the output. This thesis aims to consider BCs as heterogeneous systems with physical processes that vary both spatially and temporally.
\end{abstract}

For this study, a 5-year-old BC at Kortright Centre for Conservation in Vaughan, Ontario is used as an investigation area. The following results were observed. $\mathrm{D}_{30}$ and $\mathrm{D}_{60}$ were lower in the central flow path due to sedimentation and suspended solids deposition. Organic content was negatively correlated with bulk density. $\mathrm{K}_{\text {sat }}$ in the central pathway region and non-central pathway region showed a mild rise during and a mild decrease respectively during warm winter days possibly due to freeze-thaw action. However, after statistical outliers were identified and removed from the $\mathrm{K}_{\text {sat }}$ data, this effect was not observed. 


\section{Acknowledgments}

First and foremost, I would like to thank my Lord Jesus Christ for his grace and blessings throughout this research.

I wholeheartedly thank my research supervisor Dr. Jennifer Drake for offering me the opportunity to carry out research. It would not have been possible to produce this thesis without her support, suggestions, constructive feedback, and professionalism. I would also like to thank Dr. Elodie Passeport for providing many helpful suggestions and for being the second reader.

I would like to thank the Sustainable Technologies Evaluation Program (STEP) at the Toronto and Region Conservation Authority (TRCA) for providing the Bioretention Cell and for collaborating with me on this research. I would also like to acknowledge TRCA staff Mark Hummel, Jacob Kloeze, Tim Van Seaters, Christy Graham, and Dean Young for technical support and help with field work.

Financial support for this work was provided by NSERC, MITACS and the University of Toronto.

I would also like to acknowledge undergraduate interns Alexander Tonelli, Eric Wang, Redwan Baba and Diego Domingo for carrying out data collection during the summers of 2017 and 2018. My sincere thanks go to my colleagues Jeff Marvin, Kirti Sehgal, Yin Yin, Sylvie Spraakman, Leandra Rhodes, Kelsey Smyth, and Ceren Akdeniz who also helped with data collection.

I should not forget to express my gratitude to my friends (Anthony, Simon, Jeremy, Emma, Corina, Spencer, Pratik, Mohit, and Quan) for volunteering their time to help me with various issues involving statistics, engineering, language, and philosophy during the past two years.

Last but not least, I would also like to thank my parents and sisters for their love, prayers, and continued support. 


\section{Table of Contents}

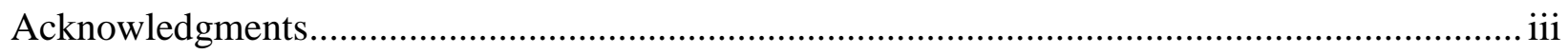

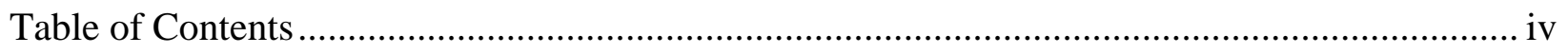

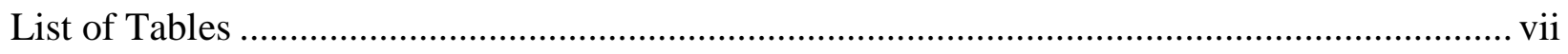

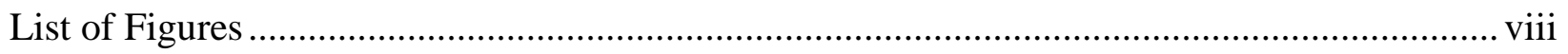

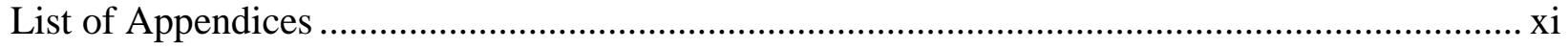

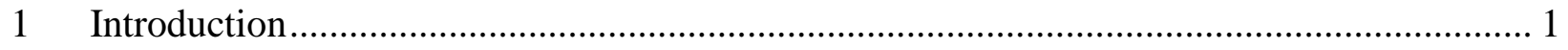

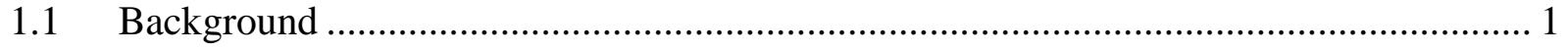

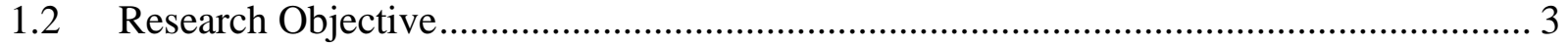

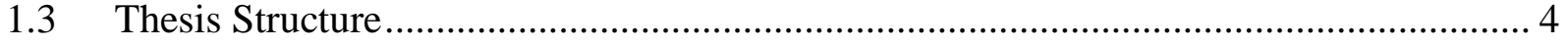

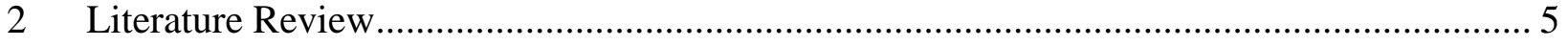

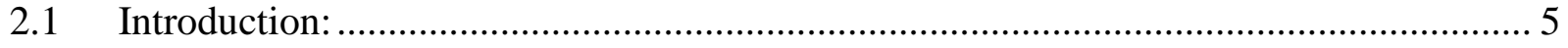

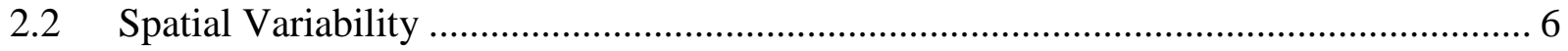

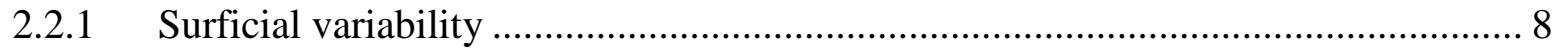

2.2.2 Vertical variability ................................................................................. 13

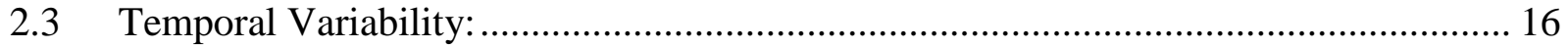

2.3.1 Effect of freeze thaw cycles on natural soil:.................................................... 16

2.3.2 Effect of freeze thaw cycles on BC media:......................................................... 17

2.3.3 Effect of aging on BC: .......................................................................... 18

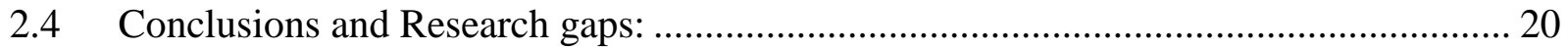

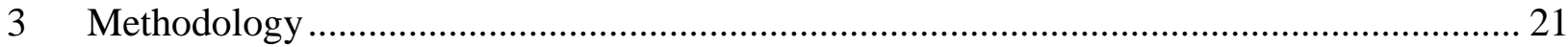

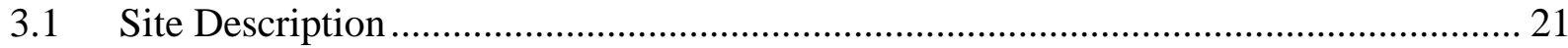

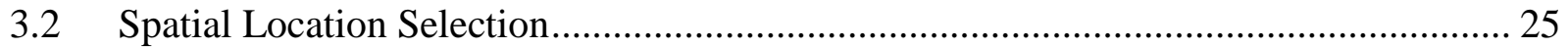

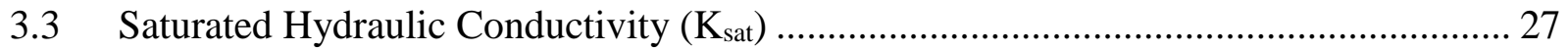

3.3.1 Guelph Permeameter (GP) ...................................................................... 27

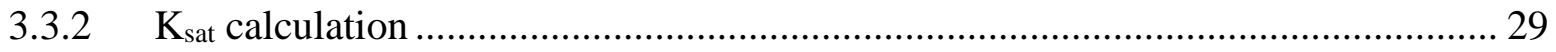

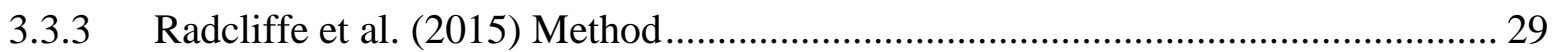

3.3.4 Elrick and Reynolds (1992) Method.................................................................... 31

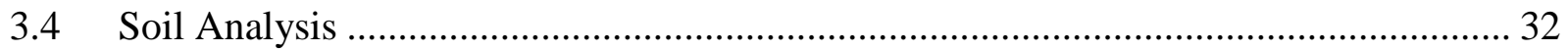

3.4.1 Bulk density, moisture content and organic content ........................................... 32

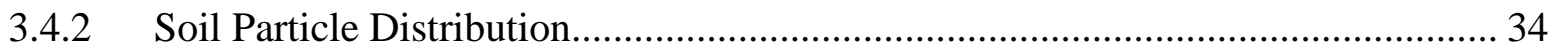

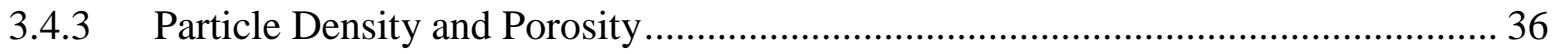

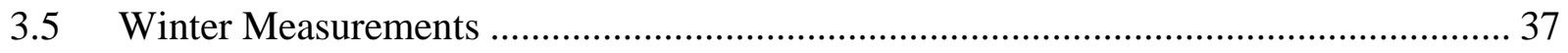




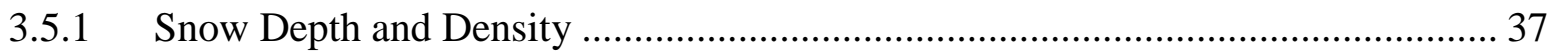

3.5.2 Frost depth ............................................................................................... 40

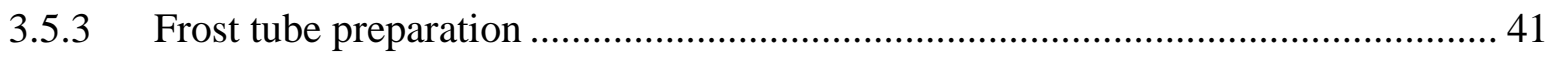

3.5.4 Surface and subsurface water levels and temperatures ....................................... 43

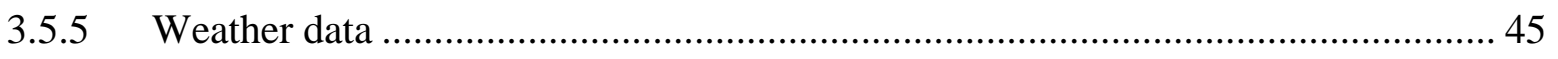

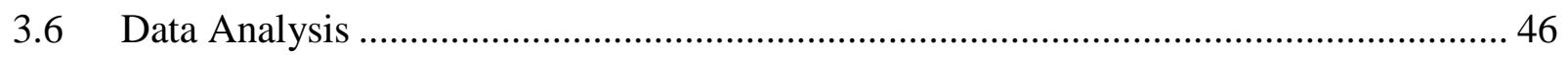

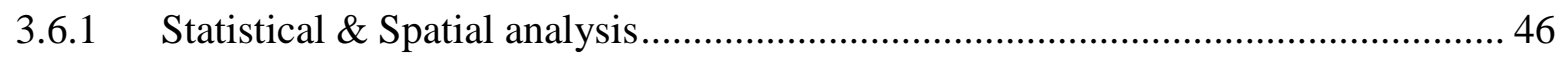

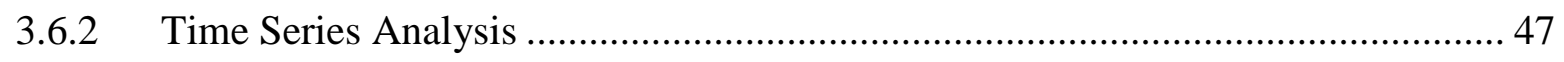

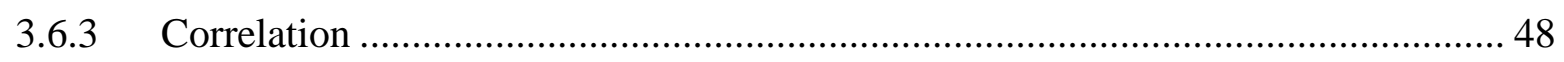

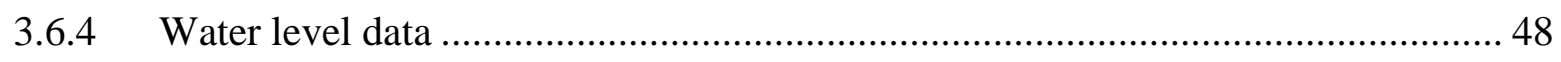

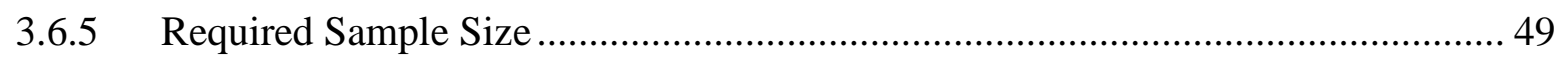

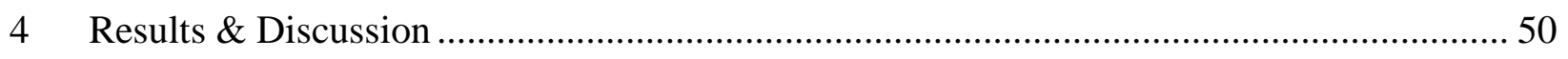

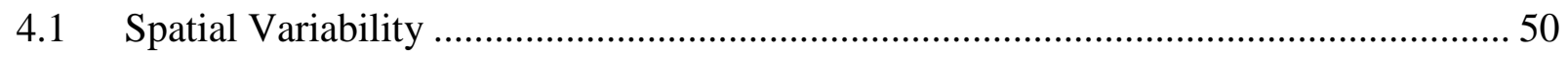

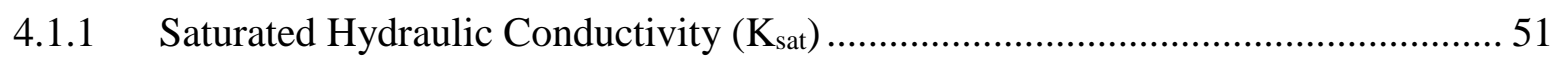

4.1.2 Bulk Density, Moisture Content and Organic Content........................................... 54

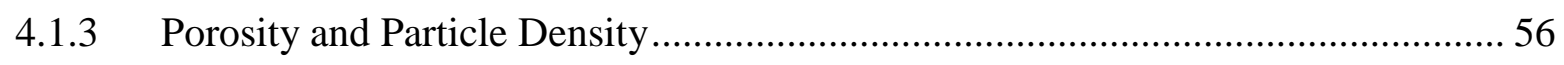

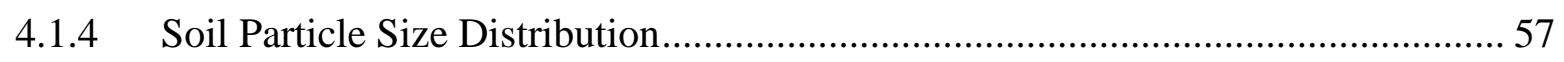

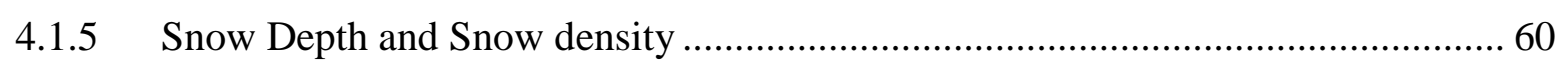

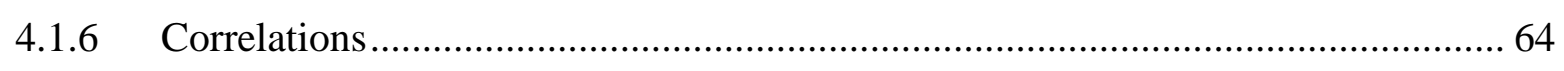

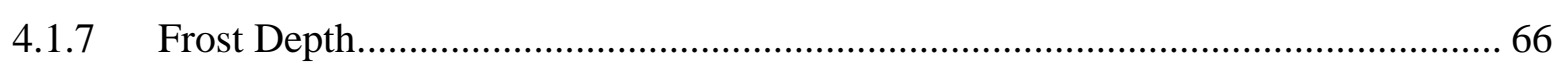

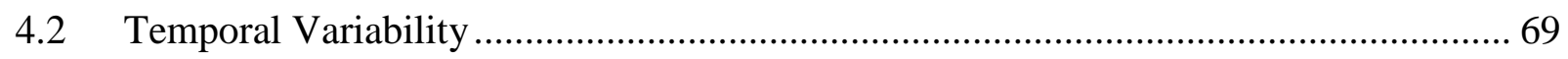

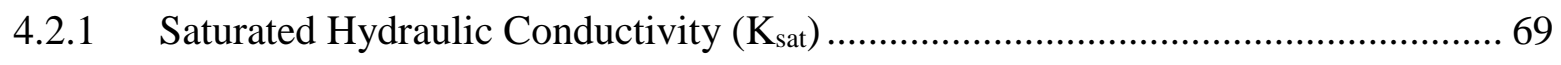

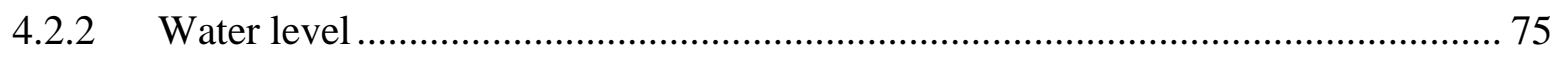

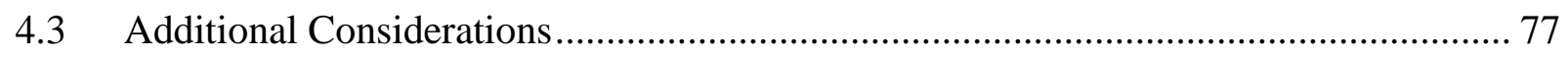

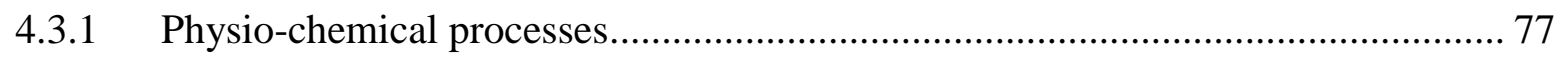

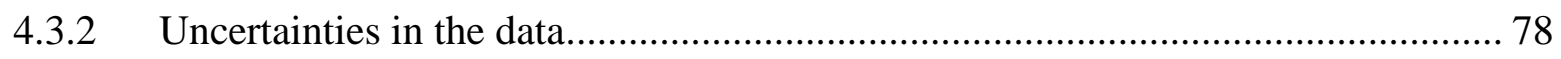

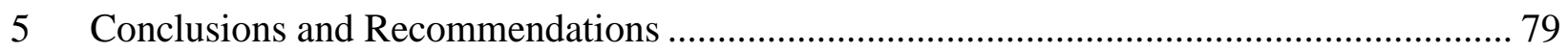

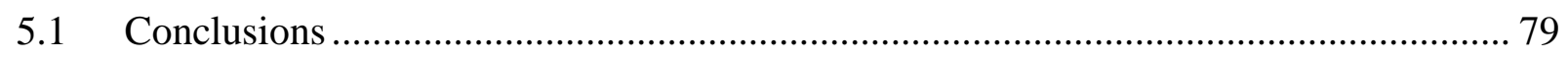

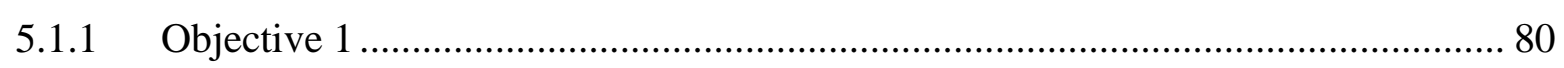

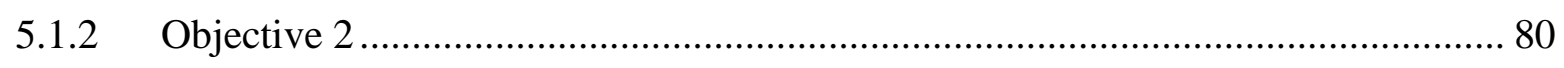

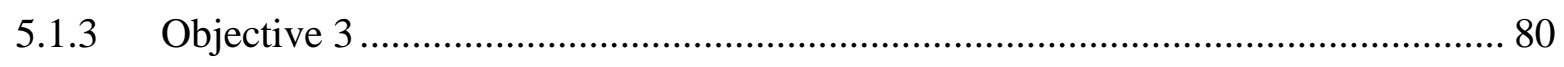

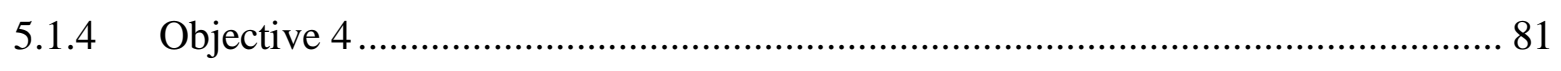

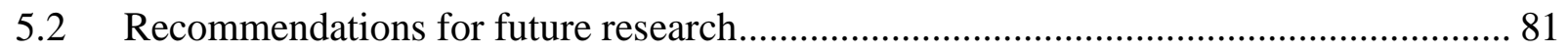

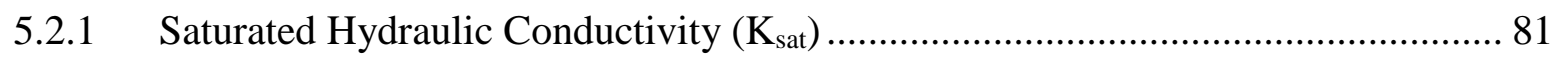




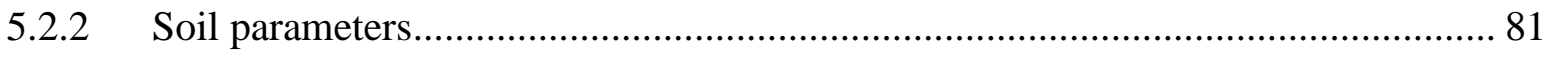

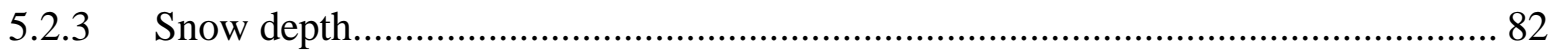

5.2.4 Water levels ........................................................................................ 82

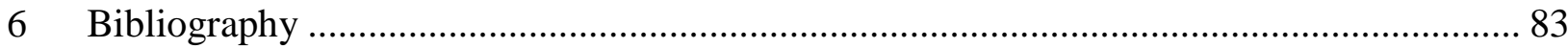

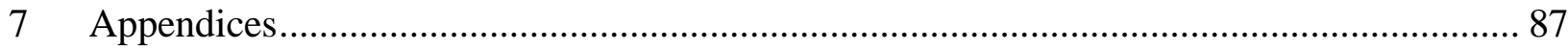

7.1 Contour Map Generation Matlab Code …………....................................................... 87

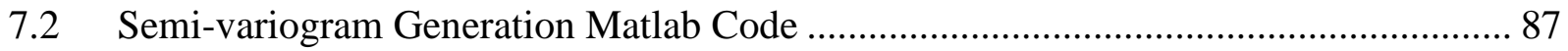

7.3 Assumptions for Grubbs test ................................................................................ 87

7.4 Assumptions for Wilcoxon signed-rank test .......................................................... 88

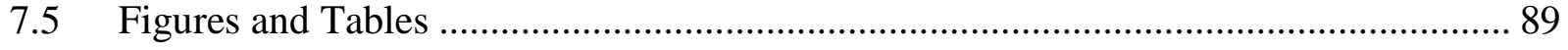




\section{List of Tables}

Table 2-1: Spatial information available in various papers, the intent and the type of study........ 7

Table 2-2: Models used in the considered papers ................................................................. 7

Table 2-3 Calculated porosity (n) values and Hydraulic Conductivity Slope (HCO) values for sand media with different column depths - Lynn et al. (2018) .............................................. 13

Table 2-4: Infiltration rates with respect to number of freeze thaw cycles - Baratta (2013) ....... 17

Table 3-1: Points considered for snow depth and soil parameters measurement ...................... 26

Table 3-2 Infiltration rate measurement dates, antecedent conditions and conditions during data

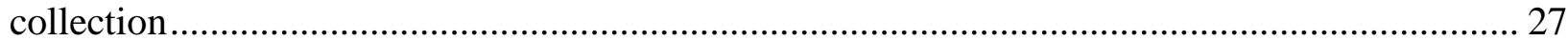

Table 3-3: Snow depth and density data collection dates and antecedent conditions ................. 38

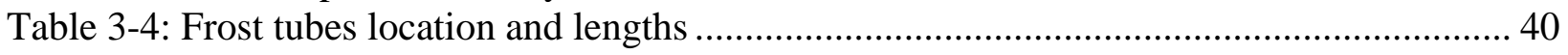

Table 3-5: Frost depth measurements dates and antecedent conditions .................................. 42

Table 4-1: Summary table for soil parameters, $\mathrm{K}_{\text {sat }}$ and Snow Depth ..................................... 51

Table 4-2: Summary table for Ksat (cm/s) - Radcliffe method and Elrick \& Reynolds method . 52

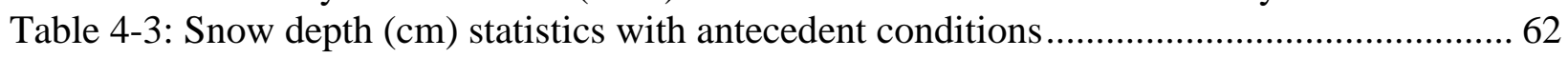

Table 4-4: Snow Density with date, time and antecedent conditions..................................... 62

Table 4-6: Frost depth $(\mathrm{cm})$ from ground surface with dates and locations with antecedent

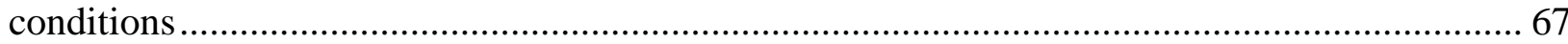

Table 4-7: $\mathrm{K}_{\text {sat }}(\mathrm{cm} / \mathrm{s})-$ Radcliffe method - Statistics and Antecedent Conditions ..................... 73

Table 4-8: Results of Grubbs test for outliers ...................................................................... 74

Table 4-9: Event statistics - Water levels ......................................................................... 76

Table 7-1: Ryan Joiner $\mathrm{P}$ value for temporal $\mathrm{k}_{\mathrm{sat}}$ data (normality test)................................. 87

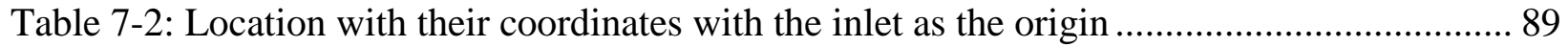

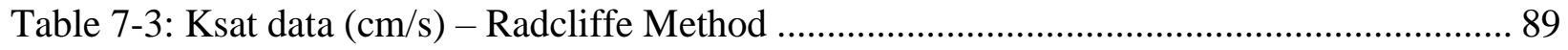

Table 7-4: Ksat data (cm/s) - Elrick and Reynolds method ................................................. 90

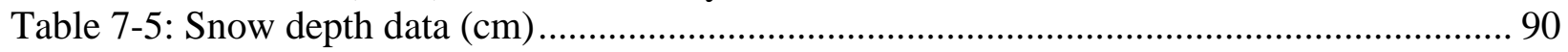

Table 7-6: Soil Particle Distribution data by location (Weight in grams)............................... 91

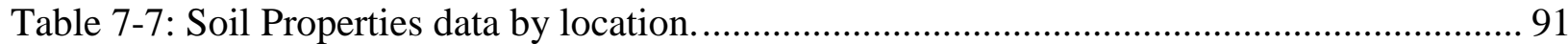

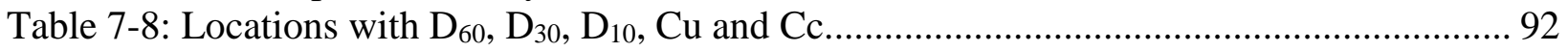




\section{List of Figures}

Figure 1-1 Conceptual diagram with the front view of the BC .............................................. 2

Figure 2-1: Spatial $\mathrm{K}_{\text {sat }}$ map of University of Minnesota BC and the parallel excel data used to

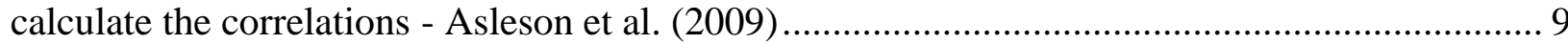
Figure 2-2: Three-dimensional view of the model configuration with 14 sand plugs and the range of $\mathrm{K}_{\text {sat }}$ values - Chavez et al. (2013). 10

Figure 2-3: BC Zn distribution in comparison to USEPA recommended thresholds, forebay

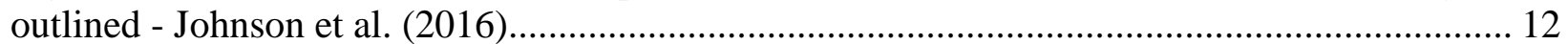

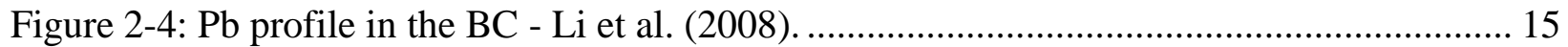

Figure 2-5: Filter media frost penetration for a range of LID systems Roseen et al. (2009)....... 15

Figure 3-1: BC and the catchment area (From Google Maps) ............................................... 21

Figure 3-2: BC location - left and Layers \& their dimensions in the BC - right (Sustainable

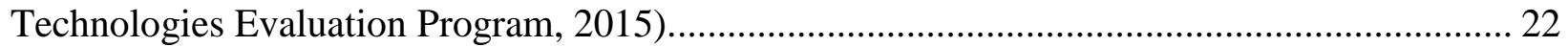

Figure 3-3: Front view of the BC showing the inlet and the marked locations .......................... 22

Figure 3-4: Rubber layer in the BC - Top View - Left and Cross-sectional View - Right

(Graham, 2016) ................................................................................................. 23

Figure 3-5: Map of focal points (shown in numbers) of the pictures shown in Figure 3-5 with

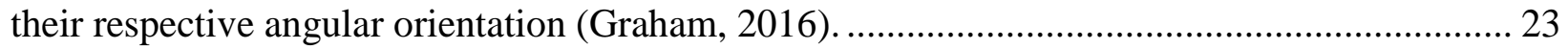

Figure 3-6: BC construction pictures numbered (Young, 2018). ......................................... 24

Figure 3-7: Map of points with their locations with respect to the inlet.................................. 26

Figure 3-8: A GP with its parts labelled (Eijkelkamp Agrisearch Equipment, 2011)................ 28

Figure 3-9: GP in the BC (Left) and a $15 \mathrm{~cm}$ deep hole for the GP (Right)........................... 29

Figure 3-10 Eight wet soil samples in porcelain dishes to be dried in the oven (Left) and the oven

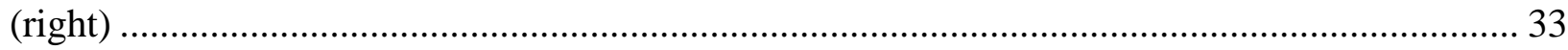

Figure 3-11: Weighing the soil samples after drying (left), before breaking (middle) and after

breaking (right). ............................................................................................... 34

Figure 3-12: Soil being poured into the fine sieve set (left) and soil retained in sieve no. 16 after

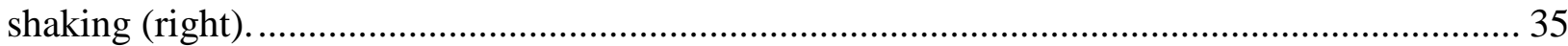

Figure 3-13: Sample holder \& the Quantachrome Stereopycnometer (left) and the soil sample

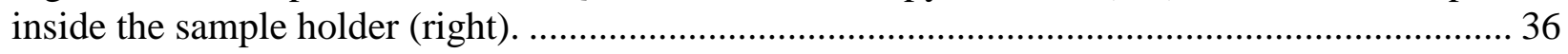

Figure 3-14: Snow density sampling using graduated cylinder and trowel (left) and the graduated

cylinder being weighed in a weighing machine (right). ...................................................... 39

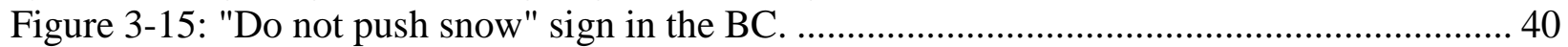

Figure 3-16: Locations of the frost tubes with respect to the inlet (origin)............................ 41

Figure 3-17: An installed frost tube during winter at point $\mathrm{O}$ near the inlet of the $\mathrm{BC}$ (left) and

coloured water being poured into transparent tube to be installed inside the frost tube (right). .. 42

Figure 3-18: Frost tube design (Institute of Northern Engineering, 2011) ............................... 43

Figure 3-19: Surface water level logger being pulled out of the well (left) and ice surrounding the

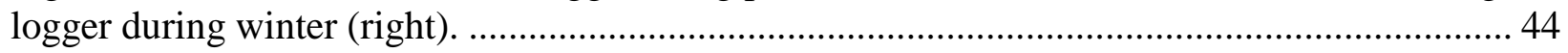

Figure 3-20: Surface and ground water level loggers with their respective elevations with the

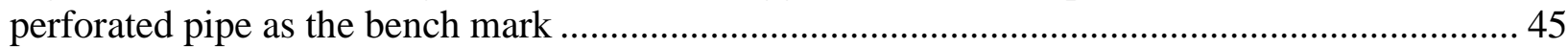

Figure 3-21: Ice inside the Geonor Weighing Gauge bucket with anti-freeze (left) and the

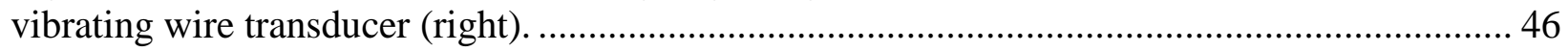

Figure 4-1: Moisture Content (top) and $\mathrm{K}_{\text {sat }}-$ Radcliffe Method (bottom) ............................... 53

Figure 4-2: Organic Content (top) and Bulk Density (bottom) ............................................. 55 
Figure 4-3: Porosity (top) and Particle Density (bottom)

Figure 4-4: Soil textural triangle classification with BC soil proportions plotted (United States

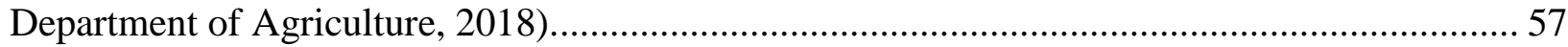

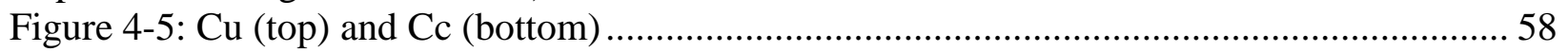

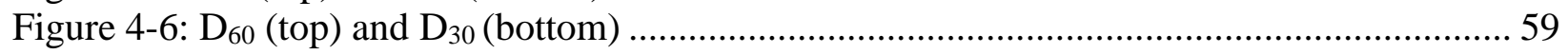

Figure 4-7: Snow depth before snow melt spatial map (top) and picture (bottom) on December 22, 2016, before thaw.

Figure 4-8: Snow depth after snow melt spatial map (top) and picture (bottom) on January 19, 2017, after thaw. 63

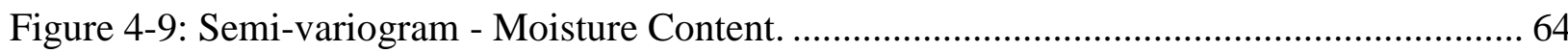

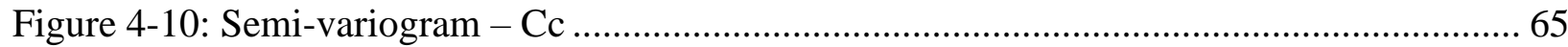

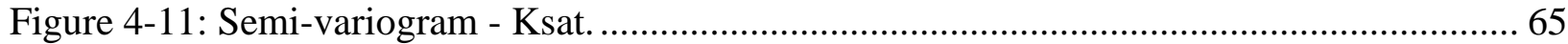

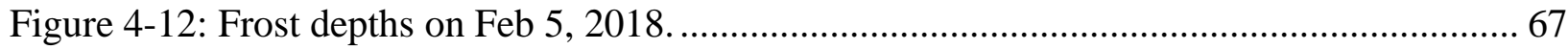

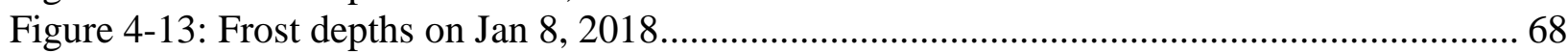

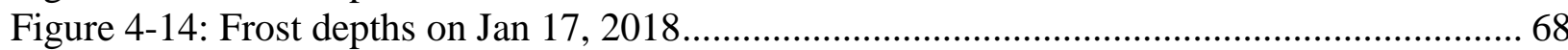

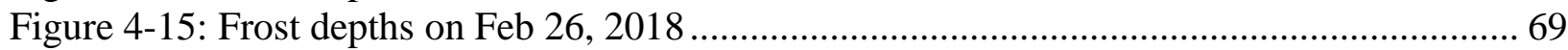

Figure 4-16: Timeline $\mathrm{K}_{\text {sat }}$ data - Radcliffe method - All locations ...................................... 71

Figure 4-17: Ksat - Elrick and Reynolds method - All locations .......................................... 72

Figure 4-18: Timeline- $\mathrm{K}_{\text {sat }}-$ Central Pathway, Radcliffe Method. ......................................... 72

Figure 4-19: $\mathrm{K}_{\text {sat }}$ - Non-Central Pathway - Radcliffe Method............................................... 73

Figure 4-20: Ksat before outlier removal (top) and after outlier removal through Grubbs test (bottom)

Figure 4-21: Rain on snow melt event reflected on the water level data (top) and temperature

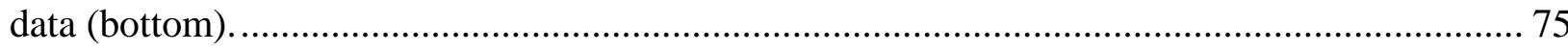

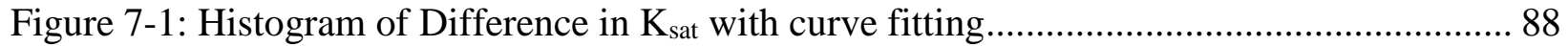

Figure 7-2: Soil particle distribution results in $\%$ - location $\mathrm{M}$.......................................... 92

Figure 7-3 Soil particle distribution results in $\%$ - location A1 ......................................... 93

Figure 7-4 Soil particle distribution results in $\%$ - location S ............................................. 93

Figure 7-5 Soil particle distribution results in $\%$ - location $\mathrm{W}$............................................. 94

Figure 7-6 Soil particle distribution results in $\%$ - location F........................................... 94

Figure 7-7 Soil particle distribution results in $\%$ - location Y ............................................ 95

Figure 7-8 Soil particle distribution results in $\%$ - location $\mathrm{O}$............................................ 95

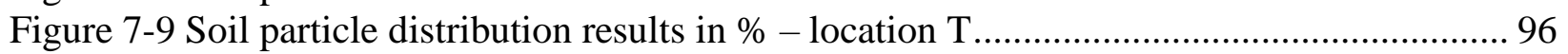

Figure 7-10 Soil particle distribution results in $\%$ - location V .......................................... 96

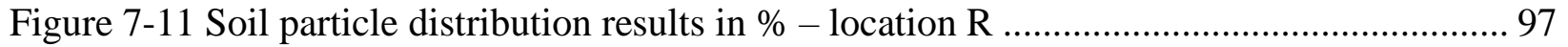

Figure 7-12 Soil particle distribution results in $\%$ - location $\mathrm{C} 1$......................................... 97

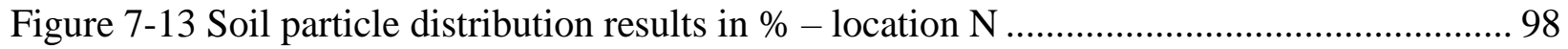

Figure 7-14: Soil particle distribution results in $\%$ - location I.......................................... 98

Figure 7-15: Soil particle distribution results in $\%$ - location E............................................ 99

Figure 7-16: Soil particle distribution results in $\%$ - location Q .......................................... 99

Figure 7-17: Soil particle distribution results in $\%$ - location B ........................................... 100

Figure 7-18: Soil particle distribution results in \% - location A ........................................... 100

Figure 7-19: Moisture Content Spatial map - All locations................................................ 101

Figure 7-20: Ksat - Radcliffe Method Spatial map - All locations....................................... 101

Figure 7-21: Organic Content spatial map - All locations ............................................... 102

Figure 7-22: Bulk Density spatial map - All locations..................................................... 102 


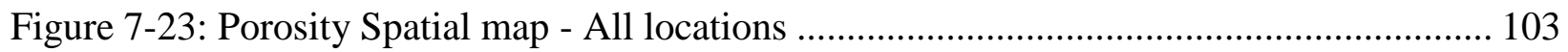

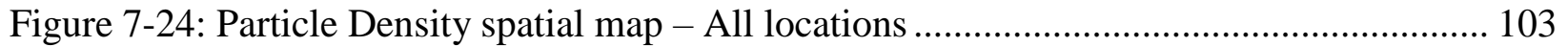

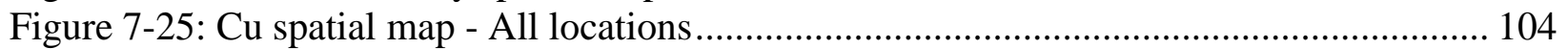

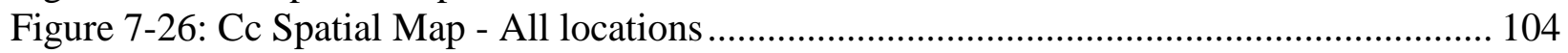

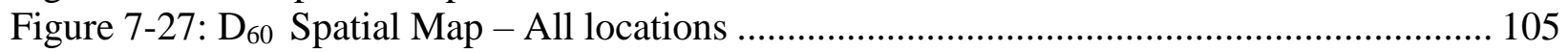

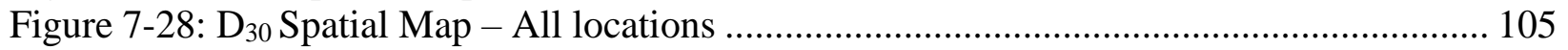

Figure 7-29: Ksat Elrick and Reynolds method average ......................................................... 106

Figure 7-30: June 5 \& 6, 2017 - Ksat Radcliffe method......................................................... 106

Figure 7-31: July 10 \& 11, 2017 - Ksat Radcliffe method ...................................................... 107

Figure 7-32: August 15 \& 16, 2017 - Ksat Radcliffe method .................................................. 107

Figure 7-33: September 19 \& 20, 2017 - Ksat Radcliffe method ................................................. 108

Figure 7-34: Oct 10 \& 11, 2017 - Ksat Radcliffe method ....................................................... 108

Figure 7-35: Oct 24 \& 25, 2017 - Ksat Radcliffe method .......................................................... 109

Figure 7-36: February 26 \& 27, 2018 - Ksat Radcliffe method................................................. 109

Figure 7-37: May 16 \& 17, 2018 - Ksat Radcliffe method..................................................... 110

Figure 7-38: June 8, 2018 - Ksat Radcliffe method.................................................................. 110

Figure 7-39: January 11, 2017 - Snow Depth ............................................................... 111

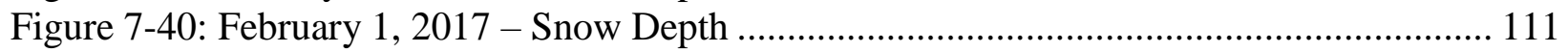

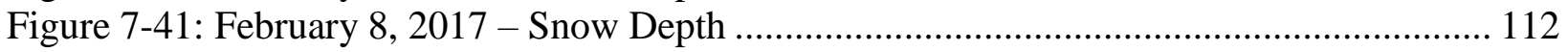

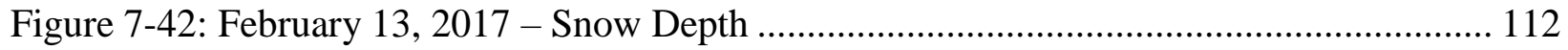

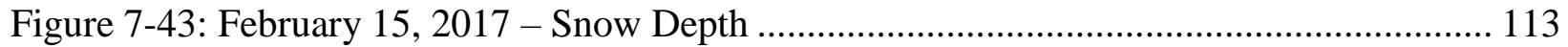

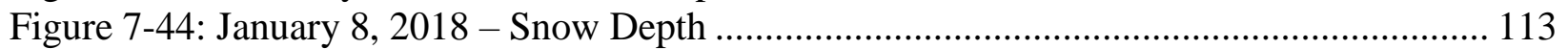

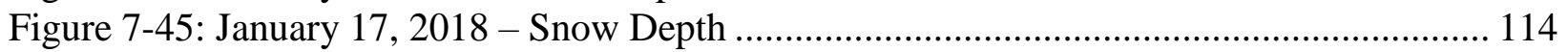

Figure 7-46: February 5, 2018 - Snow Depth ................................................................ 114

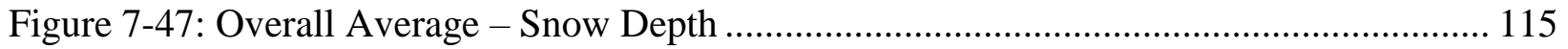




\section{List of Appendices}

1. Contour Map Generation Matlab Code

2. Semi-variogram Generation Matlab Code

3. Assumptions for Grubbs test

4. Assumptions for Wilcoxon signed-rank test

5. Figures and Tables 


\section{Introduction}

\subsection{Background}

As cities become denser and their size increases, conventional methods of centralized drainage and stormwater management are no longer feasible. Impervious surfaces within urban centres reduce infiltration and increase both runoff frequency and peak flow rates while contributing to nonpoint-source pollution. Policy makers now promote emulating the natural water cycle as the best and most sustainable way to manage urban stormwater (Credit Valley Conservation, 2010). Low Impact Development (LID) is a stormwater management approach that emphasizes the preservation of the natural water cycle in urban environments to minimize flood risks and beautify cities. Some examples of the LID systems are permeable pavements, bioretention cells (BC), underground stormwater detention chambers, infiltration trenches and green roofs.

BCs are a LID technology developed to provide distributed stormwater quantity and quality control near to its source through infiltration, retention, and evapotranspiration. BCs have been constructed and tested across the globe in many different climatic, geographical and topographical conditions for over 20 years (Prince Georges County, 1999).

Typically, BCs are designed based on the inflow quality, volume and rate and desired outflow quality, volume and rate. Designing a BC requires the catchment area characteristics, IDF curves, downstream release rate and the infiltration rate of the soil under the proposed $\mathrm{BC}$. With these data, the surface area, depth of gravel layer and the depth of BC media layer are calculated. These three boxes used to model any BC are shown in Figure 1-1. Any required chemical amendments for the BC base layer or the necessity of internal water storage layer are determined based on inflow and outflow water quality.

BCs are often treated by designers as homogeneous black boxes with emphasis on the system's inputs and outputs but with limited understanding of the internal chemical and hydraulic processes. They are sometimes designed with terrains that do not make full utilization of the BCs infiltration and treatment potential. This results in a loss of efficiency requiring more media and 
area to infiltrate and treat less water. This study aims to unpack the black box approach by investigating the spatial and temporal heterogeneity of various parameters within a monitored BC.

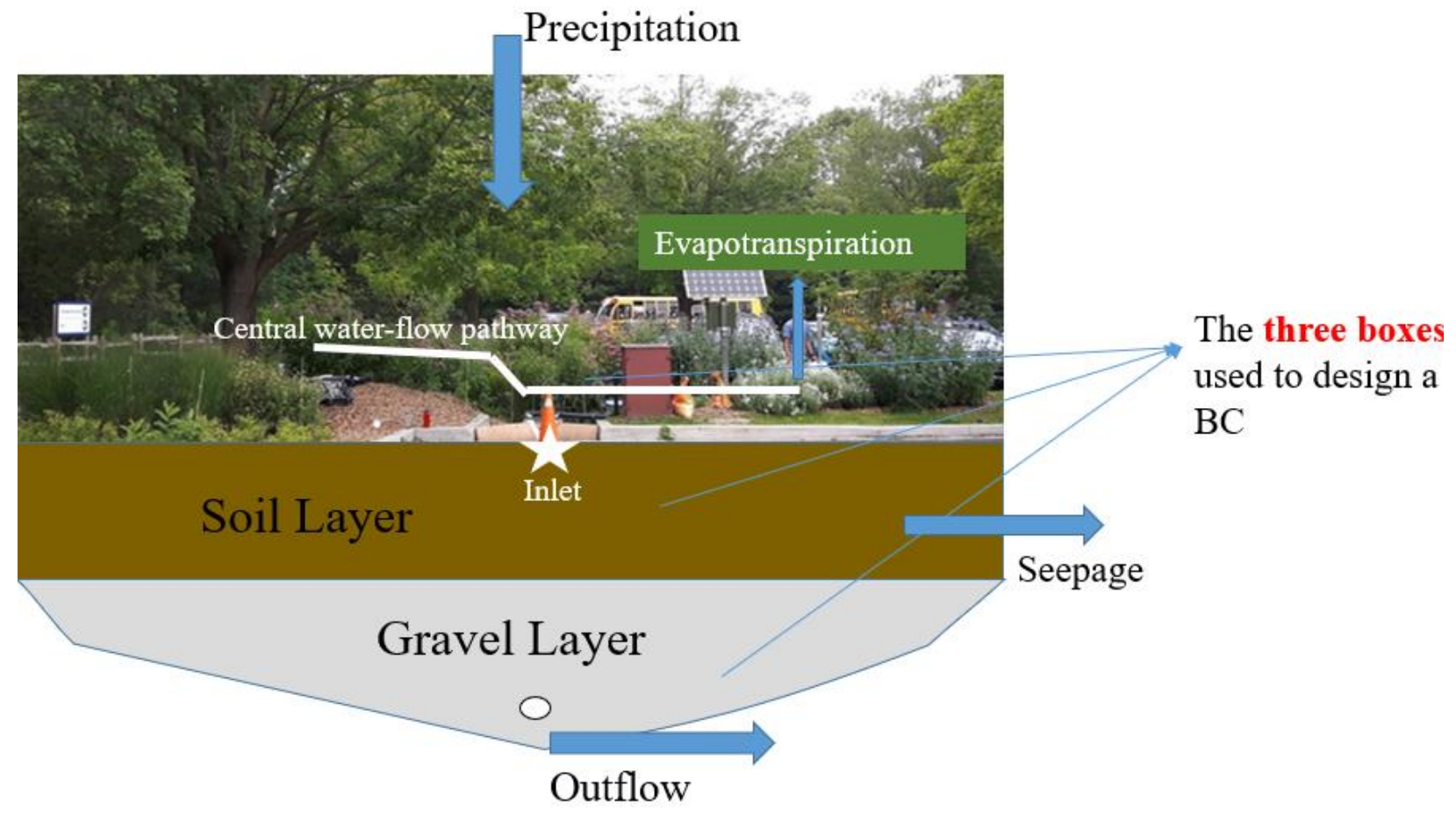

Figure 1-1 Conceptual diagram with the front view of the $B C$

Designers generally assume that BCs can be analyzed and modelled as lumped onedimensional systems. However, Asleson et. al. (2009) noted that saturated hydraulic conductivity $\left(\mathrm{K}_{\mathrm{sat}}\right)$ rates in twelve mature (i.e. > 3 years old) BCs were spatially heterogeneous. Johnson and Hunt (2016) also observed spatial heterogeneity in the deposition of heavy metals in a $\mathrm{BC}$ in Charlotte, $\mathrm{NC}$ with excessive amounts of metals concentrating near the $\mathrm{BC}$ inlet. These findings suggest that pollutant accumulation and infiltration rates are spatially heterogeneous within a typical BC. Thus, two or even three-dimensional analysis may be required to accurately describe or simulate the flow and treatment of stormwater as it moves through a $\mathrm{BC}$.

BCs experience temporal changes as the system ages. The accumulation of fines near the surface reduces a BC's capacity to infiltrate stormwater and, after several years of accumulation, this material will clog the system. For BCs located in cold climates, freeze-thaw action may also induce structural changes, within the soil. Denich et. al. (2013) has suggested that the expansion caused by freezing temperatures may increase a BC's soil pore size and thus increase its saturated hydraulic conductivity. Ding (2017 \& 2018) also observed that consecutive freeze-thaw cycles 
result in larger pores and a higher frequency of small and isolated pores through X-ray tomography imaging. According to Ding, this phenomenon helps to maintain the high infiltration rates required for the proper hydrological functioning of the BCs. Ding has also suggested that freeze-thaw cycle effects on soil structure, hydrology, and nutrient removal observed in the column studies should be evaluated at pilot and full field scales as well as over longer periods. Therefore, more work is needed to confirm these findings, determine cause of this phenomenon and to understand its implications on BC design and performance, particularly through field scale studies.

\subsection{Research Objective}

The objective of this thesis is to analyze the spatial and temporal heterogeneity of soil parameters in a BC. The BC monitored for this project is located at the Kortright Centre for Conservation, Vaughan, Ontario. A conceptual diagram with the front view of this BC is shown in Figure 1-1. This BC has an approximate area of $30 \mathrm{~m}^{2}$ and a catchment area of $265 \mathrm{~m}^{2}$ consisting of an impervious parking lot constructed with recycled tire-derived rubber composite brick pavers (Eco-flex® Churchill). The BC layers include $7.5 \mathrm{~cm}$ of shredded hardwood mulch above $40 \mathrm{~cm}$ of filter media (60\% sand and 40\% silt/clay). A geotextile wrapped $15 \mathrm{~cm}$ deep $20 \mathrm{~mm}$ clear stone gravel water reservoir is below the filter media bed. A perforated drainage pipe $(10 \mathrm{~cm}$ diameter $)$ is placed on top of the geotextile and transitions into a solid pipe as it leaves the BC.

The objectives of this research are:

1. To measure $\mathrm{K}_{\mathrm{sat}}$ spatially in the $\mathrm{BC}$ throughout a year, analyze how various locations in the $\mathrm{BC}$ behave in terms of $\mathrm{K}_{\text {sat }}$ before, during and after winter and asses how antecedent weather conditions affect estimated $\mathrm{K}_{\text {sat }}$ values.

2. To collect spatially referenced soil samples from the BC, conduct laboratory experiments to determine the organic content, bulk density, moisture content, particle density, porosity and particle size distribution and compare them using spatial maps to identify patterns and investigate spatial relations among them and $\mathrm{K}_{\text {sat. }}$.

3. To measure snow depth and density during snow events and after thaw during winter, observe spatial snow depth distribution and analyze its relationship with the other soil parameters and $\mathrm{K}_{\mathrm{sat}}$. 
4. To measure surface and subsurface water levels and temperatures, analyze them along with precipitation data and identify water level patterns during rain, snow melt or rain on snow melt conditions.

\subsection{Thesis Structure}

The thesis consists of six chapters, they are structured as follows:

\section{Chapter 1 - Introduction:}

Introduces thesis topic, outlines objectives, and presents the thesis structure.

\section{Chapter 2 - Literature Review:}

Presents a literature review on the spatial-temporal heterogeneity within BCs.

\section{Chapter 3 - Methodology:}

Outlines the characteristics of the study site, the data collection procedure, the calculation procedure used to calculate the required parameters from the collected data and the data analysis methodology used to analyze and present the data in interpretable format.

\section{Chapter 4 - Results:}

Discusses the results of the $\mathrm{K}_{\mathrm{sat}}$, soil and snow measurements from a spatial perspective through the use of spatial maps. The temporal data are analyzed and discussed using graphs produced from excel and $\mathrm{R}$.

\section{Chapter 6 - Conclusions and Recommendations:}

Presents conclusions of the thesis research and discusses future research directions and recommendations. 


\section{Literature Review}

\subsection{Introduction:}

Stormwater management practices have been evolving in the past two decades as our understanding of watershed science and management improves. Proper management of stormwater is critical to maintaining the health of our streams, rivers, lakes, fisheries and terrestrial habitats. Precipitation that lands on the ground surface infiltrates into the ground, flows as surface runoff and evaporates or gets consumed by plants. In natural watersheds, only a small part of the rainfall produces runoff due to less impermeable surfaces and more vegetated areas. In built communities, more impermeable surfaces and reduced vegetative cover alter this balance generating significantly more runoff compared to natural watersheds. Additionally, Infiltration rates are reduced in urban watersheds reducing natural recharge to our streams, wetlands and groundwater resources (Stormwater Management Criteria, 2012).

When precipitation does not infiltrate into the ground or drain through the stormwater systems but flows on the ground, it can cause surface water flooding. When runoff water carries pollutants from various parts of the urban catchments including roads, parking lots, etc., it pollutes the downstream waterbodies (London Sustainable Drainage Action Plan, 2015). LID systems like BCs, permeable pavements, underground stormwater detention chambers, infiltration trenches and green roofs are developed to mimic the natural water cycle in urban watersheds by increasing infiltration and evapotranspiration. They also treat stormwater and reduce the concentration of many pollutants carried over by them before releasing them into the natural water bodies.

Extensive research has been completed in the past two decades on BCs. Data on BCs has been collected and analysed resulting in various findings. Based on present literature on BCs and for ease of understanding, the literature review has been divided into two sections i.e., Spatial Variability and Temporal Variability. Section 2.2 discusses the literature on spatial heterogeneity of various physical parameters within the $\mathrm{BC}$ and Section 2.3 discusses the literature on temporal changes in the $\mathrm{BC}$ with weather conditions and aging. 


\subsection{Spatial Variability}

Much of the published research envisages BCs as black boxes with specific (but undefined) processes occurring inside the box temporally. From this perspective, BCs are treated as deterministic systems with spatially homogeneous processes throughout the BC media. This approach has been historically followed in field, laboratory and computer modelling studies of BCs. Published research that considers BCs as spatially heterogeneous systems is limited. Spatial heterogeneity of Physical and chemical parameters of BC media is often studied independently. There is no comprehensive review of the spatial heterogeneity of various physical or chemical parameters in the $\mathrm{BC}$ and there are no studies with comparison among the physical or chemical parameters to uncover the relationships among them.

For this review, forty-nine full text reviews were completed but only four papers explicitly studied spatial heterogeneity within a BC. Spatial information was identified in the remaining papers even if they did not have focused research objectives on spatial heterogeneity. Many papers recorded spatial data for only a part of their study. For example, the objective of Muthanna et al. (2007) is to evaluate the metal retention and fate of chloride in a BC during snowmelt. During their investigation, the authors observed that different plant species uptake metals in different rates and have different concentrations of metals in their biomass leading to spatial variability within the BC media. The authors also observed that the top mulch layer is responsible for most of the metal retention which shows spatial heterogeneity. Therefore, only 17 of the 49 reviewed papers which had either explicitly studied the spatial heterogeneity or happened to have spatially heterogeneous data for a part of their study, are discussed in this literature review.

Table 2-1 summarizes the papers considered and the spatial data each paper contains. The 'Intent of analyzing the spatial data' column shows whether the authors intentionally analyzed spatial heterogeneity, or they had different research questions and the data collected happened to be spatially heterogeneous within the BC. The papers are also classified based on whether the study is field-based, column-based, modelling-based or any combination of the three. It can be observed that out of 17 papers, 11 had a field or column experiment component and 7 had modelling components.

Different models have been used to study the BC. Table 2-2 summarizes all the models used to study BCs when spatial information is involved. The models used vary from well-known and established models to models that the authors have programmed themselves. 
Table 2-1: Spatial information available in various papers, the intent and the type of study

\begin{tabular}{|l|l|l|l|}
\hline Citation & Spatial Parameters available & $\begin{array}{l}\text { Intended } \\
\text { spatial } \\
\text { analysis }\end{array}$ & Type of study \\
\hline Asleson et al. (2009) & $\mathrm{K}_{\text {sat }}$ & Yes & Field study \\
\hline Chavez et al. (2013) & Filter media $\mathrm{K}_{\text {sat } \text { heterogeneity }}$ & Yes & Modelling \\
\hline Johnson et al. (2016) & $\begin{array}{l}\text { Accumulation and spatial distribution of } \\
\text { zinc, copper and phosphorous }\end{array}$ & Yes & Field study \\
\hline Jones et al. (2013) & $\begin{array}{l}\text { Spatial distribution of accumulated lead, } \\
\text { copper, and zinc in the media. }\end{array}$ & Yes & Field study \\
\hline LeFevre et al. (2009) & Pool depth & No & Field study \\
\hline Li et al. (2008) & Depth vs Cu, Pb and Zn at various times. & No & Field \& modelling \\
\hline Li et al. (2008) & Depth vs TSS & No & Field and column \\
\hline Lynn et al. (2018) & Depth vs several parameters & No & Modelling \\
\hline Muthanna et al. (2007) & Depth vs Cu, Zn and Pb. & No & Field - controlled \\
\hline Paus et al. (2013) & Depth vs organic matter, Cu \& Zn & No & Field study \\
\hline Quinn et al. (2014) & $\begin{array}{l}\text { Depth vs pressure head and volumetric } \\
\text { water }\end{array}$ & No & Modelling \\
\hline Roseen et al. (2009) & Frost Depth & No & Field study \\
\hline Stewart et al. (2017) & Pressure and soil moisture & No & Field \& modelling \\
\hline Thompson et al. (2008) & Depth vs Kat & No & Column Studies \\
\hline Yergeau et al. (2013) & Soil compaction depth & No & Field study \\
\hline Zhang et al. (2017) & Ground water table depth & No & Modelling \\
\hline
\end{tabular}

Table 2-2: Models used in the considered papers

\begin{tabular}{|l|l|l|}
\hline Citation & Model used & Dimensions \\
\hline Chavez et al (2013) & COMSOL Multiphysics Earth Science Module (2008) & 2D \\
\hline Cheng et al (2015) & Excel model - new & 0D \\
\hline Lynn et al. (2018) & HYDRUS -1D, SWMM & 1D \\
\hline Muthanna et al. (2007) & RECHARGA & 0D \\
\hline Quinn et al. (2014) & KWE and RECHARGE & 0D \\
\hline Stewart et al. (2017) & HYDRUS-2D/3D & 2D \\
\hline Zhang et al. (2017) & VS2DI- 2-dimensional finite difference model & 2D \\
\hline
\end{tabular}

Numerical modelling is generally carried out to reduce the expenses that would be incurred if actual field tests are conducted for the same purpose. Therefore, BCs are numerically modelled by researchers in various levels of accuracy for various purposes. 
Table 2-2 shows the number of dimensions considered in each model. 0D denotes a compartment-based approach without any spatial considerations, 1D denotes a unidimensional spatial consideration having cells based on distance from inlet and 2D denotes a two-dimensional model with distinct cells. 3D models have not yet been used to simulate internal processes for a BCs. In this literature review, modelling results are considered alongside results from field tests since the literature on this topic are limited. Furthermore, 2D LID models have not been properly integrated with Storm Water Modelling softwares like SWMM. But there are simple 1D LID modules in SWMM to include LID in the stormwater quantity and quality simulations.

\subsubsection{Surficial variability}

BC soil parameters that have been spatially analyzed by researchers include saturated $\mathrm{K}_{\mathrm{sat}}$, organic content, TSS, $\mathrm{Cu}, \mathrm{Pb}, \mathrm{Zn}$ and $\mathrm{P}$. These parameters are important to overall functionality of a BC in the following ways. $\mathrm{K}_{\text {sat }}$ governs the hydrologic performance of a BC. Organic content and TSS reflect on the sedimentation in the $\mathrm{BC} . \mathrm{Cu}, \mathrm{Pb}$ and $\mathrm{Zn}$ deposition show where most of the inflow stormwater pollutants get deposited. Heterogeneity in $\mathrm{P}$ concentration reflects the media $\mathrm{P}$ sorption capacity.

Asleson et al. (2009) has collected spatial $\mathrm{K}_{\text {sat }}$ data from 12 BCs in Minnesota. The Modified Philip-Dunne (MPD) infiltrometer is used to measure all the saturated hydraulic conductivity measurements. The MPD device was chosen because it measures the $\mathrm{K}_{\text {sat }}$ values in the surface layer where clogging typically occurs. Spatial maps with $\mathrm{K}_{\text {sat }}$ information are prepared for six of those BCs by the authors. From the maps provided by the authors it is evident that $\mathrm{K}_{\text {sat }}$ values are higher along the outer edge of the $\mathrm{BC}$ and lower along the central flow path. 

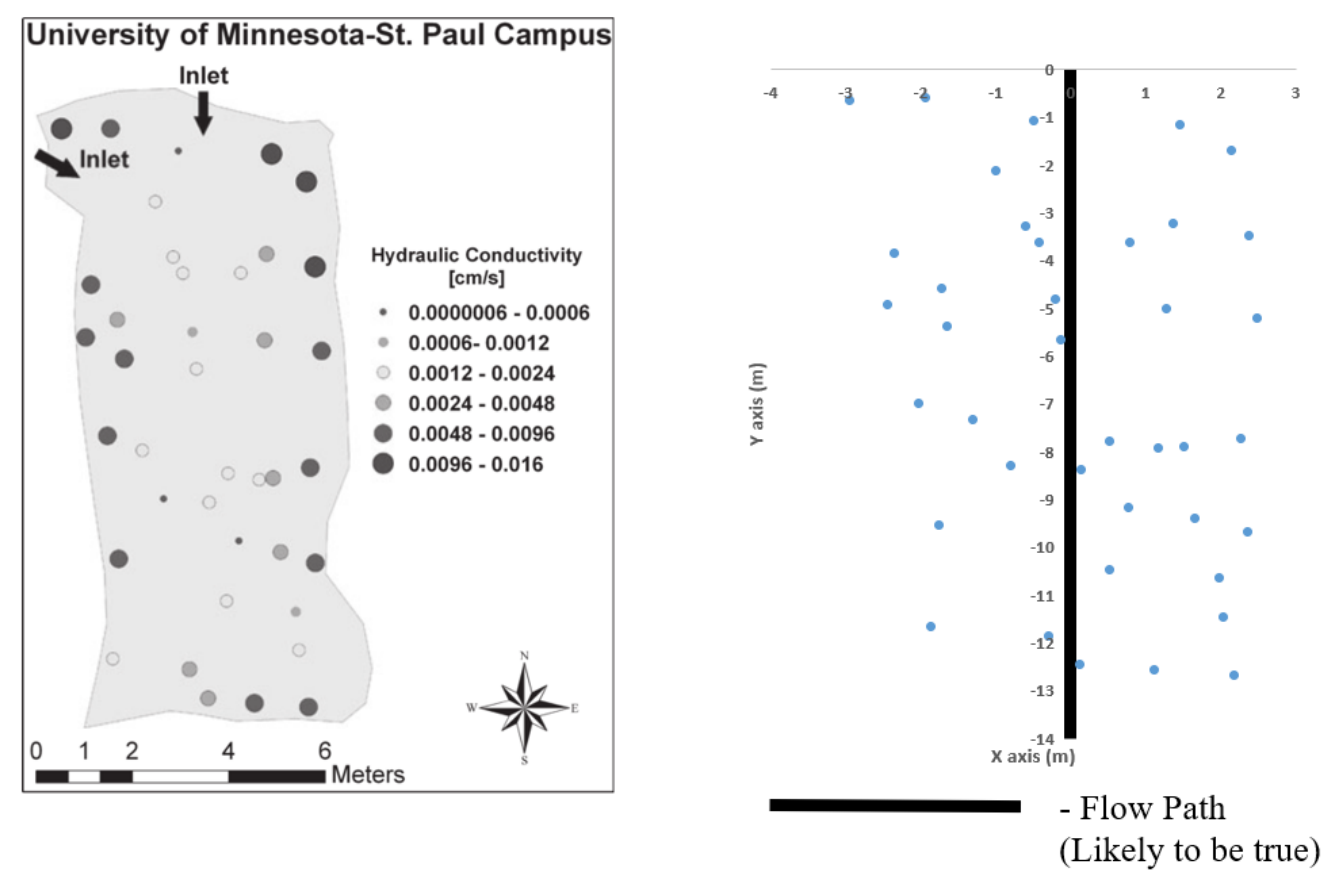

Figure 2-1: Spatial $K_{\text {sat }}$ map of University of Minnesota BC and the parallel excel data used to calculate the correlations - Asleson et al. (2009)

Chavez et al. (2013) assumed that contaminant attenuation would be maximized when there is uniform flow throughout the $\mathrm{BC}$ without concentration of flows in specific regions of the $\mathrm{BC}$ media. Therefore, the impact of $\mathrm{K}_{\mathrm{sat}}$ heterogeneity on the flow processes is analyzed. Both field experiments and modelling were carried out. The ratio of the watershed area to the BC surface area considered is 50:1 which is higher than the recommended ratio of 10:1. One hundred and sixty-two samples were collected during the construction of two BCs in Stillwater, Oklahoma. The measured $\mathrm{K}_{\text {sat }}$ varied between $2.8 \times 10^{-6}$ and $10^{-4} \mathrm{~m} / \mathrm{s}$ with a mean of $3.5 \times 10^{-5} \mathrm{~m} / \mathrm{s}$.

Through numerical simulations, they modelled a BC with a $0.10 \mathrm{~m}$ grid, filter media layer. The $\mathrm{K}_{\text {sat }}$ values in the model are randomly distributed based on the measured $\mathrm{K}_{\text {sat }}$ values. The modelled BC system also had sand plugs as shown in Figure 2-2. Using this model, the authors concluded that there is a slight increase in discharge with increased variance of the $\mathrm{BC}$ media $\mathrm{K}_{\text {sat. }}$ Therefore, the authors recommend proper mixing of the $\mathrm{BC}$ media before installation. The authors also concluded that reduction in $\mathrm{BC}$ media $\mathrm{K}_{\text {sat }}$ variance during construction had only a miniscule effect on the overall treatment performance of the BC. 


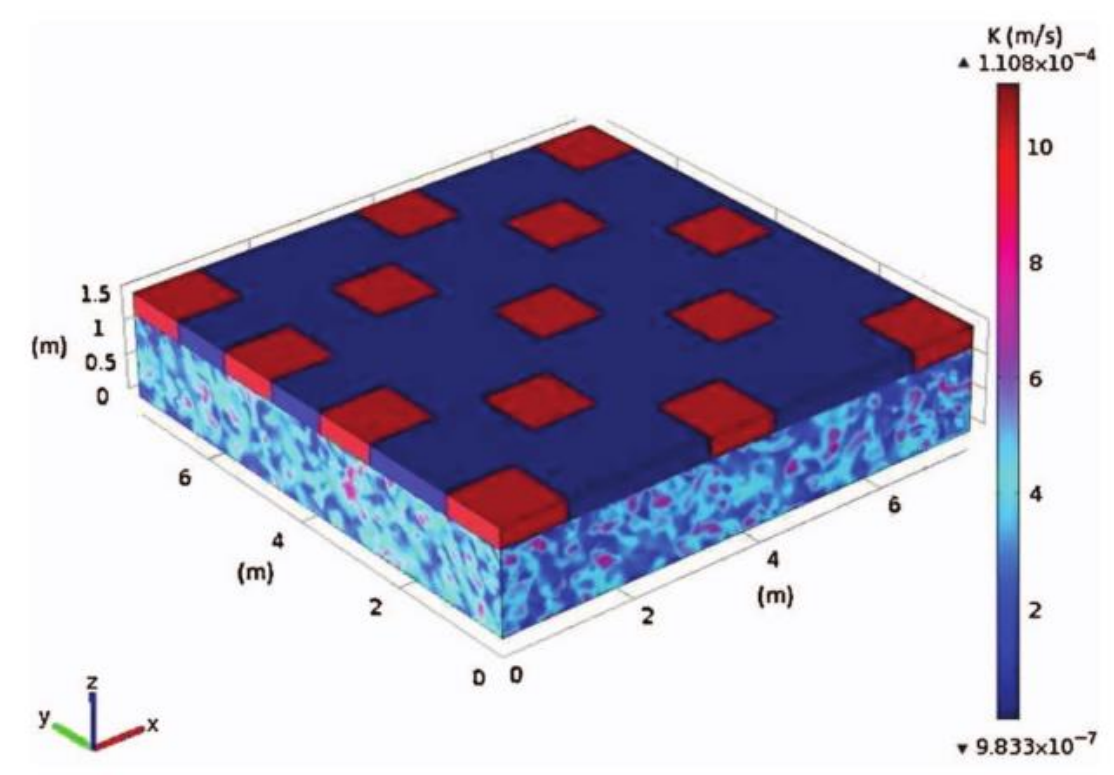

Figure 2-2: Three-dimensional view of the model configuration with 14 sand plugs and the range of $K_{\text {sat }}$ values - Chavez et al. (2013).

Chavez's modelling results applies to an ideal BC in laboratory conditions with randomly distributed $\mathrm{K}_{\text {sat }}$ throughout the BC media layer, but it may not represent an aged BC which does not have an ideal random distribution of $\mathrm{K}$. It will have a variation in $\mathrm{K}_{\text {sat }}$ with respect to topographical, hydraulic, biological and physical parameters of the BC. Hence, more research should be done in real, aged BCs to verify the results of modellers like Chavez et al. (2013).

Jones et al. (2013) observed the flow path in a BC at the University of Maryland by simulating water flow using a portable pump. The sampling locations for this field study where chosen along the flow path. The authors observed that the organic content is lowest near the inlet in a BC and increases with distance away from inlet. The appearance of the organic matter is characterized by a dark colored soil. The authors state that the organic layer appears to have evolved from the original mulch layer augmented by decaying cell vegetation. They suspected that the low organic content near the inlet is due to particle deposition and mobilization of organic layer/mulch by scouring. Scouring occurs near the inlet due to swiftly moving water that enters the $\mathrm{BC}$ that dissolves and carries the organic matter away leaving the heavy soil particles to settle down. While particle deposition reduces the organic content by increasing the proportion of inorganic material, they also reduce organic content by inhibiting plant growth. Even though the BC studied Jones et al. (2013) has an unusual length to width ratio of 5:1, it suggests that near the 
inlet, due to deposition of heavy metals, the organic content reduces and in other locations where depositions do not occur, organic content remains high.

Muthanna et al. (2007) analyzed plant uptake of heavy metals in BCs and found that the accumulation of metals including $\mathrm{Cu}$ in the roots and shoots of the plants varies greatly between species. Metal concentrations of BC plants was measured before and after snow melt. The authors were able to detect clear accumulation of metals in the above ground biomass. Therefore, the metal uptake should have taken place through the roots. This also indicates a good transport of metals from roots to the shoots in the plant. Vinca minor had the highest heavy metal absorption rate.

Li et al. (2008) conducted field and laboratory column experiments to investigate TSS deposition patterns in BC media. Inflow water was prepared in a drum with an agitator and a magnetic stirrer. Kaolin was added at a standard rate to simulate the runoff suspension. The authors note that TSS deposition is very high near the inlet and reduces with increased distance from the inlet. The authors suggest that a BC's ability to capture suspended solids is limited by clogging since surface layer clogging stops the entry of suspended solids into the BC media. The effect of breakthrough (preferential flow path) was not observed to be significant with respect to TSS reduction performance. Cake layer formation with suspended solid material is observed in most experiments. Likewise, the study also found that small clay sized deposition causes a much higher reduction of the infiltration rate than deposition of other larger sized particles due to better clogging efficiency.

Johnson et al. (2016) found that a substantial amount of $\mathrm{Zn}$ removal occurs within the forebay in BCs. While sampling, Zn concentrations within the forebay area were found to be 157 $\mathrm{mg} \mathrm{kg}-1$ compared to a mean concentration of $26 \mathrm{mg} \mathrm{kg}^{-1}$ across the remainder of the BC. In Figure 2-3, near the inlet (forebay region), the $\mathrm{Zn}$ concentration is higher than the thresholds suitable for plant growth and soil invertebrate survival. This is because as $\mathrm{Zn}$ laden water enters the $\mathrm{BC}, \mathrm{Zn}$ is deposited near the inlet.

Johnson et al. (2016) and (2013) observed a significant decrease in Zn concentration with respect to distance from the inlet $(\mathrm{p}<0.0001)$ and depth below the surface $(\mathrm{p}<0.0001)$ as shown in Figure 2-3. This accumulation of $\mathrm{Zn}$ in the forebay is suspected to be due to the two removal mechanisms; filtration and sorption. Johnson et al. (2016) also note that higher concentrations of $\mathrm{Cu}$ can be found near the inlet, again suggesting the majority of $\mathrm{Cu}$ removal occurs near the inlet. $\mathrm{Cu}$ concentrations decreased significantly with distance away from the inlet $(\mathrm{p}<0.0001)$ and 
with depth $(\mathrm{p}<0.0001)$. Like $\mathrm{Cu}, \mathrm{Zn}$ concentrations also decrease with increasing ordinate distance from the inlet.
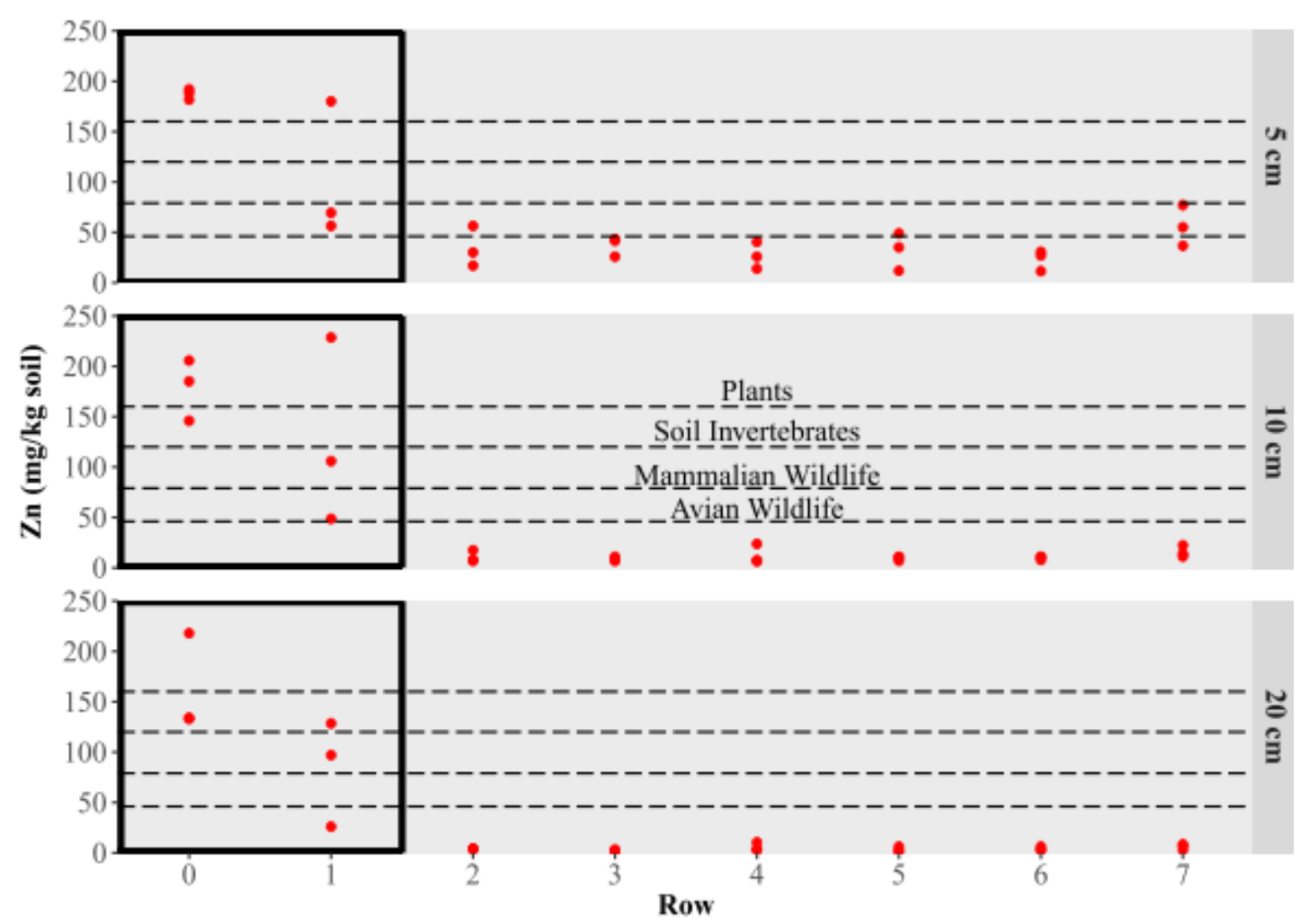

Figure 2-3: BC Zn distribution in comparison to USEPA recommended thresholds, forebay outlined - Johnson et al. (2016)

Johnson et al. (2016) recorded higher phosphorous concentrations close to the inlet and a strong correlation between $\mathrm{Zn}$ and $\mathrm{P}$ ( $\mathrm{p}<0.0001$ and a Kendall's Tau correlation coefficient of 0.88). Elevated $\mathrm{P}$ concentrations in the forebay is observed and a strong correlation was also observed between $\mathrm{P}$ and humic matter. This could be because the organic matter and mulch as well as sediment and particulate-bound metal ions are accumulated in the forebay leading to higher humic matter concentrations closer to the inlet. The authors suspect that phosphorus removal is linked to the accumulation of sediment and organic matter in the forebay. Therefore, the authors suggest that maintenance regarding removal of phosphorous rich sediment can be restricted to the BC forebay. 


\subsubsection{Vertical variability}

\subsubsection{Soil parameters and pollutant removal}

Lynn et al. (2018) attempted to improve the accuracy of the EPA SWMM model by developing a unified equation that can approximate flow rates under both saturated and unsaturated conditions with better accuracy. Calibrations for the equation required porosity and hydraulic conductivity slope. Hydraulic conductivity slope is a parameter that characterizes the exponential decrease in $\mathrm{K}_{\text {sat }}$ with decreasing moisture content. It can be calculated using the following formula:

$$
K=K_{\text {sat }} \times e^{[-H C O \times(n-M C)]}
$$

Where

- $K_{\text {sat }}$ is the saturated hydraulic conductivity,

- $H C O$ is the hydraulic conductivity slope,

- $n$ is the porosity and

- $\quad M C$ is the moisture content.

Table 2-3 Calculated porosity (n) values and Hydraulic Conductivity Slope (HCO) values for sand media with different column depths - Lynn et al. (2018)

\begin{tabular}{|l|l|l|}
\hline Depth $(\mathbf{c m})$ & Porosity & $\begin{array}{l}\text { Hydraulic } \\
\text { Conductivity Slope }\end{array}$ \\
\hline 30.48 & 4.7 & 15 \\
\hline 45.72 & 4.0 & 13 \\
\hline 60.96 & 3.7 & 12 \\
\hline 76.20 & 3.5 & 12 \\
\hline 91.44 & 3.4 & 11 \\
\hline 106.68 & 3.3 & 11 \\
\hline 121.92 & 3.2 & 11 \\
\hline
\end{tabular}

The calibration values for sand media (Table 2-3) show that as soil depth increases $\mathrm{n}$ and HCO decrease. The decrease in porosity is attributed to increasing pressure by the above lying soil and reduced biological activity. As evident from Table 2-3, $\mathrm{K}_{\text {sat }}$ decreases faster in the upper soil layers compared to the lower soil layers and is tied to increasing soil moisture content. It is suggested that this could be because the lower soil layers don't fluctuate as much as the upper soil 
layers in terms of their moisture content. Moreover, the lower soil layers are closer to the saturated zone which could limit the $\mathrm{K}_{\text {sat }}$ change since they are consistently wet compared to the upper soil layers which dry and wet parallel to fluctuating weather conditions.

Similarly, Paus et al. (2013) observed organic content is highest in the first few centimeters of depth and reduces considerably as the depth increases for six BCs in Minneapolis, USA. The authors also noted that the rate of increase of metal sorption capacity with respect to increasing organic content is higher in older media compared to newer media signifying that the organic content in older media has a higher metal sorption capacity. It is suggested that this could be because the weathering and microbial transformation reactions are likely to increase the number of oxygenated functional groups over time that in turn increases the metal sorption capacity.

Li et al. (2008) conducted field and laboratory column experiments with BC media and found that most suspended solids do not penetrate through $5-20 \mathrm{~cm}$ of the BC media. Jones et al. (2013) and Paus et al. (2013) found that a majority of $\mathrm{Zn}$ is retained in the first $5 \mathrm{~cm}$ of the BC media. Johnson et al. (2016) also observed that $\mathrm{Zn}$ and $\mathrm{Cu}$ concentrations decreased with increasing depth from $5 \mathrm{~cm}$ to $20 \mathrm{~cm}(\mathrm{p}<0.0001)$. However, Li et al. (2008) conducted similar experiments for two consecutive years (2004 and 2005) and found mixed results. It is observed that in the set of measurements collected during 2005, the $\mathrm{Cu}$ concentrations decreased with increasing depth. However, $\mathrm{Cu}$ concentrations increased with increasing depth during 2004. Li et. al. (2008) also confirmed the release of $\mathrm{Cu}$ from the media. The authors therefore, suggest that since $\mathrm{Cu}$ tends to associate with soil organic matter, it is more likely than $\mathrm{Pb}$ and $\mathrm{Zn}$ to be dissolved into highly-organic water and get released form the media. Paus et al. (2013) also identified that for $\mathrm{Zn}$ and $\mathrm{Cd}$, the amount of sorption increased with increasing organic content in the media. However, no correlation was observed for $\mathrm{Cu}$ sorption with respect to organic content.

Like $\mathrm{Cu}$ and $\mathrm{Zn}, \mathrm{Pb}$ also gets deposited in the top layer of the soil according to $\mathrm{Li}$ et al. (2008) as shown in Figure 2-4. Muthanna et al. (2007) found that the $5 \mathrm{~cm}$ thick top mulch layer retained approximately $74 \%$ of the $\mathrm{Zn}, 66 \%$ of the $\mathrm{Cu}$ and $13 \%$ of the $\mathrm{Pb}$ by mass that was retained overall in the BC system. 

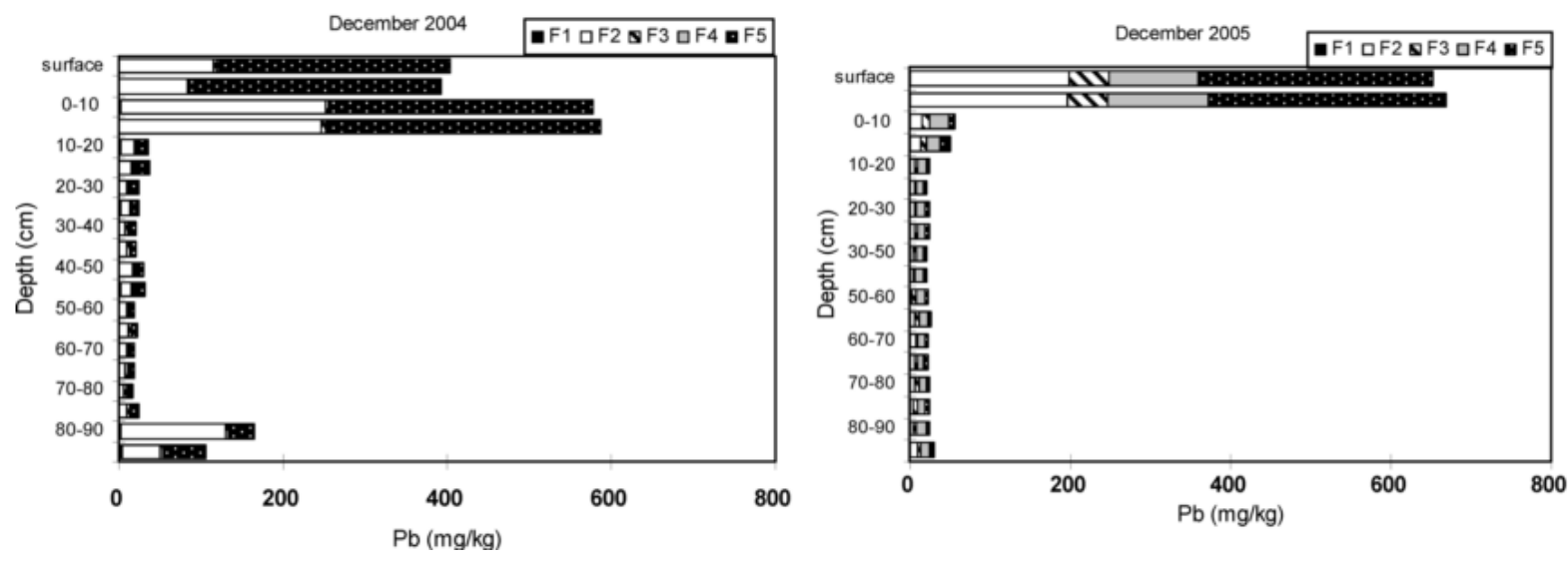

Figure 2-4: Pb profile in the BC - Li et al. (2008).

\subsubsection{Frost Depth}

Roseen et al. (2009) monitored filter media frost penetration throughout winter months on both weekly and rainfall-runoff event basis (before and after events). Frost penetration was monitored using a method developed by the U.S. Army Cold Regions Research (CRREL). Frost penetration was then compared to rainfall-runoff characteristics to evaluate hydraulic efficiency.

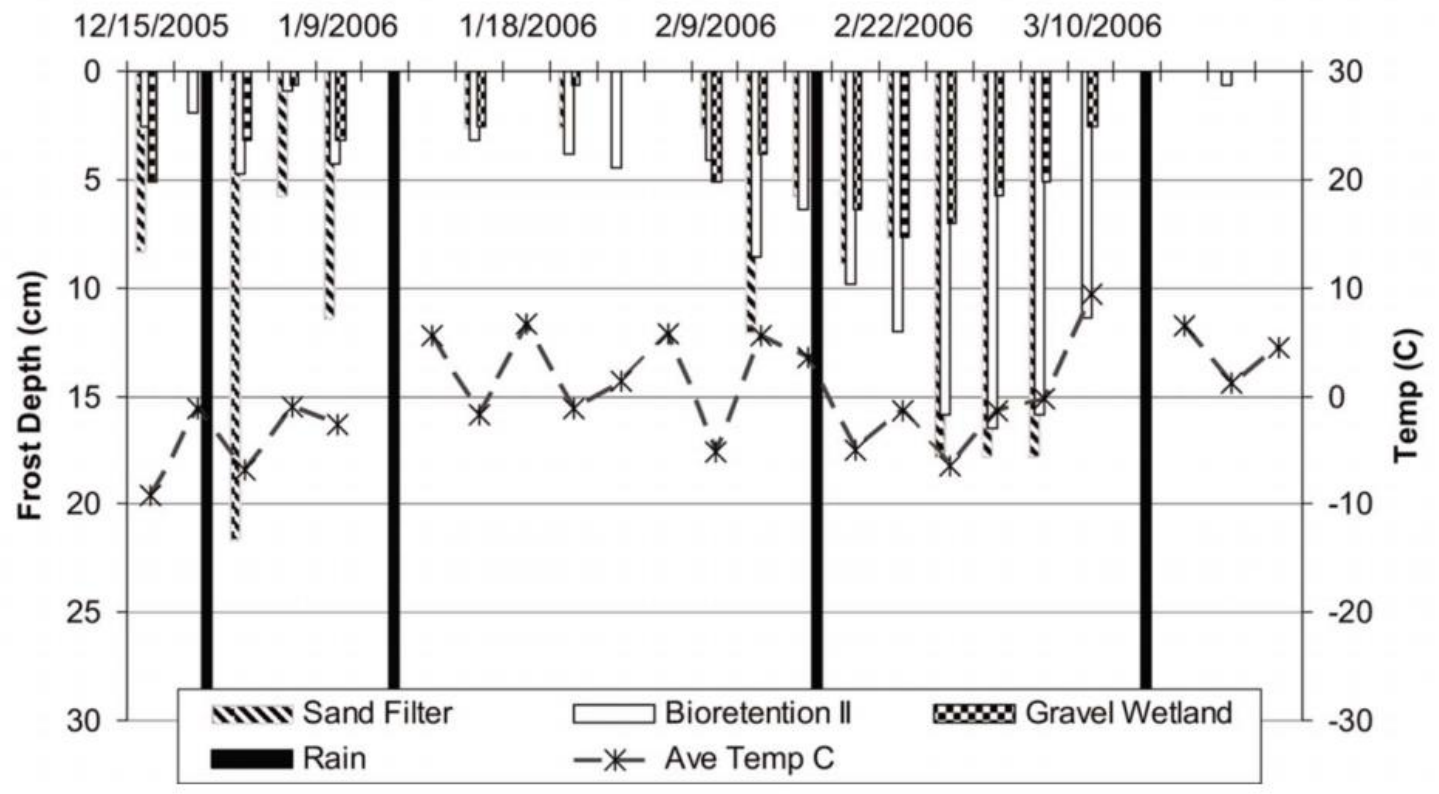

Figure 2-5: Filter media frost penetration for a range of LID systems Roseen et al. (2009)

The authors observed the frost penetration did not affect overall hydraulic performance. A predictable frost penetration cycle which includes frost penetration into a filter media before a rain 
and snowmelt event, followed by thaw and frost penetration again during subsequent belowfreezing days is observed as shown in Figure 2-5.

Roseen et al. (2009) also acknowledges that a system could thaw slowly and result in failure to properly attenuate a storm. However, this phenomenon was not observed during their study. The authors also mention that frost penetration does not necessarily equate to zero filter media permeability as frozen media may still have significant porosity and permeability.

\subsection{Temporal Variability:}

The physical processes in BCs vary temporally among seasons and as the system ages. Antecedent dry conditions have been observed to produce higher infiltration rates and freeze- thaw cycles during winter are observed cause structural changes in the BC media (Denich et al., 2013; Barrett et. al., 2013). With aging, clogging due to suspended solids deposition and excessive metal deposition near the inlet are observed (Johnson et. al., 2016; Jones et. al., 2013; Paus et. al., 2014; Li et al., 2008). These phenomena will be reviewed from the literature, in the following sections.

\subsubsection{Effect of freeze thaw cycles on natural soil:}

Konrad et al. (2000) conducted laboratory experiments to investigate changes in $\mathrm{K}_{\mathrm{sat}}$ resulting from freeze thaw cycles for various soil types. The authors found clay content, plasticity, initial void ratio and water content to be significant parameters that affect the freeze-thaw behavior of soils. A higher increase in $\mathrm{K}_{\text {sat }}$ was observed during freeze thaw for samples with lower clay content (clay content varied from $25 \%$ to $50 \%$ ) and lower void ratio. A systematic increase in $\mathrm{K}_{\text {sat }}$ was noticed for all samples that had gone through one freeze-thaw cycle, with a decrease in void ratio.

Xie et al. (2015) studied the freeze-thaw cycle form soil samples collected in the QinghaiTibet Plateau. Seven soil samples after different number of freeze-thaw cycles were tested in room temperature of $15^{\circ} \mathrm{C}$. Volume deformation is also observed during the freezing phase due to frost heaving. Soil porosity is observed to be affected. Porosity increased significantly from $23 \%$ to $32 \%$ during the 15 freeze-thaw cycles. Porosity increase rates were the highest during the first six freeze-thaw cycles. 


\subsubsection{Effect of freeze thaw cycles on BC media:}

Denich et al. (2013) has observed that the soil volumes increased during freezing of the BC mesocosms and did not return to their original level beneath the container's top edge after the soil matrix thawed. Two identical BC mesocosms were constructed based on standard bioretention design guidelines. A synthetic winter runoff was used to simulate winter runoff from roads in Guelph, Ontario. Ten applications were assumed per year based on the analysis of winter runoff and de-icer application data from roads in the City of Guelph. The mesocosms were constructed outdoors during summer to facilitate plant establishment. The initial infiltration capacity of each mesocosm is measured. During winter, the mesocosms were moved to an unheated, indoor space and the above specified synthetic urban runoff equivalent to 2 years loading was applied. The mesocosms were then moved outdoor and allowed to naturally thaw. The infiltration rates were measured again. An increase in infiltration rate is observed after the winter cycle. This increase could be attributed to the freeze-thaw action which increases the soil porosity and thus resulting in elevated infiltration rates.

Baratta (2013) tested the effects of freeze-thaw cycles on three different BC soil mixtures on laboratory conditions by measuring the infiltration rates after a series of freeze thaw cycles aiming to quantify the long-term changes in $\mathrm{BC}$ infiltration rates in cold climates. Unlike other studies, the author observed a steady decrease in infiltration rates after freeze thaw cycles as shown in Table 2-4. Infiltration rates were observed to decrease with increasing number of freeze thaw cycles.

Table 2-4: Infiltration rates with respect to number of freeze thaw cycles - Baratta (2013)

\begin{tabular}{|c|c|c|c|c|c|c|}
\hline \multicolumn{7}{|c|}{ Freeze-Thaw Column Infiltration Rates $(\mathrm{cm} / \mathrm{hr})$} \\
\hline \multirow{2}{*}{$\begin{array}{l}\text { Column } \\
\text { Number }\end{array}$} & \multirow{2}{*}{ Column Soil Composition } & \multicolumn{5}{|c|}{ Number of Freeze-Thaw Cycles } \\
\hline & & $\mathbf{0}$ & 5 & 10 & 15 & 20 \\
\hline 1 & $80 \%$ Sand \& 20\% Compost & 104.9 & 80.3 & 54.6 & 44.5 & 52.4 \\
\hline 2 & $60 \%$ Sand \& 40\% Compost & 131.8 & 92.7 & 70.1 & 57.9 & 48.7 \\
\hline 3 & 1/3 Sand: $1 / 3$ Compost: $1 / 3$ Topsoil & 57.0 & 27.6 & 11.2 & 6.8 & 4.4 \\
\hline $3 \mathrm{a}$ & 1/3 Sand: 1/3 Compost: $1 / 3$ Topsoil + 1.5 grams Sediment & 60.1 & 25.4 & 8.8 & 5.8 & 4.6 \\
\hline $3 b$ & 1/3 Sand: $1 / 3$ Compost: $1 / 3$ Topsoil + 3.0 grams Loess & 82.9 & 20.8 & 9.7 & 7.0 & 4.9 \\
\hline
\end{tabular}


Ding et al. (2017) used $50 \mathrm{~cm}$ deep BC soil cores in the laboratory to simulate freeze thaw action. Freeze thaw action is simulated by controlling the temperature of the air above the core and wrapping the soil core with an electric heater. To simulate freezing conditions, the chamber air is dropped to below $0^{\circ} \mathrm{C}$ and the soil freezes downwards from the surface. Approximately, $5 \mathrm{~cm}$ of snow is also added above the soil at the start of freezing simulation. To simulate thaw, the chamber air temperature is raised above $0^{\circ} \mathrm{C}$. During experiments, the air temperature is changed gradually to avoid abrupt temperature drop. The electric heater wrapped around the soil core is used to maintain the Ontario groundwater temperature which is approximately $8{ }^{\circ} \mathrm{C}$. It is observed that freeze thaw action caused a slight increase in the drainage rate.

Serpi (2015) assessed the variation of $\mathrm{K}_{\text {sat }}$ over time due to cyclic freezing of soil. Clayey silt soil with inorganic medium is used in the laboratory tests. The author observed permanent fractures whose size is linked to the number of freeze thaw cycles and soil compaction effort. A direct method, using a flexible wall permeameter and an indirect method, using oedometric test results to determine the $\mathrm{K}_{\mathrm{sat}}$ of the soil. A positive correlation is observed between the number of freezing-thawing cycles and the $\mathrm{K}_{\text {sat }}$ value. As expected, a negative correlation is observed between the effective stress and $\mathrm{K}_{\text {sat }}$ value. The author also suspects that the size effects of the laboratory samples and the axial stress-free condition maintained during the freezing process could have contributed positively to the soil fracture formation.

Furthermore, most research on freeze-thaw action in BC media has been completed in controlled laboratory scale mesocosms. Therefore, when all these studies with conflicting results are considered, it seems to be important that the $\mathrm{K}_{\mathrm{sat}}$ values of $\mathrm{BC}$ media are analyzed through field studies to find out the effect of freeze-thaw cycles on BC media.

\subsubsection{Effect of aging on BC:}

Although BCs have a predicted design life of 25 years, most field studies have been completed on BCs that are less than 2 years old. Aging can affect the performance of the BC both in terms of water quantity performance and water quality performance. Therefore, it becomes important to understand the literature on the long-term performance of $\mathrm{BC}$. 


\subsubsection{Water Quantity - Stormwater control capacity}

Jenkins et. al. (2010) studied a BC for a period of nine years. The soil textural profile of the $\mathrm{BC}$ is characterized prior to allowing the storm water to drain through (2001) and after aging (2006 and 2009). For the storms between 2003 and 2008, the mean and median inflow TSS values were 171 and $74 \mathrm{mg} / \mathrm{L}$ and the mean and median outflow TSS values were 17 and $4 \mathrm{mg} / \mathrm{L}$. Accumulation of fines smaller than $0.1 \mathrm{~mm}$ was observed in the BC. Infiltration rate in BCs were observed to drop immediately after installation and then level off at a sustainable level. The authors observed no significant difference between infiltration rates measured on 2006 and 2009. Therefore, they recommend no maintenance in the short term. However, they noted that the variability of the infiltration rates in 2006 is lower than the variability observed in 2009 indicating that structural changes were occurring in the $\mathrm{BC}$ media.

Barrett et. al. (2013) conducted column experiments with BC media outdoors in Austin, Texas. An initial rapid decrease in $\mathrm{K}_{\text {sat }}$ in all column experiments is observed which then stabilized. A slight increase in $\mathrm{K}_{\text {sat }}$ is also observed during summer after prior stabilization which could be because of lower soil moisture content during summer. Paus et. al. (2014) also observed a slow increase in $\mathrm{K}_{\mathrm{sat}}$ measured at the soil surface as the BC ages in a field study.

Coustumer et. al. (2008) conducted $\mathrm{K}_{\text {sat }}$ measurements in 125 BC columns at Australia over a 72-week period. Initial $\mathrm{K}_{\text {sat }}$ measurements were within Australian Guidelines $(50-200 \mathrm{~mm} / \mathrm{h})$ but after 1.5 years of operation, the $\mathrm{K}_{\text {sat }}$ values dropped $27 \%$ of the initial value (median of 51 $\mathrm{mm} / \mathrm{h}$ ). Therefore, it is clear that $\mathrm{K}_{\mathrm{sat}}$ value is in its peak just after the construction of the $\mathrm{BC}$, reduces quickly till it reaches a steady state and then increases marginally with aging. Variability in $\mathrm{K}_{\mathrm{sat}}$ values within the $\mathrm{BC}$ also increases with age.

\subsubsection{Water Quality - Pollutant removal capacity}

Deposition of metals ( $\mathrm{Zn}, \mathrm{Cu}, \mathrm{Fe}$ and $\mathrm{Pb}$ ) has been observed in aging BCs by Johnson et. al. (2016), Jones et. al. (2013), Paus et. al. (2014) and Li et al (2008). However, no reduction in metal retention capacity has been observed. Most of the metal deposition took place near the inlet and the remaining parts of the aged BCs have significantly less metal concentrations compared to the inlet. 


\subsection{Conclusions and Research gaps:}

Through the systemic literature review on the spatial heterogeneity of various parameters inside the $\mathrm{BC}$ and the literature review on the effect of freeze thaw action in a $\mathrm{BC}$, the following inferences can be made.

1. K varies spatially within a BC. $\mathrm{K}_{\text {sat }}$ increases with increasing of the location to the central flow path. $\mathrm{K}_{\mathrm{sat}}$ is lower near the inlet (Asleson et al., 2009).

2. TSS, $\mathrm{Zn}, \mathrm{Cu}$, Pband $\mathrm{P}$ have high values near the inlet suggesting heavy sediment, metal and pollutant deposition in the forebay area/ area near the inlet. They also have high values in the top soil layer i.e., near the surface (Johnson et al., 2016; Jones et al., 2013; Li et al., 2008; Muthanna et al., 2007; Paus et al., 2013; Li et al., 2008).

3. Organic content is low near the inlet as expected due to the high sediment and metal deposition. Organic content also decreases with increasing depth under the soil surface due to lesser biological activity in the lower soil layers (Paus et al., 2013).

4. There is seasonal variation in the $\mathrm{K}_{\text {sat }}$ values of the BC media, particularly in cold climate regions. Researchers have suggested that freeze thaw action could increase $\mathrm{K}_{\text {sat }}$ values by causing cracks in soil due to freezing of soil moisture based on observations (Denich et al., 2013; Ding et al., 2017; Serpi., 2015; Konrad et al., 2000; Xie et al., 2015). However, opposing observations (reduction in infiltration rate due to freeze thaw action) have also been made in laboratory experiments by some researchers (Baratta., 2013).

5. $\mathrm{K}_{\text {sat }}$ of the $\mathrm{BC}$ media is high right after installation and stabilizes to a steady state value. Even though the average $\mathrm{K}_{\text {sat }}$ of the $\mathrm{BC}$ media does not vary significantly as the system ages, the variability among the $\mathrm{K}_{\text {sat }}$ measurements within the $\mathrm{BC}$ increases as the system ages indicating the formation of preferential flow paths and soil cracks (Jenkins et. al., 2010; Barrett et. al., 2013; Coustumer et. al., 2008). There was no observation of reduction in metal retention functionality of the $\mathrm{BC}$. Leaching of nutrients out of the $\mathrm{BC}$ is also observed particularly in BCs with compost amendments (Logsdon, 2017; Hurley, 2017).

On this account, we can reasonably conclude that there is significant spatial and temporal heterogeneity within BCs and important internal processes may be overlooked when BCs are treated as black boxes by designers. 


\section{Methodology}

\subsection{Site Description}

A five-year-old Bioretention Cell (BC) located at the Kortright Centre for Conservation in Vaughan, Ontario, Canada (Figure 3-2 - left) is used as an investigation area for this study. This $\mathrm{BC}$ has an approximate area of $30 \mathrm{~m}^{2}$ and a catchment area of $265 \mathrm{~m}^{2}$ (Figure 3-1) comprised of an impervious parking lot constructed with recycled tire-derived rubber composite brick pavers (Eco-flex® Churchill).

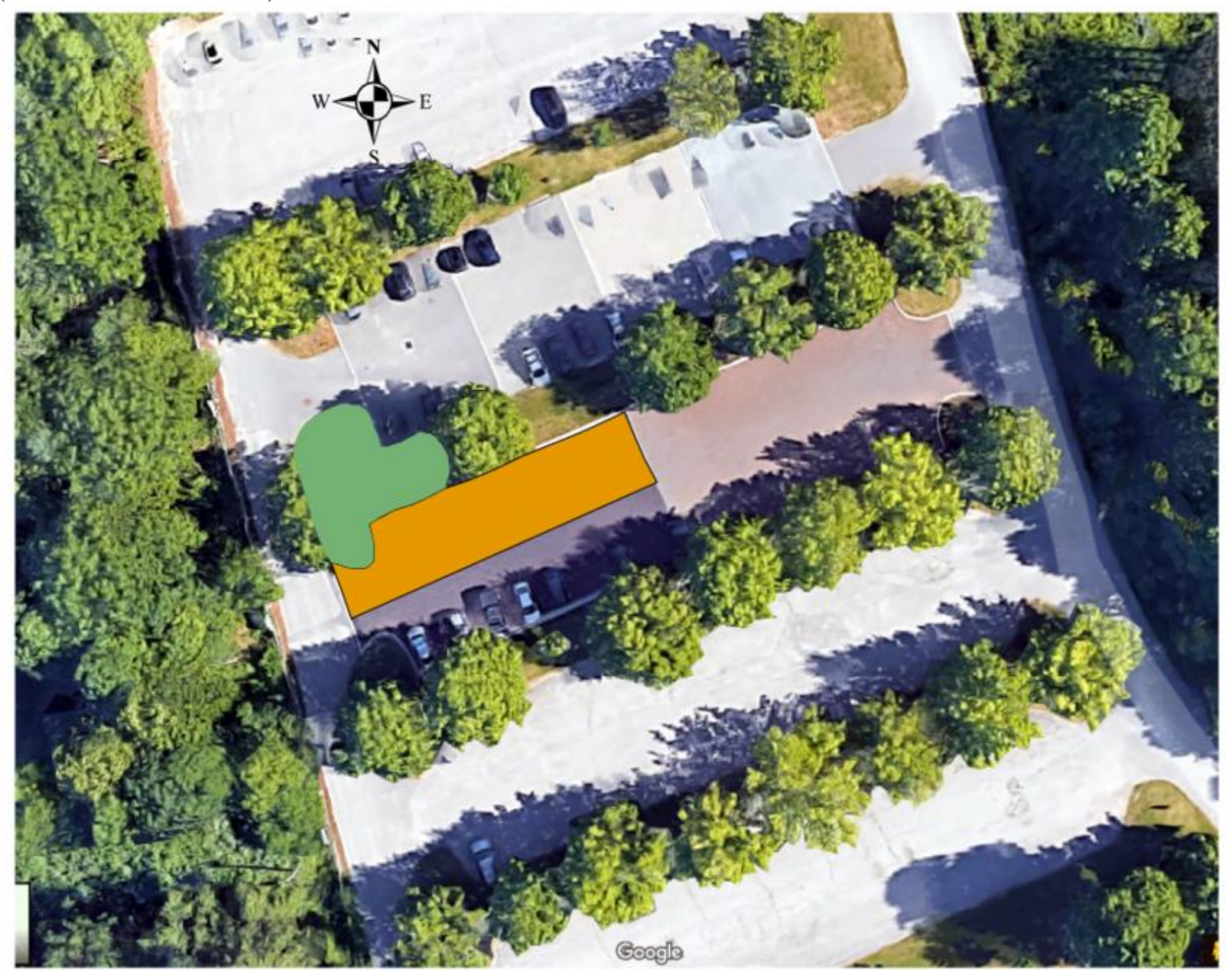

Legend

Bioretention Cell

Catchment Area

Figure 3-1: BC and the catchment area (From Google Maps) 

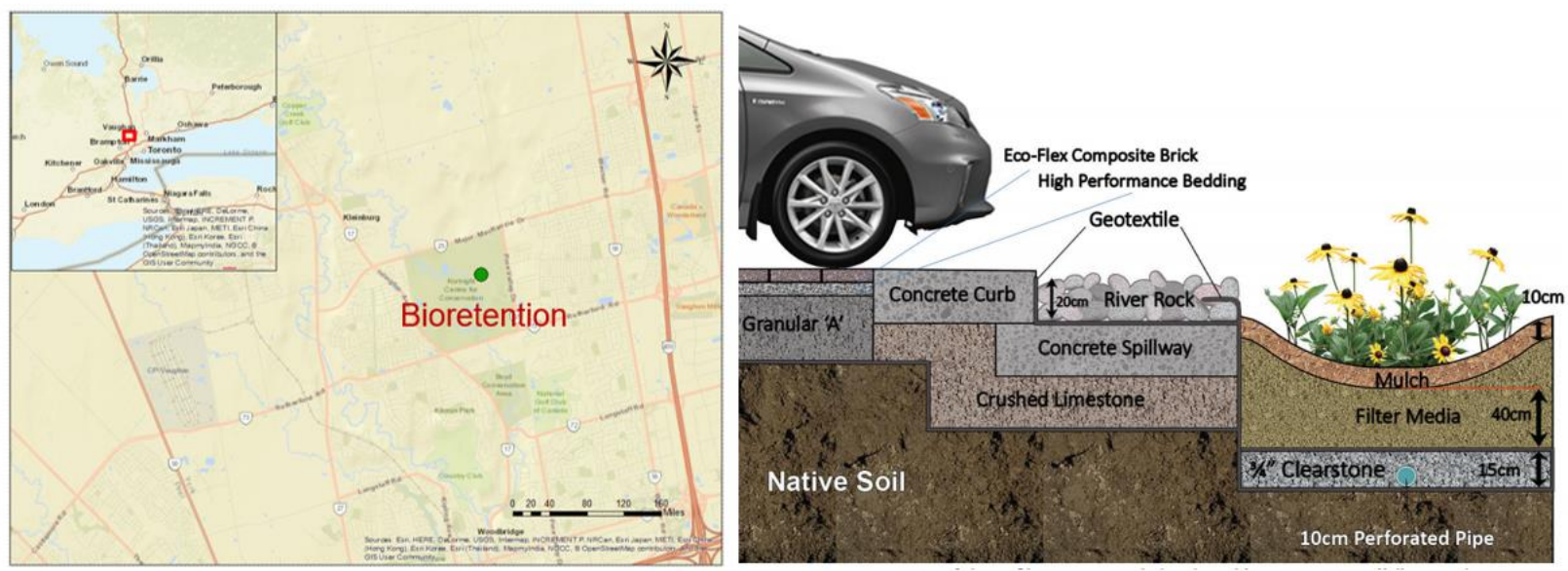

Figure 3-2: BC location - left and Layers \& their dimensions in the BC - right (Sustainable Technologies Evaluation Program, 2015).

The BC layers include $7.5 \mathrm{~cm}$ of shredded hardwood mulch, $40 \mathrm{~cm}$ of filter media $(60 \%$ sand and $40 \%$ silt/clay), $15 \mathrm{~cm}$ of $20 \mathrm{~mm}$ clear stone gravel and a geotextile (Figure 3-2). A perforated drainage pipe (10 cm diameter) is placed on top of the geotextile and transitions into a solid pipe as it leaves the $\mathrm{BC}$. The inlet into the $\mathrm{BC}$ consists of a $2 \mathrm{~m}^{2}$ concrete pad overlaid by a geotextile and river stone. Concrete collars were installed in the BC sub-base gravel perpendicular to the flow path to retain water and prevent uncontrolled release of water through the outlet. The $\mathrm{BC}$ drains to a monitoring hut where pipes are elevated to a level just below its base (Sustainable Technologies Evaluation Program, 2015).

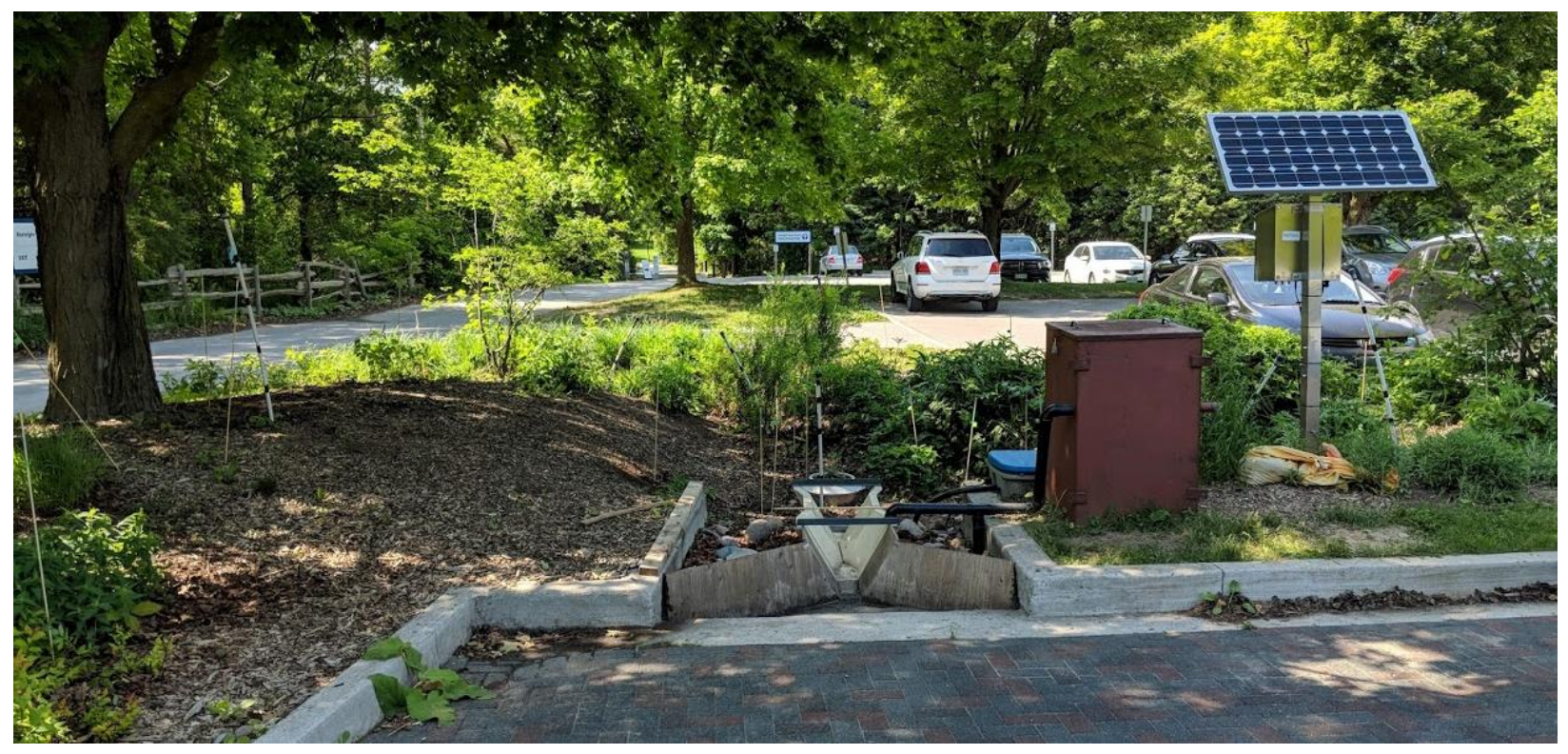

Figure 3-3: Front view of the BC showing the inlet and the marked locations 


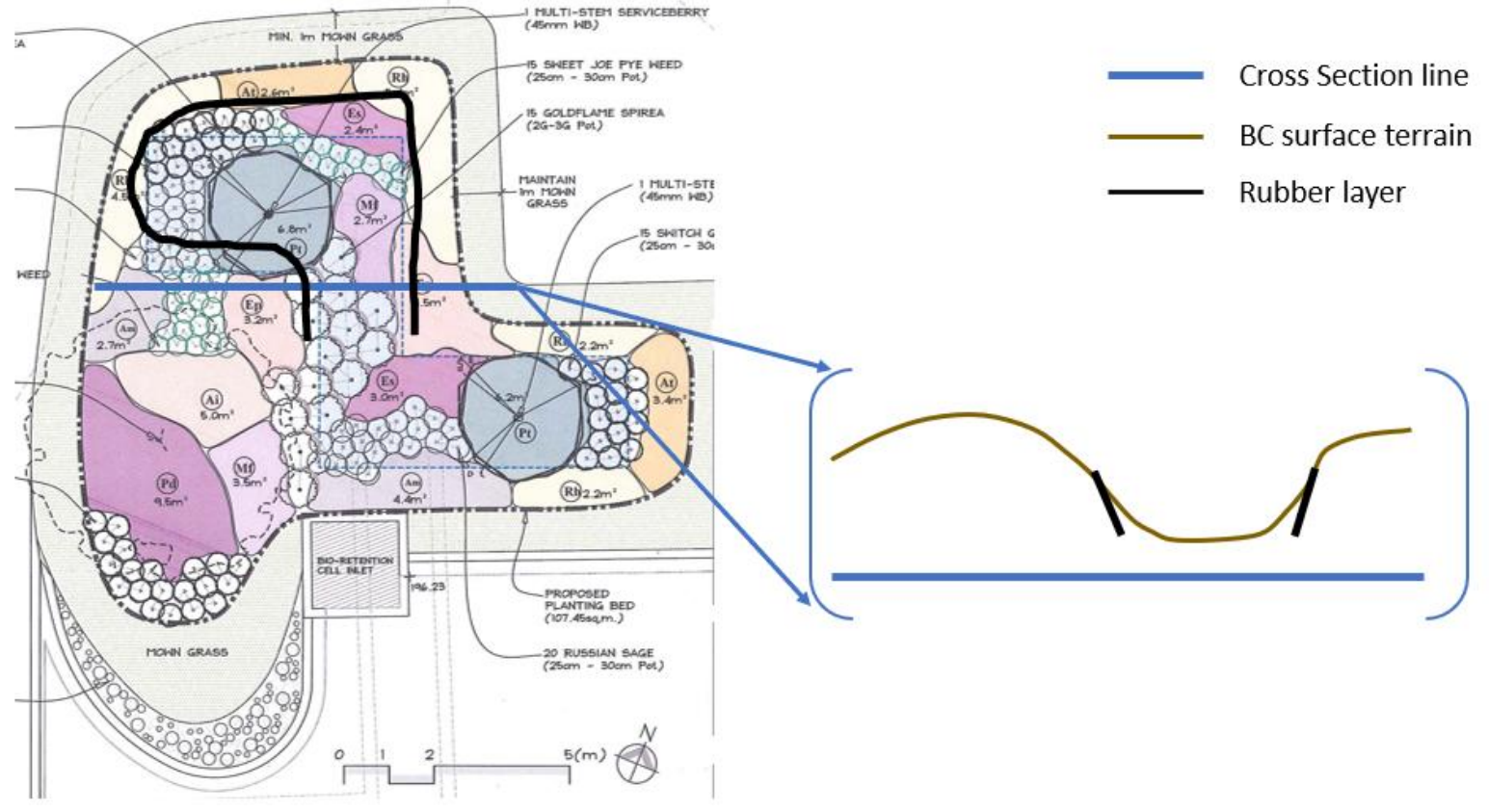

Figure 3-4: Rubber layer in the BC-Top View - Left and Cross-sectional View - Right (Graham, 2016).

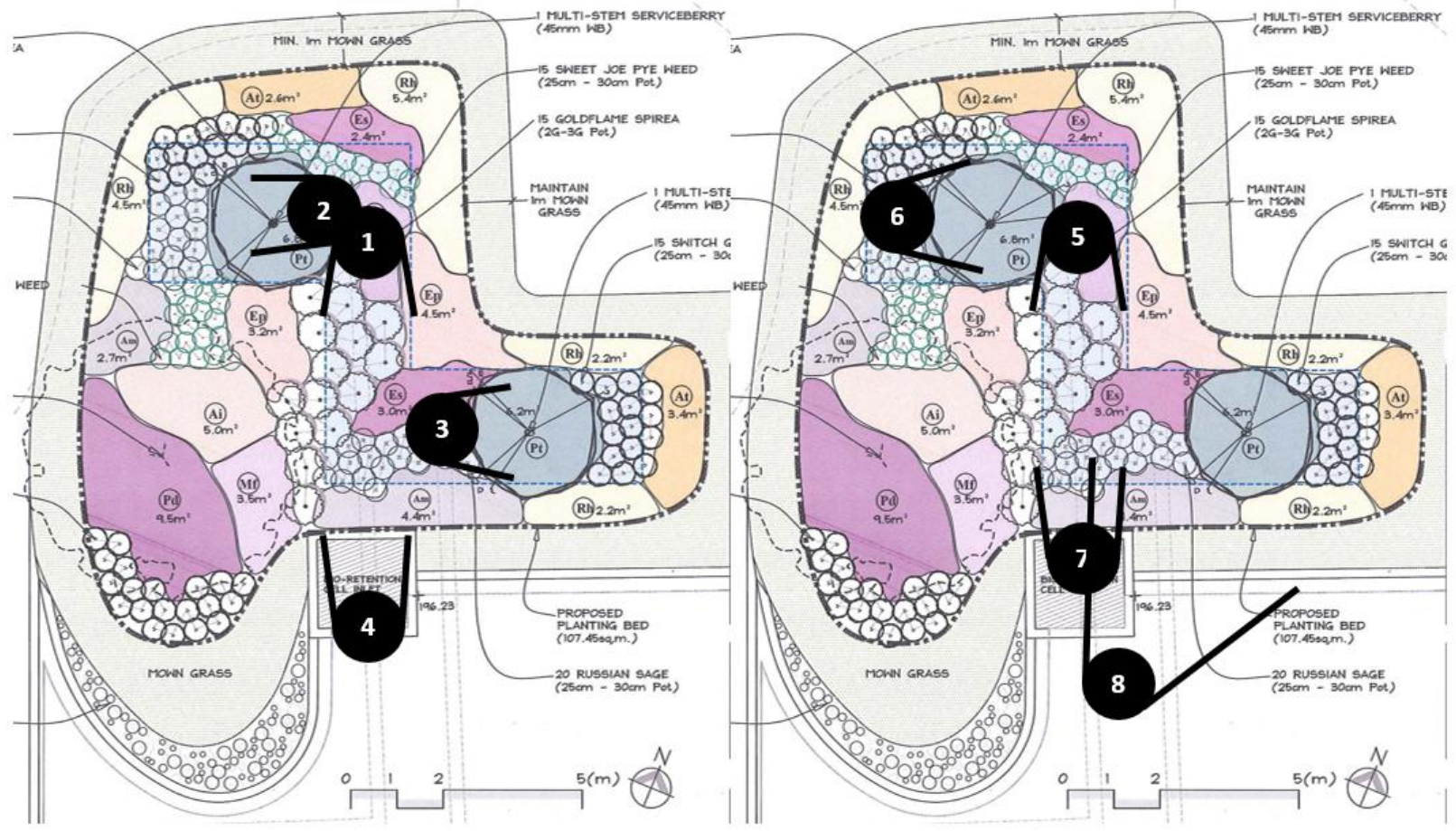

Figure 3-5: Map of focal points (shown in numbers) of the pictures shown in Figure 3-5 with their respective angular orientation (Graham, 2016). 
Figure 3-3 shows the front view of the BC with the inlet. The BC varies spatially in surface slope, plant density, shading, proximity to the inlet and proximity to the saturated zone. The lower half of the BC side slopes are lined with rubber sheets to prevent lateral seepage of water to the adjacent parking lot gravel sub base. The top view and cross-sectional view of the rubber layer are shown in Figure 3-4.
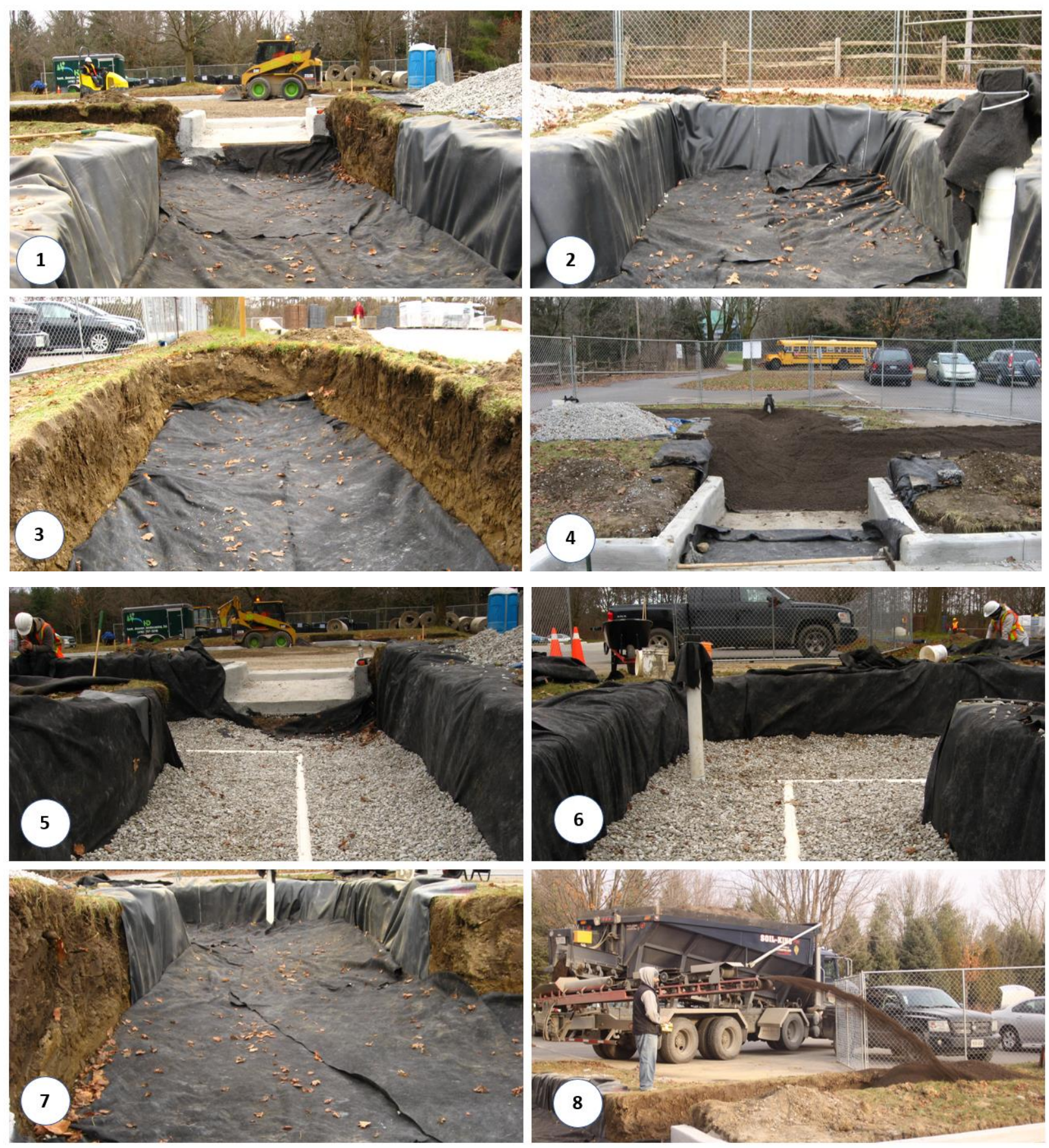

Figure 3-6: BC construction pictures numbered (Young, 2018). 
The $\mathrm{BC}$ has been operational since 2013. Water quantity and quality performance of the $\mathrm{BC}$ is measured during the first two years of its operation by Toronto and Region Conservation Authority (TRCA) staff (Sustainable Technologies Evaluation Program, 2015). Basic maintenance including pruning, replacing of the mulch layer and planting of dead plants is conducted annually.

The pictures taken during BC construction are shown in Figure 3-6. A map of the focal points of the pictures are shown along with the angular orientation to facilitate easy visualization in Figure 3-5. Pictures numbered 1, 2 and 7 in Figure 3-6 shows the rubber sheets installed to prevent lateral seepage. Picture numbered 8 in Figure 3-6 shows the BC media being poured into the site and picture numbered 4 in Figure 3-6 shows the BC media after it has been poured. Picture numbered 3 in Figure 3-6 shows the part of the BC central pathway without the rubber sheet. Pictures numbered 5 and 6 in Figure 3-6 shows the gravel sub-base layer before the geotextile is folded to separate the BC media from the gravel sub-base layer. Pictures numbered 1, 2 and 7 in Figure 3-6 shows the geotextile after it has been folded over the gravel sub-base layer.

\subsection{Spatial Location Selection}

Thirty points were selected throughout the BC as shown in Figure 3-7. Locations were selected to ensure that spatially diverse physical conditions (i.e. surface slope, plant density, whether it is in the water flow path or in the hills, and the distance from the inlet) were included. Points were marked with drive way markers and labelled (A - Z, A1- D1). The location of each point with respect to the origin (i.e. Inlet) was measured with tapes manually. The soil parameters were measured in seventeen points only as summarized in Table 3-1. Snow depths were measured in all the thirty points. Table 3-1 describes each monitoring point and measurements that were collected. 


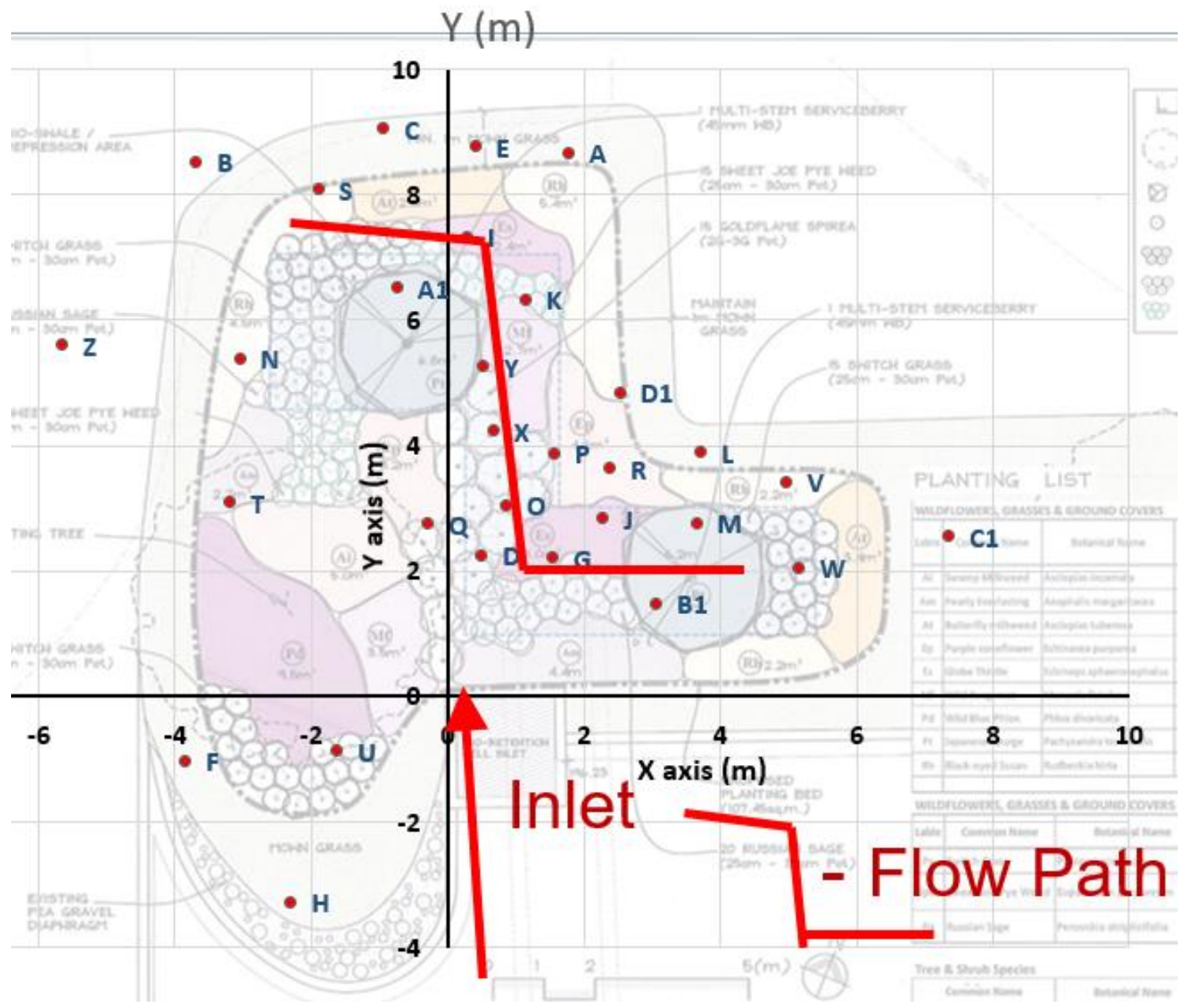

Figure 3-7: Map of points with their locations with respect to the inlet

Table 3-1: Points considered for snow depth and soil parameters measurement

\begin{tabular}{|l|l|l|}
\hline Spatial parameter & $\begin{array}{l}\text { Points considered for } \\
\text { snow depth }\end{array}$ & $\begin{array}{l}\text { Points considered for } \\
\text { soil parameters }\end{array}$ \\
\hline Central pathway & M,J,G,D,O,X,Y,S,I & M,O,Y,S,I \\
\hline On slope & W,V,R,Q,A1,E,C,K & W,V,R,Q,A1,E \\
\hline On hills & N,T,C1,B1,C1,L,D1,A,C & N,C1,A,T \\
\hline Near inlet & D,O,G,Q & O,Q \\
\hline High plant density & L,R,D1,F,U,C,N & R,F,N \\
\hline Near the outline of the BC & H,F,Z,B,C1,A,D1 & F,B,C1,A \\
\hline
\end{tabular}




\subsection{Saturated Hydraulic Conductivity (Ksat)}

\subsubsection{Guelph Permeameter (GP)}

Infiltration rates were measured on nine different dates with a GP throughout 2017/2018 (Table 3-2). When possible, measurements were collected in two consecutive days with similar weather conditions. Figure 3-8 shows a GP with its parts labelled. Table 3-2 lists the various dates at which the GP measurements were taken.

Table 3-2 Infiltration rate measurement dates, antecedent conditions and conditions during data collection

\begin{tabular}{|l|l|l|l|}
\hline No & Dates & $\begin{array}{l}\text { Antecedent } \\
\text { conditions }\end{array}$ & $\begin{array}{l}\text { Conditions during data } \\
\text { collection }\end{array}$ \\
\hline 1 & $6 / 5 / 2017$ and $6 / 6 / 2017$ & Wet & Light rain \\
\hline 2 & $7 / 10 / 2017$ and $7 / 11 / 2017$ & Wet & Sprinkles \\
\hline 3 & $8 / 15 / 2017$ and $8 / 16 / 2017$ & Wet & Dry \\
\hline 4 & $\begin{array}{l}9 / 19 / 2017 \text { and } 9 / 20 / 2017 \\
* 9 / 29 / 2017\end{array}$ & Dry & $\begin{array}{l}\text { Dry } \\
* \text { Rain }\end{array}$ \\
\hline 5 & $10 / 10 / 2017$ and $10 / 11 / 2017$ & Wet & Light rain \\
\hline 6 & $10 / 24 / 2017$ and $10 / 25 / 2017$ & Wet & Light rain \\
\hline 7 & $2 / 26 / 2018$ and $2 / 27 / 2018$ & Freezing & Dry \\
\hline 8 & $5 / 16 / 2018$ and $5 / 17 / 2018$ & Wet & Dry \\
\hline 9 & $6 / 8 / 2018$ & Dry & Dry \\
\hline$*$ denotes that some measurements are found to be erroneous and are measured again later \\
\hline
\end{tabular}

All measurements were completed at a depth of $15 \mathrm{~cm}$ below the surface. For each location, two measurements were completed, one with a $5 \mathrm{~cm}$ hydraulic head and another with a $10 \mathrm{~cm}$ hydraulic head. Infiltration rates from both measurements are used to arrive at the $\mathrm{K}_{\mathrm{sat}}$ as per Soilmoisture Corporation recommendations (Eijkelkamp Agrisearch Equipment, 2011). 


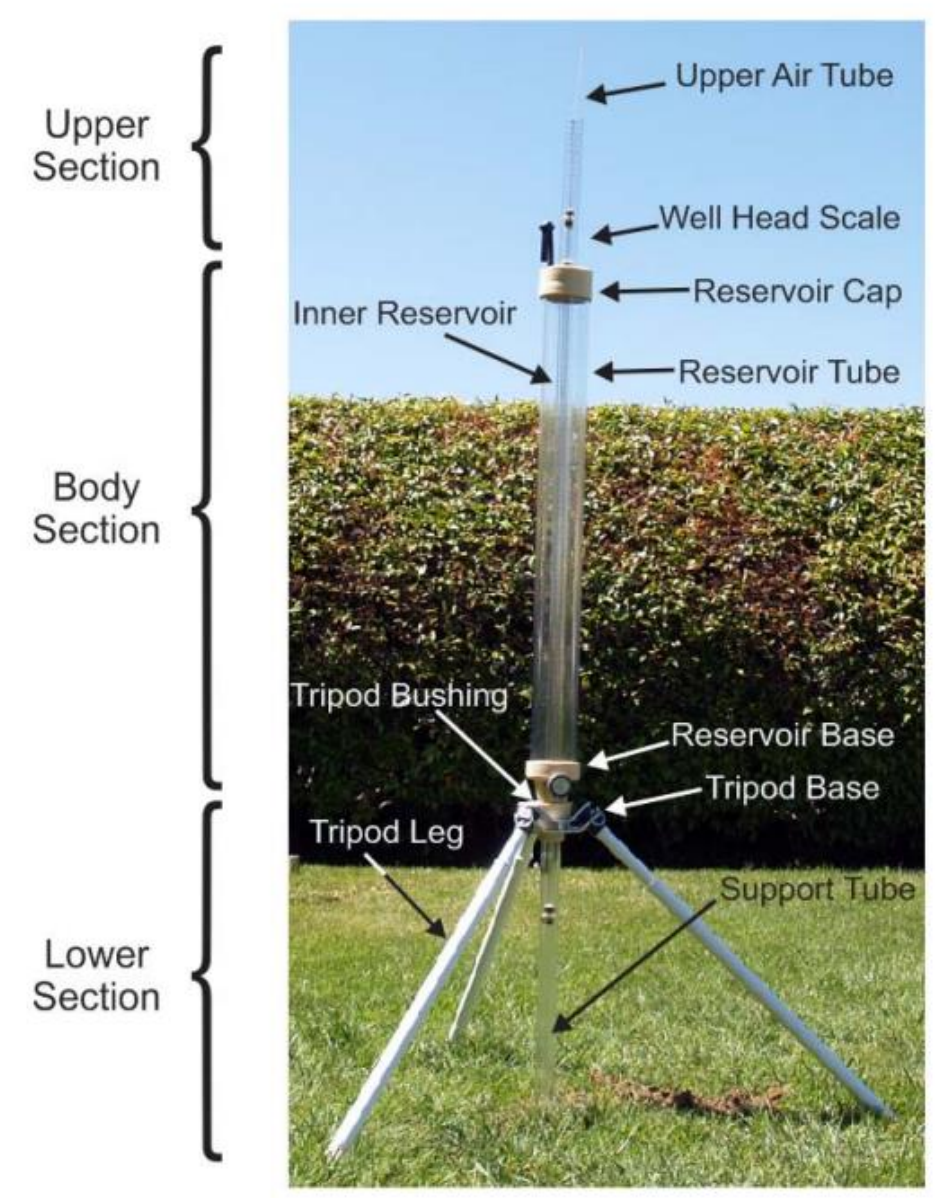

Figure 3-8: A GP with its parts labelled (Eijkelkamp Agrisearch Equipment, 2011).

During the first four data sets infiltration measurements were repeated in the the same bore hole. This practice was discontinued after 9/19/2017 because it was suspected that preferential flow paths were forming below the GP. This phenomenon is suspected to have caused excessive infiltration rates observed at locations $N$ and $F$ on 9/19/2017 and 9/20/2017. Consequently, measurements were repeated at these locations again on 9/29/2017. The antecedent conditions were the same in all the three dates mentioned. After this observation of preferential flow paths, the holes made already were closed and a new hole was augured for every measurement during the remaining data collection period. Figure 3-9 shows the GP in the BC at location $\mathrm{N}$ on the left and a $15 \mathrm{~cm}$ deep hole made in the $\mathrm{BC}$ on the right. 

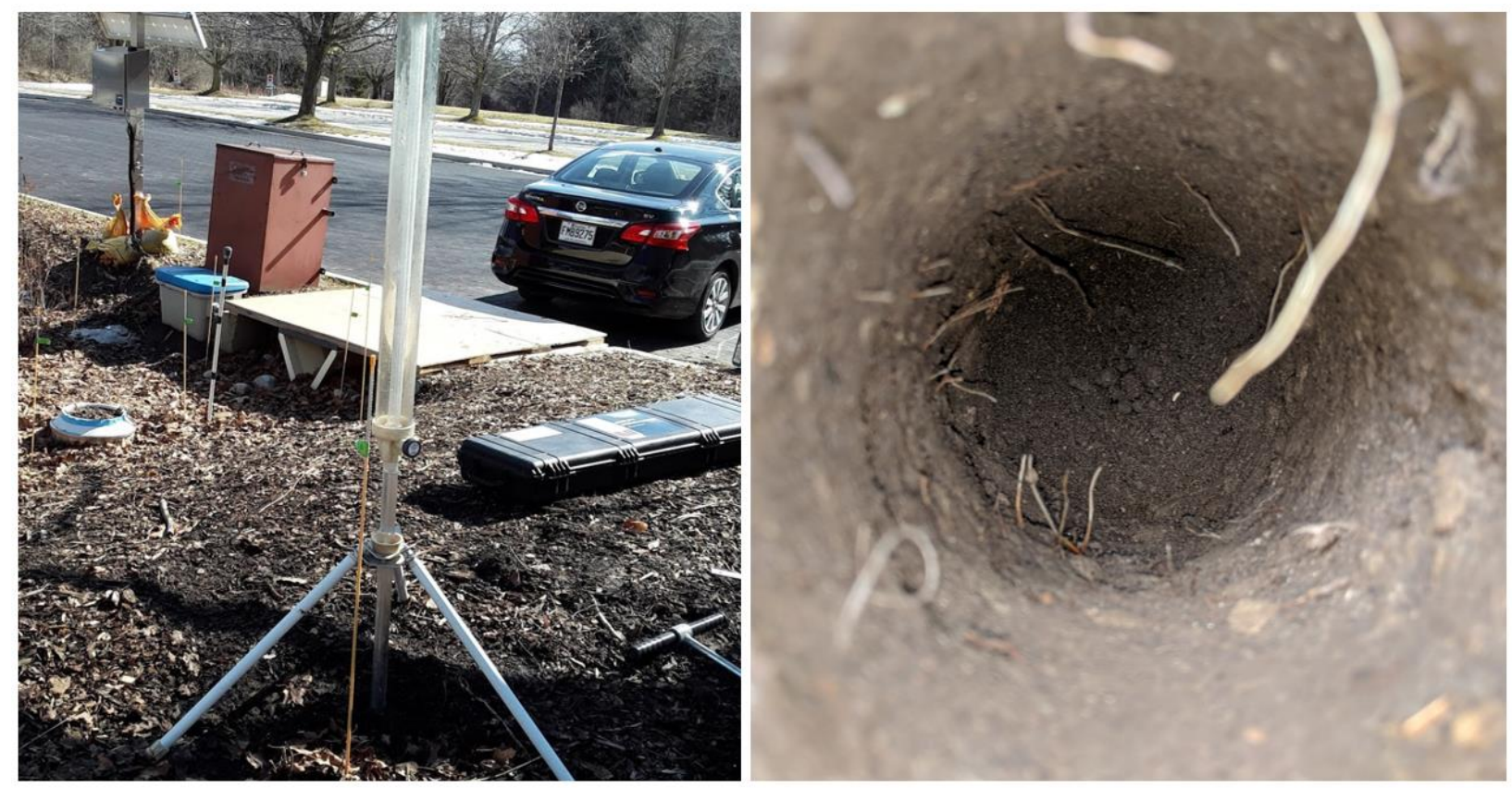

Figure 3-9: GP in the BC (Left) and a $15 \mathrm{~cm}$ deep hole for the GP (Right).

\subsection{2 $\mathrm{K}_{\text {sat }}$ calculation}

Infiltration rates can be used to estimate a soil's $\mathrm{K}_{\mathrm{sat}}$. Methods generally assume a bore hole of specific diameter and depth, soil type and require a with an observed steady state infiltration rate t. Two methods i.e., Elrick \& Reynolds (1992) and Radcliffe \& West (2015) are used to calculate $\mathrm{K}_{\text {sat }}$ from the observed steady state infiltration rate.

\subsubsection{Radcliffe et al. (2015) Method}

The equations from SOILMOISTURE Ksat Calculator was used to estimate the $\mathrm{K}_{\text {sat. }}$ In all calculations, the BC media was considered to be Sandy Clay Loam. SOILMOISTURE Ksat Calculator uses the Radcliffe et al. (2015) method to calculate the $\mathrm{K}_{\text {sat. }}$ This method was formulated to eliminate the necessity of two infiltration measurements with different heads to calculate $\mathrm{K}_{\mathrm{sat}}$ and to improve the accuracy of the resultant $\mathrm{K}_{\mathrm{sat}}$ by including the effect of gravity and capillarity on water flow (Radcliffe et al., 2015). The equations used are as shown below and they are only for unstructured medium sands, fine sands and loams.

$$
Q_{1}=\bar{I}_{1} \times 35.22 \quad[5 \mathrm{~cm} \mathrm{depth}]
$$




$$
\begin{aligned}
& Q_{2}=\bar{I}_{2} \times 35.22 \quad[10 \mathrm{~cm} \text { depth }] \\
& G_{1}=\frac{1}{2 \pi} \times\left[0.083+0.514 \times \frac{H_{1}}{R}-0.053 \times\left[\frac{H_{1}}{R}\right]^{2}+0.002 \times\left[\frac{H_{1}}{R}\right]^{3}\right] \\
& K_{\text {sat }} \text { for } H_{1}=\frac{Q_{1}}{\pi a^{2}\left[1+\frac{H_{1}\left(\lambda+H_{1}\right)}{G_{1} \times \pi R^{2}}\right]} \\
& G_{2}=\frac{1}{2 \pi} \times\left[0.083+0.514 \times \frac{H_{2}}{R}-0.053 \times\left[\frac{H_{2}}{R}\right]^{2}+0.002 \times\left[\frac{H_{2}}{R}\right]^{3}\right] \\
& K_{\text {sat }} \text { for } H_{2}=\frac{Q_{2}}{\pi a^{2}\left[1+\frac{H_{2}\left(\lambda+H_{2}\right)}{G_{2} \times \pi R^{2}}\right]} \\
& \text { Overall } K_{\text {sat }}=\frac{K_{\text {sat }} \text { for } H_{1}+K_{\text {sat }} \text { for } H_{2}}{2}
\end{aligned}
$$

Where,

- $\mathrm{G}_{1}$ and $\mathrm{G}_{2}$ are geometric factors that depend on the ratio of $\mathrm{H} / \mathrm{R}$.

- $\mathrm{H}_{1}$ and $\mathrm{H}_{2}$ are $5 \mathrm{~cm}$ and $10 \mathrm{~cm}$ respectively. These are the two water depths at which the experiment is replicated at every location.

- $\mathrm{I}_{1}$ and $\mathrm{I}_{2}$ are the steady state infiltration rates in $\mathrm{cm} / \mathrm{min}$ for water depths $\mathrm{H}_{1}$ and $\mathrm{H}_{2}$ respectively.

- $\mathrm{Q}_{1}$ and $\mathrm{Q}_{2}$ are the steady state infiltration rates in $\mathrm{cm}^{3} /$ min for water depths $\mathrm{H}_{1}$ and $\mathrm{H}_{2}$ respectively.

- $\mathrm{R}$ is the radius of the borehole which is on average $3 \mathrm{~cm}$.

$\lambda=8.3$ (for unstructured medium sands, fine sands and loams)

Radcliffe method is able to calculate $\mathrm{K}_{\text {sat }}$ with one steady-state infiltration rate. However, since infiltration rates were measured using both depths for Elrick and Reynolds method, the both $\mathrm{K}_{\mathrm{sat}}$ values are averaged in the Radcliffe method calculations for better accuracy. 


\subsubsection{Elrick and Reynolds (1992) Method}

This method improved upon several older methods of $\mathrm{K}_{\text {sat }}$ calculation by partitioning the flow into its field-saturated and unsaturated components (Elrick and Reynolds, 1992). The two head combined reservoir method used to determine the $\mathrm{K}_{\text {sat }}$.

$$
\begin{gathered}
G_{3}=\frac{H_{2} C_{1}}{\pi\left(2 H_{1} H_{2}\left(H_{2}-H_{1}\right)+R^{2}\left(H_{1} C_{2}-H_{2} C_{1}\right)\right)} \\
G_{4}=\frac{H_{1} C_{2}}{\pi\left(2 H_{1} H_{2}\left(H_{2}-H_{1}\right)+R^{2}\left(H_{1} C_{2}-H_{2} C_{1}\right)\right)} \\
C_{1}=\left[\frac{\frac{H_{1}}{R}}{2.074+\frac{0.093 \times H_{1}}{R}}\right]^{0.754} \\
C_{2}=\left[\frac{\frac{H_{2}}{R}}{2.074+\frac{0.093 \times H_{1}}{R}}\right]^{0.754} \\
K_{\text {sat }}=G_{4} Q_{2}-G_{3} Q_{1}
\end{gathered}
$$

Where,

- $\mathrm{C}_{1}$ and $\mathrm{C}_{2}$ are shape factors.

- $\mathrm{G}_{3}$ and $\mathrm{G}_{4}$ are geometric factors. All other parameters are the same as outlined for Equation $2-8$.

If the calculated $\mathrm{K}_{\text {sat }}$ is negative, it is because, $\mathrm{I}_{1}$ with $5 \mathrm{~cm}$ head is higher than $\mathrm{I}_{2}$ with $10 \mathrm{~cm}$ water depth. If that is the case, a sub-optimal solution is to find $K_{\text {sat }}$ separately without combining $5 \mathrm{~cm}$ and $10 \mathrm{~cm}$ depth measurements and averaging them to get the overall $\mathrm{K}_{\mathrm{sat}}$. In this case the following formulae applies.

$$
\begin{aligned}
& K_{\text {sat }} \text { for } H_{1}=\frac{C_{1} \times Q_{1}}{2 \pi H_{1}^{2}+\pi a^{2} C_{1}+2 \pi\left(\frac{H_{1}}{a^{*}}\right)} \\
& K_{\text {sat }} \text { for } H_{2}=\frac{C_{2} \times Q_{2}}{2 \pi H_{2}^{2}+\pi a^{2} C_{2}+2 \pi\left(\frac{H_{2}}{a^{*}}\right)}
\end{aligned}
$$

Where,

- $\quad a^{*}$ is the macroscopic capillary length parameter, 0.12 for unsaturated medium and fine sands. 


\subsection{Soil Analysis}

Two soil samples were collected from the 17 points on Oct $25^{\text {th }}, 2017$. First, a bulk density measuring kit was used to collect undisturbed samples at 15 to $20 \mathrm{~cm}$ depth below the BC surface. Rubber caps were used to close both sides of the cylinder to ensure that the soil inside is not disturbed and to make it a closed system. Following, disturbed samples were collected manually. The wooden mulch at the top was removed manually so that the soil was visible. The top 10 to 15 $\mathrm{cm}$ of soil was removed using a spade. The soil below was collected in zipper bags using the spade. Samples were analyzed at University of Toronto labs...

\subsubsection{Bulk density, moisture content and organic content}

Standard ASTM tests were completed to determine bulk density, moisture content and organic content of soil samples (ASTM C29/C29M - 17a, 2017 and ASTM D2974 - 14, 2014).

Samples were weighed, and the bulk densities were calculated using the formulae below.

$$
B D=\frac{W_{s}}{V_{s}} \times \frac{1000000}{1000}
$$

Where,

- $\mathrm{BD}=$ Bulk density $\left(\mathrm{Kg} / \mathrm{m}^{3}\right)$

- $\mathrm{W}_{\mathrm{s}}=$ Weight of the soil $(\mathrm{g})$

- $\mathrm{V}_{\mathrm{s}}=$ Volume of the soil $\left(\mathrm{cm}^{3}\right)$

$$
W_{s}=W_{t}-W_{c}-W_{r}
$$

Where,

- $\mathrm{W}_{\mathrm{t}}=$ Total weight of the cylinder with the soil $(\mathrm{g})$

- $\mathrm{W}_{\mathrm{c}}=$ Weight of the cylinder $(\mathrm{g})$

- $\mathrm{W}_{\mathrm{r}}=$ Weight of the rubber caps on both ends of the cylinder $(\mathrm{g})$. 

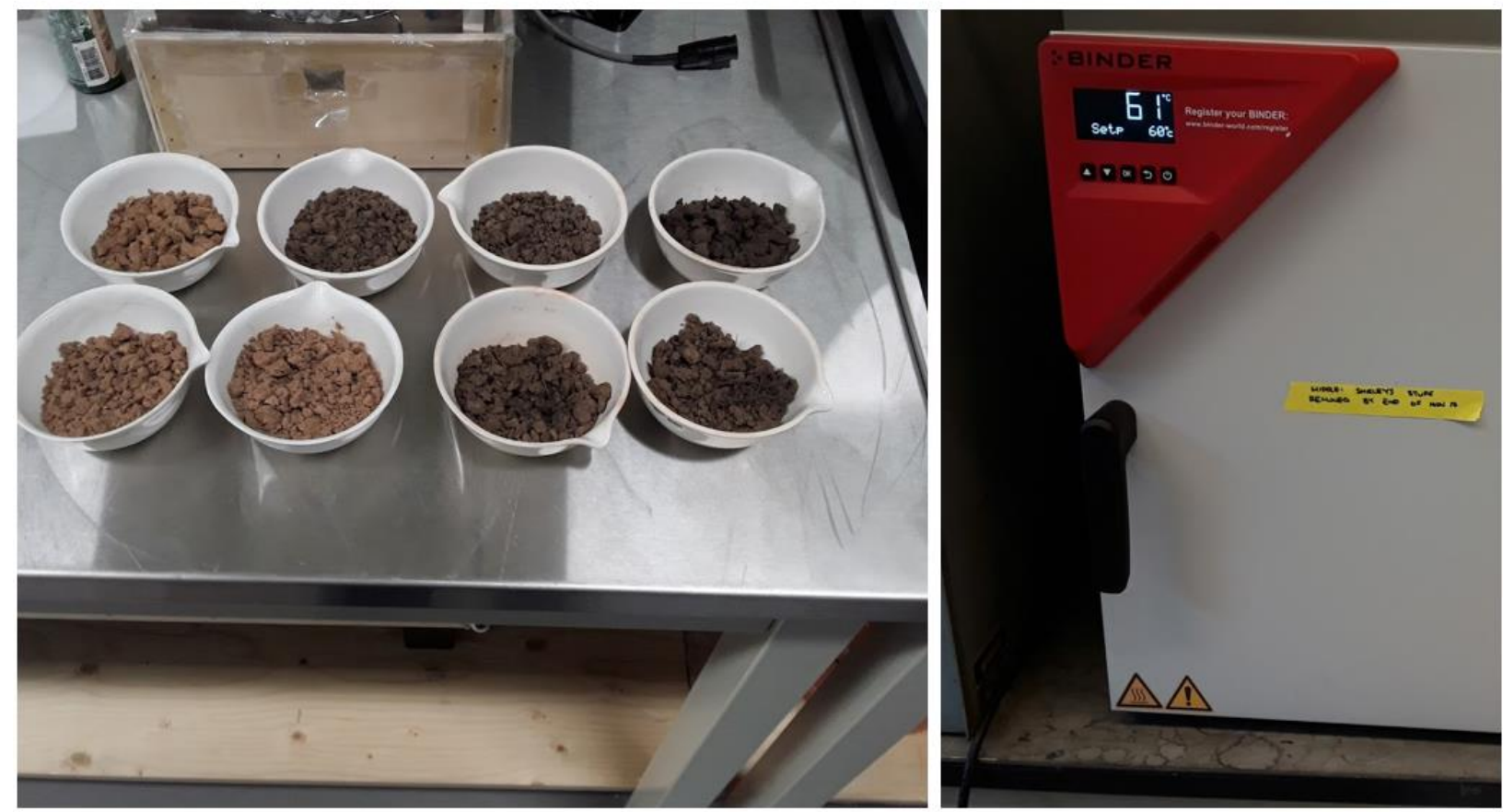

Figure 3-10 Eight wet soil samples in porcelain dishes to be dried in the oven (Left) and the oven (right)

After weighing for bulk density, the soil samples were transferred to individual washed porcelain dishes. The soil samples were then dried at $115^{\circ} \mathrm{C}$ in an oven for a minimum of 24 hours (Figure 3-11). The dried samples are taken and weighed again. The percent moisture content is calculated using the following formulae.

$$
\begin{aligned}
M C & =\frac{W_{m}}{W_{w+p}} \times 100 \% \\
W_{m} & =W_{w+p}-W_{d+p}
\end{aligned}
$$

Where,

- $\quad \mathrm{MC}=$ Moisture content $(\%)$

- $\mathrm{W}_{\mathrm{m}}=$ Weight of moisture in the soil sample $(\mathrm{g})$

- $\mathrm{W}_{\mathrm{w}+\mathrm{p}}=\mathrm{Weight}$ of wet soil sample including the porcelain dish $(\mathrm{g})$

- $\mathrm{W}_{\mathrm{d}+\mathrm{p}}=$ Weight of soil sample after being oven dried including the porcelain dish $(\mathrm{g})$

After being oven dried, the sample is then maintained at $450{ }^{\circ} \mathrm{C}$ in a Muffle furnace overnight to burn away the organic matter. The sample is then weighed again to find out the 
inorganic weight of the soil. The percent organic matter of the soil is calculated using the following formulae.

$$
\begin{aligned}
& O C=\frac{W_{o}}{W_{d+p}} \times 100 \% \\
& W_{o}=W_{d+p}-W_{i+p}
\end{aligned}
$$

Where,

- $\quad$ OC = Organic content $(\%)$

- $\mathrm{W}_{\mathrm{o}}=$ Weight of the organic matter in the soil $(\mathrm{g})$

- $\mathrm{W}_{\mathrm{d}+\mathrm{p}}=$ Weight of the soil with organic matter and porcelain dish $(\mathrm{g})=$ Weight of soil sample after being oven dried including the porcelain dish $(\mathrm{g})$

- $\mathrm{W}_{\mathrm{i}+\mathrm{p}}=$ Weight of inorganic soil and porcelain dish $(\mathrm{g})$

\subsubsection{Soil Particle Distribution}

Standard ASTM tests were completed to determine the soil particle distribution (ASTM D4513 - 11, 2017) with the collected disturbed samples. Soil was sieved with No. 1-1/2, 3/4, 3/8, 4, 10, 16, 30, 50, 100 and 200 sieves.

Standard ASTM procedures are followed. However, the soil had many lumps. Therefore, after the sample is dried, it is broken down using mortar and pestle iron so that no visible lumps of particles are observed as shown in Figure 3-11.
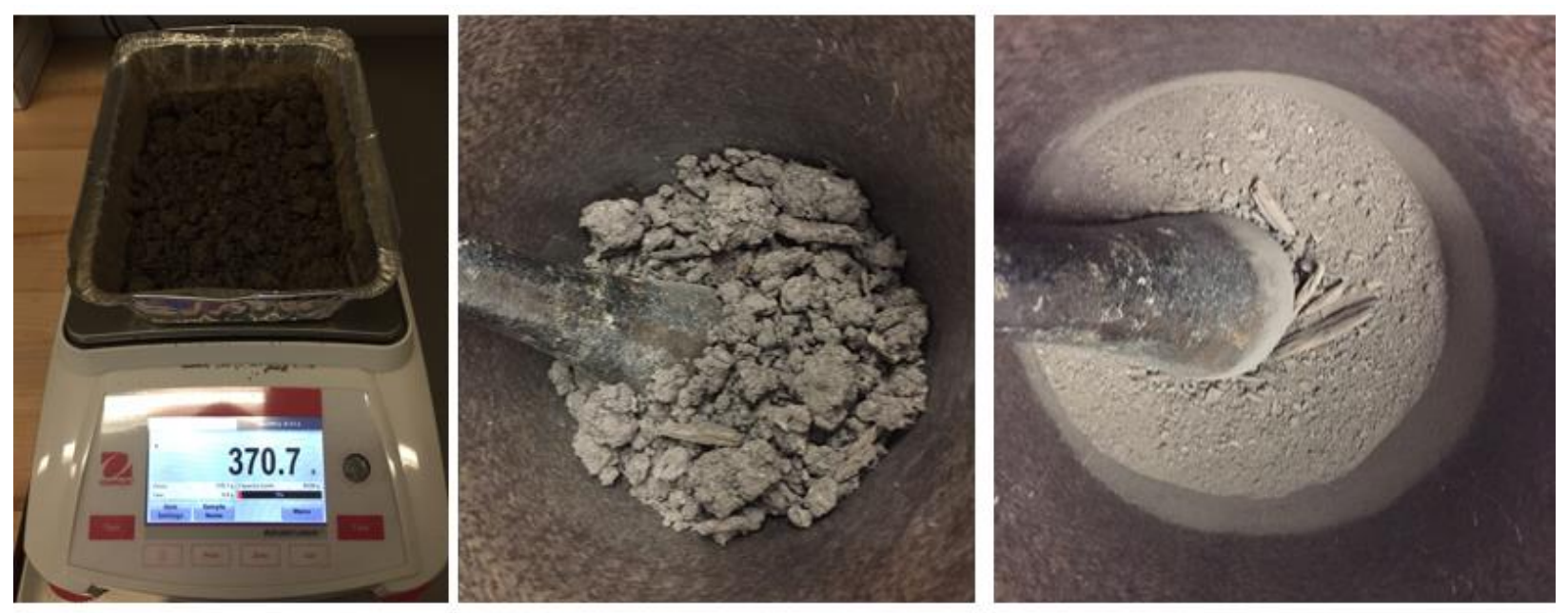

Figure 3-11: Weighing the soil samples after drying (left), before breaking (middle) and after breaking (right). 
Moreover, All the pre-cleaned individual sieves are taken and coated with antistatic spray. Antistatic coating is performed before every experiment run to ensure that there are no soil particles smaller than any mesh size sticking in the mesh due to magnetic forces (sieve shaker has an electric motor and that might cause magnetic induction). Soil being poured into the fine sieve set and soil retained in sieve no. 16 after shaking are shown in Figure 3-12 left and right respectively.
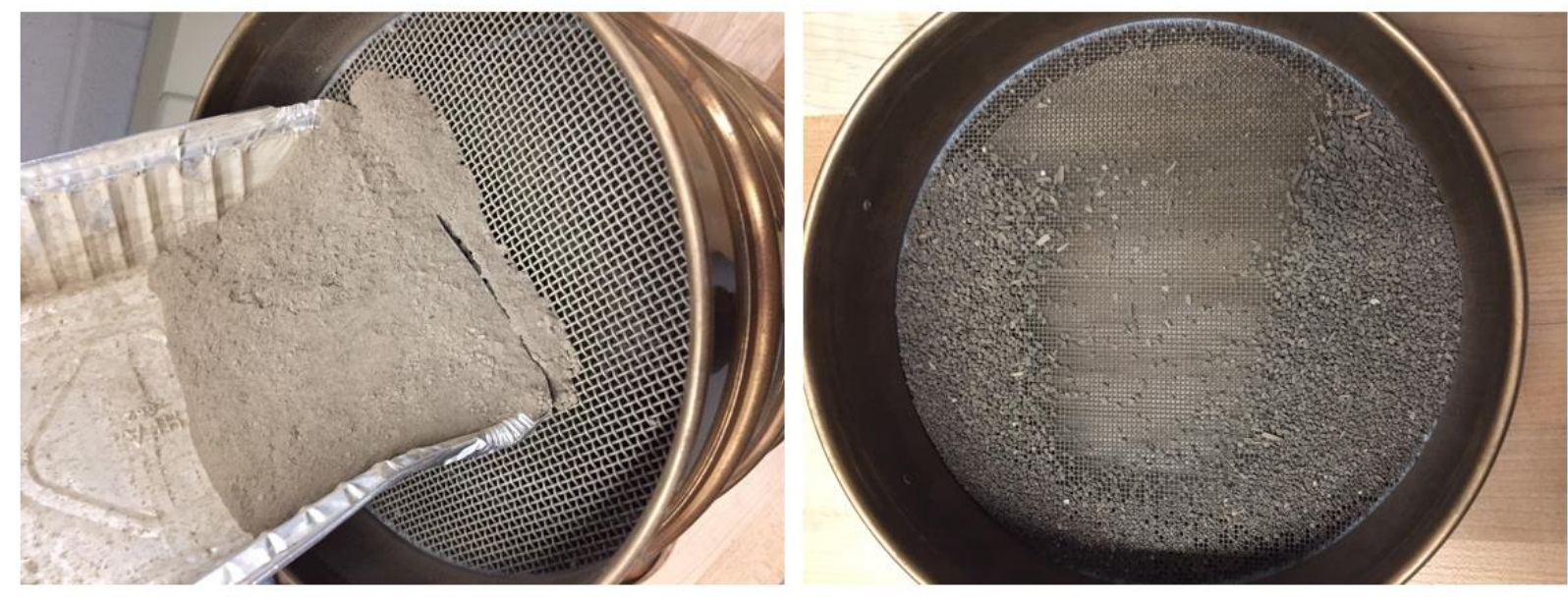

Figure 3-12: Soil being poured into the fine sieve set (left) and soil retained in sieve no. 16 after shaking (right).

Tables are produced as shown in Table 7-6, using the data collected from the sieve analysis experiments. The following formula is used to calculate the percentage of overall weight retained in each individual sieve.

$$
\% \text { Weight Retained }=\frac{\text { Weight of soil in a particular sieve }}{\text { Sum of weights of soils in all sieves }}
$$

The weight of soil that is above a particular sieve size can be calculated by arranging the weights in the descending order of mesh sizes and cumulatively adding the weight retained at each mesh with all the weights retained in all the other bigger meshes. This cumulative \% weight retained in each sieve is then plotted in a log normal graph with the mesh sizes along the $\mathrm{x}$ axis $(\log )$ and the \% cumulative weight retained on the y axis (cartesian) as shown from Figure 7-2 to Figure 7-18. $\mathrm{D}_{60}$, the grain diameter of $60 \%$ passing at a specific location is calculated by measuring the corresponding mesh size for $60 \%$ cumulative soil weight as shown from Figure 7-2 
to Figure 7-18. Similarly, $\mathrm{D}_{30}$ and $\mathrm{D}_{10}$ are also calculated. The coefficient of uniformity, $\mathrm{C}_{\mathrm{u}}$ is a natural shape parameter and is calculated using the following equation.

$$
C_{u}=\frac{D_{60}}{D_{10}}
$$

The coefficient of curvature, $\mathrm{C}_{\mathrm{c}}$ is also a shape parameter and is calculated using the following equation.

$$
C_{u}=\frac{\left(D_{30}\right)^{2}}{D_{10} \times D_{60}}
$$

\subsubsection{Particle Density and Porosity}

Particle densities were measured using the Quantachrome Stereopycnometer.Soil samples were dried by heating in an oven at $115^{\circ} \mathrm{C}$ overnight. Following $10 \mathrm{~g}$ of soil was broken down using a mortar and pestle iron to facilitate access to all soil pores by nitrogen gas within the Quantachrome Stereopycnometer.

and the prepared samples were placed inside the Quantachrome Stereopycnometer as shown in Figure 3-13 andnitrogen gas is allowed to accumulate in the soil container and the pressure is measured. Using the volume of gas required to attain the pressure, the volume of soil already present in the container is determined.
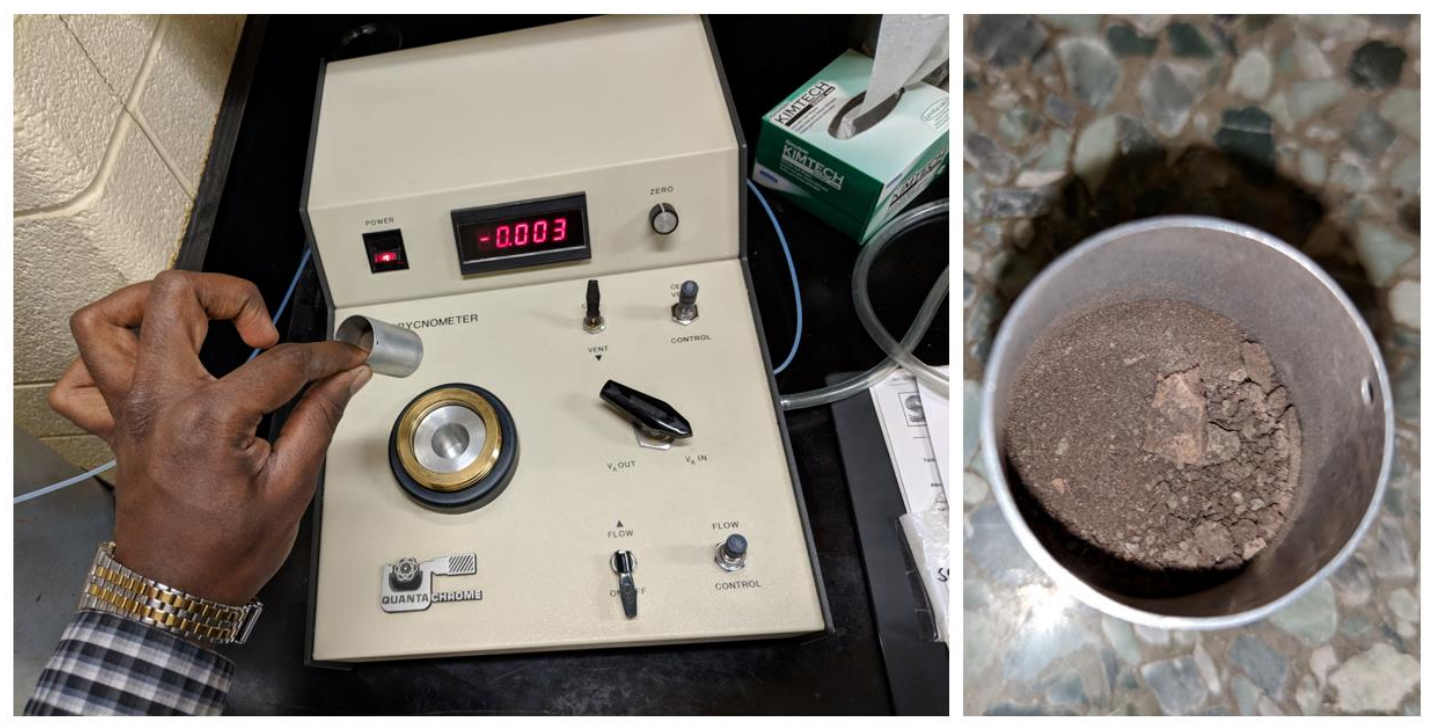

Figure 3-13: Sample holder \& the Quantachrome Stereopycnometer (left) and the soil sample inside the sample holder (right). 
The weight of the sample soil is measured before measuring the volume. The volume of particles in the selected sample is calculated using the formula provided below.

$$
V_{p}=V_{c}+\frac{V_{a}}{\left(1-\frac{P_{2}}{P_{3}}\right)}
$$

Where,

- $\mathrm{V}_{\mathrm{p}}=$ Volume of soil (cc).

- $\mathrm{V}_{\mathrm{c}}=$ Volume of sample cell holder $(\mathrm{cc})$.

- $\mathrm{V}_{\mathrm{a}}=$ Added volume of nitrogen gas.

- $\mathrm{P}_{2}=$ Pressure reading after pressurizing cell.

- $\mathrm{P}_{3}=$ Pressure reading after adding $\mathrm{V}_{\mathrm{a}}$.

It should be noted that $\mathrm{V}_{\mathrm{c}}$ and $\mathrm{V}_{\mathrm{a}}$ are calibration values and they might change as the equipment ages. Hence, they are measured again during June 2018 by the lab manager.

The particle density of the soil is calculated using the following formula.

$$
P D=\frac{W_{s p}}{V_{p}}
$$

Where,

- $\quad \mathrm{Wsp}=$ Weight of soil sample taken for particle density measurement.

- $\quad \mathrm{PD}=$ Particle density of the soil.

The porosity of the soil is calculated using the following formula.

$$
P t=1-\frac{B D}{P D}
$$

Where,

- $\quad \mathrm{Pt}=$ Porosity of the soil.

\subsection{Winter Measurements}

\subsubsection{Snow Depth and Density}

Snow depth and density was measured in all thirty points on nine different dates manually with a ruler. Table 3-3 summarizes the measurement dates and antecedent conditions. Snow density measurements were completed with a $500 \mathrm{ml}$ glass jar. is the jar was inverted and thrust through the undisturbed snow layer in the ground. A trowel was then used to remove the snow 
adjacent to the measuring jar till the lower end of the jar can be seen. Then the trowel is pierced into the snow right beneath the jar such as it closes the mouth of the jar. The jar is then removed and the volume of snow in the jar is arrived at using the graduations in the measuring jar.

Table 3-3: Snow depth and density data collection dates and antecedent conditions

\begin{tabular}{|l|l|l|}
\hline No & Date & Antecedent Conditions \\
\hline 1 & $12 / 22 / 2016$ & Snow \\
\hline 2 & $1 / 11 / 2017$ & Rain on snow melt \\
\hline 3 & $1 / 19 / 2017$ & Rain on snow melt \\
\hline 4 & $2 / 1 / 2017$ & Snow \\
\hline 5 & $2 / 8 / 2017$ & Rain on snow melt \\
\hline 6 & $2 / 13 / 2017$ & Snow \\
\hline 7 & $2 / 15 / 2017$ & Snow \\
\hline 8 & $1 / 8 / 2018$ & Snow \\
\hline 9 & $1 / 17 / 2018$ & Snow \\
\hline 10 & $2 / 5 / 2018$ & Snow \\
\hline 11 & $2 / 26 / 2018$ & Rain on snow melt \\
\hline
\end{tabular}

In most of the measurements, the snow did not fill the jar completely. So, it is not possible to measure the snow volume since the jar does not have graduations at the top and the graduations start from the bottom. The jar is twirled rapidly so that the snow settles near the bottom of the cylinder before measuring the snow volume. The weight of the jar is also measured before and after collecting snow. Snow density is then calculated using the following formula.

$$
S D=\frac{W J_{a}-W J_{b}}{V_{s}}
$$

Where,

- $\quad \mathrm{SD}=$ Snow density,

- $\mathrm{WJ}_{\mathrm{a}}=$ Weight of jar after collecting snow

- $\mathrm{WJ}_{\mathrm{b}}=\mathrm{Weight}$ of jar before collecting snow

- $\mathrm{V}_{\mathrm{s}}=$ Volume of snow

Before the availability of a weighing scale, the snow is allowed to melt near a space heater and the snow water equivalent is measured. In this case, the snow density is calculated using the following formula. 


$$
S D=\frac{V_{W}}{V_{s}} \times 1000 \mathrm{~kg} / \mathrm{m}^{3}
$$

Where,

- $\mathrm{V}_{\mathrm{w}}=$ Snow water equivalent i.e., volume of melted water.

Figure 3-14 shows the sampling method explained above on the left and the cylinder being weighed in the weighing machine on the right.
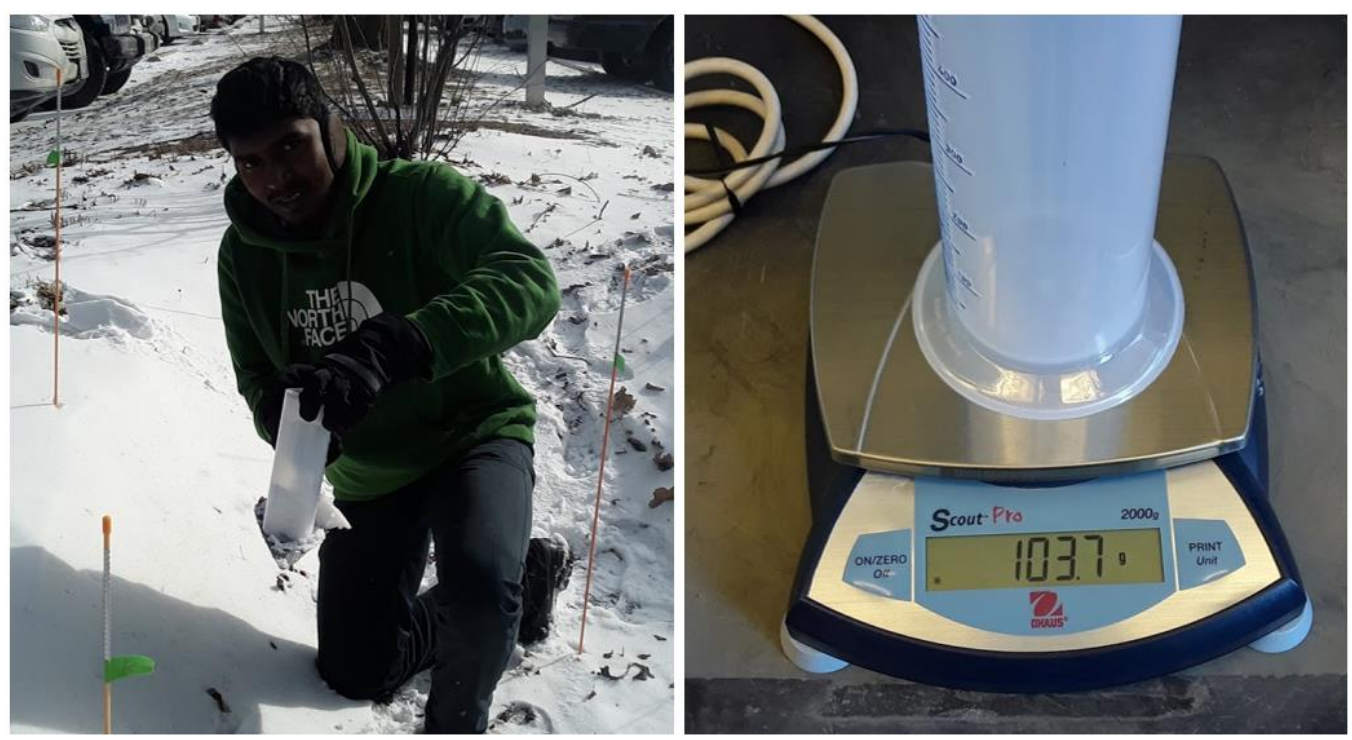

Figure 3-14: Snow density sampling using graduated cylinder and trowel (left) and the graduated cylinder being weighed in a weighing machine (right).

It should be noted that while measuring snow depths near the inlet, due to river stone riprap, snow was accumulated over them but there was space underneath that had air. Therefore, only the snow depth above the stones were considered for data analysis. Moreover, since this BC is beside a parking lot, during winter snow is pushed by the shovelling equipment into the BC. Signage is placed during winter 2017 to reduce artificial accumulation of snow in the BC as shown in Figure 3-15. 


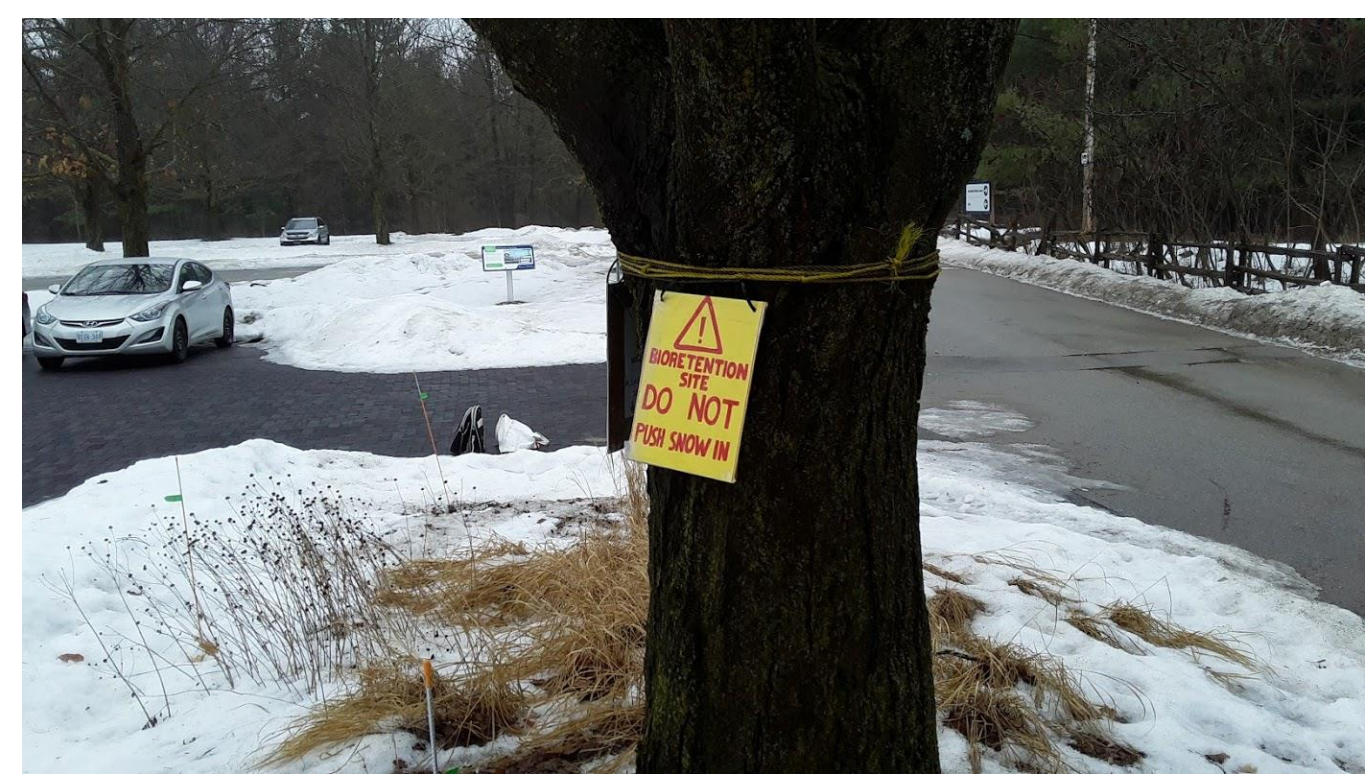

Figure 3-15: "Do not push snow" sign in the BC.

\subsubsection{Frost depth}

Frost depth was measured using seven frost tubes during winter 2018. Six of them were installed inside the BC. The remaining one is installed outside as a reference point. The locations were selected based on terrain but four of them were installed in the central water flow pathway since that is the most hydrologically active area.

\section{Table 3-4: Frost tubes location and lengths}

\begin{tabular}{|l|l|l|}
\hline Point & Locations inside the BC & $\begin{array}{l}\text { Length of frost } \\
\text { tube }(\mathbf{c m})\end{array}$ \\
\hline 1 & Near T (Tree) - In the hill & 200 \\
\hline 2 & S - In the central pathway & 150 \\
\hline 3 & $\begin{array}{l}\text { Between I \& Y - In the central } \\
\text { pathway }\end{array}$ & 150 \\
\hline 4 & Near O - In the central pathway & 150 \\
\hline 5 & Near M - In the central pathway & 150 \\
\hline 6 & Between W \&V - On slope & 200 \\
\hline 7 & External location & 300 \\
\hline
\end{tabular}




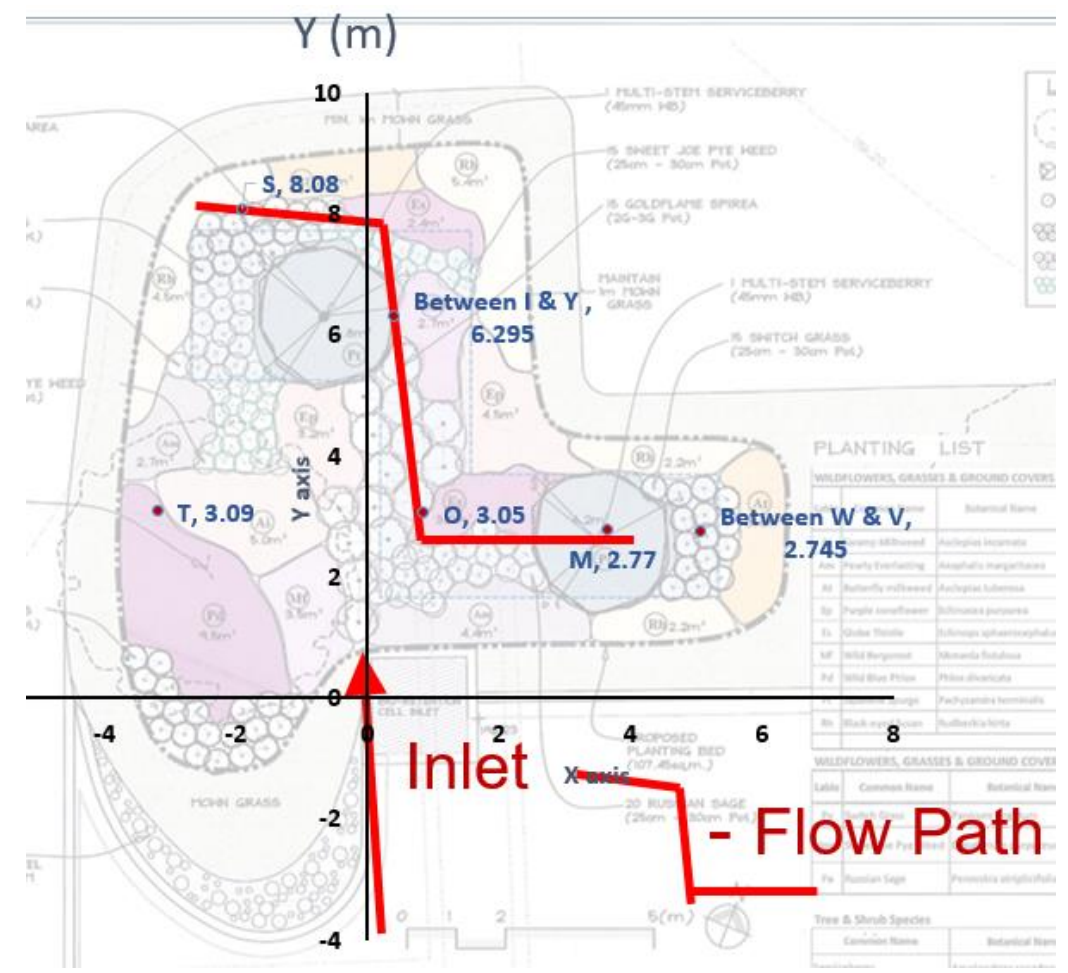

Figure 3-16: Locations of the frost tubes with respect to the inlet (origin).

The frost tube depths beneath the ground surface were selected based on the anticipated maximum frost depth and the depth of the gravel layer in the BC. Frost tube locations and the length of the frost tube are given in Table 3-4. Figure 3-16 has a map of the frost tube locations with respect to the inlet of the $\mathrm{BC}$.

\subsubsection{Frost tube preparation}

Frost tubes were prepared based on the model provided in (Institute of Northern Engineering, 2011). However, due to non-availability of the pipe sizes recommended in the document, different pipe sizes were used to device the frost tube. A half inch radiant heat tube is cut in the appropriate length. The length of the frost tube in each location is given in Table 3-4. Tubes were extended $1 \mathrm{~m}$ above the ground for easy identification during snow accumulation. Half inch PVC pipe was cut longitudinally in half to 'sandwich' around the radiant heat tube and taped together using a Gorilla Duct Tape. The bottom of the frost tube was sealed with epoxy putty. A 7/16 inch outside diameter clear tubing was cut to the same length as the PVC and radiant tubing and filled with a mixture of water and food colouring. Tube ends were heat sealed. Graduations were added to clear tubing to facilitate quick measurement. The clear tubing is then inserted into 
the PVC-radiant heat tube. Figure 3-18 shows the frost tube sketch and Figure 3-17 (right) shows the coloured water being poured into the clear tubing in the frost tube during preparation phase.
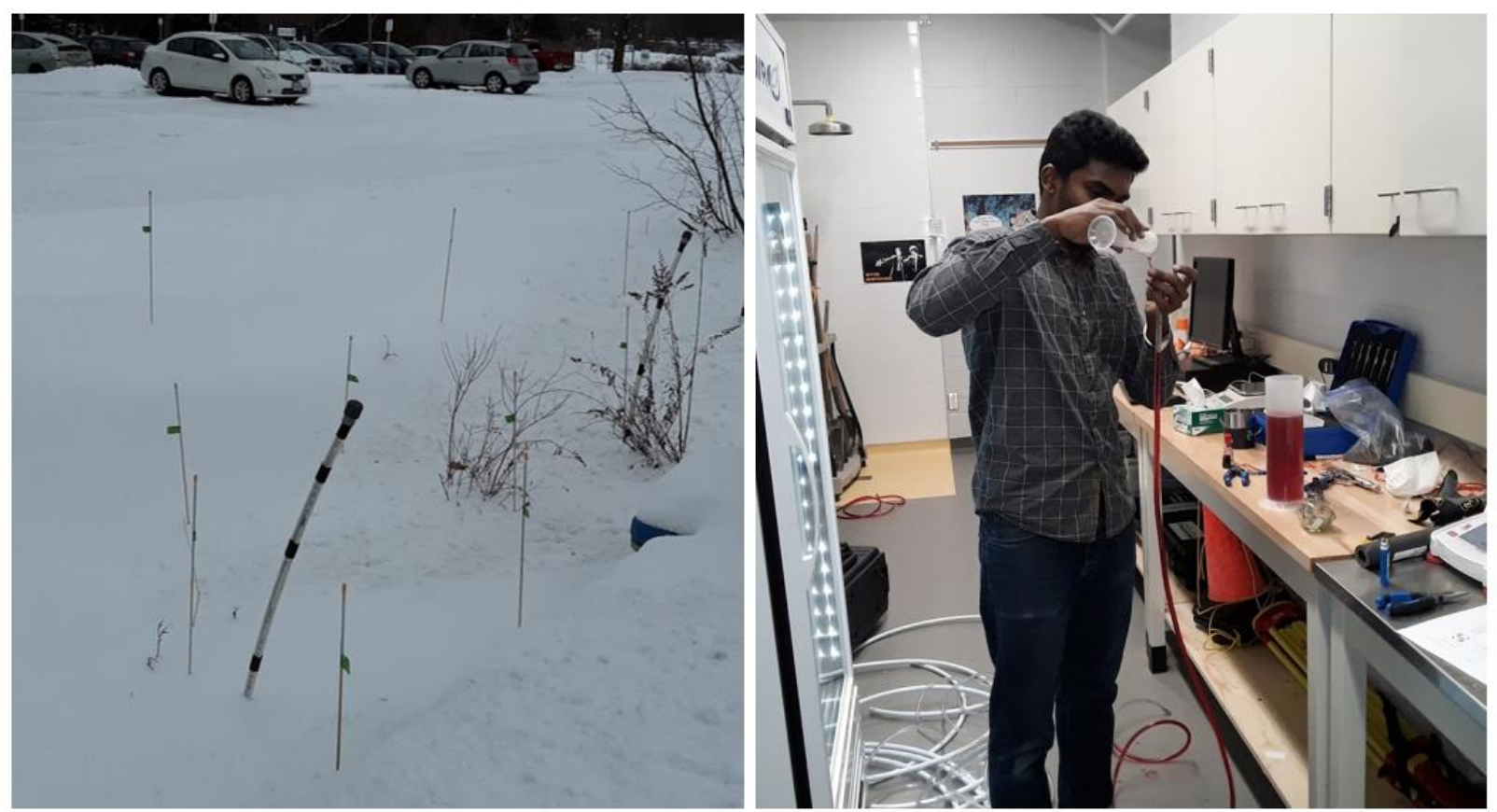

Figure 3-17: An installed frost tube during winter at point $O$ near the inlet of the $B C$ (left) and coloured water being poured into transparent tube to be installed inside the frost tube (right).

On site soil was augured till the appropriate depth and the frost tubes were installed. The remaining gap in the drilled hole was then filled with the excavated soil. A gas auger was used for holes deeper than $50 \mathrm{~cm}$. A cap is installed in the top of the frost tube to prevent precipitation from entering the tubing. Figure 3-17 (left) shows an installed frost tube during winter in the BC.

Table 3-5: Frost depth measurements dates and antecedent conditions

\begin{tabular}{|l|l|l|}
\hline No & Date & Antecedent Conditions \\
\hline 1 & $1 / 8 / 2018$ & Snow \\
\hline 2 & $1 / 17 / 2018$ & Snow \\
\hline 3 & $2 / 5 / 2018$ & Snow \\
\hline 4 & $2 / 26 / 2018$ & Rain on snow melt \\
\hline
\end{tabular}




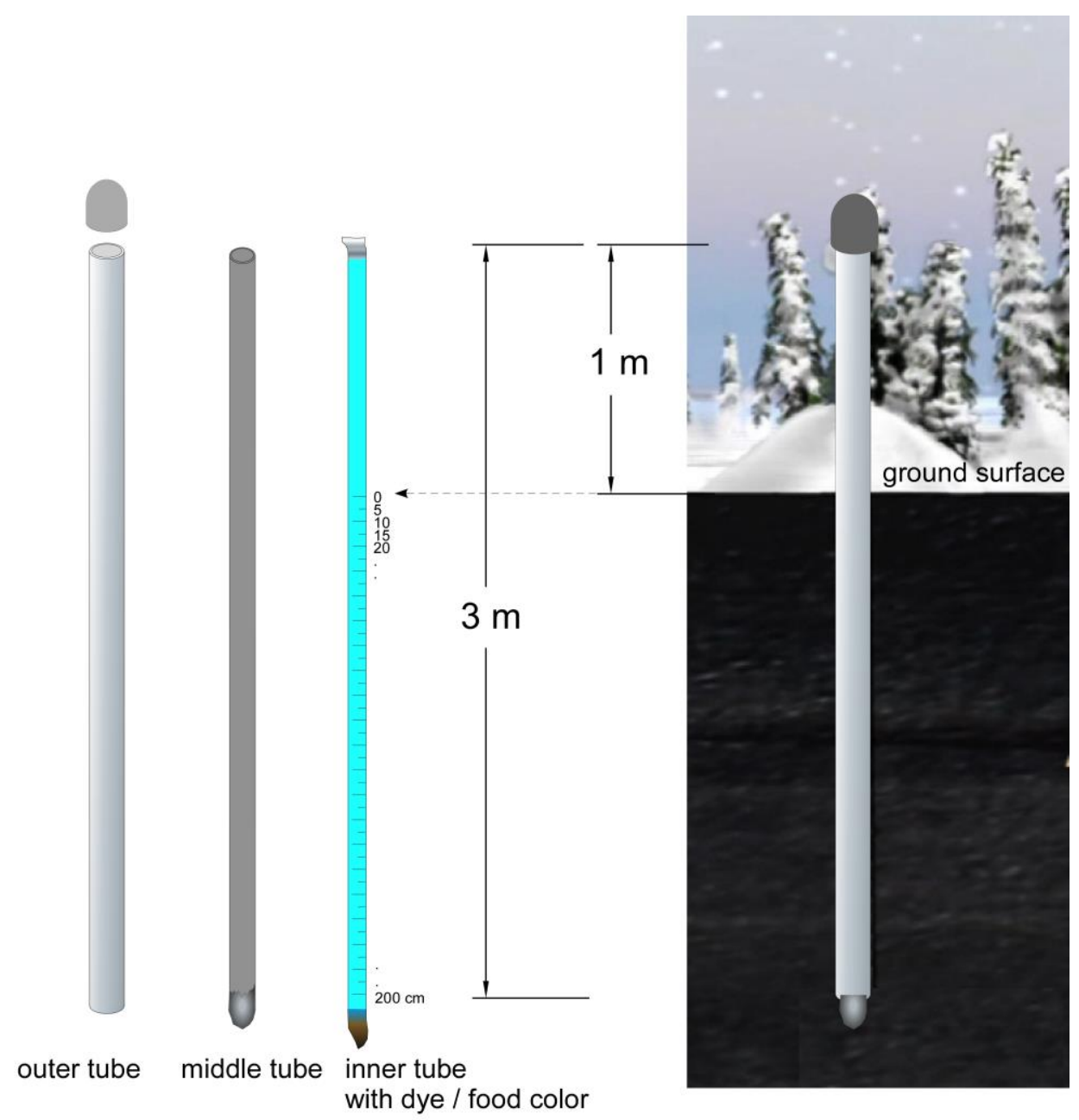

Figure 3-18: Frost tube design (Institute of Northern Engineering, 2011)

The installation locations were chosen to cover the central pathway clearly and to have one representative measurement in the hills and one in the slope inside the bioretention. One reference measurement is also taken outside the bioretention in natural soil. During 2018 winter, four frost depth measurements were taken. The date and the antecedent weather condition associated with the measurements are given in Table 3-5.

\subsubsection{Surface and subsurface water levels and temperatures}

Surface water ponding and subsurface water levels and temperatures were measured every two minutes by Diver loggers. To compensate for atmospheric pressure variation, a barometric Diver logger is also installed on site. The barometric logger also measures the on-site air temperature. 
During extremely low temperatures, the surface water level logger froze and produced erroneous high temperature and pressure values as shown in Figure 3-19 (right). However, since this phenomenon is irregular, it was not possible to find out a threshold temperature below which this happens. Moreover, no ice formation was observed in the subsurface water level logger. Figure 3-19 (left) shows the surface water level logger being pulled out of the surface water well during winter. The surface water logger failed to start on 1/15/2018 and was replaced with a HOBO logger.

Compensation for barometric pressure variation is done by subtracting the pressure measured in the surface water logger and the ground water logger at every time step by the atmospheric pressure at those time steps. This atmospheric pressure correction is done using the diver office software provided by Van Essen Instruments for the diver loggers. For the period during which the surface water level is measured using the HOBO logger, this compensation is done manually in Excel. For relating the water depths i.e., the surface ponding and the saturated zone with the $\mathrm{K}_{\text {sat }}$ measurements, elevation differences were measured manually (Figure 3-20) and used for the respective calculations.
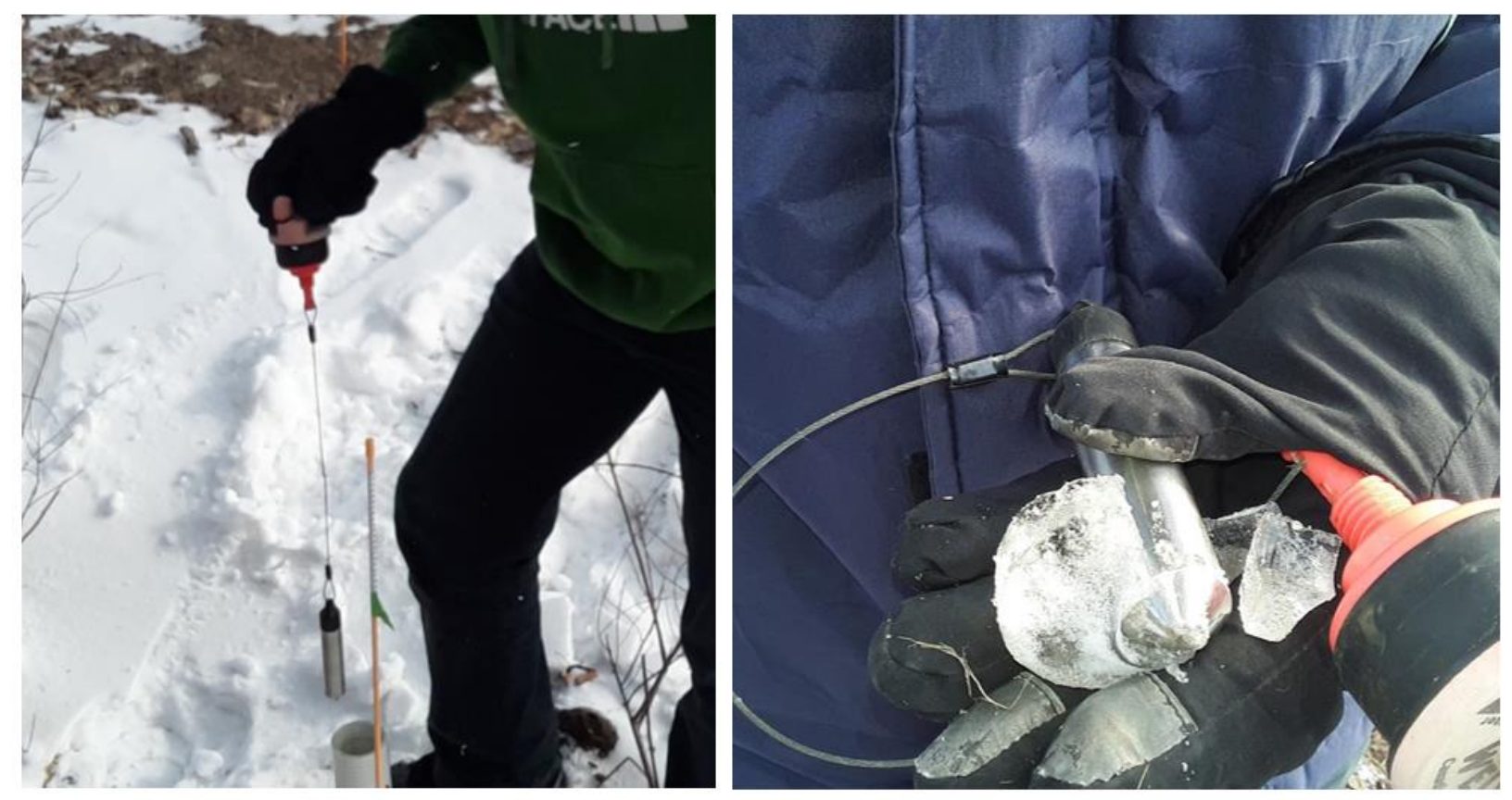

Figure 3-19: Surface water level logger being pulled out of the well (left) and ice surrounding the logger during winter (right). 


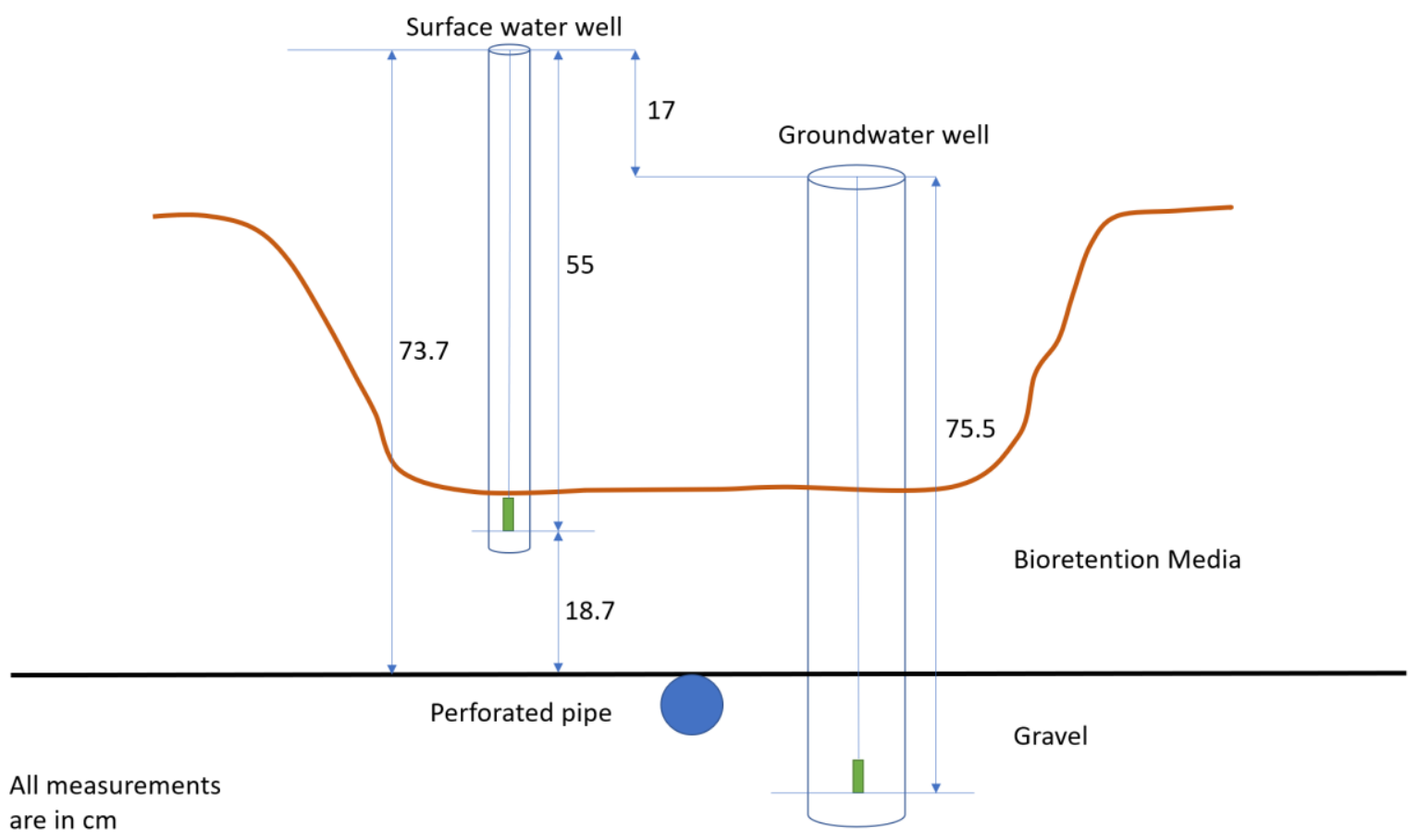

Figure 3-20: Surface and ground water level loggers with their respective elevations with the perforated pipe as the bench mark

\subsubsection{Weather data}

Precipitation during non-winter conditions and snow water equivalent during winter conditions was measured with a Geonor Weighing Precipitation Gauge located on site. The $\mathrm{p}$ gauge has a $12 \mathrm{~L}$ bucket suspended by three chains from the gauge frame. A vibrating wire transducer is placed replacing one of the chains as shown in Figure 3-21 (right). The vibrating wire transducer returns the frequency it measures in Hertz $(\mathrm{Hz})$. That frequency is then used to arrive at the water quantity in the bucket through the following empirical equation.

$$
P=A\left(f-f_{0}\right)+B\left(f-f_{0}\right)^{2}
$$

Where

$\mathrm{P}=$ Precipitation in $\mathrm{cm}$

$\mathrm{A}=$ given calibration constant

$\mathrm{B}=$ given calibration constant

$\mathrm{f}=$ frequency reading from the datalogger at any time step $(\mathrm{Hz})$

$\mathrm{f}_{0}=$ frequency of empty bucket at calibration $(\mathrm{Hz})$ 
The frequency was logged every five minutes by a Sutron Logger. During the winter, to prevent the water inside the rain gauge bucket from freezing, anti-freeze solution is added as recommended by the Geonor Weighing Precipitation Gauge manual (Campbell Scientific (Canada)Corp., 2011) however, even after adding anti-freeze solution, mild icing was occasionally observed (Figure 3-21).
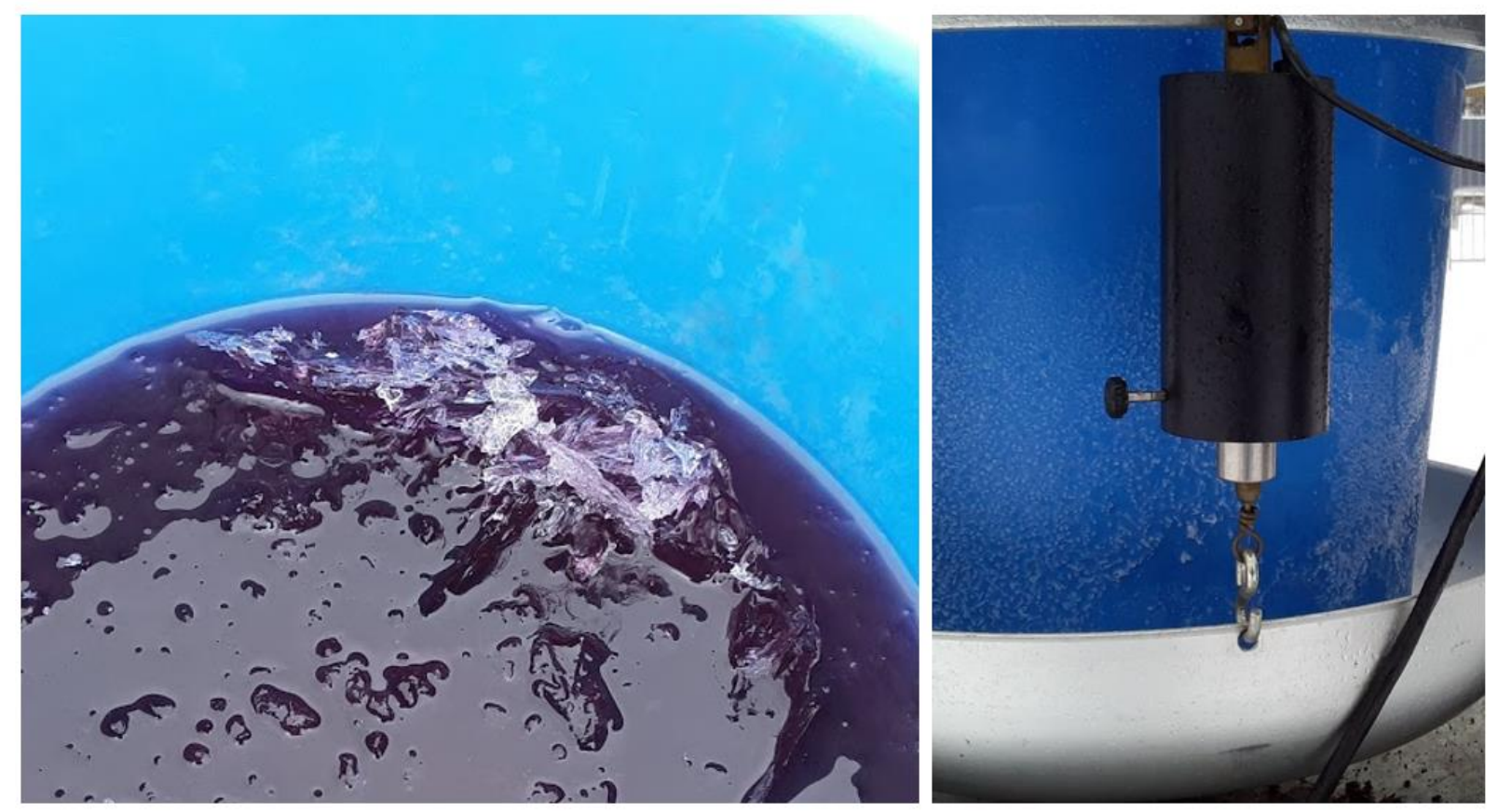

Figure 3-21: Ice inside the Geonor Weighing Gauge bucket with anti-freeze (left) and the vibrating wire transducer (right).

\subsection{Data Analysis}

\subsubsection{Statistical \& Spatial analysis}

General statistics (range, mean median, standard deviation, skewness) were calculated for all measured soil parameters. Contour maps were generated using MATLAB's contour function. This function uses a linear interpolation method to generate contours. The relative $\mathrm{x}$ and $\mathrm{y}$ axis distance from the inlet is used as the location information of each point to generate the contour maps. The MATLAB code used to generate the contour maps is provided in the Appendix 7.1. 
The MATLAB code uses the MATLAB function "meshgrid" to generate a mesh between the cartesian coordinates $(-5,-4)$ to $(8,10)$. The mesh grid size is $0.005 \mathrm{~m} \mathrm{x} 0.005 \mathrm{~m}$. Following this step, the "griddata" function takes in the soil parameter data and interpolates it so that each grid in the mesh has an individual soil parameter value. The interpolation method used is linear interpolation. "Contourf" function then plots a contour map by connecting the grids that have the same soil parameter value. The colour scheme is then adjusted to clearly portray the important parts of the spatial map.

\subsubsection{Time Series Analysis}

A summary table is prepared for the temporal snow depth data as shown in Table 4-3. The summary table contains range, mean, median, standard deviation, coefficient of variation and antecedent conditions. Snow depth spatial maps are generated using MATLAB's contour function. Two snow depth maps are provided to compare before and after thaw conditions (Figure 4-7 - top and Figure 4-8 - top). The remaining snow depth spatial maps are provided in the appendix (Figure 7-39 to Figure 7-46). An overall average snow depth spatial map is also provided in the appendix (Figure 7-47).

All analysis on $\mathrm{K}_{\text {sat }}$ are carried out using $\mathrm{K}_{\text {sat }}$ generated from infiltration rates through Radcliffe method. A summary table is prepared for the temporal $\mathrm{K}_{\text {sat }}$ data as shown in Table 4-6. The summary table contains range, mean, median, standard deviation, coefficient of variation and antecedent conditions. An average $\mathrm{K}_{\text {sat }}$ spatial map generated using MATLAB's contour function is given in Figure 4-1 (bottom). $\mathrm{K}_{\text {sat }}$ spatial maps are generated for temporal data and are given in the appendix (Figure 7-30 to Figure 7-38).

$\mathrm{K}_{\text {sat }}$ measurements are also plotted in timeline box-whisker plots to study the temporal variability as shown in Figure 4-16. The $\mathrm{K}_{\text {sat }}$ measurements are also grouped into central pathway and non-central pathway locations and the timeline box-whisker plots are prepared for both categories as shown in Figure 4-18 and Figure 4-19 respectively. Since outliers are suspected to distort the incarnate $\mathrm{K}_{\text {sat }}$ trend, after checking for normality using Ryan - Joiner normality test, Grubbs test is used to check for outliers. Both above mentioned statistical tests are carried out using Minitab. The outliers are removed, and a temporal graph is prepared with average $\mathrm{K}_{\text {sat }}$ before outlier removal (all, central pathway and non-central pathway locations) and after outlier removal (all, central pathway and non-central pathway locations) as shown in Figure 4-20. 
$\mathrm{K}_{\text {sat }}$ is also calculated using Elrick and Reynolds method. A temporal box whisker plot and an average spatial map are prepared as shown in Figure 4-17 and Figure 7-29. A Wilcoxon signed rank test is also conducted using Minitab to verify the statistical difference between the $\mathrm{K}_{\text {sat }}$ values calculated by the two methods.

\subsubsection{Correlation}

Semi-variograms are prepared using MATLAB and the code used to generate the semivariogram graphs are given in Appendix 7.2. The Semi-variogram depicts the spatial autocorrelation of the measured sample points. The Experimental (Semi-) Variogram tool is downloaded from the MATLAB file exchange. The tool is then imported into MATLAB and used to generate the semi-variograms.

Spatial autocorrelation (Moran's I test) has not been performed since carrying it out in MATLAB required the usage of certain functions and was more complicated. Therefore, spatial correlation was discussed in light of the semi-variograms without utilizing Moran's I value.

\subsubsection{Water level data}

Water level data and temperature data collected by the loggers are observed. An example rain on snow melt event is plotted to show the temporal surface water level, ground water level, precipitation events, surface water temperature, ground water temperature and air temperature. The datum used for water levels is the axis of the perforated pipe shown in Figure 3-20. The relative elevation of the tops of the wells from the datum are measured. The measured lengths are shown in Figure 3-20. They are used to calculate the water levels with respect to the datum.

Events are generated based on the surface water level data using PCSWMM software. The criteria used for event classification is as follows.

1. Minimum interevent time $=1 \mathrm{hr}$,

2. Event threshold $=15 \mathrm{~cm}$,

3. Extend events by $1 \mathrm{hr}$ following and $1 \mathrm{hr}$ preceding and

4. Events with maximum surface water level more than $100 \mathrm{~cm}$ are discarded. 


\subsubsection{Required Sample Size}

The required sample size has been calculated using the following equation.

$$
S S=\frac{Z^{2} \times(s d) \times(1-s d)}{C^{2}}
$$

Where,

$\mathrm{SS}=$ required sample size

$\mathrm{Z}=\mathrm{Z}$ score

sd $=$ standard deviation

$\mathrm{C}=$ acceptable margin of error.

The $\mathrm{z}$ score for $95 \%$ and $90 \%$ confidence is 1.96 and 1.645 respectively. The margin of error for $95 \%$ and $90 \%$ confidence is 0.05 and 0.1 respectively. 


\section{Results \& Discussion}

This chapter presents the spatial and temporal analysis results from the field experiments and data collection carried out between Fall 2016 and Summer 2018. It includes

1. a discussion of the spatial variability of $\mathrm{K}_{\mathrm{sat}}$, moisture content, bulk density, organic content, particle density, porosity, $\mathrm{D}_{60}, \mathrm{D}_{30}, \mathrm{Cc}, \mathrm{Cu}$, Snow depth \& density and frost depth.

2. an analysis on the temporal variability of $\mathrm{K}_{\text {sat. }}$

Weather conditions and anecdotal observations were taken into consideration for the analysis to facilitate better interpretation of the above-mentioned soil parameters, snow depth \& density and $\mathrm{K}_{\text {sat }}$ data. Spatial maps were prepared to analyze the heterogeneity and box-whisker plots are prepared to analyze the temporal changes.

\subsection{Spatial Variability}

In the following sections, soil data from location $Q$ has been removed from the dataset. First iteration maps that included Q (Figure 7-19 to Figure 7-28 in the Appendix) consistently identified Q as an outlier with distinctly different soil characteristics than neighboring samples. This outlier identification is done by visual examination of the spatial maps. All soil samples are collected between $15 \mathrm{~cm}$ to $20 \mathrm{~cm}$ underground within the top soil layer, but the top soil layer was comparatively narrow ( $<15 \mathrm{~cm}$ thick) at Q. This resulted in samples being collected from under the $\mathrm{BC}$ media / topsoil in the native soil which has considerably distinct soil properties.

Therefore, all statistical analysis and summaries were completed without Q. However, the snow depth maps have 30 points including Q. A summary of all the measured soil parameters, $\mathrm{K}_{\text {sat }}$ and Snow Depth is given in Table 4-1. The table also shows distinct summaries for the locations in the central flow path and the non-central flow path regions. The differences between these two groups of locations as shown in the spatial maps in sections 4.1.1 to 4.1 .5 can be numerically observed in this summary. 
Table 4-1: Summary table for soil parameters, $K_{\text {sat }}$ and Snow Depth

\begin{tabular}{|c|c|c|c|c|c|c|c|c|c|c|c|}
\hline & & & & & Overall & & & & & & \\
\hline & BD & MC & OC & PD & Porosity & D60 & D30 & $\mathrm{Cu}$ & $\mathrm{Cc}$ & $\mathbf{K}_{\text {sat }}$ & SD \\
\hline Number & 16 & 16 & 16 & 16 & 16 & 16 & 16 & 16 & 16 & 16 & 16 \\
\hline Max & 1895 & 26 & 8 & 5153 & 80 & 1.4 & 0.4 & 10.6 & 1.0 & 0.006 & 20 \\
\hline Min & 610 & 14 & 5 & 2750 & 31 & 0.5 & 0.2 & 3.1 & 0.6 & 0.000 & 6 \\
\hline Range & 1285 & 12 & 3 & 2403 & 49 & 0.9 & 0.2 & 7.5 & 0.4 & 0.005 & 14 \\
\hline Mean & 1590 & 20 & 6 & 3230 & 50 & 0.7 & 0.3 & 6.0 & 0.8 & 0.002 & 12 \\
\hline Median & 1794 & 19 & 6 & 3126 & 45 & 0.6 & 0.2 & 5.7 & 0.8 & 0.002 & 12 \\
\hline StdDev & 468 & 4 & 1 & 554 & 16 & 0.3 & 0.1 & 2.2 & 0.1 & 0.002 & 3 \\
\hline \multirow[t]{3}{*}{$\mathrm{COV}$} & 29 & 19 & 19 & 17 & 31 & 36 & 21 & 37 & 16 & 77 & 26 \\
\hline & & & & \multicolumn{3}{|c|}{ Central Flow Path } & & & & & \\
\hline & BD & MC & OC & PD & Porosity & D60 & D30 & $\mathrm{Cu}$ & $\mathrm{Cc}$ & $\mathbf{K}_{\text {sat }}$ & SD \\
\hline Number & 6 & 6 & 6 & 6 & 6 & 6 & 6 & 6 & 6 & 6 & 6 \\
\hline Max & 1825 & 26 & 6 & 3396 & 46 & 0.8 & 0.3 & 8.2 & 1.0 & 0.003 & 15 \\
\hline Min & 1793 & 18 & 5 & 2842 & 37 & 0.5 & 0.2 & 3.3 & 0.8 & 0.000 & 10 \\
\hline Range & 32 & 8 & 1 & 553 & 10 & 0.3 & 0.1 & 4.9 & 0.2 & 0.003 & 5 \\
\hline Mean & 1806 & 23 & 5 & 3174 & 43 & 0.6 & 0.2 & 5.7 & 0.9 & 0.001 & 12 \\
\hline Median & 1801 & 24 & 5 & 3185 & 43 & 0.5 & 0.2 & 5.7 & 0.9 & 0.001 & 12 \\
\hline StdDev & 13 & 3 & 1 & 196 & 4 & 0.1 & 0.0 & 1.6 & 0.1 & 0.001 & 2 \\
\hline \multirow[t]{3}{*}{$\mathrm{COV}$} & 1 & 14 & 11 & 6 & 8 & 19 & 12 & 29 & 10 & 113 & 15 \\
\hline & & & & \multicolumn{4}{|c|}{ Non-Central Flow Path } & & & & \\
\hline & BD & MC & OC & PD & Porosity & D60 & D30 & $\mathbf{C u}$ & Ce & $\mathbf{K}_{\text {sat }}$ & SD \\
\hline Number & 10 & 10 & 10 & 10 & 10 & 10 & 10 & 10 & 10 & 10 & 10 \\
\hline Max & 1895 & 21 & 8 & 5153 & 80 & 1.4 & 0.4 & 10.6 & 0.9 & 0.006 & 20 \\
\hline Min & 610 & 14 & 5 & 2750 & 31 & 0.5 & 0.2 & 3.1 & 0.6 & 0.001 & 6 \\
\hline Range & 1285 & 6 & 3 & 2403 & 49 & 0.9 & 0.2 & 7.5 & 0.3 & 0.004 & 14 \\
\hline Mean & 1461 & 18 & 6 & 3264 & 55 & 0.8 & 0.3 & 6.2 & 0.8 & 0.003 & 13 \\
\hline Median & 1747 & 18 & 6 & 3091 & 47 & 0.7 & 0.3 & 5.7 & 0.8 & 0.003 & 12 \\
\hline StdDev & 562 & 2 & 1 & 698 & 18 & 0.3 & 0.1 & 2.6 & 0.1 & 0.002 & 4 \\
\hline $\mathrm{COV}$ & 38 & 13 & 19 & 21 & 34 & 37 & 23 & 41 & 15 & 53 & 31 \\
\hline \multicolumn{12}{|c|}{ Legend } \\
\hline $\mathrm{BD}\left(\mathrm{Kg} / \mathrm{m}^{3}\right)$ & \multicolumn{3}{|c|}{ Bulk Density } & D60 (mm) & \multicolumn{3}{|c|}{$60 \%$ passing mesh size } & \multirow[b]{2}{*}{$\mathrm{K}_{\mathrm{sat}}(\mathrm{cm} / \mathrm{s})$} & \multirow{2}{*}{\multicolumn{3}{|c|}{$\begin{array}{l}\text { Saturated hydraulic } \\
\text { conductivity }\end{array}$}} \\
\hline $\mathrm{MC}(\%)$ & \multicolumn{3}{|c|}{ Moisture Content } & $\mathrm{D} 30(\mathrm{~mm})$ & \multirow{2}{*}{\multicolumn{3}{|c|}{$\begin{array}{l}30 \% \text { passing mesh size } \\
\text { Coeff. of uniformity }\end{array}$}} & & & & \\
\hline $\mathrm{OC}(\%)$ & \multicolumn{3}{|c|}{ Organic Content } & $\mathrm{Cu}$ (no unit) & & & & $\mathrm{SD}(\mathrm{cm})$ & \multicolumn{3}{|c|}{ Snow Depth } \\
\hline $\mathrm{PD}\left(\mathrm{Kg} / \mathrm{m}^{3}\right)$ & \multicolumn{3}{|c|}{ Particle Density } & Cc (no unit) & \multicolumn{3}{|c|}{ Coeff. of curvature } & $\operatorname{COV}(\%)$ & \multicolumn{3}{|c|}{ Coeff. of Variation } \\
\hline
\end{tabular}

\subsubsection{Saturated Hydraulic Conductivity $\left(\mathrm{K}_{\mathrm{sat}}\right)$}

On the day of soil samples collection i.e., Oct $25^{\text {th }}, 2017$, the moisture content was high in the central water flow pathway as shown in Figure 4-1 (top). In the low-lying central path soil 
moisture ranged from 26 - 18\% while for locations at higher elevation moisture ranged from 14 $21 \%$.

It should be noted that between the two methods used for $\mathrm{K}_{\text {sat }}$ calculation i.e., Radcliffe Method and Elrick \& Reynolds method, Elrick \& Reynolds method is derived from Glover's equation (Elrick \& Reynolds, 1992). Glover's equation has been identified to work well in coarse textured soils where the capillary effect is minimal and initial water content in the soil is near the field capacity (Jabro \& Evans, 2006). Glovers equation also ignores the effect of gravity and capillary water flow (Radcliffe \& West, 2015). On the contrary, Radcliffe method has been formulated to include the effect of gravity and capillary water flow (Radcliffe \& West, 2015). Both these phenomena are understood to be prominent and enhanced near the ground surface, particularly in a BC. Therefore, Radcliffe method is the primary method used for analysis. Furthermore, Elrick \& Reynold method results are shown and discussed briefly since it is the primary method provided in the online Guelph Permeameter $\mathrm{K}_{\text {sat }}$ excel calculator provided by the Soilmoisture Equipment Corporation.

Table 4-2: Summary table for Ksat $(\mathrm{cm} / \mathrm{s})$ - Radcliffe method and Elrick \& Reynolds method

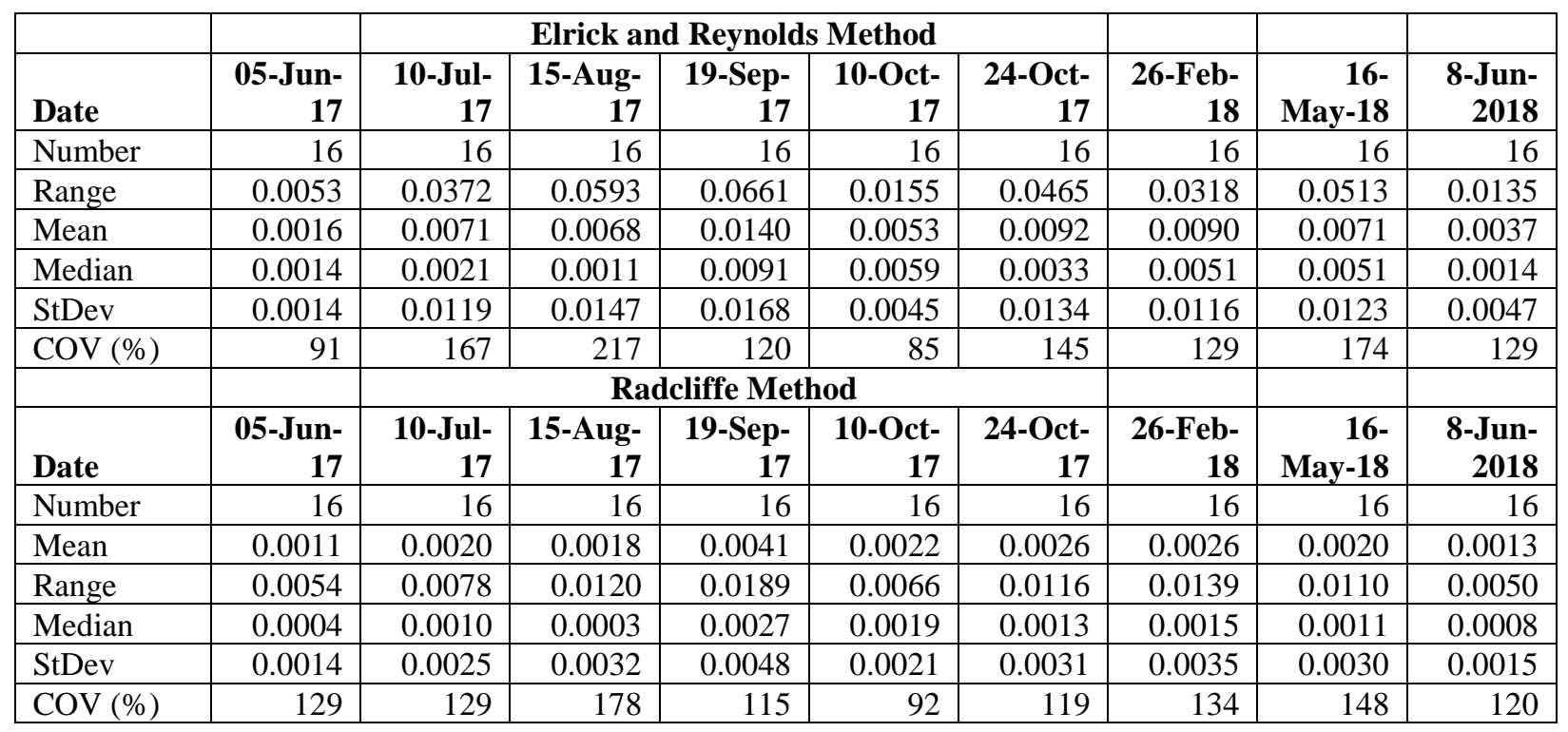

$\mathrm{K}_{\text {sat }}$ data is summarized in Table 4-1 \& Table 4-2 and average $\mathrm{K}_{\text {sat }}$ values are mapped in Figure 4-1 (bottom). $\mathrm{K}_{\text {sat }}$ values were lowest in the central pathway. The average $\mathrm{K}_{\text {sat }}$ in the central flow path was 0.33 times that of the average $\mathrm{K}_{\text {sat }}$ at the remaining locations. The central flow path 
being the hydrologically active area in a $\mathrm{BC}$, measuring infiltration rates outside this area might not provide representative measurements indicating the $\mathrm{BC}$ performance.
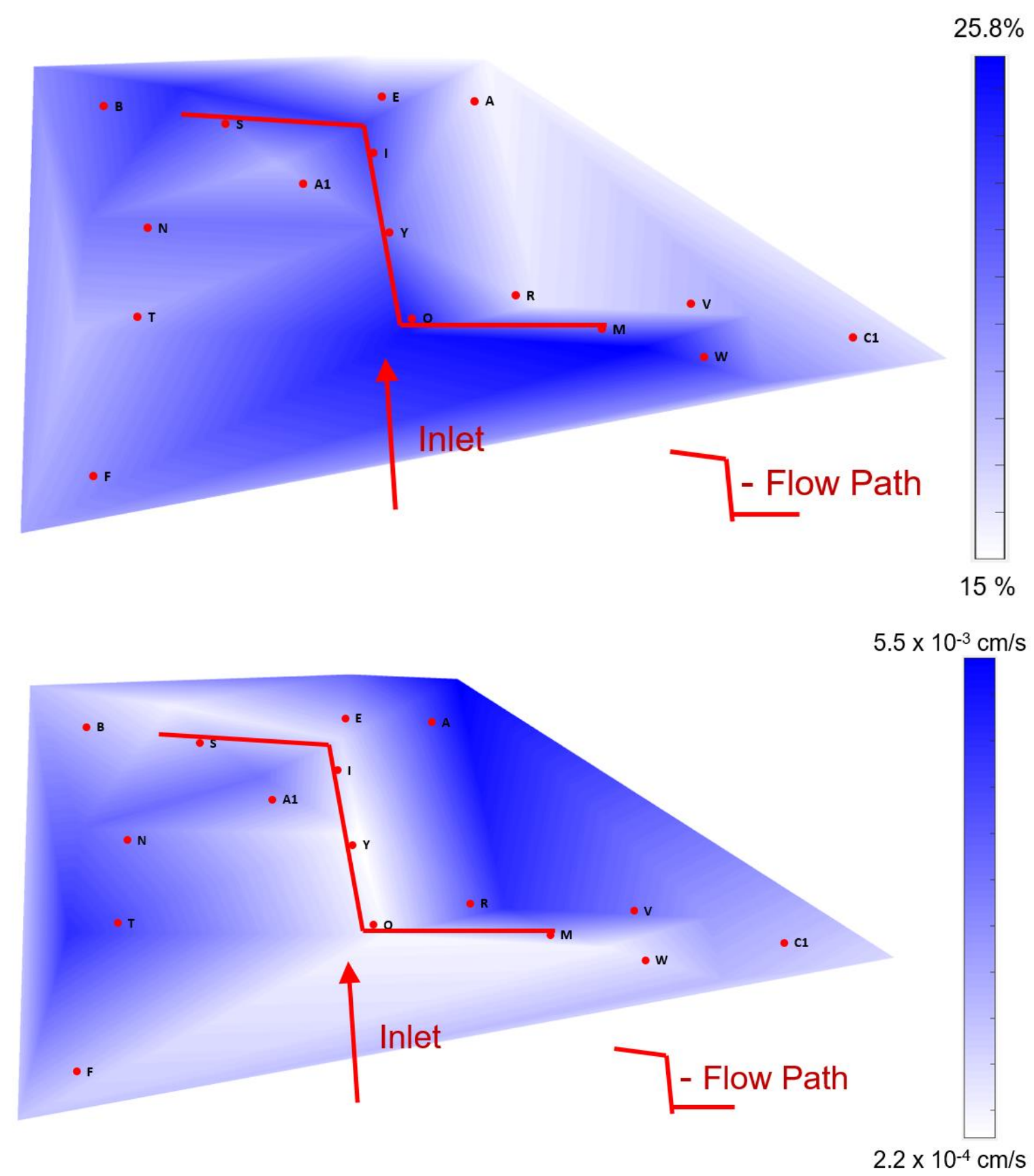

Figure 4-1: Moisture Content (top) and $K_{\text {sat }}-$ Radcliffe Method (bottom)

Overall the $\mathrm{BC}$ has acceptable infiltration rates and met recommended minimum infiltration rates for BC, i.e. $15 \mathrm{~mm} / \mathrm{hr}$ (Toronto and Region Conservation Authority, 2012). There were significantly fewer plants located in the central flow path compared to BC hills. Plants sustain infiltration processes through several mechanisms. Root structures maintaining soil structure, 
mitigate erosion, and create macro-structure within the subsurface (Valtanen et. al., 2016; Le Coustumer et. al., 2012). Additionally, plants absorb moisture content from the soil and evapotranspire water, leaving the soil with lesser moisture. Therefore, BCs should have a diverse terrain (for plant growth in hills and infiltration/stagnation in the flow path) with more than one flow path facilitating infiltration, seepage and snow melt.

For moisture content, the required sample size for $90 \%$ and $95 \%$ confidence interval are 4 and 12 respectively. For $\mathrm{K}_{\text {sat }}$ averaged, the required sample size for $90 \%$ and $95 \%$ confidence interval are 5 and 14 respectively. Since, 16 measurements have been taken (excluding Q), the number of samples required to confidently estimate moisture content and $\mathrm{K}_{\text {sat }}$ are met in this study. However, the number of $\mathrm{K}_{\mathrm{sat}}$ measurements required to estimate the $\mathrm{K}_{\mathrm{sat}}$ within the central flow path with statistical certainty could not be calculated with the available data. For the central flow path $\mathrm{K}_{\text {sat }}$, the number of samples formula (Equation 30) returned a negative sample size because the standard deviation to mean ratio in the central flow path is greater than one.

\subsubsection{Bulk Density, Moisture Content and Organic Content.}

Organic content is lower in the central pathway and higher in the hills (Figure 4-2 - top). The average organic content in the central flow path and non-central flow path are $5 \%$ and $6 \%$ respectively at 15 to $20 \mathrm{~cm}$ depth below the surface. The difference in average organic content is however very low and this could be due to some locations in non-central pathway regions having lower organic content. But in general, the central pathway having a lower organic content can be clearly seen in Figure 4-2 (top). There is anecdotal evidence that the number of plants is lower in the central pathway compared to the number of plants in the hills. As organic content is a direct consequence of plants, it is not surprising that lower organic content lower due to the lower plant density. Moreover, incoming stormwater likely deposits minerally-based sediments within the central pathway thus increasing the proportion of inorganic materials observed in collected soil samples.

It can be observed from Figure 4-2 (bottom) that bulk density is lower along the outline of the $\mathrm{BC}$, particularly the points $\mathrm{B}, \mathrm{E}$ and $\mathrm{C} 1$ has very low bulk density. Based on observations, it is suspected that a very loose soil has caused the low bulk density in E. Loose soil and mulch are suspected to have caused low bulk density and high organic content in B and C1. Moreover, the average bulk density in the central flow path and non - central flow path regions are $1806 \mathrm{Kg} / \mathrm{m}^{3}$ 
and $1461 \mathrm{Kg} / \mathrm{m}^{3}$ respectively. The higher bulk density in the central flow path could be due to higher moisture content and sedimentation.

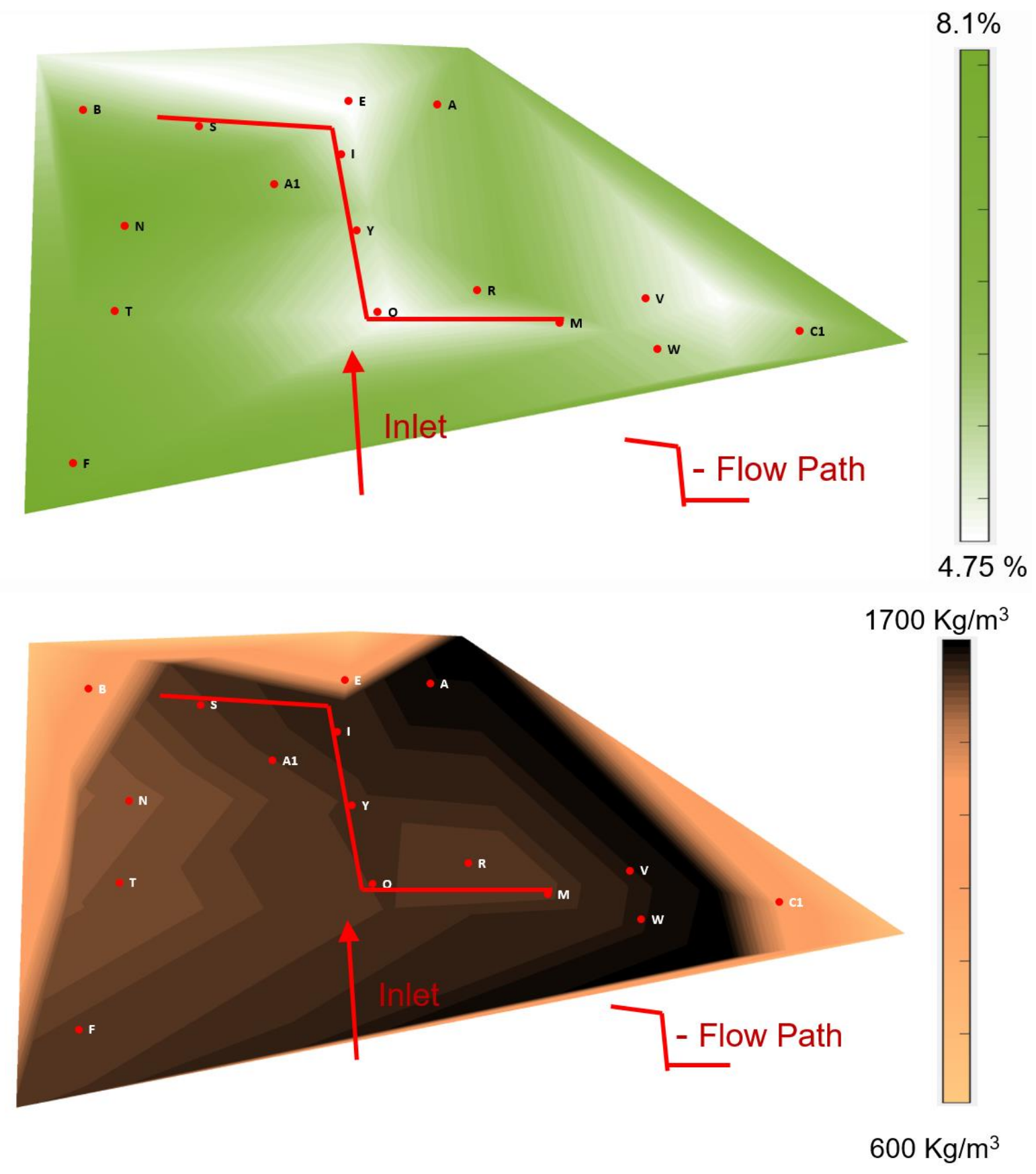

Figure 4-2: Organic Content (top) and Bulk Density (bottom)

For organic content, the required sample size for $90 \%$ and $95 \%$ confidence interval are 4 and 12 respectively. For bulk density, the required sample size for $90 \%$ and $95 \%$ confidence interval are 6 and 16 respectively. Since, 16 measurements have been taken (excluding Q), the 
number of samples required to confidently estimate organic content and bulk density are met in this study.

\subsubsection{Porosity and Particle Density}

There was no clear distinction between central pathway and hill regions for porosity. Porosity is calculated from particle density and bulk density as shown in Equation 24. Since, both of these parameters are measured from soil samples collected though different methods, there could be some dissonance between the two data sets. This uncertainty is discussed in section 4.5.
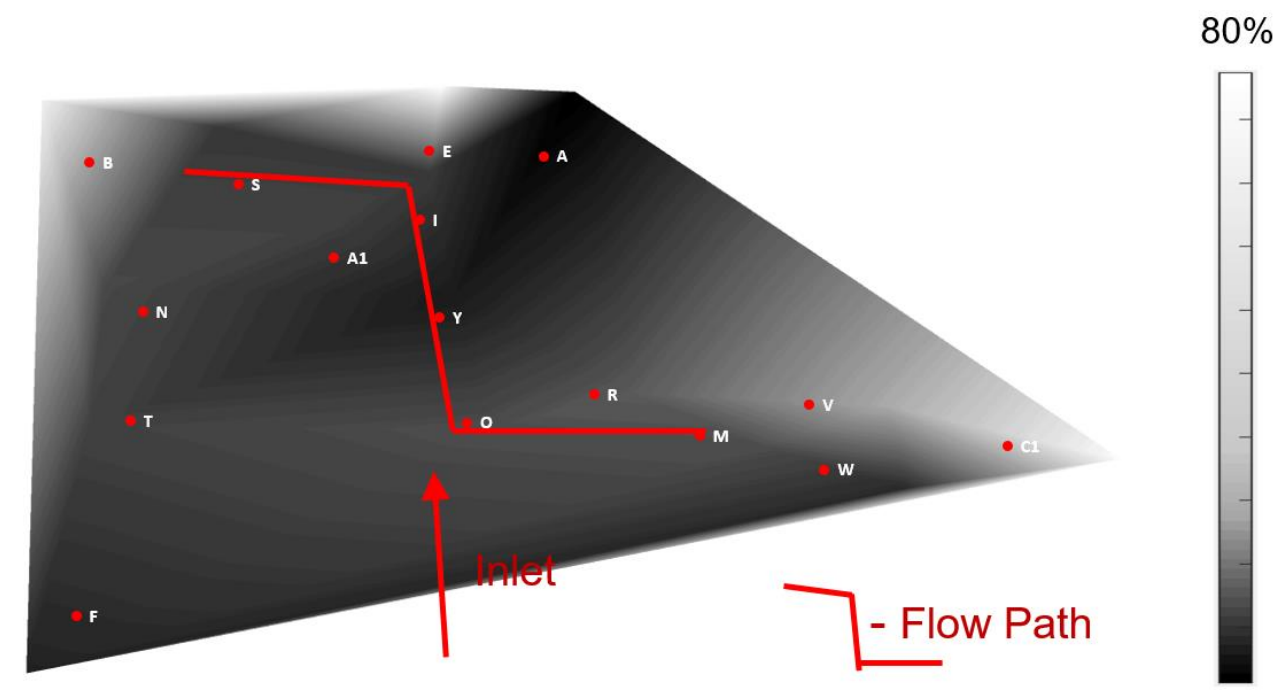

$31 \%$

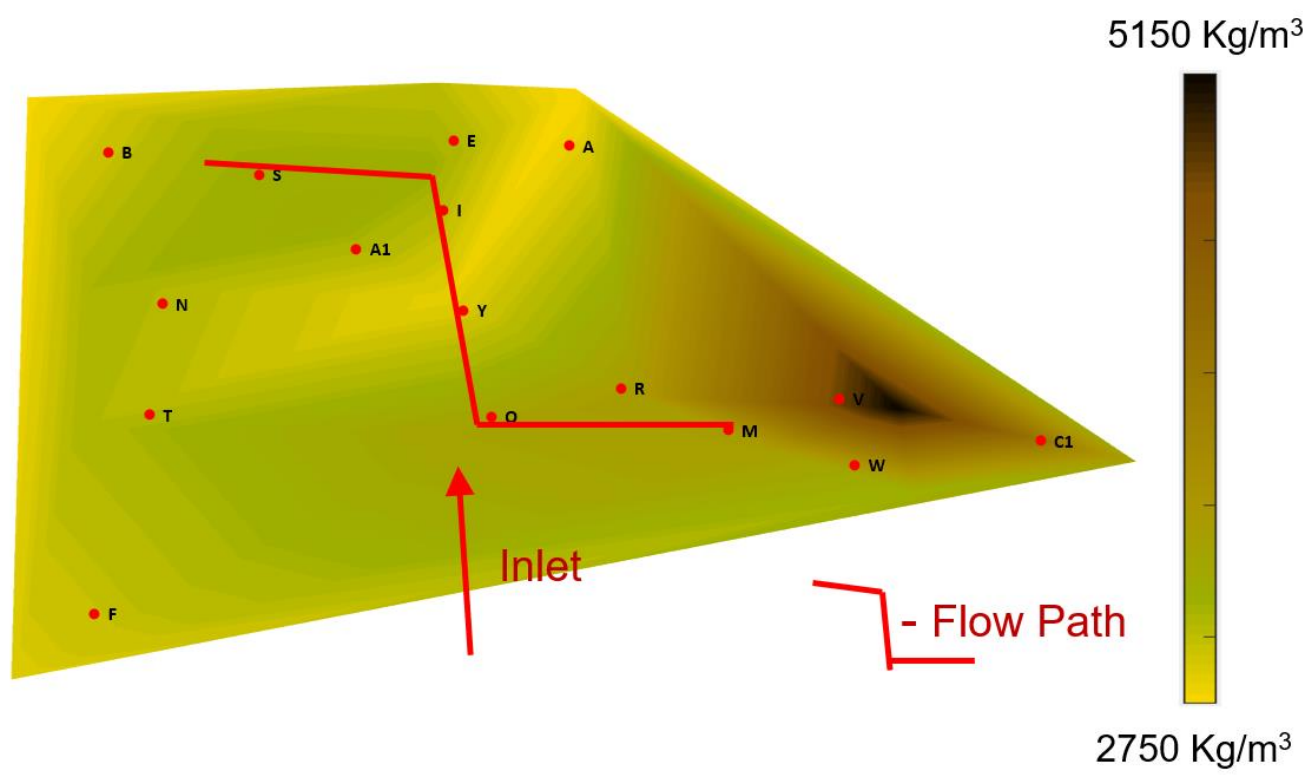

Figure 4-3: Porosity (top) and Particle Density (bottom) 
From Figure 4-3 (bottom), particle density is higher in the central pathway regions compared to the hill region. However, this effect is particularly high in the central pathway arm near the inlet. Therefore, the sedimentation could be higher in the central pathway arm near the inlet compared to the other arm. The particle density near V is very high and it is considered as an outlier.

For porosity, the required sample size for $90 \%$ and $95 \%$ confidence interval are 6 and 16 respectively. For particle density, the required sample size for $90 \%$ and $95 \%$ confidence interval are 4 and 11 respectively. Since, 16 measurements have been taken (excluding Q), the number of samples required to confidently estimate porosity and particle density are met in this study

\subsubsection{Soil Particle Size Distribution}

The soil is classified as sand, silt or clay using the soil textural triangle shown in Figure 44. Collected BC samples had an average proportion of Sand - $91.51 \%$ and Silt \& Clay - $8.49 \%$ classifying the media is Sandy Soil. Coefficient of uniformity $(\mathrm{Cu})$ and Coefficient of curvature (Cc) describe the grading quality of the soil. According to the ASTM standard D2487 - 17, well graded sandy soil has ( $\mathrm{Cu}$ greater than 4 and $\mathrm{Cc}$ between 1 and 3 .

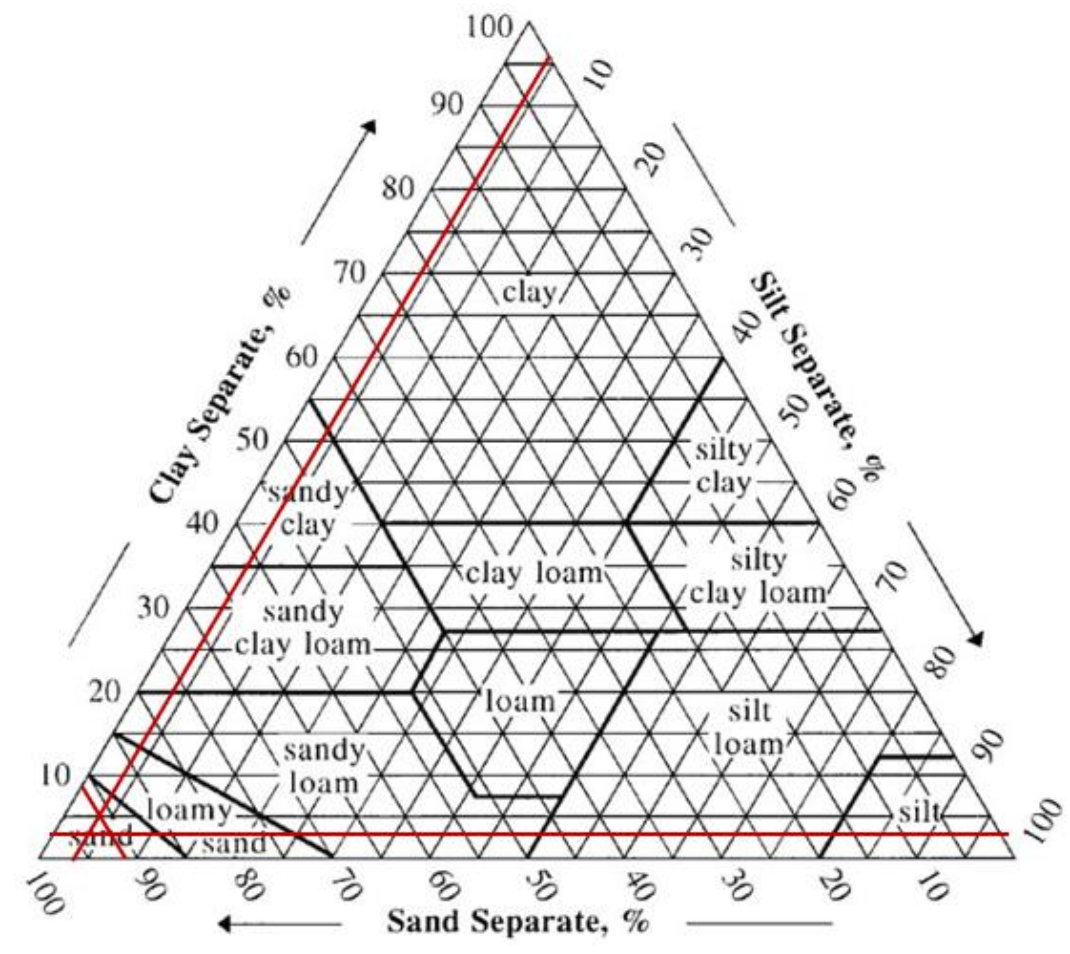

Figure 4-4: Soil textural triangle classification with BC soil proportions plotted (United States Department of Agriculture, 2018). 
For sand to be classified as well graded, $\mathrm{Cu}$ should be greater than or equal to 6 and $\mathrm{Cc}$ should be between 1 and 3. A classification of well graded does not necessarily mean that the soil is ideal for BC functionality (high infiltration rate and high plant growth support). The ideal BC media installed initially might not have been well graded. For the media to be well graded now, the particle sizes that are not represented enough should have been brought by sediment deposition or native soil erosion/mixing so in this context, well graded soil may not be preferable for BC functionality.

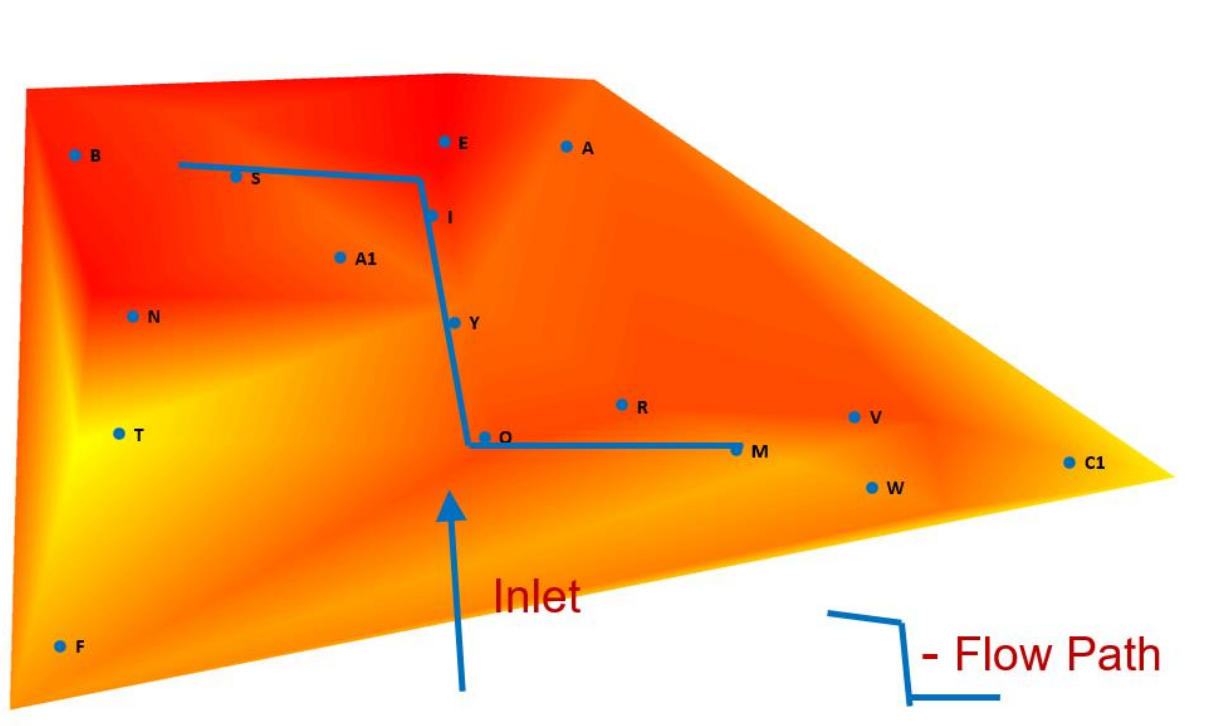

11

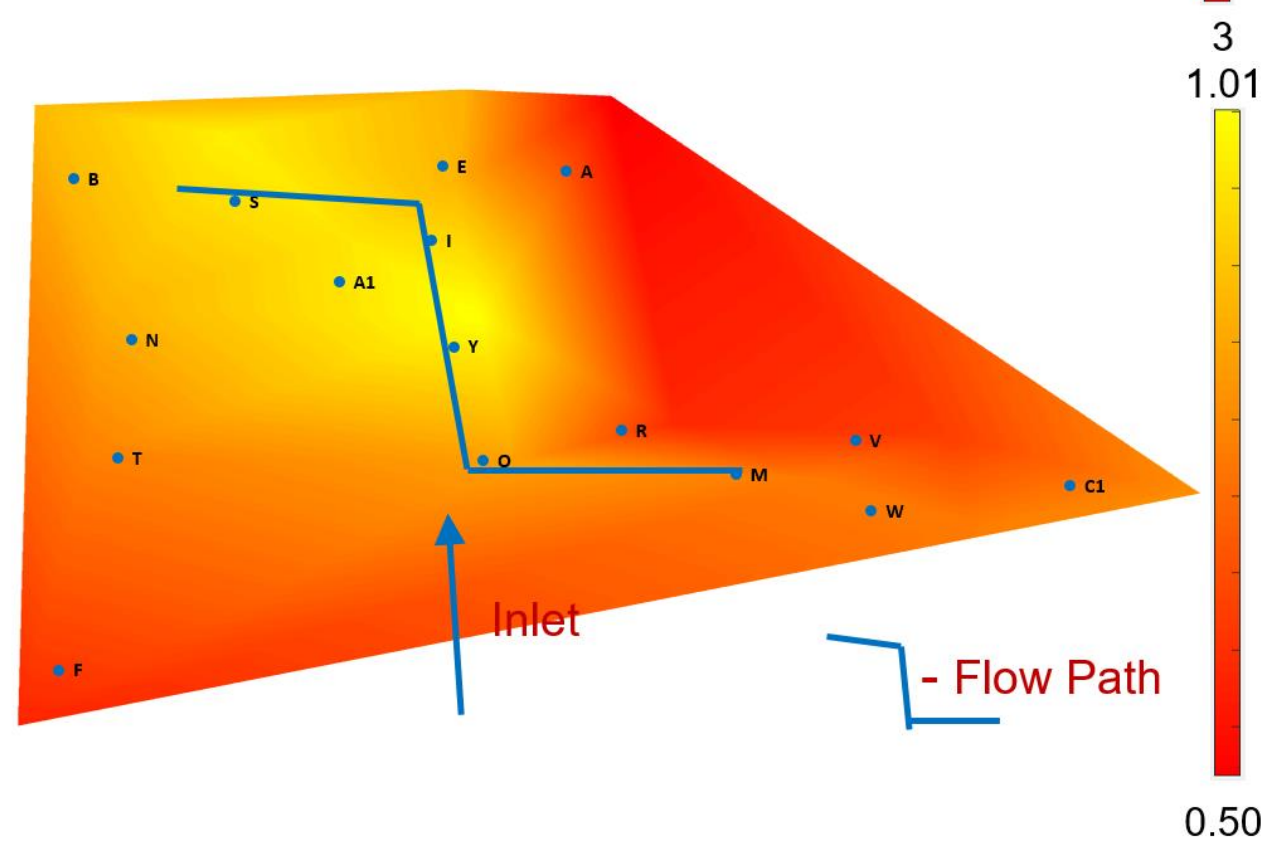

Figure 4-5: $\mathrm{Cu}$ (top) and Cc (bottom) 
For $\mathrm{Cu}$, the required sample size for $90 \%$ and $95 \%$ confidence interval are 6 and 18 respectively. For $\mathrm{Cc}$, the required sample size for $90 \%$ and $95 \%$ confidence interval are 4 and 10 respectively. Since, 16 measurements have been taken (excluding Q), the number of samples required to confidently estimate $\mathrm{Cc}(90 \& 95 \% \mathrm{CI})$ and $\mathrm{Cu}$ (only 90\% CI) are met in this study. However, since $\mathrm{Cu}$ requires 18 samples for $95 \%$ confidence interval (>16), $\mathrm{Cu}$ cannot be estimated with $95 \%$ confidence interval.

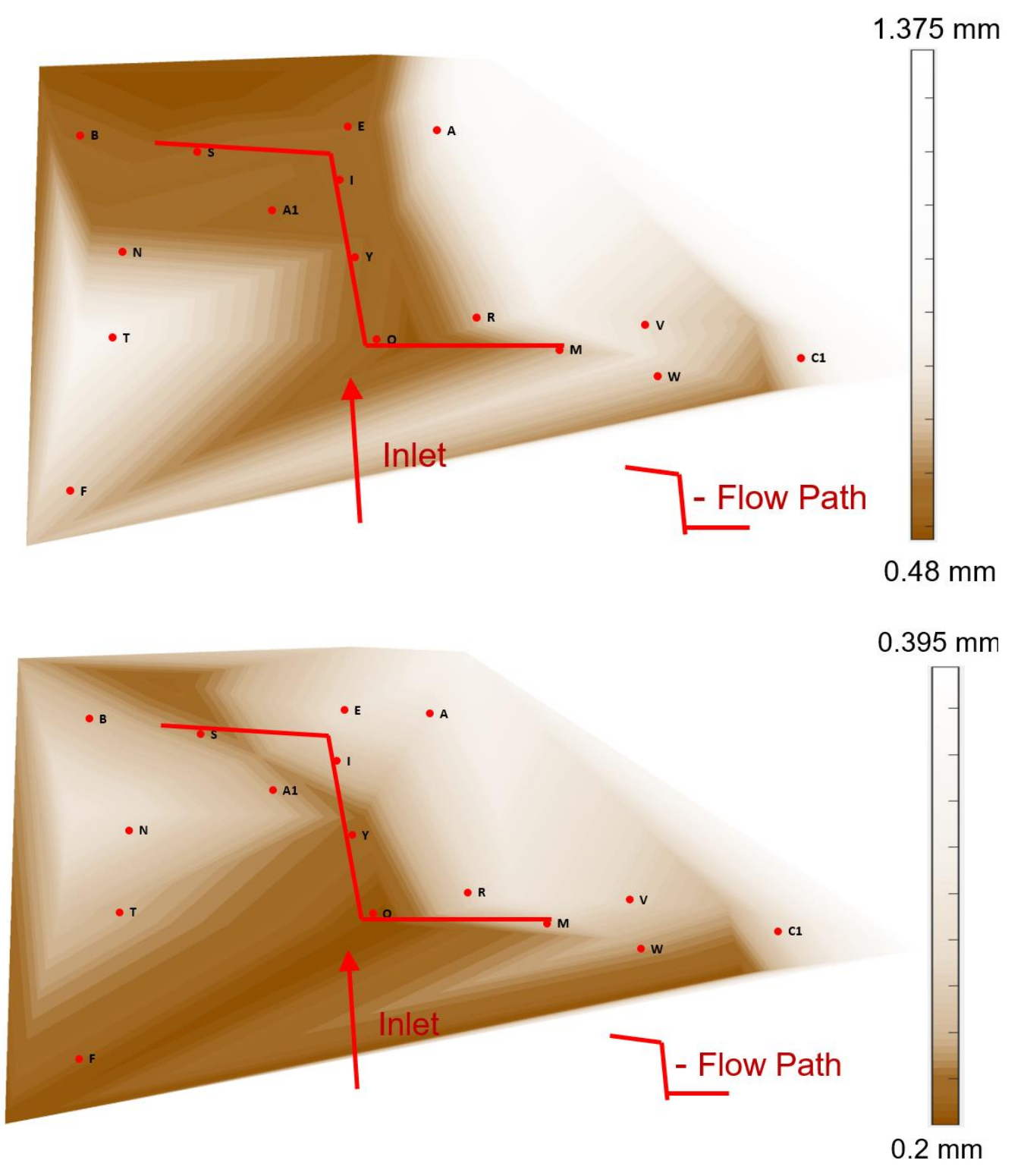

Figure 4-6: $D_{60}$ (top) and $D_{30}$ (bottom) 
From Figure 4-5 (top), it can be recognized that the soil is well graded in most of the regions except near T. From Figure 4-5 (bottom), it can be recognized that in the central pathway is well graded. Therefore, based on both $\mathrm{Cc}$ and $\mathrm{Cu}$, the soil is well graded in the central pathway particularly in the arm further from the inlet. This could be because, sediment deposition takes place in the central pathway, which is filled with the BC media. Sediment deposition causes the soil to be well graded because, the installed BC media is predominantly sandy. Sediments that are deposited are either silt or clay (smaller than sand particles). Therefore, the BC media in regions with sedimentation becomes well graded (a mix of sand, silt and clay).

The $\mathrm{BC}$ soil $\mathrm{D}_{60}$ and $\mathrm{D}_{30}$ i.e., the sieve size at which $60 \%$ and $30 \%$ of the soil is retained, is low in the central pathway and near the inlet (Figure 4-6) suggests sediment deposition may have occurred in these areas. Moreover, majority of the suspended solids are below the $\mathrm{D}_{30}$ size and therefore they are settled near the inlet showing smaller sizes near the inlet. They are also settled in the central flow path throughout the BC. The average $\mathrm{D}_{60}$ in the central pathway and non-central pathway region are $0.6 \mathrm{~mm}$ and $0.8 \mathrm{~mm}$ respectively. The average $\mathrm{D}_{30}$ in the central pathway and non-central pathway region are $0.2 \mathrm{~mm}$ and $0.3 \mathrm{~mm}$ respectively. This proportional difference also confirms that there is clogging through fines deposition in the central pathway.

For $\mathrm{D}_{60}$, the required sample size for $90 \%$ and $95 \%$ confidence interval are 6 and 18 respectively. For $\mathrm{D}_{30}$, the required sample size for $90 \%$ and $95 \%$ confidence interval are 5 and 13 respectively. Since, 16 measurements have been taken (excluding Q), the number of samples required to confidently estimate $\mathrm{D}_{30}(90 \& 95 \% \mathrm{CI})$ and $\mathrm{D}_{60}$ (only $\left.90 \% \mathrm{CI}\right)$ are met in this study. However, since $\mathrm{D}_{60}$ requires 18 samples for $95 \%$ confidence interval $(>16), \mathrm{D}_{60}$ cannot be estimated with $95 \%$ confidence interval.

\subsubsection{Snow Depth and Snow density}

Snow depth and snow densities were measured during 10 instances between 2016 and 2018 during winter. Shown in Table 4-3 the covariances of the snow depths are very high during events after or during rain on snow melt. A coefficient of variation $(\mathrm{CV})$ is a statistical measure of the dispersion of data points in a data series around the mean. This shows that snow melts in heterogeneous rates throughout the $\mathrm{BC}$. Because, just after snow before snow melt, the CV is comparatively low suggesting uniformity in the deposited snow depth. Since standard deviation is a quantity calculated to indicate the extent of deviation for a set of data, it increases when the mean 
increases and decreases when the mean decreases. Therefore, standard deviation cannot be used as a reliable measure in this situation to measure heterogeneity in snow depth.
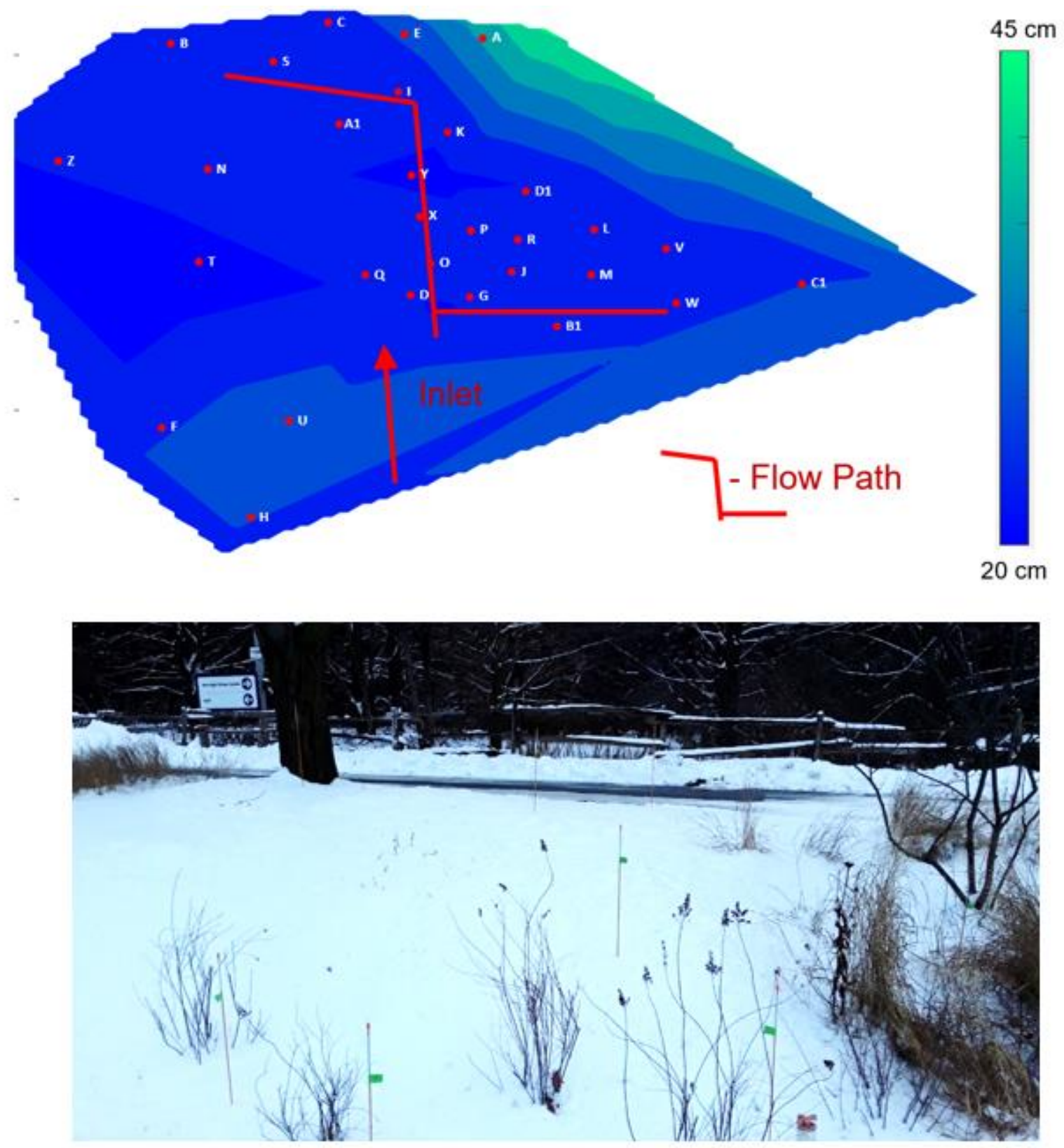

Figure 4-7: Snow depth before snow melt spatial map (top) and picture (bottom) on December 22, 2016, before thaw.

Example spatial snow depth data sets are presented to show the increase in heterogeneity in snow depths during snow melt. Figure 4-7 (top and bottom) are the spatial map from the snow depth data collected and picture taken on December 22, 2016 just after a snow event. Figure 4-8 
(top and bottom) are the spatial map from the snow depth data collected and picture taken on January 19, 2017 four days of snow melt after a snow event. On Dec 22 $2^{\text {nd }}$, the snow depth was mostly homogeneous throughout the BC except for the peak near the top right corner. This was determined to be due to snow being pushed from the parking lot by snow ploughs. On Jan 19th, after four days of warm weather (daily temperature highs $>0^{\circ} \mathrm{C}$ ), snow varied with location and reflected different rates of snow melt. The homogeneity and heterogeneity in snow depths are visible in pictures collected from the site on Dec $22^{\text {nd }}$ and Jan $19^{\text {th }}$ as shown in Figure 4-7 (bottom) and Figure 4-8 (bottom) respectively.

Table 4-3: Snow depth (cm) statistics with antecedent conditions

\begin{tabular}{|l|l|l|l|l|l|l|}
\hline Date & $\begin{array}{l}\text { Range } \\
(\mathbf{c m})\end{array}$ & $\begin{array}{l}\text { Mean } \\
(\mathbf{c m})\end{array}$ & $\begin{array}{l}\text { Median } \\
(\mathbf{c m})\end{array}$ & $\begin{array}{l}\text { StDev } \\
(\mathbf{c m})\end{array}$ & $\begin{array}{l}\text { COV } \\
(\boldsymbol{\%})\end{array}$ & $\begin{array}{l}\text { Antecedent } \\
\text { Conditions }\end{array}$ \\
\hline $12 / 22 / 2016$ & 29.50 & 23.80 & 22.25 & 5.25 & 22.05 & Snow \\
\hline $1 / 11 / 2017$ & 32.50 & 14.04 & 13.75 & 6.36 & 45.29 & Rain on snow melt \\
\hline $1 / 19 / 2017$ & 24.00 & 6.30 & 6.00 & 5.45 & 86.48 & Rain on snow melt \\
\hline $2 / 1 / 2017$ & 10.50 & 4.40 & 4.00 & 1.98 & 45.00 & Snow \\
\hline $2 / 8 / 2017$ & 12.00 & 2.13 & 1.75 & 2.42 & 113.48 & Rain on snow melt \\
\hline $2 / 13 / 2017$ & 14.00 & 16.62 & 16.50 & 2.53 & 15.21 & Snow \\
\hline $2 / 15 / 2017$ & 8.00 & 8.29 & 8.00 & 1.73 & 20.82 & Snow \\
\hline $1 / 8 / 2018$ & 22.00 & 21.18 & 20.25 & 5.21 & 24.58 & Snow \\
\hline $1 / 17 / 2018$ & 18.50 & 9.65 & 9.50 & 4.16 & 43.07 & Snow \\
\hline $2 / 5 / 2018$ & 25.50 & 12.35 & 11.25 & 5.22 & 42.28 & Snow \\
\hline
\end{tabular}

Table 4-4: Snow Density with date, time and antecedent conditions.

\begin{tabular}{|l|l|l|}
\hline Date and Time & $\begin{array}{l}\text { Snow Density } \\
\left(\mathbf{K g} / \mathbf{m}^{\mathbf{3}}\right)\end{array}$ & $\begin{array}{l}\text { Antecedent } \\
\text { Conditions }\end{array}$ \\
\hline $12 / 22 / 201612.00 \mathrm{pm}$ & 209.3 & Snow \\
\hline $1 / 11 / 20179.25 \mathrm{pm}$ & 366.2 & Rain on snow melt \\
\hline $1 / 19 / 201710.05 \mathrm{pm}$ & 490 & Rain on snow melt \\
\hline $2 / 1 / 20179.45 \mathrm{am}$ & 137.5 & Snow \\
\hline $2 / 8 / 201712.30 \mathrm{pm}$ & 507.5 & Rain on snow melt \\
\hline $2 / 13 / 20179.00 \mathrm{am}$ & 169.8 & Snow \\
\hline $2 / 15 / 2017$ & 287.1 & Snow \\
\hline
\end{tabular}

From Table 4-4, it can be observed that snow density is significantly higher after rain on snow melt. The average snow density with antecedent snow conditions is $200 \mathrm{Kg} / \mathrm{m}^{3}$, whereas the average snow density with antecedent rain on snow melt conditions is $455 \mathrm{Kg} / \mathrm{m}^{3}$. This $128 \%$ increase could be because during snow fall, snow gets deposited, but it does not get compressed. However, during rain on snow melt, even though a significant proportion of snow melts away, the remaining snow gets consolidated due to the kinetic force of rain droplets or the weight of water 
over them. Moreover, snow once melted, if freezes again, becomes like ice thereby increasing the snow density significantly. During snow density measurements, it is also observed that there are layers of snow with the lower layers are denser than the upper layers due to repeated snow before complete thaw.
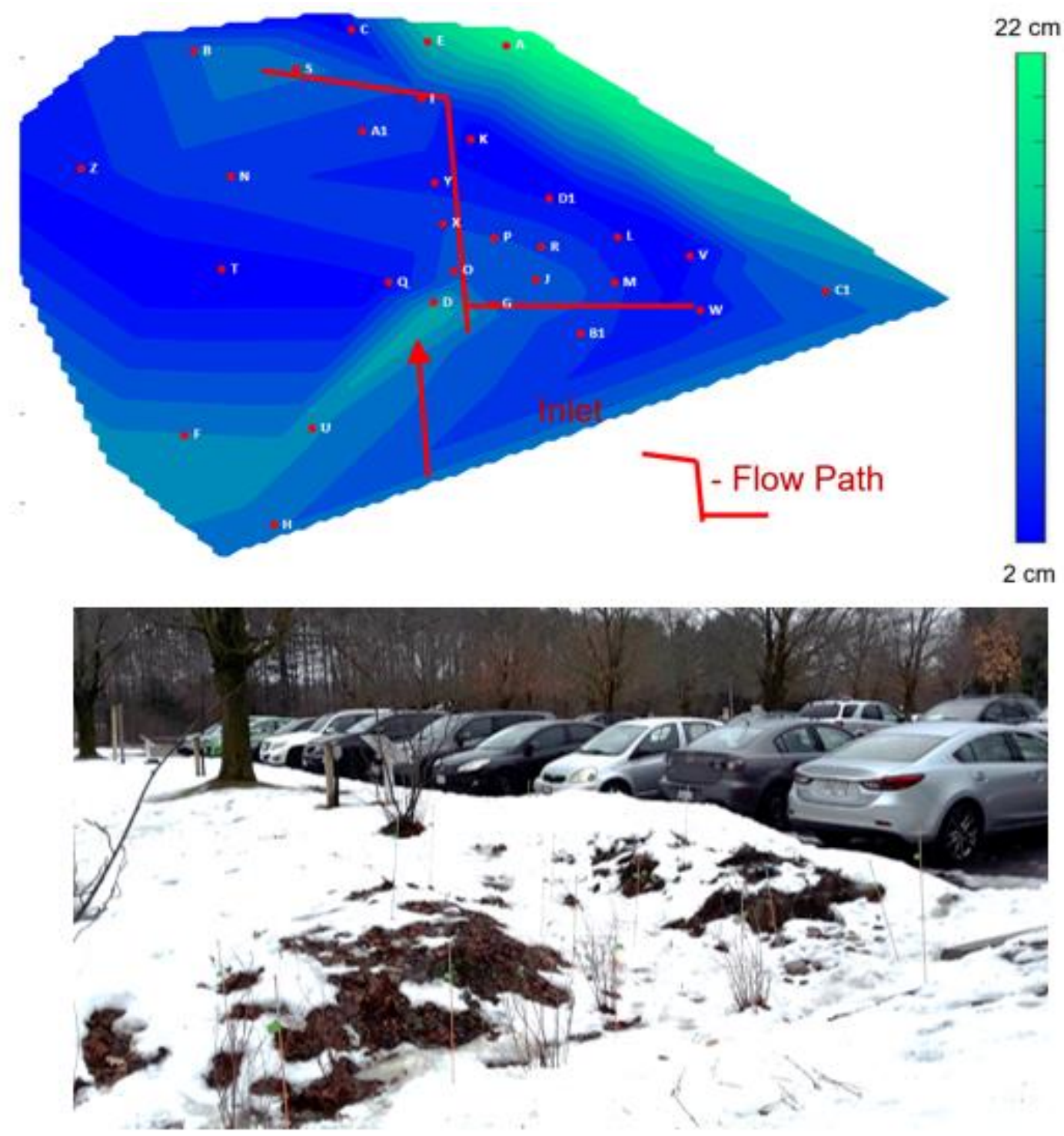

Figure 4-8: Snow depth after snow melt spatial map (top) and picture (bottom) on January 19, 2017, after thaw.

Based on the observations discussed above, parameters that were observed to have an effect in the thaw rates included:

1. Surface slope: the snow melts and slides down into the central flow path during thaw resulting in low snow depth in the slope between the hills and the flow path. 
2. Whether or not the location is in the hills or the flow path: any snow melt results in liquid water that flows to the flow path. Hence, this water melts any snow left in the flow path resulting in faster thaw rates in the flow path compared to the hills.

3. The direction where the slope is facing: if the slope is facing south, it receives significantly higher exposure to sunlight compared to north facing slopes. This results in higher thaw rates in South facing slopes and lower thaw rates in North facing slopes.

For Snow Depth, the required sample size for $90 \%$ and $95 \%$ confidence interval are 5 and 15 respectively. Since, 30 measurements have been taken, the number of samples required to confidently estimate Snow Depth (90 \& 95\% CI) are met in this study.

\subsubsection{Correlations}

The semi-variograms generated using MATLAB for all measured parameters are examined for positive trend (increasing variance with increasing distance). A parameter has high spatial correlation if its semi-variogram exhibits a positive trend. Moisture content, $\mathrm{K}_{\mathrm{sat}}$ and $\mathrm{Cc}$ have semivariograms with positive trends as shown in Figure 4-9, Figure 4-10 and Figure 4-11.

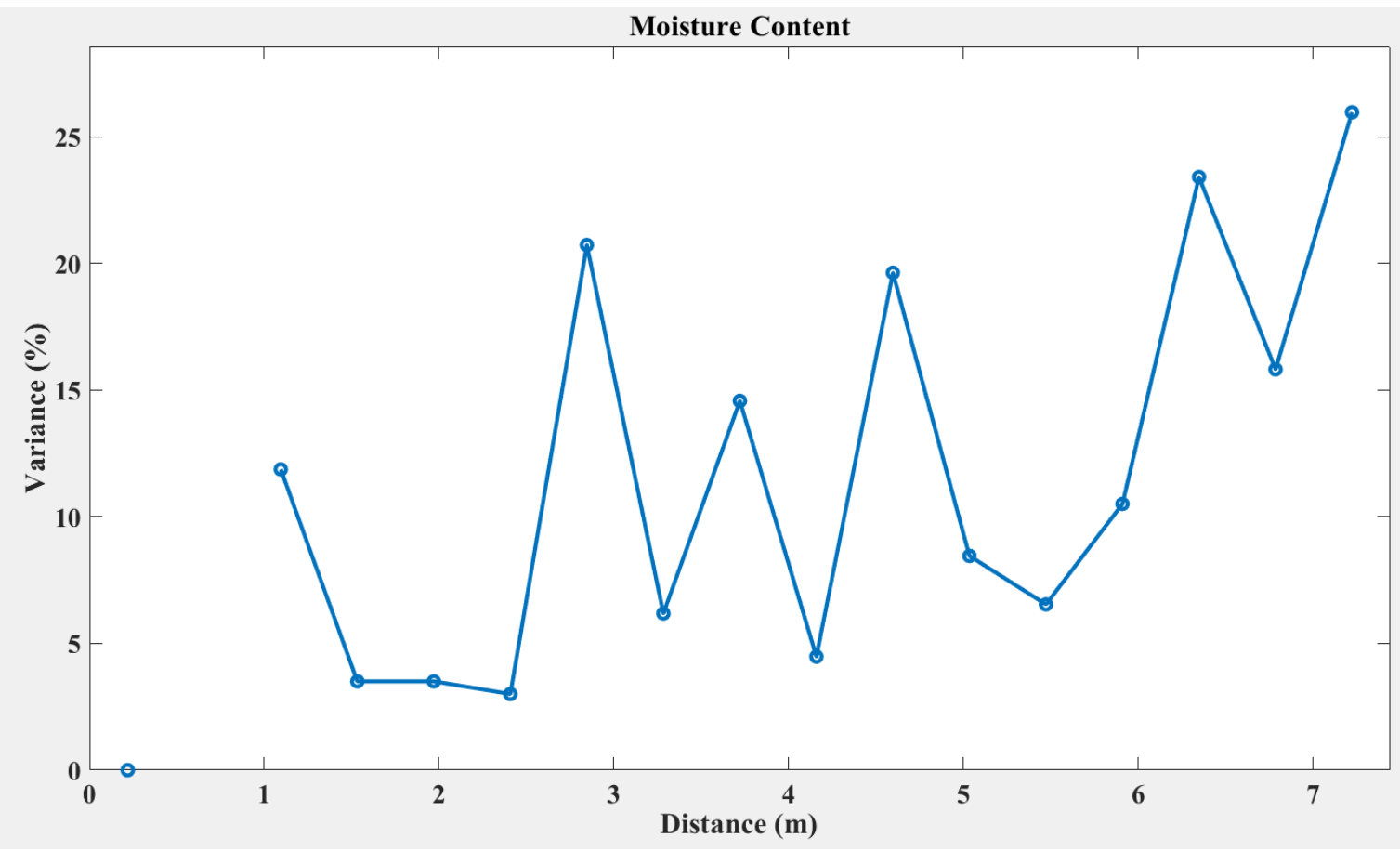

Figure 4-9: Semi-variogram - Moisture Content. 


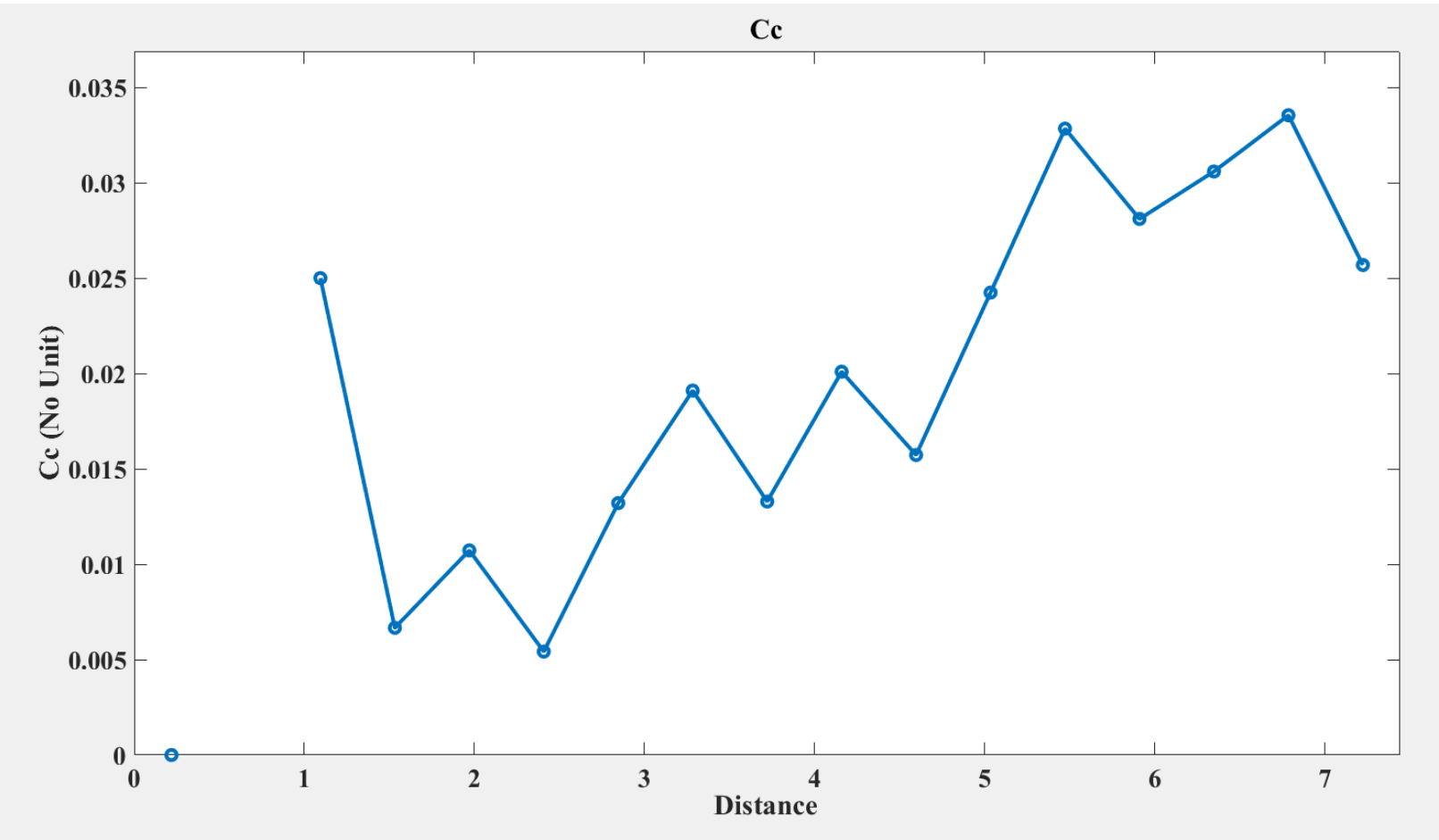

Figure 4-10: Semi-variogram-Cc

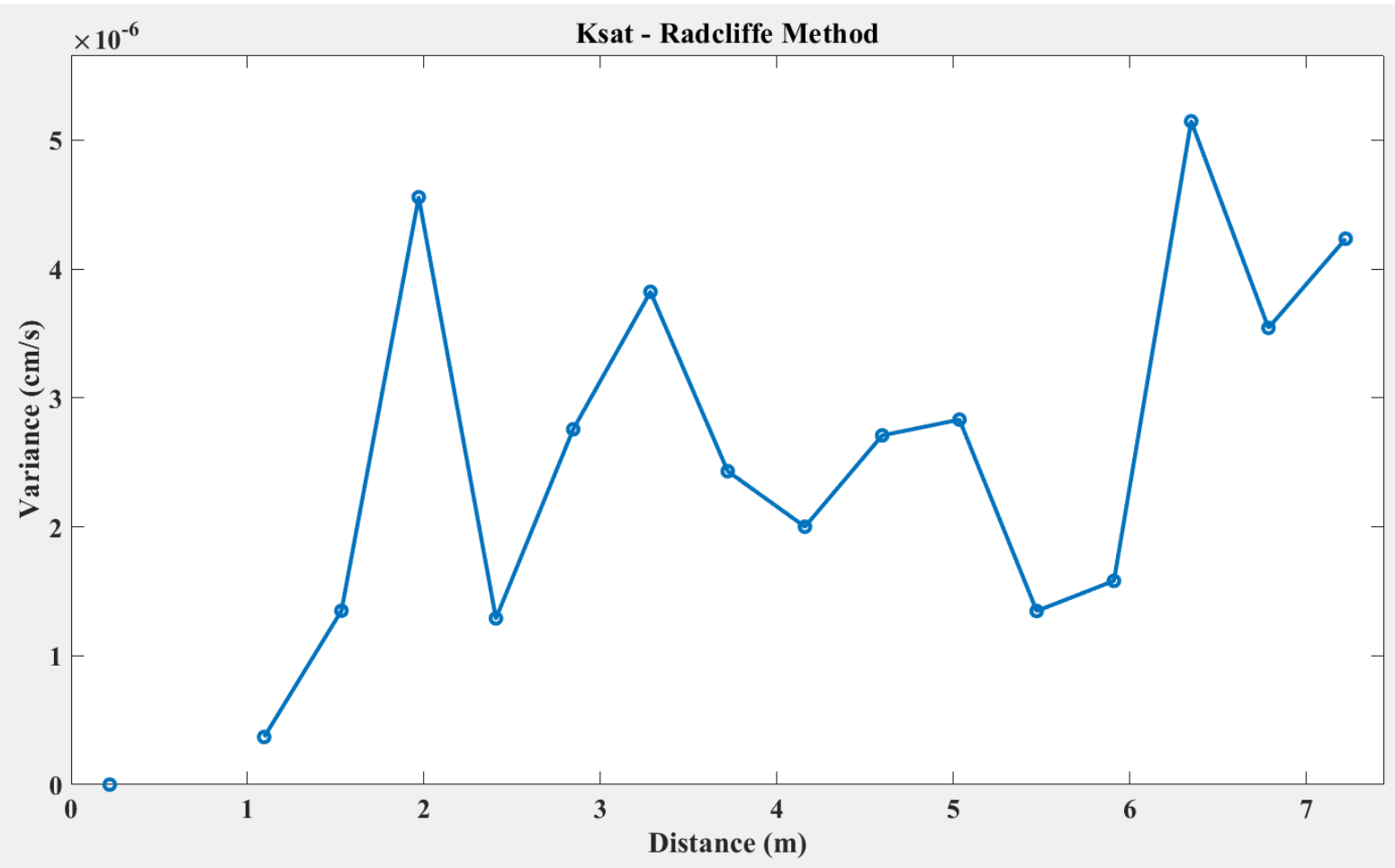

Figure 4-11: Semi-variogram - Ksat. 
Moisture content and Ksat could have better spatial autocorrelation because, closer points in the central pathway have high moisture content / low Ksat and closer points in the hills have low moisture content / high Ksat except for the outliers. Therefore, the further two points are, the lesser chances are they have a similar moisture content / Ksat. However, it should be noted that near the slopes, this condition doesn't exist i.e., two close points, one in the central pathway and one in the slope could have very different moisture content / Ksat. Both these parameters are also highly negatively correlated.

\subsubsection{Frost Depth}

It can be observed from Table 4-5 and from Figure 4-15 that there is almost no frost depth on the day with rain on snow melt i.e., February $26^{\text {th }}$. This is the day when a set of Guelph Permeameter measurements are carried out to test the effect of winter on $\mathrm{K}_{\text {sat. }}$ The locations in Table 4-5 can be referenced from Figure 3-16. $\mathrm{T}$ is the location at the top of the hill near the tree. The lengths of the frost tubes in each location are given in Table 3-4.

For better visualization of the data, figures have been produced for each individual set of data (Figure 4-12 to Figure 4-15). It should be noted that these figures are not engineering drawings. From Table 4-5, location T corresponds to the frost tube labelled 'Hill' in the figures, location $\mathrm{W} \& \mathrm{~V}$ corresponds to the frost tube labelled 'Slope' in the figures, 'reference' corresponds to the location 'External reference' and the 'Central pathway average' is the average frost depths of S, I\&Y, O and M.

As expected, the measured frost depth is higher in the hill, because the effect of warmer saturated zone is lesser in the hills. In location between $\mathrm{W} \& \mathrm{~V}$, which is in a slope, the frost depth is lower than the frost depth in the hill but higher than the frost depth in the central pathway locations. This could also be due to the proximity to the warmer saturated zone. The reference location is located in natural soil and it has higher frost depth. All locations that are in the central pathway have relatively similar frost depth in the order of $10 \mathrm{~cm}$ (Figure 3-16 and Table 4-5) . This could be because the gravel layer is at $40 \mathrm{~cm}$ depth, the warm saturated layer is close, and the snow melt from any location in the $\mathrm{BC}$ is going to flow towards and accumulate in the central pathway. 
Table 4-5: Frost depth (cm) from ground surface with dates and locations with antecedent conditions

\begin{tabular}{|l|l|l|l|l|l|l|l|l|}
\hline & $\mathbf{T}$ & $\mathbf{S}$ & $\begin{array}{l}\mathbf{I} \boldsymbol{\mathbf { S }} \\
\mathbf{Y}\end{array}$ & $\mathbf{O}$ & $\mathbf{M}$ & $\begin{array}{l}\mathbf{W} \\
\mathbf{\& V}\end{array}$ & Reference & $\begin{array}{l}\text { Antecedent } \\
\text { Conditions }\end{array}$ \\
\hline $2 / 5 / 2018$ & 33.5 & 12 & 10 & 9.5 & 7 & 19 & 12 & Snow \\
\hline $1 / 8 / 2018$ & 31.5 & 9.5 & 9 & 11.5 & 9 & 14 & $30+10 *$ & Snow \\
\hline $1 / 17 / 2018$ & 26 & 15 & 7.75 & 6.5 & 6.4 & 8 & 10 & Snow \\
\hline $2 / 26 / 2018$ & $0+11 *$ & 0 & 0 & 0 & 0 & 0 & 0 & Rain on snow melt \\
\hline$*$
\end{tabular}

The two data points with two numbers indicated by a $*$ are instances when two patches of frozen layers are identified. The $11 \mathrm{~cm}$ patch in Feb $26^{\text {th }}$ was between $21 \mathrm{~cm}$ to $32 \mathrm{~cm}$ under the ground surface and the $9 \mathrm{~cm}$ patch on $8^{\text {th }}$ January was between $23 \mathrm{~cm}$ to $33 \mathrm{~cm}$ under the ground surface. These phenomena could have happened either because the frozen water inside the frost tube did not defreeze properly or because there is a frozen layer under the soil surface below a non-frozen layer.

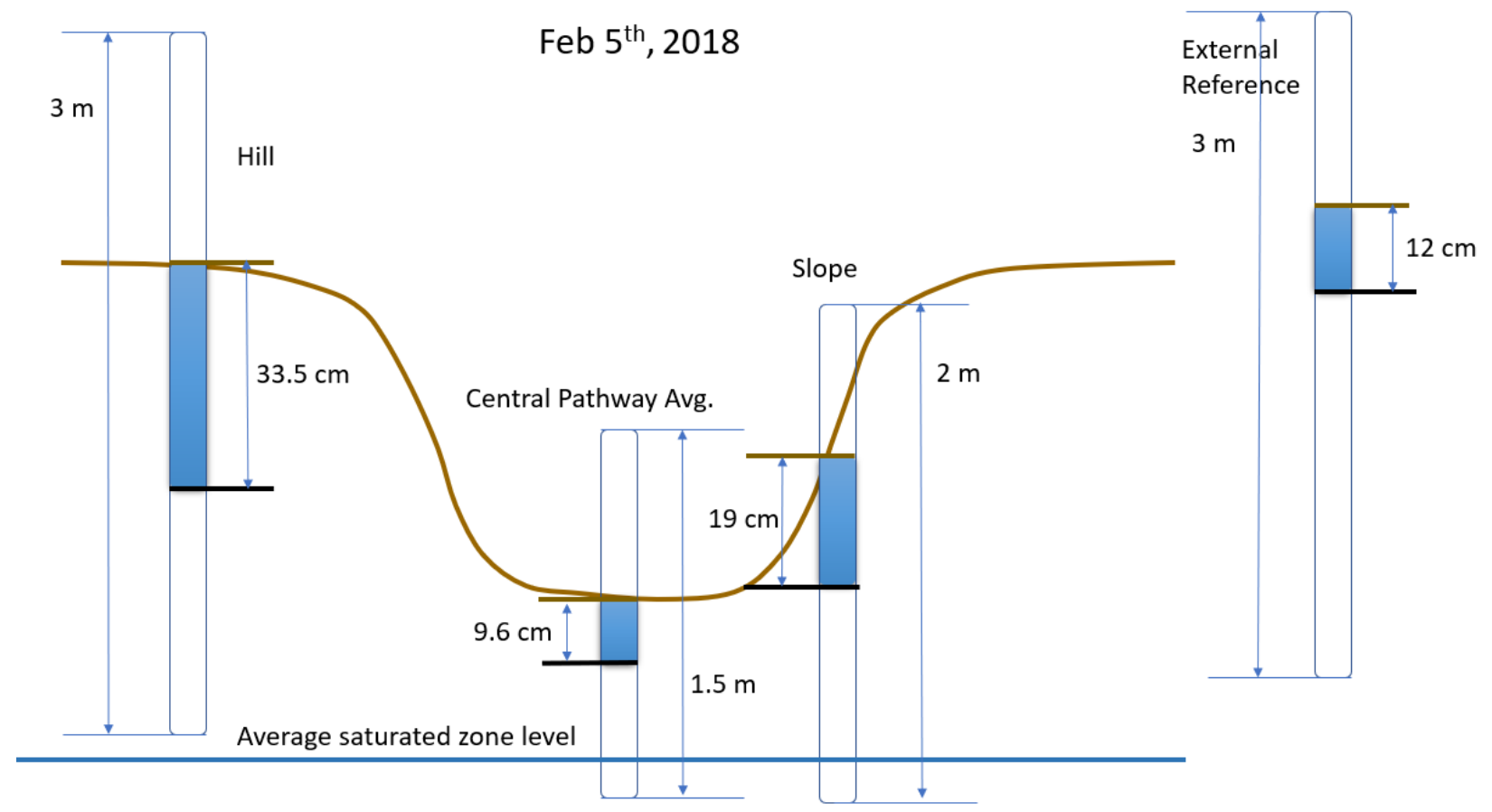

Figure 4-12: Frost depths on Feb 5, 2018. 


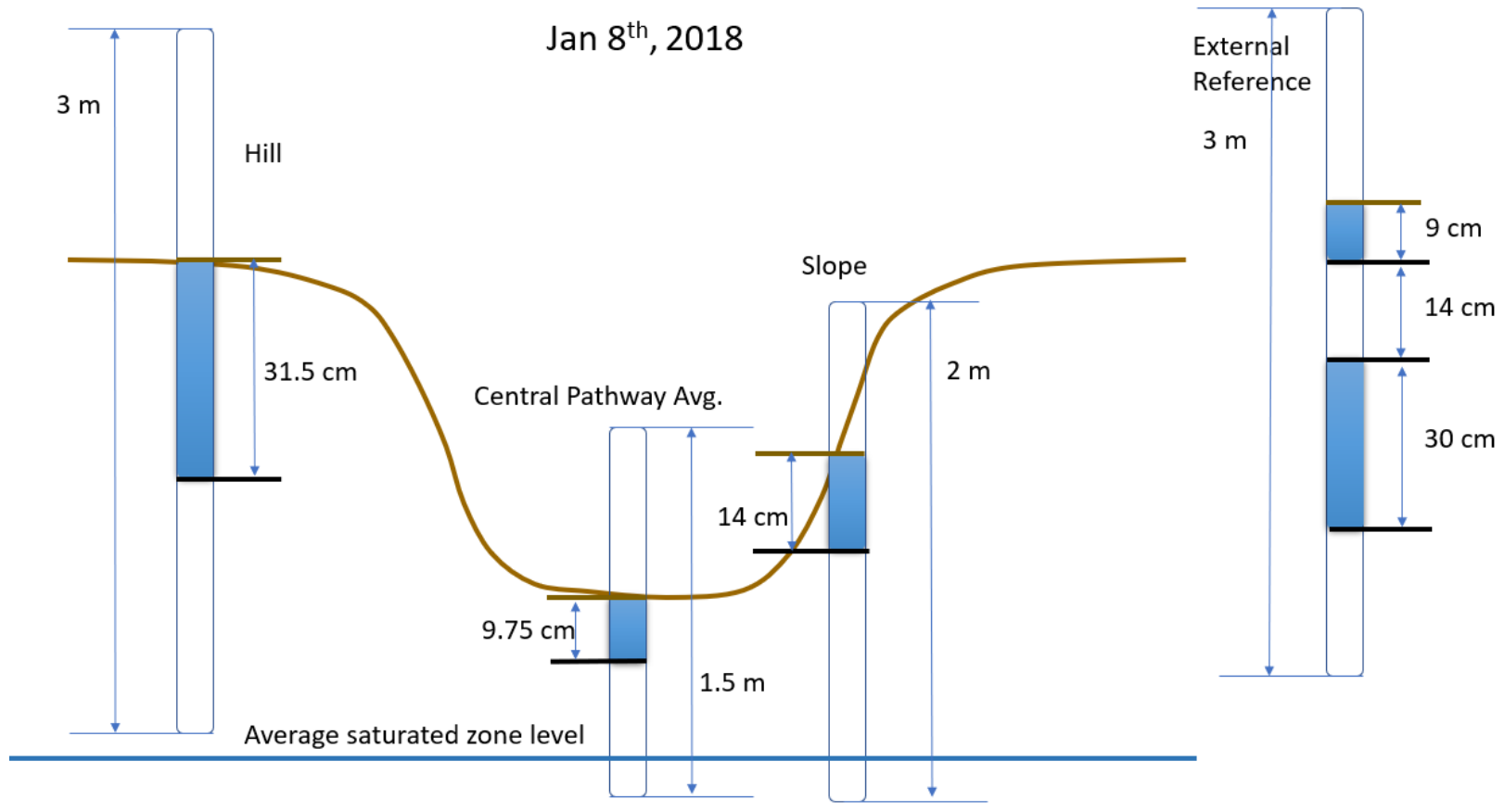

Figure 4-13: Frost depths on Jan 8, 2018

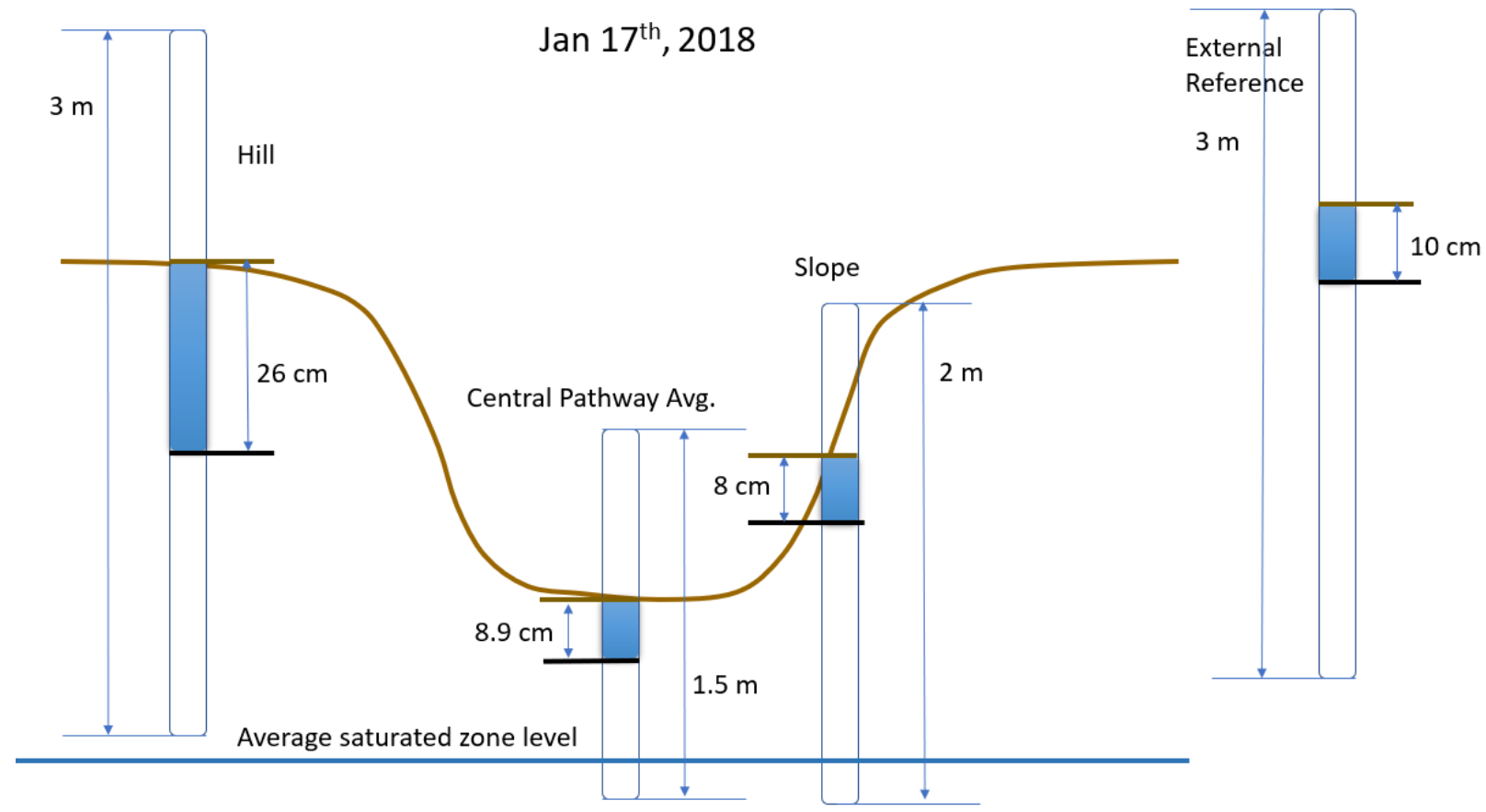

Figure 4-14: Frost depths on Jan 17, 2018 


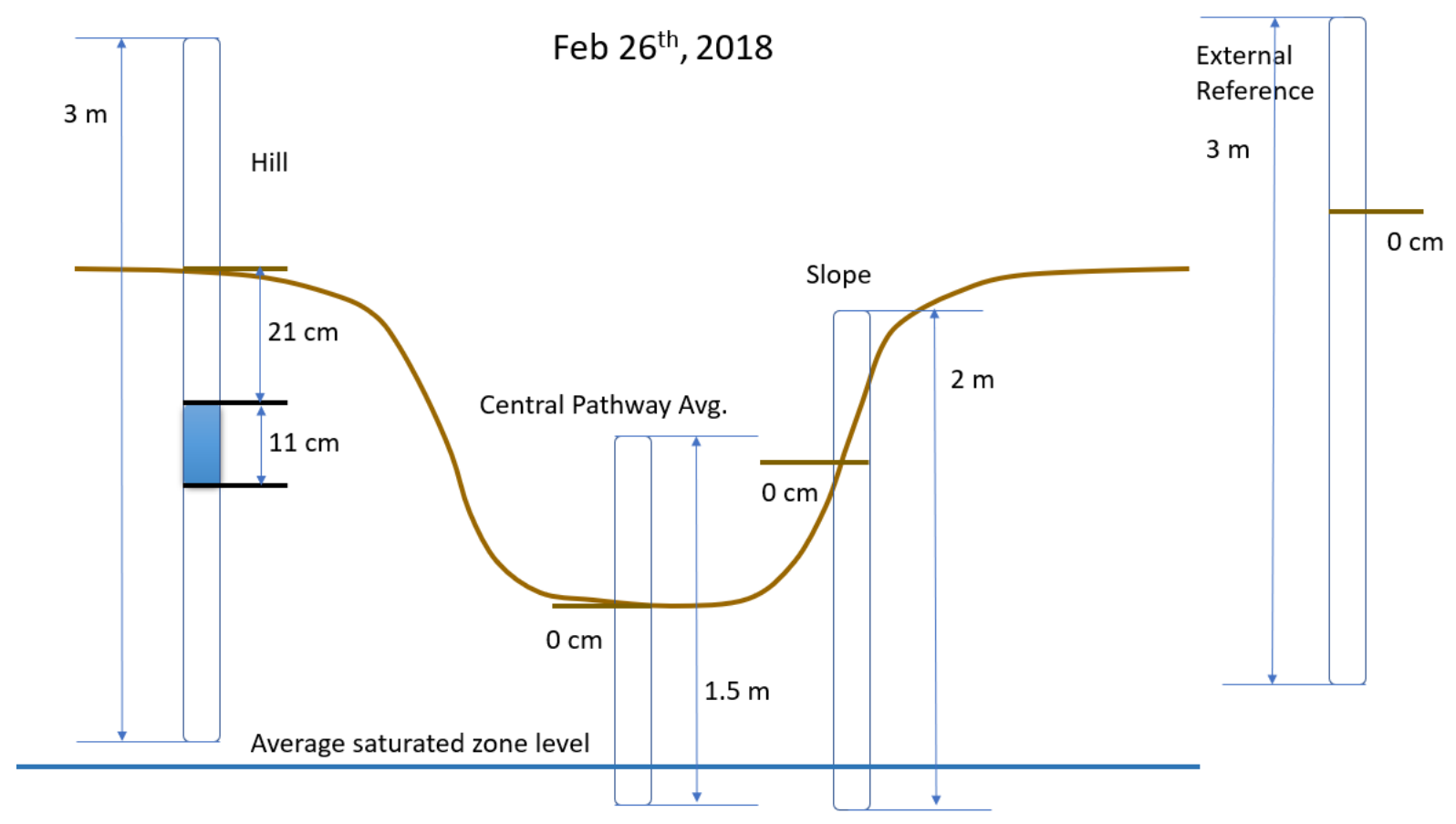

Figure 4-15: Frost depths on Feb 26, 2018

Custom made frost tubes have also been used in BCs by other researchers to measure frost depth (LeFevre et. al., 2009). It should also be noted that while this is an attempt to develop an approach to measure frost depth in BCs and it did show some promise, there were some erroneous issues as well. Also, It was not possible to get the right pipe dimensions recommended in the guidance (Institute of Northern Engineering, 2011). Furthermore, during February 26, 2018, since it was warm, ice was observed to be moving inside the tube due to melting of water along the circumference of the pipe. Therefore, this experimental set up to check the frost depths in BCs need to be further explored to produce reliable results.

\subsection{Temporal Variability}

\subsubsection{Saturated Hydraulic Conductivity $\left(\mathrm{K}_{\mathrm{sat}}\right)$}

From Figure 4-17, it can be observed that $\mathrm{K}_{\text {sat }}$ calculated using the older Elrick and Reynolds method follows the same pattern observed in Figure 4-16. However, the $\mathrm{K}_{\text {sat }}$ values are significantly higher when calculated using the Elrick and Reynolds method. When compared with $\mathrm{K}_{\text {sat }}$ values measured using Mini Disk Infiltrometer measurements by Ding (2017), which should be theoretically higher than Guelph Permeameter measurements, Elrick and Reynolds method of 
calculation produced $\mathrm{K}_{\text {sat }}$ values lower than the $\mathrm{K}_{\text {sat }}$ values produced by Mini Disk Infiltrometer measurements. However, the $\mathrm{K}_{\text {sat }}$ values arrived at using the newer Radcliffe method produced satisfactory values.

A Wilcoxon signed rank test was run on the $\mathrm{K}_{\text {sat }}$ data by Radcliffe method and Elrick \& Reynolds method to determine whether there is a statistically significant median difference in $\mathrm{K}_{\text {sat }}$ values between the two methods. The assumptions of Wilcoxon signed test (independence, continuity and symmetrical distribution of the differences between the two related groups) are met and the assumption test results are shown in Section 7.4. $\mathrm{K}_{\text {sat }}$ calculated through Radcliffe method $(0.00219 \mp 0.00089 \mathrm{~cm} / \mathrm{s})$ was lower than the $\mathrm{K}_{\text {sat }}$ calculated through Elrick \& Reynolds method $(0.00708 \mp 0.00354 \mathrm{~cm} / \mathrm{s})$. A statistically significant median difference of $0.0050247 \mathrm{~cm} / \mathrm{s}$ was identified, $\mathrm{W}=45.00, \mathrm{p}=0.009$. $\mathrm{Q}$ was not included in this analysis as discussed earlier. However, the statistical outliers in individual $\mathrm{K}_{\text {sat }}$ data sets as provided in Table 4-7 were not removed. Since Radcliffe method produced more realistic values of $\mathrm{K}_{\text {sat }}$ compared to Elrick and Reynolds method, the former used for all discussion purposes and the latter is used just to be compared with the former. The Guelph Permeameter manual has shown the calculation method in the GuelphPermeamter-Calculator.xls file which can be downloaded from Soilmoisture website. The calculator file has Elrick and Reynolds method (both 1 head and 2 head). For this research, the two head method is used for better accuracy. It should be noted that, Radcliffe method is not the default method of $\mathrm{K}_{\mathrm{sat}}$ calculation from Guelph Permeameter measurements.

While the accuracy of Elrick and Reynolds method in natural soil is out of the scope of this thesis, for BC media, it is recommended to use Radcliffe method of calculation as discussed in section 3.3.3. Using Elrick and Reynolds method as by consultors and regulators causes over prediction of $\mathrm{BC}$ media $\mathrm{K}_{\mathrm{sat}}$ as discussed above. It should be noted that the overall mean $\mathrm{K}_{\mathrm{sat}}(0.002$ $\mathrm{cm} / \mathrm{s})$, central pathway mean Ksat $(0.001 \mathrm{~cm} / \mathrm{s})$ and non - central pathway mean $\mathrm{K}_{\mathrm{sat}}(0.003 \mathrm{~cm} / \mathrm{s})$ all meet the TRCA guideline i.e., infiltration rate $-15 \mathrm{~mm} / \mathrm{hr}$ or $0.00042 \mathrm{~cm} / \mathrm{s}$ (Toronto and Region Conservation Authority, 2012). The average $\mathrm{K}_{\text {sat }}$ values for all points, central pathway and non central pathway points also fall within the $\mathrm{K}_{\mathrm{sat}}$ values provided for fine sandy loam / sandy loam or sandy soil (United States Department of Agriculture, 2018). Moreover, fluctuations in mean $\mathrm{K}_{\text {sat }}$ were attributed to isolated outlier measurements that produced a single point of notably higher $\mathrm{K}_{\text {sat }}$ Individual spatial maps of $\mathrm{K}_{\text {sat }}$ values are provided from Figure 7-30 to Figure 7-38 in the 
appendix. A spatial map with average $\mathrm{K}_{\text {sat }}$ calculated from Reynolds method is provided in Figure 4-1 (bottom).

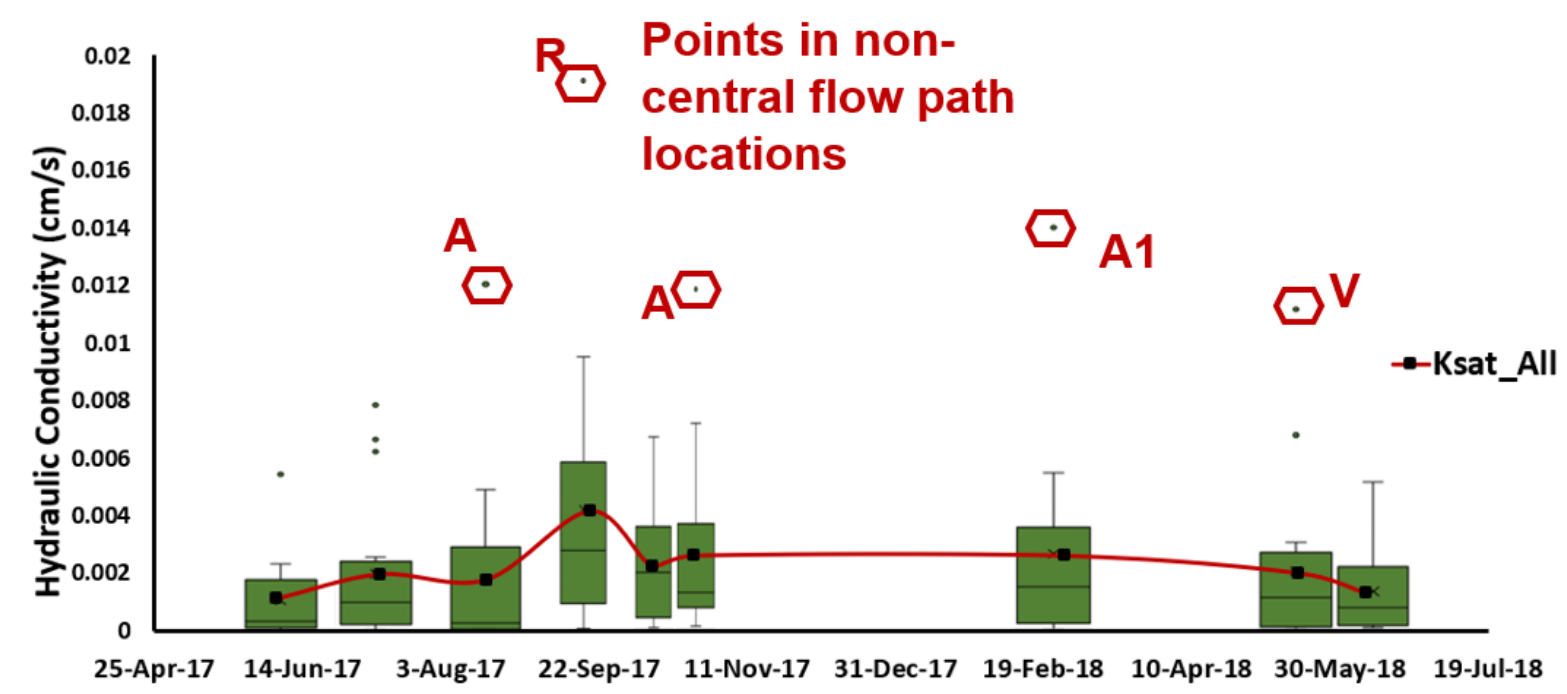

Figure 4-16: Timeline $K_{\text {sat }}$ data-Radcliffe method-All locations

In some instances, temporal variability was strong suspected to be due to measurement error and not due of naturally changes in in-situ soil conditions. For example, on September $20^{\text {th }}$, 2017 , the mean $\mathrm{K}_{\text {sat }}$ is particularly higher compared to the mean $\mathrm{K}_{\text {sat }}$ in all other days (Table 4-6). The high infiltration rates were attributed to the formation of preferential flow paths. For the first four sets of $\mathrm{K}_{\text {sat }}$ measurements, the same augured holes were used repeatedly to place the Guelph Permeameters after cleaning. The locations for each measurement was shifted slightly following this measurement date and mean and variability of infiltration rates decreased significantly. The next is that the antecedent dry conditions might have caused a low moisture content media that soaked more water (Gray \& Norum, 1967). Therefore, it is suspected by the authors that the repeated infiltration measurements combined with dry antecedent conditions created localized preferential flow paths. 


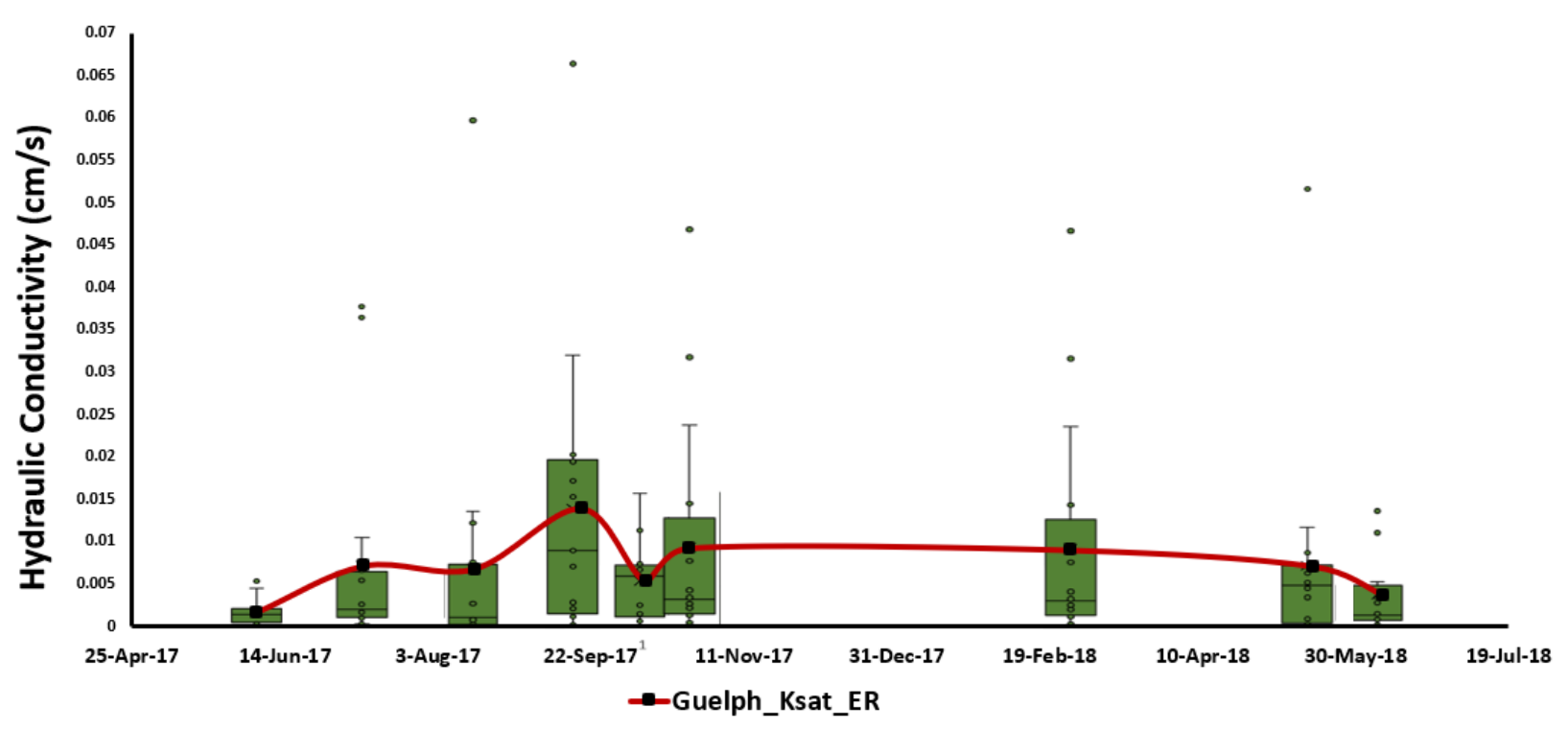

Figure 4-17: Ksat - Elrick and Reynolds method - All locations

The occurrence of outlying measurements with high infiltration appeared to occur randomly but were confined to measurement locations outside of the BC central flow path. Therefore, it is important to focus on the central flow areas for infiltration measurements since it reduces the risk of outliers and provides better estimates of infiltration rates in the hydrologically active area of the $\mathrm{BC}$.

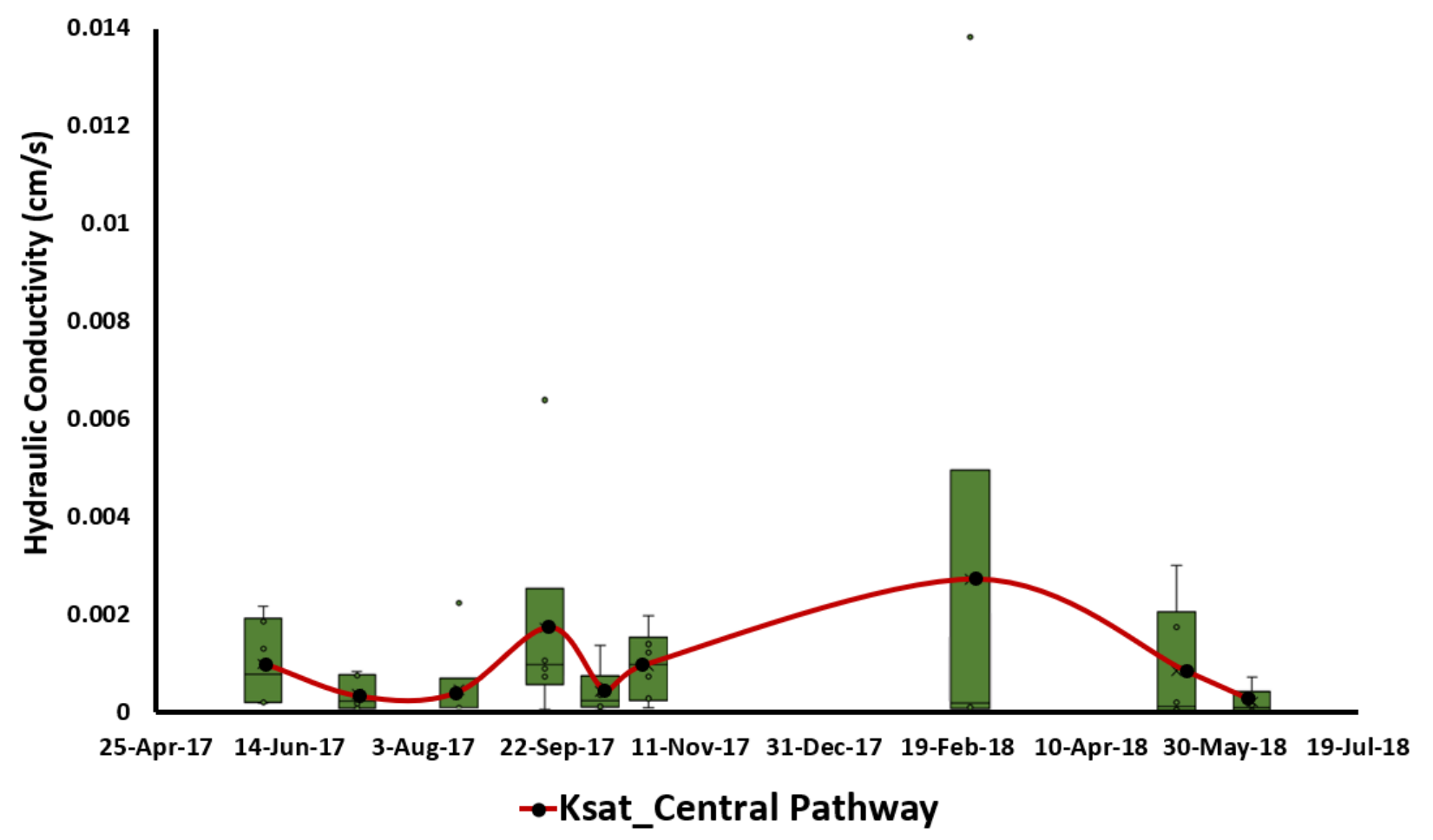

Figure 4-18: Timeline- $K_{\text {sat }}-$ Central Pathway, Radcliffe Method. 
From Figure 4-18, it can be seen that there is a marginal rise in $\mathrm{K}_{\text {sat }}$ in the central pathway locations during a warm day $(26 \mathrm{Feb}, 2018)$ in winter and there is a marginal decrease in Ksat in the non-central pathway locations in the same day. Though this seems to provide evidence for freeze-thaw action, the increase in Ksat in the central pathway is primarily driven by a peak value. And based on the observation of the box whisker plot, the $\mathrm{K}_{\text {sat }}$ in other locations are comparatively low. From Figure 7-33, it can be observed that the outlier is slightly left to the central flow path. This point, A1, is in the slope close to the central flow path but not in the central flow path like other locations in the central flow path. Ironically, there is no outlier among the locations in the non-central pathway regions as observed from Figure 7-36.

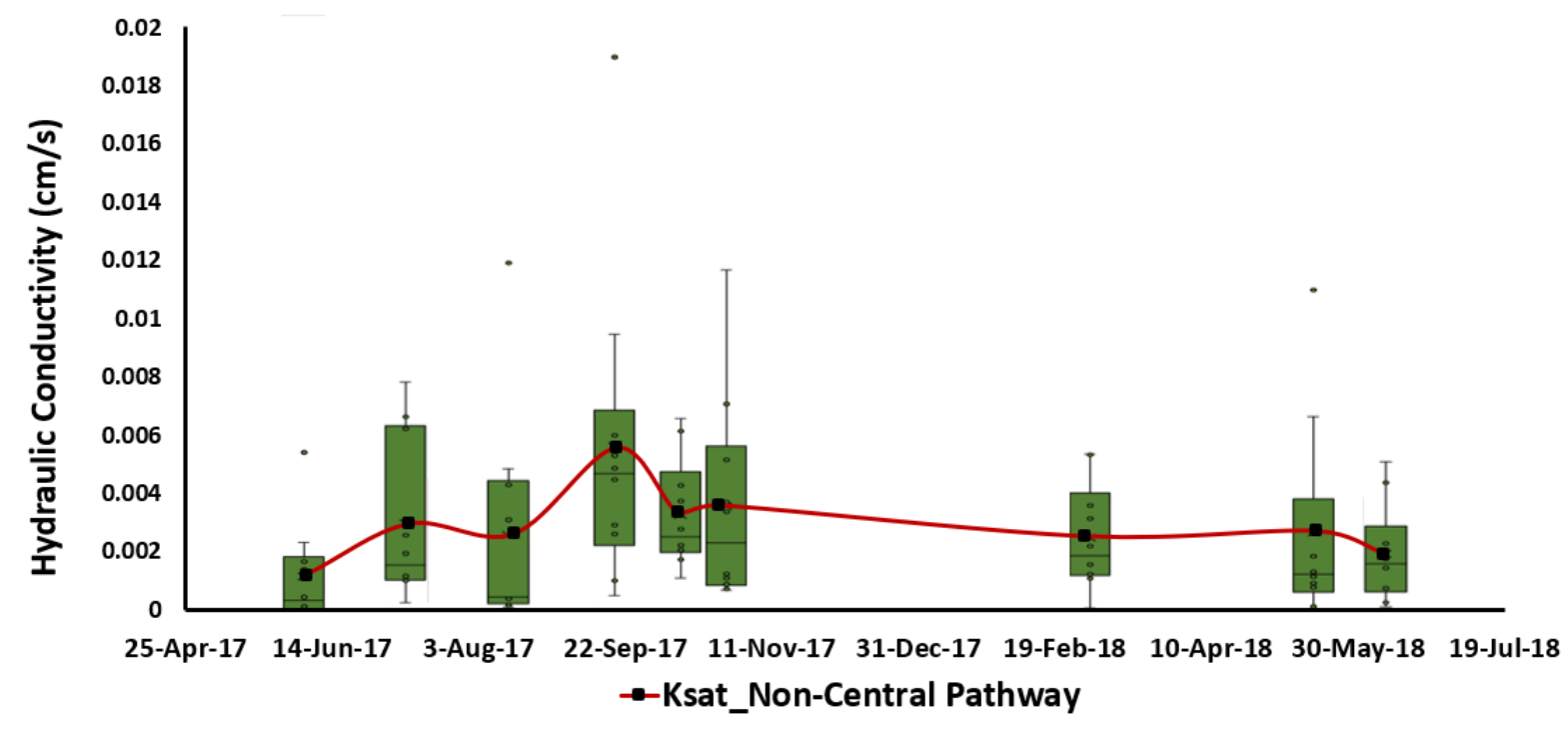

Figure 4-19: $K_{\text {sat }}$ - Non-Central Pathway - Radcliffe Method

Table 4-6: $K_{\text {sat }}(\mathrm{cm} / \mathrm{s})$ - Radcliffe method-Statistics and Antecedent Conditions

\begin{tabular}{|l|l|l|l|l|l|l|}
\hline Date & Range & Mean & Median & StDev & CV & Antecedent Conditions \\
\hline 5-Jun-17 & 0.005 & 0.001 & 0.000 & 0.001 & 129 & Wet \\
\hline 10-Jul-17 & 0.008 & 0.002 & 0.001 & 0.003 & 129 & Wet \\
\hline 15-Aug-17 & 0.012 & 0.002 & 0.000 & 0.003 & 178 & Wet \\
\hline 19-Sep-17 & 0.019 & 0.004 & 0.003 & 0.005 & 115 & Dry \\
\hline 10-Oct-17 & 0.007 & 0.002 & 0.002 & 0.002 & 92 & Wet \\
\hline 24-Oct-17 & 0.012 & 0.003 & 0.001 & 0.003 & 119 & Wet \\
\hline 26-Feb-18 & 0.014 & 0.003 & 0.001 & 0.003 & 134 & Freezing \\
\hline 16-May-18 & 0.011 & 0.002 & 0.001 & 0.003 & 148 & Wet \\
\hline 8-Jun-2018 & 0.005 & 0.001 & 0.001 & 0.002 & 120 & Wet \\
\hline
\end{tabular}


Table 4-7: Results of Grubbs test for outliers

\begin{tabular}{|c|c|c|c|c|}
\hline Date & Outliers & $\begin{array}{l}\text { Significance } \\
\text { Level }\end{array}$ & G value & $\begin{array}{l}\mathbf{P} \\
\text { value }\end{array}$ \\
\hline 05-Jun-17 & $\mathrm{N}$ & 0.05 & 3.04 & 0.002 \\
\hline 10-Jul-17 & - & 0.05 & 2.3 & 0.188 \\
\hline 15-Aug-17 & $\mathrm{A}$ & 0.05 & 3.22 & 0.000 \\
\hline 19-Sep-17 & $\mathrm{R}$ & 0.05 & 3.1 & 0.001 \\
\hline $10-$ Oct-17 & - & 0.05 & 2.12 & 0.361 \\
\hline 24-Oct-17 & $\mathrm{A}$ & 0.05 & 2.94 & 0.005 \\
\hline 26-Feb-18 & $\mathrm{A} 1$ & 0.05 & 3.24 & 0.000 \\
\hline 16-May-18 & $\mathrm{V}$ & 0.05 & 3.05 & 0.002 \\
\hline 8-Jun-18 & - & 0.05 & 2.44 & 0.100 \\
\hline
\end{tabular}

\section{Before Outlier Removal}

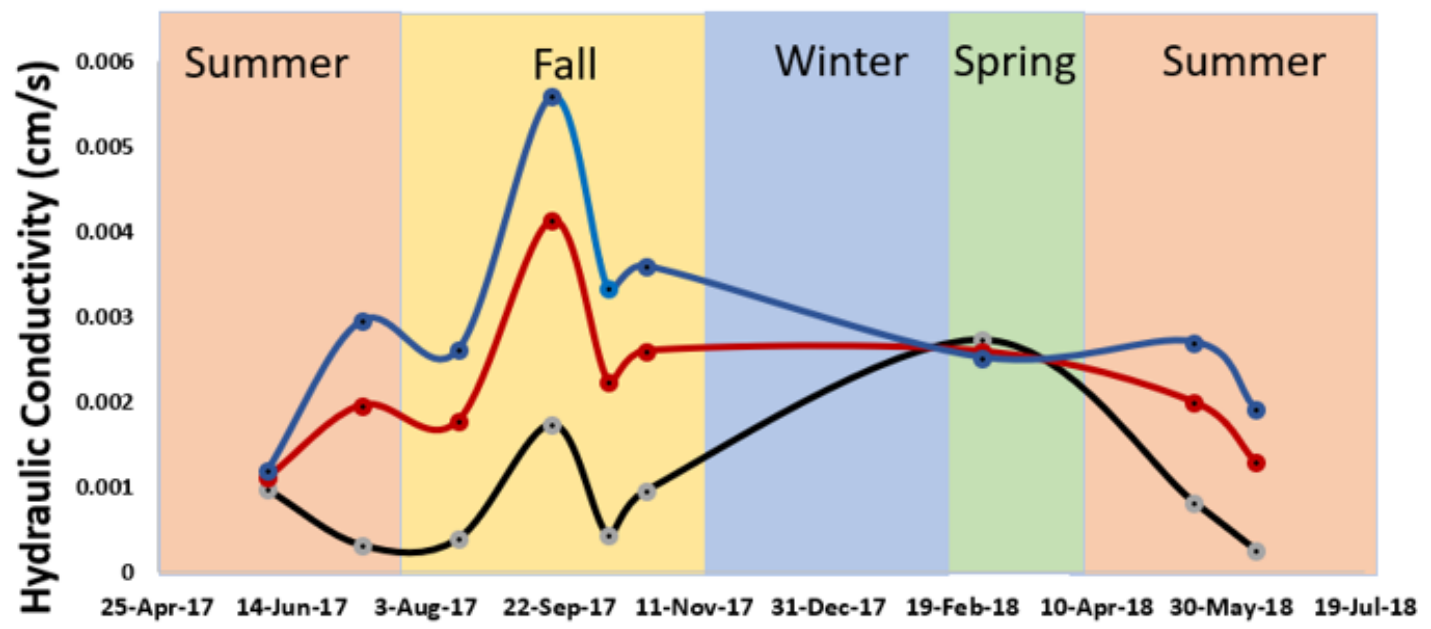

After Outlier Removal

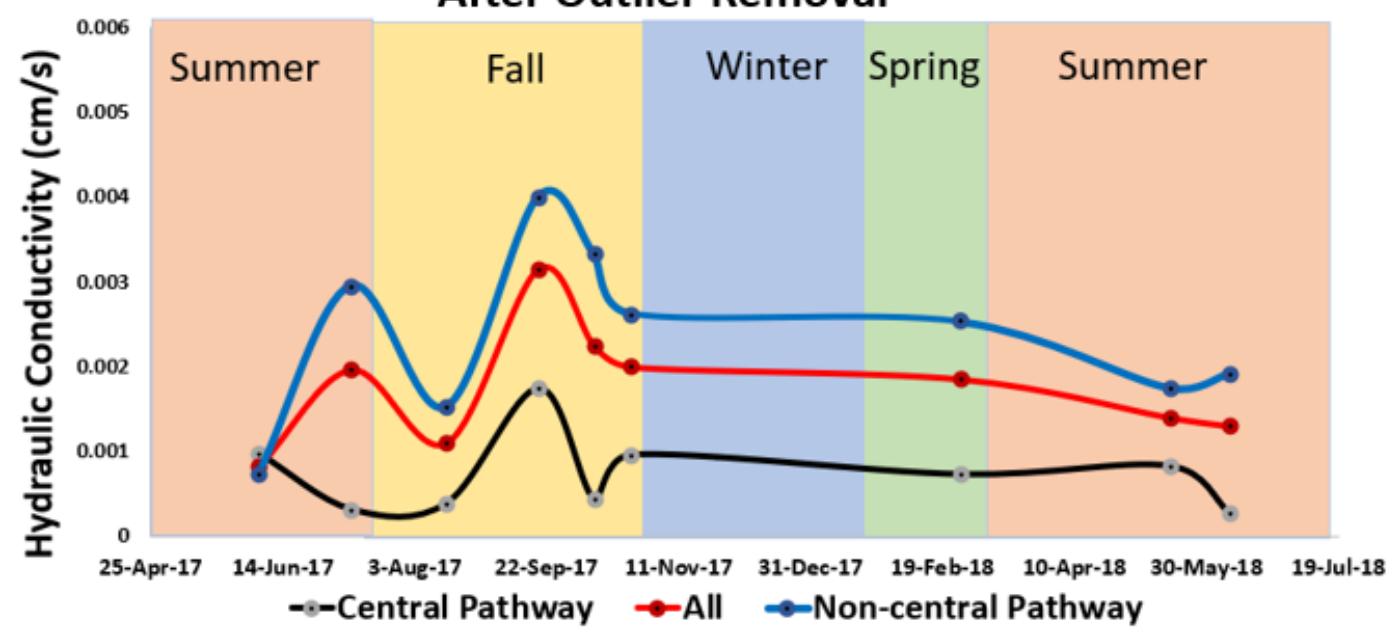

Figure 4-20: Ksat before outlier removal (top) and after outlier removal through Grubbs test (bottom). 
Due to outliers distorting the overall mean of the temporal $\mathrm{K}_{\mathrm{sat}}$ data, the Grubbs test is performed individually to each temporal data set to spot the outliers. The results of the Grubbs test for outliers are given in Table 4-7. The assumption of normality is checked through the Ryan Joiner test. The results of that test are shown in section 7.3. After the statistical outliers are removed, the average temporal $\mathrm{K}_{\text {sat }}$ calculated through Radcliffe method is plotted. The central pathway, noncentral pathway and all locations, before and after outlier removal through Grubbs test are shown in Figure 4-20 top and bottom respectively. It can be observed that increasing $\mathrm{K}_{\text {sat }}$ during winter observed in the central pathway in Figure 4-18 is not observed in Figure 4-20 (bottom). To clearly understand if there are seasonal changes in $\mathrm{K}_{\mathrm{sat}}$, we would need more data during the spring and multiple years of data collection.

\subsubsection{Water level}

One series of snow events with a rain on snow melt event at the end is shown in Figure 4-21 (top and bottom). It should be noted that when the Baro - temperature (air temperature) is close to or higher than zero, the precipitation is likely to be rainfall and when it is clearly lesser than zero, the precipitation is likely to be snowfall.
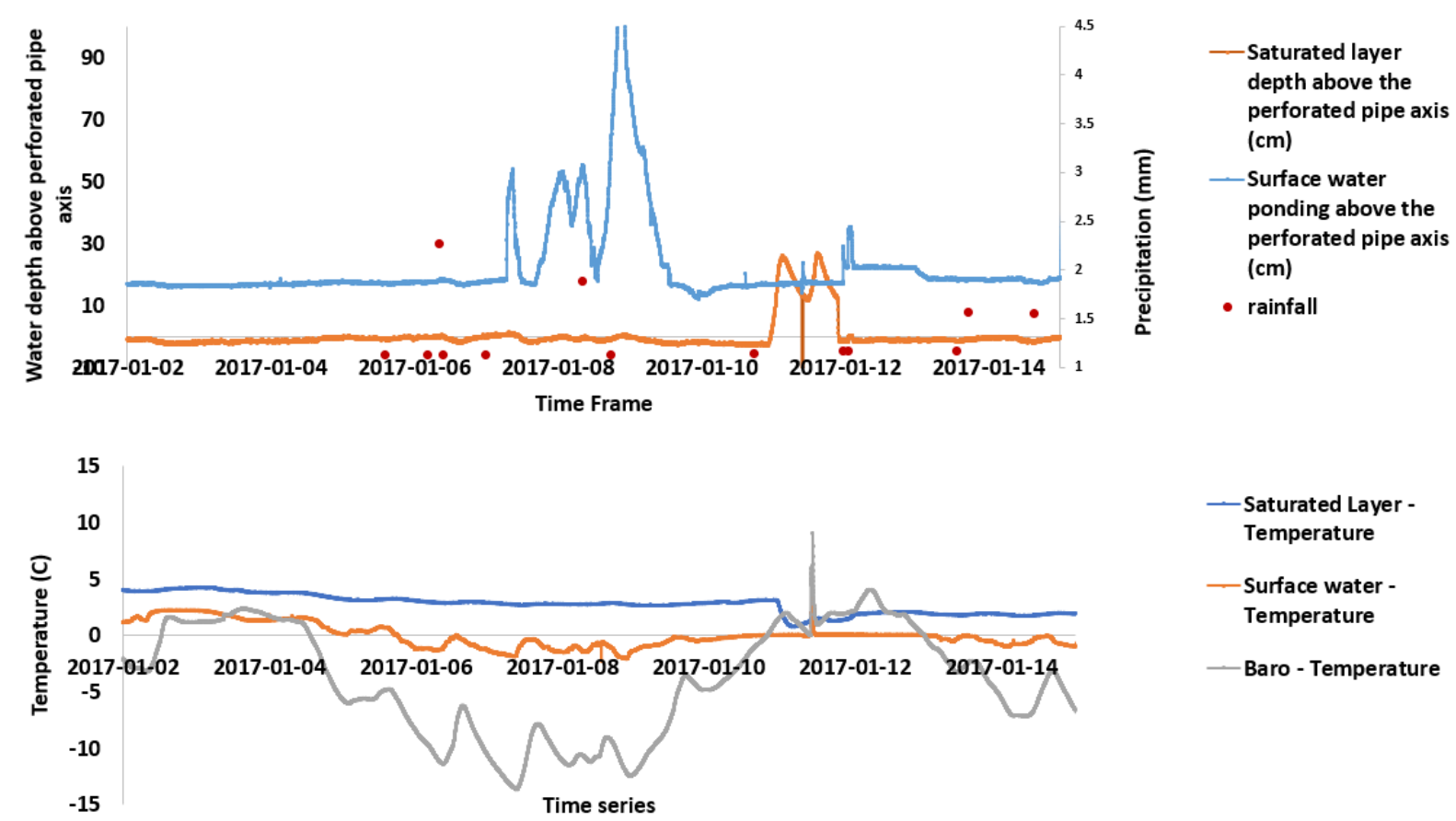

Figure 4-21: Rain on snow melt event reflected on the water level data (top) and temperature data (bottom). 
From January $6^{\text {th }}, 2017$ to January $8^{\text {th }}, 2017$, there were snow events and the air temperature is below zero. When the air temperature comes closer to zero, on January $9^{\text {th }}$, during a precipitation event, there is an increase in surface water temperature and a peak in surface water level which suggests rain on snow melt. Two days later, the peak can be observed in the saturated zone levels and a clear temperature drop is also observed in the saturated zone temperature suggesting transfer of surface water into sub-surface water. The datum used to graph surface water level data and saturated zone data is the axis of the perforated pipe in the $\mathrm{BC}$.

Table 4-8: Event statistics - Water levels

\begin{tabular}{|r|r|r|r|r|r|r|}
\hline Event & Start Time & Duration (h) & Avg. SZL & Avg. SWL & Max. SZL & Max. SWL \\
\hline 1 & $2017-01-0705: 55$ & 4.67 & 0.71 & 41.03 & 1.44 & 57.61 \\
\hline 2 & $2017-01-0719: 30$ & 16.17 & -0.5 & 47.57 & 0.52 & 58.82 \\
\hline 3 & $2017-01-0815: 00$ & 18.67 & -0.66 & 70.19 & 0.83 & 134.9 \\
\hline 4 & $2017-01-1200: 40$ & 2.17 & -0.4 & 33.491 & 0.54 & 39.01 \\
\hline 5 & $2017-01-1423: 20$ & 11.92 & -0.72 & 56.19 & 0.07 & 77.99 \\
\hline 6 & $2017-01-1519: 55$ & 40.08 & -1.78 & 80.15 & -0.41 & 243 \\
\hline 7 & $2017-02-0322: 10$ & 14.25 & 0.44 & 43.39 & 1.11 & 48.67 \\
\hline 8 & $2017-02-0906: 25$ & 8.33 & -0.07 & 43.22 & 0.9 & 58.81 \\
\hline 9 & $2017-02-0916: 50$ & 19.75 & -0.21 & 55.97 & 0.91 & 65.43 \\
\hline 10 & $2017-02-1508: 25$ & 2.33 & -0.97 & 28.97 & -0.13 & 52.76 \\
\hline 11 & $2017-03-0503: 20$ & 5.83 & 0.94 & 38.61 & 1.45 & 48.58 \\
\hline 12 & $2017-05-1804: 15$ & 2 & 0.72 & 25.726 & 1.16 & 40.9 \\
\hline 13 & $2017-06-1713: 50$ & 3.08 & 6.6 & 36.87 & 19.03 & 51.17 \\
\hline 14 & $2017-06-1807: 45$ & 2.25 & 1.77 & 32.269 & 4.27 & 43.38 \\
\hline 15 & $2017-06-2302: 10$ & 3.67 & 2.41 & 35.55 & 4.07 & 41.35 \\
\hline 16 & $2017-06-2306: 05$ & 3 & 3.94 & 37.77 & 12.93 & 55.65 \\
\hline 17 & $2017-06-2820: 50$ & 2 & 2.07 & 27.539 & 2.59 & 42.38 \\
\hline 18 & $2017-06-2919: 00$ & 2.08 & 1.29 & 32.922 & 1.82 & 40.15 \\
\hline 19 & $2017-07-0718: 10$ & 2.67 & 1.83 & 35.54 & 3.47 & 47.13 \\
\hline 20 & $2017-07-1215: 25$ & 3.17 & 2.16 & 36.88 & 2.78 & 48.07 \\
\hline 21 & $2017-07-1221: 10$ & 2.42 & 2.51 & 37.42 & 3.36 & 45.42 \\
\hline 22 & $2017-07-2010: 10$ & 2.67 & 2.86 & 33.561 & 5.97 & 46.45 \\
\hline 23 & $2017-08-0416: 30$ & 2 & 2.23 & 34.79 & 2.74 & 38.86 \\
\hline 24 & $2017-09-0213: 40$ & 2 & 0.25 & 26.138 & 1.02 & 41.45 \\
\hline 25 & $2017-09-0417: 45$ & 2.33 & 2.18 & 33.288 & 2.86 & 41.86 \\
\hline 26 & $2018-01-0814: 35$ & 19.17 & 0.69 & 39.03 & 1.43 & 41.83 \\
\hline 27 & $2018-01-0914: 35$ & 9.5 & 0.79 & 38.55 & 1.44 & 38.87 \\
\hline 28 & $2018-01-1000: 30$ & 3 & 0.95 & 38.23 & 1.83 & 38.59 \\
\hline 29 & $2018-01-1014: 55$ & 2.33 & 0.87 & 38.41 & 1.25 & 38.72 \\
\hline 30 & $2018-01-1016: 50$ & 2.17 & 0.64 & 38.26 & 1.08 & 38.66 \\
\hline 31 & $2018-01-1204: 05$ & 2 & 0.49 & 37.79 & 1.01 & 39.37 \\
\hline 32 & $2018-01-1206: 45$ & 9.67 & 1.28 & 38.8 & 2.12 & 39.51 \\
\hline Legend & & & & & & \\
\hline SZL & Saturated Zone Level & SWL & Surface Water Level & & \\
\hline
\end{tabular}

Table 4-8 shows the event statistics for the water level data. It should be noted that the perforated pipe axis is used as the datum for these calculations. Since, the saturated zone logger is 
beneath the perforated pipe axis, for some events, the saturated zone water levels are negative. The criteria used for events generation is given in section 3.6.4. It should be noted that the surface water ponding did not exceed 48 hours for any event which shows that the BC is functioning well.

\subsection{Additional Considerations}

\subsubsection{Physio-chemical processes}

Physio-chemical processes are suspected to cause structural changes in the soil by causing flocculation of aggregates according to literature (Kakuturu \& Clark, 2015). No chemical analysis has been carried out as part of this study, but salt concentrations are assumed to be higher in the central flow pathway. Based on the physical data presented above, it can be speculated that

1. Higher salt concentrations in the central pathway could cause flocculation of aggregates in the central pathway resulting in a lower $\mathrm{K}_{\text {sat }}$ as shown in Figure 4-1 (bottom). Higher salt concentrations in the central pathway could cause unfavorable conditions for plants to thrive resulting in lower organic content (Figure 4-2- top) and lower $\mathrm{K}_{\text {sat }}$ (Figure 4-1 - bottom). Lower organic content could be a direct result of lower plant density as observed through anecdotal evidence. Lower $\mathrm{K}_{\text {sat }}$ could be due to lower number of roots causing preferential flow paths due to lower plant density.

2. It can be observed from Figure 4-2 (bottom) that bulk density is lower along the outline of the $\mathrm{BC}$, particularly the points $\mathrm{B}, \mathrm{E}$ and $\mathrm{C} 1$ has very low bulk density. Based on observations, it is suspected that a very loose soil has caused the low bulk density in E. Loose soil and mulch are suspected to have caused low bulk density and high organic content in B and C1. Moreover, the average bulk density in the central flow path and non - central flow path regions are $1806 \mathrm{Kg} / \mathrm{m}^{3}$ and $1461 \mathrm{Kg} / \mathrm{m}^{3}$ respectively. The higher bulk density in the central flow path could be due to higher moisture content and sedimentation.

For organic content, the required sample size for $90 \%$ and $95 \%$ confidence interval are 4 and 12 respectively. For bulk density, the required sample size for $90 \%$ and $95 \%$ confidence interval are 6 and 16 respectively. Since, 16 measurements have been taken (excluding Q), the number of samples required to confidently estimate organic content and bulk density are met in this study. 


\subsubsection{Uncertainties in the data}

One of the uncertainties in the data collected is due to the immiscibility of the soil properties data collected using the two different methods. On this account, it should be noted there that porosity is calculated from bulk density and particle density. Bulk density is measured using the bulk density measuring kit and particle density is measured using Quantachrome Stereopycnometer. The samples for both measurements are collected using different methods. The former is collected using the bulk density measuring kit whereas the latter is collected using spade. Measures were taken to make sure that there is no mulch in the soil samples collected using spade. However, the soil samples collected using the bulk density had some mulch particles in them which could not be avoided. This might have caused a lower than actual bulk density measurement which could have resulted in a higher than actual porosity (Figure 4-2- bottom and Figure 4-3 - top). 


\section{Conclusions and Recommendations}

\subsection{Conclusions}

This study highlights the temporal and spatial heterogeneity that is present in BCs. For simplicity, designers often treat BCs as black-boxes ignoring heterogenous internal processes. In this study, the physical soil properties were distinct within the central flow pathway and all other locations surveyed in the BC. The central flow pathway is where the majority of stormwater will collect and infiltrate, hence it is important to better understand the spatial and temporal processes that influence parameters such as $\mathrm{K}_{\mathrm{sat}}$ in this region of the BC. The role of snow pack, freeze-thaw action and winter pollutants on long-term and seasonal BC processes is still poorly understood. While there was some evidence that freeze-thaw action may temporarily increase $\mathrm{K}_{\text {sat }}$ (in theory due to increasing pore sizes and preferential flow paths) the effect was limited to the central flow path.

In the introduction, the research objectives provided were

1. To measure $\mathrm{K}_{\mathrm{sat}}$ spatially in the $\mathrm{BC}$ throughout a year, analyze how various locations in the $\mathrm{BC}$ behave in terms of $\mathrm{K}_{\text {sat }}$ before, during and after winter and also study how antecedent weather conditions affect $\mathrm{BC} \mathrm{K}_{\text {sat }}$ value.

2. To collect spatially referenced soil samples from the BC, conduct laboratory experiments to determine the organic content, bulk density, moisture content, particle density, porosity and particle size distribution and compare them using spatial maps to identify patterns and establish spatial relations among them and $\mathrm{K}_{\text {sat. }}$

3. To measure snow depth and density during snow events and after thaw during winter, observe spatial snow depth distribution and analyze its relationship with the other soil parameters and $\mathrm{K}_{\text {sat. }}$.

4. To measure surface \& ground water levels and surface water, ground water $\&$ air temperatures, analyze them along with precipitation data and identify water level patterns during rain, snow melt or rain on snow melt conditions. 


\subsubsection{Objective 1}

Infiltration rates has been spatially measured at 17 locations in the $\mathrm{BC}$ throughout the year using Guelph Permeameters and the $\mathrm{K}_{\text {sat }}$ values are arrived at through Radcliffe method and Elrick \& Reynolds method. The data is analyzed for specific spatial patterns by plotting contour maps. The specific spatial and temporal patterns identified are

$1 \mathrm{~K}_{\mathrm{sat}}$ is lower in the central pathway and higher in the hills or slopes due to relative distance from the saturated zone and differences in moisture content.

$2 \mathrm{~K}_{\mathrm{sat}}$ remains stable without fluctuations overall. Any minor shift from the mean is due to antecedent dry conditions or preferential flow paths.

$3 \mathrm{~K}_{\text {sat }}$ in the central pathway shows a mild rise during warm winter days and $\mathrm{K}_{\text {sat }}$ in the noncentral pathway shows a mild decrease during winter.

\subsubsection{Objective 2}

1 Moisture content is negatively correlated with $\mathrm{K}_{\text {sat. }}$.

2 Organic content is negatively correlated with bulk density.

3 Moisture content is higher in the central flow path compared to the hill regions due to proximity to the saturated zone and inflow runoff.

$4 \mathrm{D}_{30}$ and $\mathrm{D}_{60}$ are lower in the central flow path due to sediment and suspended solids deposition.

\subsubsection{Objective 3}

Snow depth is measured manually inside the BC and spatial maps have been prepared using the collected data. Snow density is also measured manually. Using these information, the following inferences were deduced.

1 After every snow event, snow deposition is predominantly homogeneous.

2 Snow is pushed into the $\mathrm{BC}$ from the parking lots on the sides using mechanical shovels.

3 Snow melts at heterogeneous rates inside the BC i.e., faster in the central flow path and slopes and slower in the hills. Snow also melts faster in locations facing the south. 
4 Snow density after rain on snow melt is $128 \%$ higher than the snow density just after snow before snow melt.

\subsubsection{Objective 4}

Water level in the $\mathrm{BC}$ has been measured using a surface water and a ground water logger. A barometric logger is used for varying air pressure correction. A rain on snow melt event is pinned down and analyzed. The following processes were determined using the above-mentioned data.

1. Surface water level peaks during rain on snow melt events.

2. The surface water level peak is transferred to the ground water with a lag time of roughly two days during rain on snow melt events.

\subsection{Recommendations for future research}

\subsubsection{Saturated Hydraulic Conductivity $\left(\mathrm{K}_{\mathrm{sat}}\right)$}

The equipment used for the $\mathrm{K}_{\text {sat }}$ measurement in this research is Guelph Permeameter which can measure at a minimum depth of $15 \mathrm{~cm}$ or higher. Therefore, this caused a limitation in terms of measuring the spatial $\mathrm{K}_{\mathrm{sat}}$ values in the top $5 \mathrm{~cm}$ layer where the clogging could have been identified with much more certainty. However, using other equipments like the Mini Disk Infiltrometer or the Modified Philip - Dunne Infiltrometer has associated problems like the shredded wood mulch layer on the top $10 \mathrm{~cm}$ which has to be removed as well. Furthermore, while removing the mulch, based on observation there are always wooden particles sticking into the first $5 \mathrm{~cm}$ of the BC media layer which has to be removed as well. Therefore, even methods that does not require a depth of $15 \mathrm{~cm}$ might not be able to measure the undisturbed $\mathrm{K}_{\text {sat }}$ value in the $\mathrm{BC}$ media surface.

\subsubsection{Soil parameters}

As mentioned above, the $\mathrm{K}_{\text {sat }}$ values are measured at $15 \mathrm{~cm}$ depth and to be consistent all soil samples are measured at 15 to $20 \mathrm{~cm}$ depth as well. However, measuring soil samples at the 
top $5 \mathrm{~cm}$ could have provided a clearer look on the soil parameters to substantiate the presence of sediments and the occurrence of clogging.

It is also recommended to auger/take more than one soil sample in the same location and mix them to get a representative sample for the location to eliminate the effects of outliers and variability.

One of the other major limitations of this study is that no chemical tests are carried out to produce a spatial data of salt concentrations. This data could have helped analyze any potential physio-chemical processes (e.g. salt loading) that could lead to structural changes in soil.

\subsubsection{Snow depth}

Even though snow depth has been measured at several instances and the identified patterns has been discussed, there is no temporal snow melt observations of the snow pack to substantiate the contention. Therefore, dynamic image capture cameras or laser snow depth sensors could provide with better data to verify the assertions in this research with certainty.

\subsubsection{Water levels}

Even though water levels have been measured continuously for about a two-year period, they have not been much useful in terms of research output other than identifying rain on snow melt water lag time because the inflow and outflow are not monitored during winter. There has been research on cold weather flow monitoring with flumes. There are also flumes with embedded heat, but they might modify the winter flow characteristics. Therefore, measuring inflow and outflow during winter will facilitate winter water balance studies. 


\section{Bibliography}

Americal Society of Testing Materials. (2017). Standard Practice for Classification of Soils for Engineering Purposes (Unified Soil Classification System) D 2487 - 17. West Conshohocken, Pennsylvania, United States: ASTM.

Asleson, B. C., Nestingen, R. S., Gulliver, J. S., Hozalski, R. M., \& Nieber, J. L. (2009). Performance assessment of rain gardens. Journal of the American Water Resources Association, 1019-1031.

ASTM. (2014). Standard Test Methods for Moisture, Ash, and Organic Matter of Peat and Other Organic Soils. D2974 - 14. West Conshohocken, Pennsylvania, United States: ASTM International.

ASTM. (2017). Standard Test Method for Bulk Density ("Unit Weight”) and Voids in Aggregate. C29/C29M - 17a. West Conshohocken, Pennsylvania, United States: ASTM International.

ASTM. (2017). Standard Test Method for Particle Size Distribution of Catalytic Materials by Sieving. D4513 - 11. West Conshohocken, Pennsylvania, United States: ASTM International .

Baratta, V. M. (2013). The Effects of Freeze-Thaw Cycles on the Infiltration Rates of Three Bioretention Cell Soil Mixtures. Iowa: University of Iowa.

Barrett, M. E., Limouzin, M., \& Lawler, D. F. (2013). Effects of Media and Plant Selection on Biofiltration Performance. Reston, Virginia, United States: Journal of Environmental Engineering @ ASCE.

Campbell Scientific (Canada)Corp. (2011). GEONOR T-200B Series Precipitation Gauge. Campbell Scientific (Canada)Corp.

Carsel, R. F. (1988). Developing Joint Probability Distributions of soil Water Retention Characteristics. Water Resources Research Journal, 755 - 769.

Chavez, R. A., Brown, G. O., \& Storm, D. E. (2013). Impact of Variable Hydraulic Conductivity on Bioretention Cell Performance and Implications for Construction Standards. Journal of Hydraulic Engineering, 707-715.

Cheng, Y. (2015). A Saturated Seepage Flow Model for Low Impact Development Devices. Low Impact Development Technology: Design Methods and Case Studies, pp. 141-146.

Coustumer, S. L., Fletcher, T., Deletic, A., \& Barraud, S. (2008). Influence of time and design on the hydrualic performance of biofiltration systems for stormwater management. Edinburgh, Scotland, UK: 11th International Conference on Urban Drainage.

Credit Valley Conservation. (2010). Low Impact Development Storm Water Management Planning and Design Guide. Toronto: Credit Valley Conservation.

Denich, C., Bradford, A., \& Drake, J. (2013). Bioretention: assessing effects of winter salt and aggregate application on plant health, media clogging and effluent quality. Water Quality Research Journal of Canada, 387-399.

Ding, B., Rezanezhad, F., Gharedagloo, B., Cappellen, P. V., \& Passeport, E. (2018).

Bioretention cells under cold climate conditions: Effects of freezing and thawing on water infiltration, soil structure, and nutrient removal. Science of the Total Environment, 749-759.

Ding, X. R. (2017). Bioretention cells under cold climate conditions: the effect of freezing and thawing on water infiltration and nutrient removal. Toronto: University of Toronto.

Eijkelkamp Agrisearch Equipment. (2011, November). Operating Instructions. Retrieved from Eijkelkamp: https://www.eijkelkamp.com/download.php?file=b2082939 
Elrick, D. E., \& Reynolds, W. D. (1992). Methods for analyzing constant head well permeameter data. Journal of Soil Science Society of America, 320-323.

Ewing, C. (2013). Retrieved from Vand I Buyer: http://www.vandibyer.dk/media/1040/ewing2013_comparison-of-bioretention-soil-media.pdf

Graham, C. (2016, October 18). Personal Email. Toronto, Ontario, Canada.

Gray, D., \& Norum, D. (1967). The Effect of Soil Moisture on Infitlration as Related to Runoff and Recharge. Hydrology Symposium No. 6. National Research Council of Canada.

Hurley, S., Shrestha, P., \& Cording, A. (2017). Nutrient Leaching from Compost: Implications for Bioretention and Other Green Stormwater Infrastructure. Journal of Sustainable Water Built Environment @ ASCE, 04017006- 1 to 8.

Institute of Northern Engineering. (2011, July 16). Permafrost. Retrieved from University of Alaska Fairbanks Permafrost Outreach: http://ine.uaf.edu/werc/projects/permafrost/howto.pdf

Jabro, J., \& Evans, R. (2006). Discrepancies Between Analytical Solutions of Two Borehole Permeameters for Estimating Field-Saturated Hydraulic Conductivity. American Society of Agricultural and Biological Engineers, 549 - 554.

Jenkins, J. K., Wadzuk, B. M., \& Welker, A. L. (2010). Fines Accumulation and Distribution in a Storm-Water Rain Garden Nine Years Postconstruction. Reston, Virginia, United States.: Journal of Irrigation and Drainage Engineering @ ASCE.

Johnson, J. P., \& Hunt, W. F. (2016). Evaluating the spatial distribution of pollutants and associated maintenance requirements in an 11 year-old bioretention cell in urban Charlotte, NC. Journal of Environmental Management, 363-370.

Jones, P. S., \& Davis, A. P. (2013). Spatial Accumulation and Strength of Affliation of Heavy Metals in Bioretention Media. Journal of Environmental Engineering, 479-487.

Kakuturu, S. P., \& Clark, S. E. (2015). Clogging Mechanism of Stormwater Filter Media by $\mathrm{NaCl}$ as a Deicing Salt. Environmental Engineering Science, 142-152.

Konrad, J.-M., \& Samson, M. (2000). Hydraulic conductivity of kaolinite-silt mixtures subjected to closed-system freezing and thaw consolidation. Canadian Geotechnical Journal, 857869.

LeFevre, N. J., Davidson, J. D., \& Oberts, G. L. (2009). Bioretention of Simulated Snowmelt: Cold Climate Performance and Design Criteria. Cold Regions Engineering , (pp. 145154).

Li, H., \& Davis, A. P. (2008). Heavy Metal Capture and Accumulation in Bioretention Media. Journal of Environmental Science and Technology, 5247-5253.

Li, H., \& Davis, A. P. (2008). Urban Particle Capture in Bioretention Media. I: Laboratory and Field Studies. Journal of Environmental Engineering, 409-418.

Liberati, A., Altman, D. G., Tetzlaff, J., Mulrow, C., Gotzsche, P. C., Loannidis, J. P., . . . Moher, D. (2009). The PRISMA Statement for Reporting Systematic Reviews and MetaAnalyses of Studies That Evaluate Health Care Interventions: Explanation and Elaboration. PLoS Medicine, 1-28.

Logsdon, S. D. (2017). Nutrient Leaching When Soil Is Part of Plant Growth Media. Water, 1-7.

Lynn, T. J., Nachabe, M. H., \& Ergas, S. J. (2018). SWMM5 Unsaturated Drainage Models for Stormwater Biofiltration with an Internal Water Storage Zone. Journal of Sustainable Water Built Environment, 04017018 1-10.

Mayor of London. (2015). London Sustainable Drainage Action Plan. London: Greater London Authority. 
METER Group Inc., USA. (2018, May 11). Mini Disk Infiltrometer. Retrieved from Decagon: http://manuals.decagon.com/Manuals/10564_Mini\%20Disk\%20Infiltrometer_Web.pdf

Muthanna, T. M., Viklander, M., Blecken, G., \& Thorolfsson, S. T. (2007). Snowmelt pollutant removal in bioretention areas. Journal of Water Research, 4061-4072.

Pan, L., \& Wierenga, P. J. (1995). A transformed pressure head-based approach to solve Richards' equation for variably saturated soils. Water Resources Research Journal, 925931.

Paus, K. H., Morgan, J., Gulliver, J. S., Leiknes, T., \& Hozalski, R. M. (2013). Assessment of the Hydraulic and Toxic Metal Removal Capacities of Bioretention Cells After 2 to 8 Years of Service. Journal of Water, Air and Soil Pollution, 1-12.

Quinn, R., \& Dussaillant, A. (2014). Predicting infiltration pollutant retention in bioretention sustainable drainage systems: model development and validation. Journal of Hydrology Research, 855-867.

Radcliffe, D. E., \& West, L. T. (2015). Relating Saturated Hydraulic Conductivity to Percolation and Borehole Permeameter Tests. Journal of Soil Horizons, 99-103.

Roseen, R. M., Ballestero, T. P., Houle, J. J., Avellaneda, P., Briggs, J., Fowler, G., \& Wildey, R. (2009). Seasonal Performance Variations for Storm-Water Management Systems in Cold Climate Conditions. Journal of Environmental Engineering, 128-137.

Sheng-bo, X., Jian-jun, Q., Yuan-ming, L., Zhi-wei, Z., \& Xiang-tian, X. (2015). Effects of Freeze - thaw Cycles on Soil Mechanical and Physical Properties in the Qinghai - Tibet Plateau. Journal of Mountain Science, 999-1009.

Sterpi, D. (2015). Effect of freeze-thaw cycles on the hydraulic conductivity of a compacted clayey silt and influence of the compaction energy. Soils and Foundations, 1326-1332.

Stewart, R. D., Lee, J. G., Shuster, W. D., \& Darner, R. A. (2017). Modelling hydrological responce to a fully-monitored urban bioretention cell. Journal of Hydrological Processes, 4626-4638.

Sustainable Technologies Evaluation Program. (2015, July). Performance Comparison of Surface and Underground Stormwater Infiltration Practices. Retrieved from www.sustainabletechnologies.ca: https://sustainabletechnologies.ca/app/uploads/2016/08/BioVSTrench_TechBrief_July2 015.pdf

The Prince Gorge's County. (1999). Low-Impact Development Design Strategies: An integrated design approach. The Prince Gorge's County, Maryland: Department of Environmental Resources, Programs and Planning Division.

Thompson, A. M., Paul, A. C., \& Balster, N. J. (2008). Physical and Hydraulic properties of Engineered Soil Media for Bioretention Basins. Transactions of the ASABE (pp. 499514). American Society of Agricultural and Biological Engineers.

Toronto and Region Conservation Authority. (2012). Stormwater Management Criteria. Toronto: Toronto and Region Conservation Authority.

United States Department of Agriculture. (2018, August 2). Natural Resources Conservation Service - Soils. Retrieved from United States Department of Agriculture: https://www.nrcs.usda.gov/wps/portal/nrcs/detail/soils/survey/?cid=nrcs142p2_054167

Veen, B. D. (2014). An Interactive Plant List Model for Bio-retention Facilities: Using the Happy Plant Model to predict preferred plant species. Guelph: University of Guelph.

Yergeau, S. E., \& Obropta, C. C. (2013). Preliminary Field Evaluation of Soil Compaction in Rain Gardens. Jounal of Environmental Engineering, 1233-1236. 
Young, D. (2018, July 17). Personal Email. Toronto, Ontario, Canada.

Zhang, K., \& Chui, T. F. (2017). Evaluating hydrologic performance of bioretention cells in shallow groundwater. Journal of Hydrological Processes, 4122-4135.

Zhang, R. (1997). Determination of Soil Sorptivity and Hydraulic Conductivity from the Disk Infiltrometer. Science Society of America Journal, 1024 - 1030. 


\section{Appendices}

\subsection{Contour Map Generation Matlab Code}

$$
\begin{aligned}
& \mathrm{S}=\text { xlsread('S'); } \\
& \mathrm{a}=\mathrm{S}(:, 1) ; \\
& \mathrm{b}=\mathrm{S}(:, 2) ; \\
& \mathrm{c}=\mathrm{S}(:, 14) ; \\
& \text { [xi,yi] = meshgrid(-5:0.005:8,-4:0.005:10); } \\
& \text { zi = griddata(a,b,c,xi,yi); } \\
& \text { [m,n] = contourf(xi,yi,zi,100); } \\
& \text { clabel(m, n); }
\end{aligned}
$$

\subsection{Semi-variogram Generation Matlab Code}

$$
\begin{aligned}
& \mathrm{S}=\operatorname{xlsread}\left(\mathrm{FF}^{\prime}\right) \\
& \mathrm{a}=\mathrm{S}(1: 17,1: 2) ; \\
& \mathrm{b}=\mathrm{S}(:, 13) ; \\
& \mathrm{d}=\text { variogram (a,b, 'plotit',true,'nrbins',17,'anisotropy',false); }
\end{aligned}
$$

\subsection{Assumptions for Grubbs test}

Table 7-1: Ryan Joiner $P$ value for temporal $k_{\text {sat }}$ data (normality test)

\begin{tabular}{|l|r|}
\hline & $\begin{array}{l}\text { Ryan Joiner P } \\
\text { Value for } \mathrm{K}_{\text {sat }}\end{array}$ \\
\hline 05-Jun-17 & 0.01 \\
\hline 10-Jul-17 & 0.01 \\
\hline 15-Aug-17 & 0.01 \\
\hline 19-Sep-17 & 0.01 \\
\hline 10-Oct-17 & 0.074 \\
\hline 24-Oct-17 & 0.01 \\
\hline 26-Feb-18 & 0.01 \\
\hline 16-May-18 & 0.01 \\
\hline 8-Jun-2018 & 0.01 \\
\hline
\end{tabular}




\subsection{Assumptions for Wilcoxon signed-rank test}

1. Independence: The $\mathrm{K}_{\mathrm{sat}}$ values through Elrick \& Reynolds method and Radcliffe method are independent because the infiltration rate data which is used to calculate these $\mathrm{K}_{\text {sat }}$ values are collected in random days with diverse weather conditions.

2. Continuity: Both the dependent variable (Radcliffe method $\mathrm{K}_{\mathrm{sat}}$ for the purpose of the statistical test) is continuous data.

3. The distribution of the differences between the two related groups are symmetrical in shape: This assumption is also met, and it is verified by calculating the differences between those two values and plotting it in a histogram as shown in Figure 7-1.

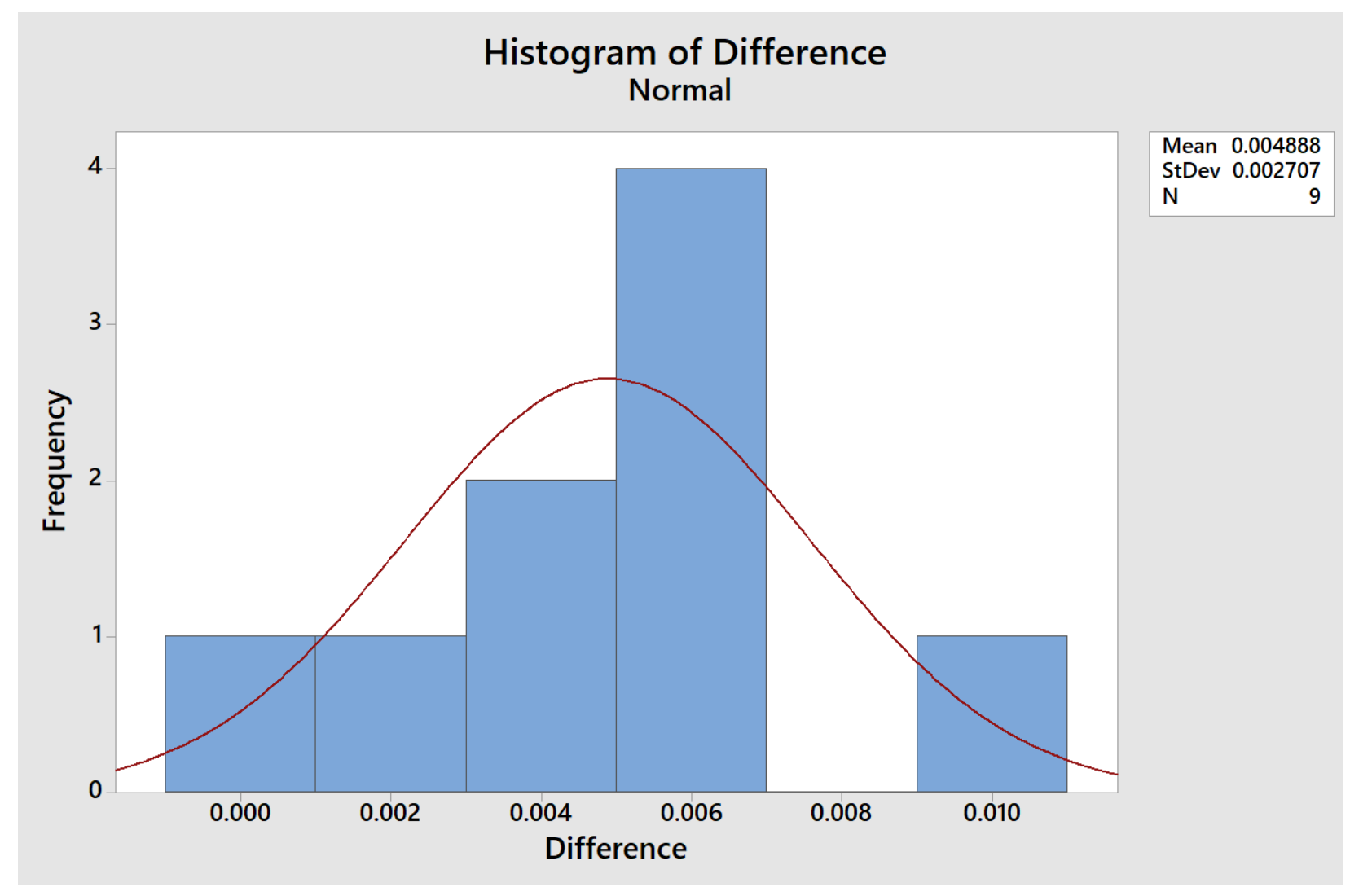

Figure 7-1: Histogram of Difference in $K_{\text {sat }}$ with curve fitting 


\subsection{Figures and Tables}

Table 7-2: Location with their coordinates with the inlet as the origin

\begin{tabular}{|l|l|l|}
\hline Point & $\mathbf{X}(\mathbf{m})$ & $\mathbf{Y}(\mathbf{m})$ \\
\hline A & 1.77 & 8.67 \\
\hline B & -3.69 & 8.53 \\
\hline C & -0.94 & 9.05 \\
\hline D & 0.5 & 2.26 \\
\hline E & 0.4 & 8.77 \\
\hline F & -3.85 & -1.03 \\
\hline G & 1.54 & 2.22 \\
\hline H & -2.3 & -3.28 \\
\hline I & 0.28 & 7.33 \\
\hline J & 2.28 & 2.84 \\
\hline K & 1.14 & 6.33 \\
\hline L & 3.71 & 3.9 \\
\hline M & 3.65 & 2.77 \\
\hline N & -3.05 & 5.39 \\
\hline O & 0.85 & 3.05 \\
\hline P & 1.56 & 3.88 \\
\hline Q & -0.29 & 2.76 \\
\hline R & 2.38 & 3.64 \\
\hline S & -1.9 & 8.08 \\
\hline T & -3.2 & 3.09 \\
\hline U & -1.63 & -0.87 \\
\hline V & 4.97 & 3.43 \\
\hline W & 5.15 & 2.06 \\
\hline X & 0.66 & 4.23 \\
\hline Y & 0.52 & 5.26 \\
\hline Z & -5.66 & 5.6 \\
\hline A1 & -0.75 & 6.52 \\
\hline B1 & 3.06 & 1.48 \\
\hline C1 & 7.35 & 2.55 \\
\hline D1 & 2.52 & 4.85 \\
\hline & & \\
\hline
\end{tabular}

Table 7-3: Ksat data $(\mathrm{cm} / \mathrm{s})$ - Radcliffe Method

\begin{tabular}{|l|l|l|l|l|l|l|l|l|l|}
\hline Date & $\begin{array}{l}\mathbf{5} \text {-Jun- } \\
\mathbf{1 7}\end{array}$ & $\begin{array}{l}\mathbf{1 0 - J u l -} \\
\mathbf{1 7}\end{array}$ & $\begin{array}{l}\mathbf{1 5} \text {-Aug- } \\
\mathbf{1 7}\end{array}$ & $\begin{array}{l}\mathbf{1 9 - S e p - ~} \\
\mathbf{1 7}\end{array}$ & $\begin{array}{l}\mathbf{1 0 - O c t -} \\
\mathbf{1 7}\end{array}$ & $\begin{array}{l}\mathbf{2 4 - O c t} \\
\mathbf{1 7}\end{array}$ & $\begin{array}{l}\mathbf{2 6 - F e b -} \\
\mathbf{1 8}\end{array}$ & $\begin{array}{l}\mathbf{1 6 -} \\
\text { May-18 }\end{array}$ & $\begin{array}{l}\mathbf{8} \text {-Jun- } \\
\mathbf{1 8}\end{array}$ \\
\hline A & 0.0024 & 0.0362 & 0.0593 & 0.0662 & 0.0113 & 0.0466 & 0.0273 & 0.0062 & 0.0007 \\
\hline A1 & 0.0014 & 0.0011 & 0.0067 & 0.0319 & 0.0030 & 0.0021 & 0.0317 & 0.0051 & 0.0034 \\
\hline B & 0.0003 & 0.0016 & 0.0011 & 0.0072 & 0.0062 & 0.0034 & 0.0061 & 0.0070 & 0.0014 \\
\hline C1 & 0.0003 & 0.0066 & 0.0007 & 0.0029 & 0.0025 & 0.0033 & 0.0170 & 0.0072 & 0.0109 \\
\hline E & 0.0014 & 0.0104 & 0.0074 & 0.0154 & 0.0073 & 0.0076 & 0.0012 & 0.0116 & 0.0135 \\
\hline F & 0.0002 & 0.0017 & 0.0028 & 0.0172 & 0.0155 & 0.0042 & 0.0016 & 0.0004 & 0.0027 \\
\hline I & 0.0006 & 0.0002 & 0.0001 & 0.0090 & 0.0006 & 0.0144 & 0.0041 & 0.0065 & 0.0007 \\
\hline M & 0.0021 & 0.0002 & 0.0001 & 0.0003 & 0.0006 & 0.0012 & 0.0000 & 0.0000 & 0.0006 \\
\hline N & 0.0053 & 0.0054 & 0.0134 & 0.0195 & 0.0059 & 0.0030 & 0.0118 & 0.0033 & 0.0135 \\
\hline O & 0.0018 & 0.0009 & 0.0001 & 0.0022 & 0.0001 & 0.0001 & 0.0004 & 0.0002 & 0.0008 \\
\hline Q & 0.0001 & 0.0049 & 0.0036 & 0.0020 & 0.0274 & 0.0026 & 0.0002 & 0.0038 & 0.0024 \\
\hline R & 0.0044 & 0.0014 & 0.0009 & 0.0197 & 0.0059 & 0.0316 & 0.0318 & 0.0044 & 0.0010 \\
\hline S & 0.0013 & 0.0003 & 0.0003 & 0.0012 & 0.0010 & 0.0022 & 0.0001 & 0.0009 & 0.0001 \\
\hline T & 0.0014 & 0.0375 & 0.0121 & 0.0091 & 0.0062 & 0.0236 & 0.0054 & 0.0513 & 0.0034 \\
\hline
\end{tabular}




\begin{tabular}{|l|l|l|l|l|l|l|l|l|l|}
\hline $\mathrm{V}$ & 0.0000 & 0.0021 & 0.0026 & 0.0014 & 0.0114 & 0.0027 & 0.0001 & 0.0086 & 0.0052 \\
\hline $\mathrm{W}$ & 0.0012 & 0.0025 & 0.0003 & 0.0202 & 0.0066 & 0.0012 & 0.0051 & 0.0003 & 0.0004 \\
\hline $\mathrm{Y}$ & 0.0016 & 0.0058 & 0.0001 & 0.0000 & 0.0014 & 0.0004 & 0.0001 & 0.0002 & 0.0001 \\
\hline
\end{tabular}

Table 7-4: Ksat data $(\mathrm{cm} / \mathrm{s})$ - Elrick and Reynolds method

\begin{tabular}{|l|l|l|l|l|l|l|l|l|l|}
\hline Date & $\begin{array}{l}\mathbf{5 - J u n -} \\
\mathbf{1 7}\end{array}$ & $\begin{array}{l}\mathbf{1 0 - J u l -} \\
\mathbf{1 7}\end{array}$ & $\begin{array}{l}\mathbf{1 5 -} \\
\text { Aug-17 }\end{array}$ & $\begin{array}{l}\mathbf{1 9 - S e p -} \\
\mathbf{1 7}\end{array}$ & $\begin{array}{l}\mathbf{1 0 -} \\
\text { Oct-17 }\end{array}$ & $\begin{array}{l}\mathbf{2 4 -} \\
\text { Oct-17 }\end{array}$ & $\begin{array}{l}\mathbf{2 6 - F e b -} \\
\mathbf{1 8}\end{array}$ & $\begin{array}{l}\mathbf{1 6 -} \\
\text { May-18 }\end{array}$ & $\begin{array}{l}\mathbf{8 - J u n -} \\
\mathbf{1 8}\end{array}$ \\
\hline A & 0.0024 & 0.0362 & 0.0593 & 0.0662 & 0.0113 & 0.0466 & 0.0273 & 0.0062 & 0.0007 \\
\hline A1 & 0.0014 & 0.0011 & 0.0067 & 0.0319 & 0.0030 & 0.0021 & 0.0317 & 0.0051 & 0.0034 \\
\hline B & 0.0003 & 0.0016 & 0.0011 & 0.0072 & 0.0062 & 0.0034 & 0.0061 & 0.0070 & 0.0014 \\
\hline C1 & 0.0003 & 0.0066 & 0.0007 & 0.0029 & 0.0025 & 0.0033 & 0.0170 & 0.0072 & 0.0109 \\
\hline E & 0.0014 & 0.0104 & 0.0074 & 0.0154 & 0.0073 & 0.0076 & 0.0012 & 0.0116 & 0.0135 \\
\hline F & 0.0002 & 0.0017 & 0.0028 & 0.0172 & 0.0155 & 0.0042 & 0.0016 & 0.0004 & 0.0027 \\
\hline I & 0.0006 & 0.0002 & 0.0001 & 0.0090 & 0.0006 & 0.0144 & 0.0041 & 0.0065 & 0.0007 \\
\hline M & 0.0021 & 0.0002 & 0.0001 & 0.0003 & 0.0006 & 0.0012 & 0.0000 & 0.0000 & 0.0006 \\
\hline N & 0.0053 & 0.0054 & 0.0134 & 0.0195 & 0.0059 & 0.0030 & 0.0118 & 0.0033 & 0.0135 \\
\hline O & 0.0018 & 0.0009 & 0.0001 & 0.0022 & 0.0001 & 0.0001 & 0.0004 & 0.0002 & 0.0008 \\
\hline Q & 0.0001 & 0.0049 & 0.0036 & 0.0020 & 0.0274 & 0.0026 & 0.0002 & 0.0038 & 0.0024 \\
\hline R & 0.0044 & 0.0014 & 0.0009 & 0.0197 & 0.0059 & 0.0316 & 0.0318 & 0.0044 & 0.0010 \\
\hline S & 0.0013 & 0.0003 & 0.0003 & 0.0012 & 0.0010 & 0.0022 & 0.0001 & 0.0009 & 0.0001 \\
\hline T & 0.0014 & 0.0375 & 0.0121 & 0.0091 & 0.0062 & 0.0236 & 0.0054 & 0.0513 & 0.0034 \\
\hline V & 0.0000 & 0.0021 & 0.0026 & 0.0014 & 0.0114 & 0.0027 & 0.0001 & 0.0086 & 0.0052 \\
\hline W & 0.0012 & 0.0025 & 0.0003 & 0.0202 & 0.0066 & 0.0012 & 0.0051 & 0.0003 & 0.0004 \\
\hline Y & 0.0016 & 0.0058 & 0.0001 & 0.0000 & 0.0014 & 0.0004 & 0.0001 & 0.0002 & 0.0001 \\
\hline
\end{tabular}

Table 7-5: Snow depth data $(\mathrm{cm})$

\begin{tabular}{|l|l|l|l|l|l|l|l|l|l|l|}
\hline Year & $\mathbf{2 0 1 6}$ & & & $\mathbf{2 0 1 7}$ & & & & & $\mathbf{2 0 1 8}$ & \\
\hline Date & $\mathbf{1 2 / 2 2}$ & $\mathbf{1 1 / 1}$ & $\mathbf{1 / 1 9}$ & $\mathbf{1 / 2}$ & $\mathbf{8 / 2}$ & $\mathbf{2 / 1 3}$ & $\mathbf{2 / 1 5}$ & $\mathbf{8 / 1}$ & $\mathbf{1 / 1 7}$ & $\mathbf{5 / 2}$ \\
\hline A & 46.0 & 32.5 & 24.0 & 12.5 & 12.0 & 26.0 & 13.0 & 16.0 & 4.0 & 9.5 \\
\hline B & 25.0 & 14.8 & 5.0 & 4.0 & 5.0 & 18.5 & 10.0 & 16.0 & 8.0 & 4.5 \\
\hline C & 22.0 & 8.8 & 0.0 & 4.0 & 0.0 & 17.5 & 8.0 & 20.0 & 9.0 & 8.5 \\
\hline D & 19.5 & 20.0 & 14.0 & 8.5 & 6.0 & 15.0 & 8.0 & 27.0 & 9.0 & 14.5 \\
\hline E & 31.0 & 29.0 & 16.0 & 3.3 & 1.5 & 17.0 & 8.0 & 29.0 & 22.5 & 13.5 \\
\hline F & 23.5 & 19.5 & 12.0 & 5.0 & 0.0 & 17.5 & 8.0 & 19.5 & 7.5 & 11.0 \\
\hline G & 22.0 & 13.5 & 7.0 & 7.0 & 0.0 & 21.5 & 11.5 & 21.5 & 7.0 & 13.0 \\
\hline H & 23.5 & 15.8 & 9.0 & 3.8 & 1.0 & 16.0 & 7.0 & 17.5 & 9.5 & 11.0 \\
\hline I & 22.0 & 14.5 & 6.0 & 3.6 & 2.5 & 14.0 & 7.5 & 18.5 & 12.0 & 11.5 \\
\hline J & 21.0 & 13.5 & 7.0 & 4.5 & 3.5 & 14.5 & 7.5 & 23.0 & 10.5 & 12.5 \\
\hline K & 26.0 & 7.5 & 0.5 & 2.5 & 1.5 & 16.5 & 7.0 & 27.0 & 12.0 & 12.0 \\
\hline L & 23.0 & 12.0 & 0.0 & 3.5 & 0.0 & 15.5 & 6.0 & 21.5 & 9.5 & 14.0 \\
\hline M & 21.5 & 19.5 & 1.5 & 4.2 & 2.5 & 18.0 & 10.3 & 30.5 & 14.5 & 30.0 \\
\hline N & 22.0 & 11.3 & 5.0 & 3.0 & 2.0 & 15.0 & 9.0 & 13.0 & 6.5 & 11.0 \\
\hline O & 21.5 & 16.5 & 8.0 & 4.0 & 3.0 & 16.5 & 7.0 & 22.0 & 11.5 & 13.0 \\
\hline P & 24.0 & 12.5 & 6.0 & 4.5 & 0.0 & 16.5 & 7.5 & 20.5 & 11.0 & 9.5 \\
\hline Q & 21.0 & 5.0 & 1.0 & 4.5 & 2.0 & 14.0 & 8.0 & 18.5 & 7.0 & 8.5 \\
\hline R & 22.0 & 13.3 & 5.0 & 3.0 & 0.0 & 15.0 & 6.0 & 19.0 & 8.0 & 7.5 \\
\hline S & 24.0 & 14.5 & 10.0 & 4.5 & 3.5 & 17.0 & 11.0 & 19.5 & 9.5 & 11.5 \\
\hline T & 16.5 & 0.0 & 0.0 & 2.0 & 0.0 & 12.0 & 5.0 & 13.0 & 5.0 & 5.0 \\
\hline U & 29.5 & 18.9 & 11.0 & 5.0 & 3.0 & 16.0 & 9.0 & 20.5 & 13.5 & 19.0 \\
\hline
\end{tabular}




\begin{tabular}{|l|l|l|l|l|l|l|l|l|l|l|}
\hline $\mathrm{V}$ & 22.5 & 15.0 & 8.0 & 4.5 & 0.0 & 16.0 & 7.0 & 35.0 & 20.0 & 22.0 \\
\hline $\mathrm{W}$ & 28.0 & 14.0 & 6.0 & 3.5 & 2.0 & 17.5 & 9.5 & 27.0 & 10.0 & 17.0 \\
\hline $\mathrm{X}$ & 21.0 & 15.0 & 6.0 & 4.5 & 3.5 & 17.0 & 7.5 & 25.5 & 11.0 & 12.5 \\
\hline $\mathrm{Y}$ & 19.0 & 9.5 & 3.0 & 4.5 & 2.5 & 14.0 & 7.5 & 25.0 & 10.5 & 21.0 \\
\hline $\mathrm{Z}$ & 19.0 & 6.4 & 1.0 & 2.5 & 1.0 & 18.0 & 10.0 & 15.0 & 10.0 & 9.5 \\
\hline $\mathrm{A} 1$ & 24.0 & 11.8 & 3.0 & 4.0 & 1.5 & 17.0 & 8.5 & 15.5 & 5.0 & 8.0 \\
\hline $\mathrm{B} 1$ & 25.0 & 12.0 & 3.0 & 4.5 & 1.0 & 18.5 & 9.5 & 19.0 & 4.0 & 10.0 \\
\hline $\mathrm{C} 1$ & 28.0 & 15.5 & 10.0 & 3.0 & 1.5 & 15.0 & 7.5 & 21.5 & 5.0 & 10.0 \\
\hline $\mathrm{D} 1$ & 21.0 & 9.2 & 1.0 & 4.0 & 2.0 & 16.0 & 7.5 & 19.0 & 7.0 & 10.0 \\
\hline
\end{tabular}

Table 7-6: Soil Particle Distribution data by location (Weight in grams).

\begin{tabular}{|l|l|l|l|l|l|l|l|l|l|l|l|l|l|}
\hline & $\begin{array}{l}\mathbf{1 -} \\
\mathbf{1 / 2}\end{array}$ & $\mathbf{3 / 4}$ & $\mathbf{3 / 8}$ & $\mathbf{4}$ & $\mathbf{1 0}$ & $\mathbf{P a n}$ & $\mathbf{1 0}$ & $\mathbf{1 6}$ & $\mathbf{3 0}$ & $\mathbf{5 0}$ & $\mathbf{1 0 0}$ & $\mathbf{2 0 0}$ & Pan \\
\hline $\mathrm{A}$ & 0.3 & 0.3 & 7.7 & 38.2 & 74.8 & 301.7 & 0.6 & 39.0 & 62.4 & 91.6 & 97.5 & 4.9 & 6.1 \\
\hline $\mathrm{A} 1$ & 0.0 & 0.0 & 1.9 & 19.5 & 62.0 & 335.5 & 0.4 & 31.4 & 48.0 & 89.2 & 108.3 & 29.4 & 29.9 \\
\hline $\mathrm{B}$ & 0.0 & 0.0 & 3.8 & 12.0 & 0.0 & 325.8 & 0.5 & 30.7 & 56.2 & 91.3 & 86.6 & 13.0 & 22.0 \\
\hline $\mathrm{C} 1$ & 0.0 & 0.0 & 4.3 & 25.7 & 83.1 & 280.2 & 1.4 & 82.4 & 68.5 & 60.2 & 58.7 & 28.0 & 16.3 \\
\hline $\mathrm{E}$ & 0.0 & 0.0 & 1.6 & 16.7 & 40.5 & 334.3 & 0.7 & 26.5 & 46.9 & 145.9 & 120.8 & 11.8 & 14.7 \\
\hline $\mathrm{F}$ & 0.0 & 0.1 & 6.1 & 13.0 & 64.3 & 336.4 & 0.9 & 45.0 & 53.9 & 69.7 & 84.2 & 68.0 & 16.3 \\
\hline $\mathrm{I}$ & 0.0 & 0.1 & 1.7 & 16.5 & 45.4 & 326.0 & 0.4 & 26.5 & 46.6 & 125.8 & 98.6 & 15.2 & 12.5 \\
\hline $\mathrm{M}$ & 0.0 & 0.0 & 1.2 & 19.6 & 63.9 & 271.7 & 0.5 & 31.6 & 42.7 & 68.6 & 77.6 & 23.8 & 27.5 \\
\hline $\mathrm{N}$ & 0.0 & 0.0 & 0.9 & 13.4 & 37.9 & 319.9 & 0.4 & 32.1 & 60.4 & 111.1 & 85.8 & 14.2 & 14.9 \\
\hline $\mathrm{O}$ & 0.0 & 0.2 & 0.9 & 14.1 & 50.1 & 348.4 & 0.8 & 32.9 & 45.1 & 87.3 & 107.7 & 54.6 & 21.9 \\
\hline $\mathrm{Q}$ & 0.1 & 0.1 & 1.0 & 25.2 & 117.7 & 293.3 & 1.1 & 61.8 & 69.4 & 52.3 & 106.7 & 3.8 & 0.0 \\
\hline $\mathrm{R}$ & 0.0 & 0.0 & 4.1 & 24.7 & 65.2 & 336.9 & 0.9 & 64.7 & 57.7 & 104.6 & 98.1 & 24.6 & 22.3 \\
\hline $\mathrm{S}$ & 0.0 & 0.0 & 3.5 & 8.0 & 25.0 & 303.9 & 0.4 & 22.3 & 46.8 & 84.3 & 101.2 & 24.2 & 26.3 \\
\hline $\mathrm{T}$ & 0.0 & 0.0 & 8.9 & 5.2 & 52.7 & 363.7 & 1.3 & 90.9 & 70.9 & 72.3 & 81.9 & 43.2 & 38.4 \\
\hline $\mathrm{V}$ & 0.0 & 0.0 & 3.1 & 12.2 & 50.7 & 354.9 & 1.0 & 67.2 & 57.7 & 96.6 & 108.8 & 36.7 & 21.3 \\
\hline $\mathrm{W}$ & 0.0 & 0.1 & 6.8 & 15.0 & 48.6 & 324.1 & 0.5 & 36.0 & 49.1 & 76.5 & 91.0 & 42.7 & 29.8 \\
\hline $\mathrm{Y}$ & 0.0 & 0.1 & 0.7 & 19.2 & 43.1 & 327.1 & 0.8 & 29.6 & 48.1 & 89.5 & 99.1 & 28.7 & 34.4 \\
\hline
\end{tabular}

Table 7-7: Soil Properties data by location.

\begin{tabular}{|l|l|l|l|l|l|}
\hline Point & $\begin{array}{l}\text { Bulk } \\
\text { Density }\end{array}$ & $\begin{array}{l}\text { Moisture } \\
\text { Content }\end{array}$ & $\begin{array}{l}\text { Organic } \\
\text { Content }\end{array}$ & $\begin{array}{l}\text { Particle } \\
\text { Density }\end{array}$ & Porosity \\
\hline Unit & Kg/m3 & \% & \% & Kg/m3 & \% \\
\hline A & 1892.59 & 14.90 & 6.10 & 2749.87 & 31.18 \\
\hline A1 & 1799.87 & 17.83 & 6.07 & 3206.13 & 43.86 \\
\hline B & 643.01 & 19.54 & 4.95 & 2771.09 & 76.80 \\
\hline C1 & 707.03 & 16.00 & 6.62 & 3302.09 & 78.59 \\
\hline E & 609.89 & 14.42 & 5.25 & 3010.02 & 79.74 \\
\hline F & 1788.83 & 18.65 & 8.14 & 2891.51 & 38.14 \\
\hline I & 1818.63 & 23.25 & 4.71 & 3163.95 & 42.52 \\
\hline M & 1825.26 & 26.26 & 5.61 & 3395.56 & 46.25 \\
\hline N & 1698.31 & 20.69 & 7.91 & 3107.89 & 45.35 \\
\hline O & 1794.35 & 25.39 & 4.72 & 3333.91 & 46.18 \\
\hline Q & 1941.16 & 19.06 & 2.11 & 2797.07 & 30.60 \\
\hline R & 1767.86 & 15.72 & 6.22 & 3432.56 & 48.50 \\
\hline S & 1793.24 & 24.33 & 4.70 & 3101.31 & 42.18 \\
\hline T & 1725.91 & 17.62 & 6.81 & 3074.32 & 43.86 \\
\hline V & 1878.24 & 18.41 & 4.74 & 5152.62 & 63.55 \\
\hline & & & & & \\
\hline
\end{tabular}




\begin{tabular}{|l|l|l|l|l|l|}
$\mathrm{W}$ & 1894.80 & 20.08 & 5.40 & 3144.17 & 39.74 \\
\hline $\mathrm{Y}$ & 1802.08 & 20.93 & 5.44 & 2842.12 & 36.59 \\
\hline
\end{tabular}

Table 7-8: Locations with $D_{60}, D_{30}, D_{10}, C u$ and $C c$.

\begin{tabular}{|l|l|l|l|l|l|}
\hline Location & $\mathrm{D}_{60}$ & $\mathrm{D}_{30}$ & $\mathrm{D}_{10}$ & $\mathbf{C u}$ & $\mathbf{C c}$ \\
\hline Am) & $(\mathbf{m m})$ & $(\mathbf{m m})$ & & \\
\hline A1 & 1.10 & 0.34 & 0.19 & 5.95 & 0.57 \\
\hline B & 0.58 & 0.23 & 0.10 & 6.11 & 0.96 \\
\hline C1 & 0.50 & 0.24 & 0.13 & 4.00 & 0.88 \\
\hline E & 1.40 & 0.40 & 0.14 & 10.00 & 0.82 \\
\hline F & 0.51 & 0.27 & 0.17 & 3.09 & 0.87 \\
\hline I & 0.70 & 0.21 & 0.10 & 7.37 & 0.63 \\
\hline M & 0.54 & 0.28 & 0.17 & 3.27 & 0.88 \\
\hline N & 0.78 & 0.24 & 0.10 & 8.21 & 0.78 \\
\hline O & 0.59 & 0.30 & 0.17 & 3.47 & 0.87 \\
\hline Q & 0.50 & 0.20 & 0.10 & 5.26 & 0.84 \\
\hline R & 1.60 & 0.40 & 0.20 & 8.21 & 0.50 \\
\hline S & 0.85 & 0.30 & 0.16 & 5.31 & 0.64 \\
\hline T & 0.48 & 0.21 & 0.10 & 5.00 & 0.98 \\
\hline V & 0.90 & 0.25 & 0.09 & 10.59 & 0.78 \\
\hline W & 0.68 & 0.24 & 0.13 & 5.44 & 0.68 \\
\hline Y & 0.60 & 0.21 & 0.09 & 6.67 & 0.78 \\
\hline
\end{tabular}

M

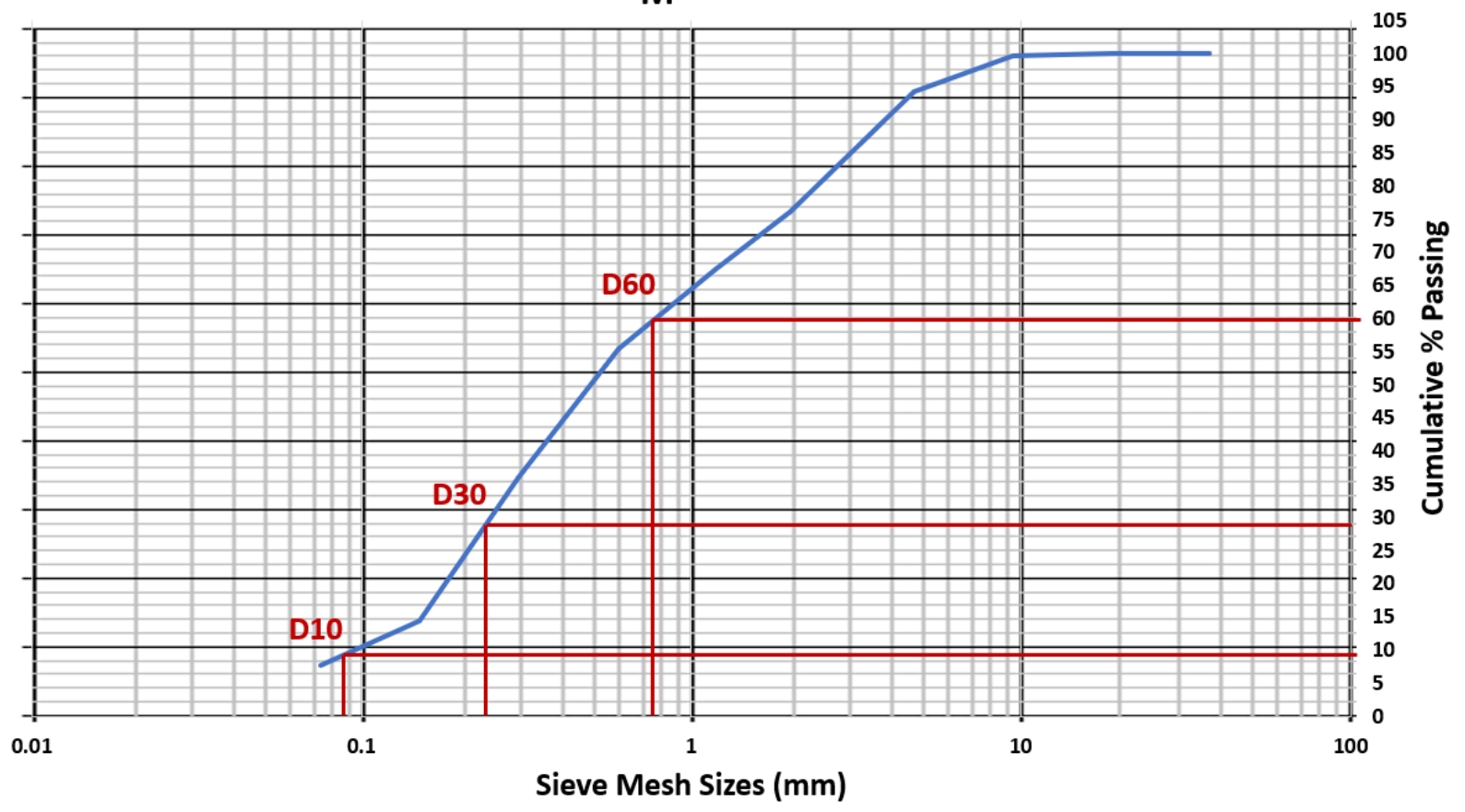

Figure 7-2: Soil particle distribution results in $\%$ - location $M$ 
A1

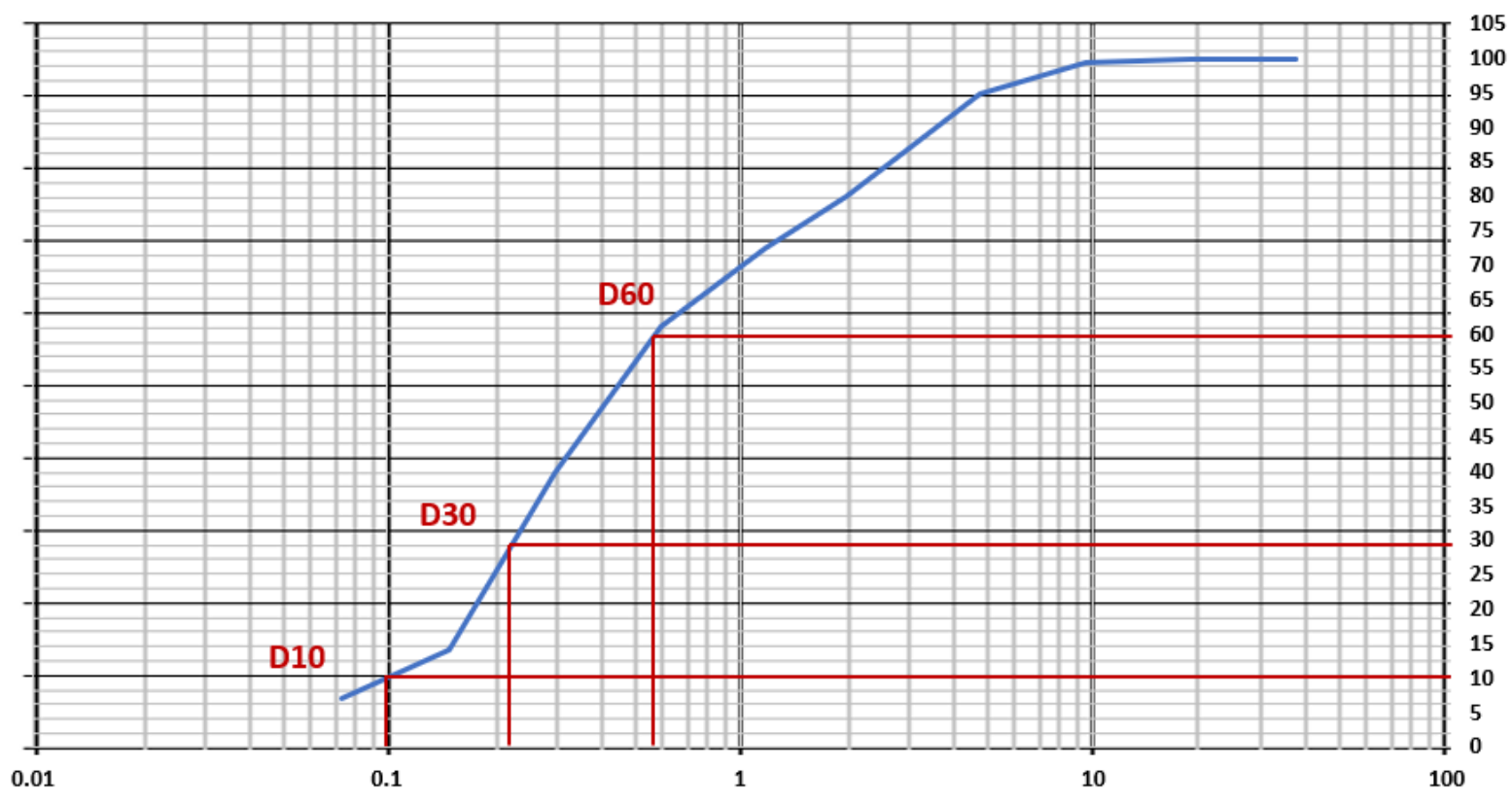

Sieve Mesh Sizes (mm)

Figure 7-3 Soil particle distribution results in \% - location A1

S

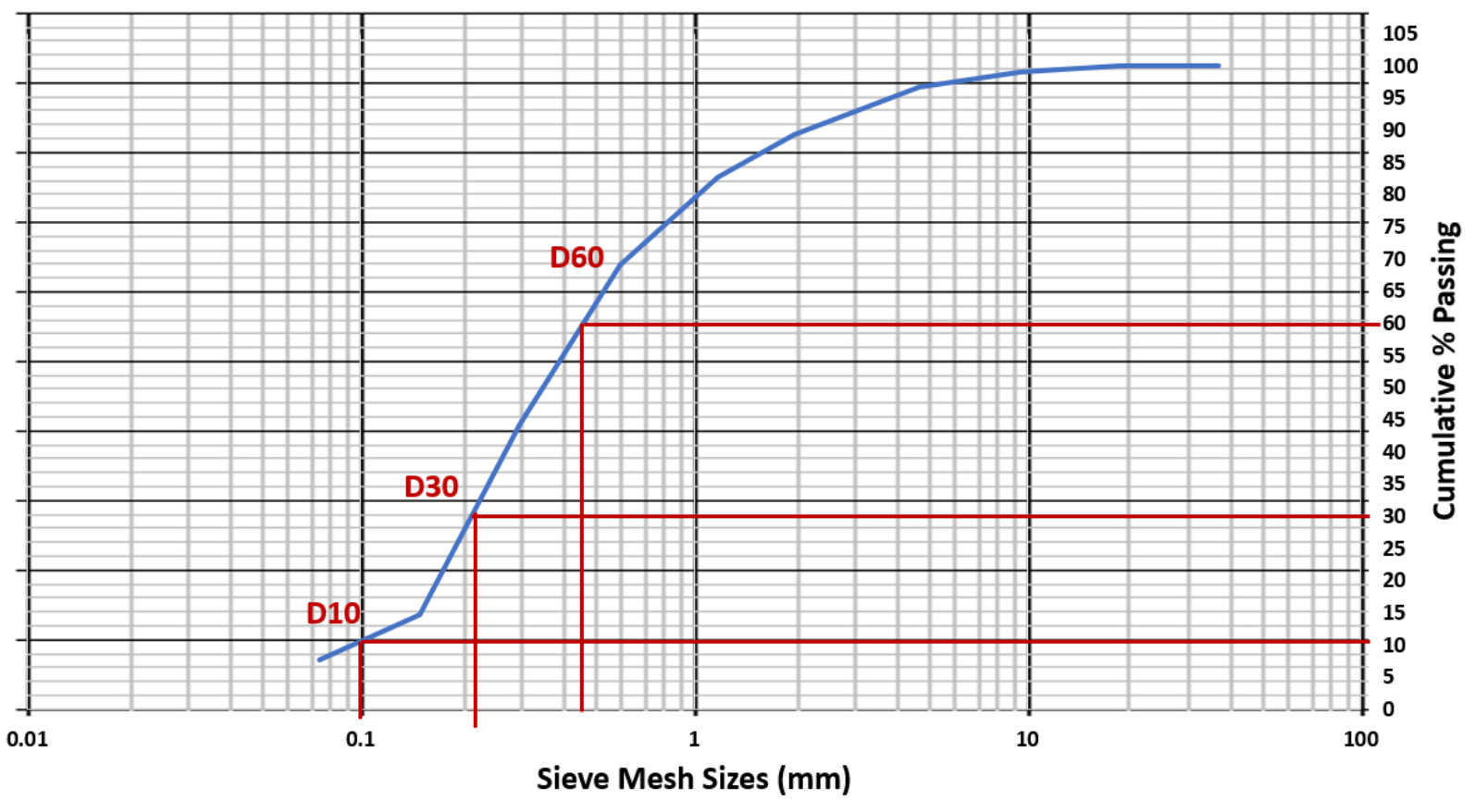

Figure 7-4 Soil particle distribution results in \%-location S 


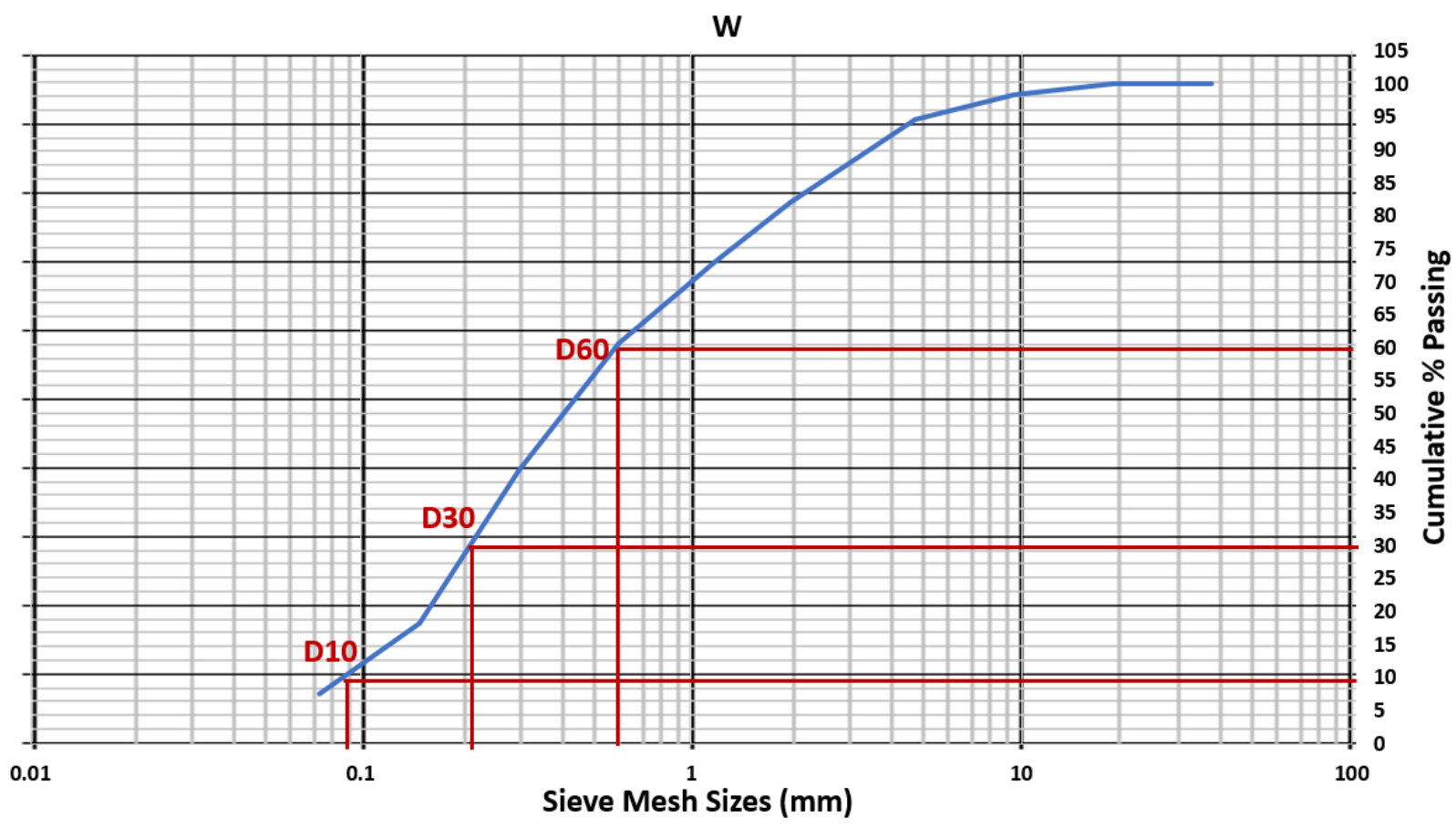

Figure 7-5 Soil particle distribution results in \%-location $W$

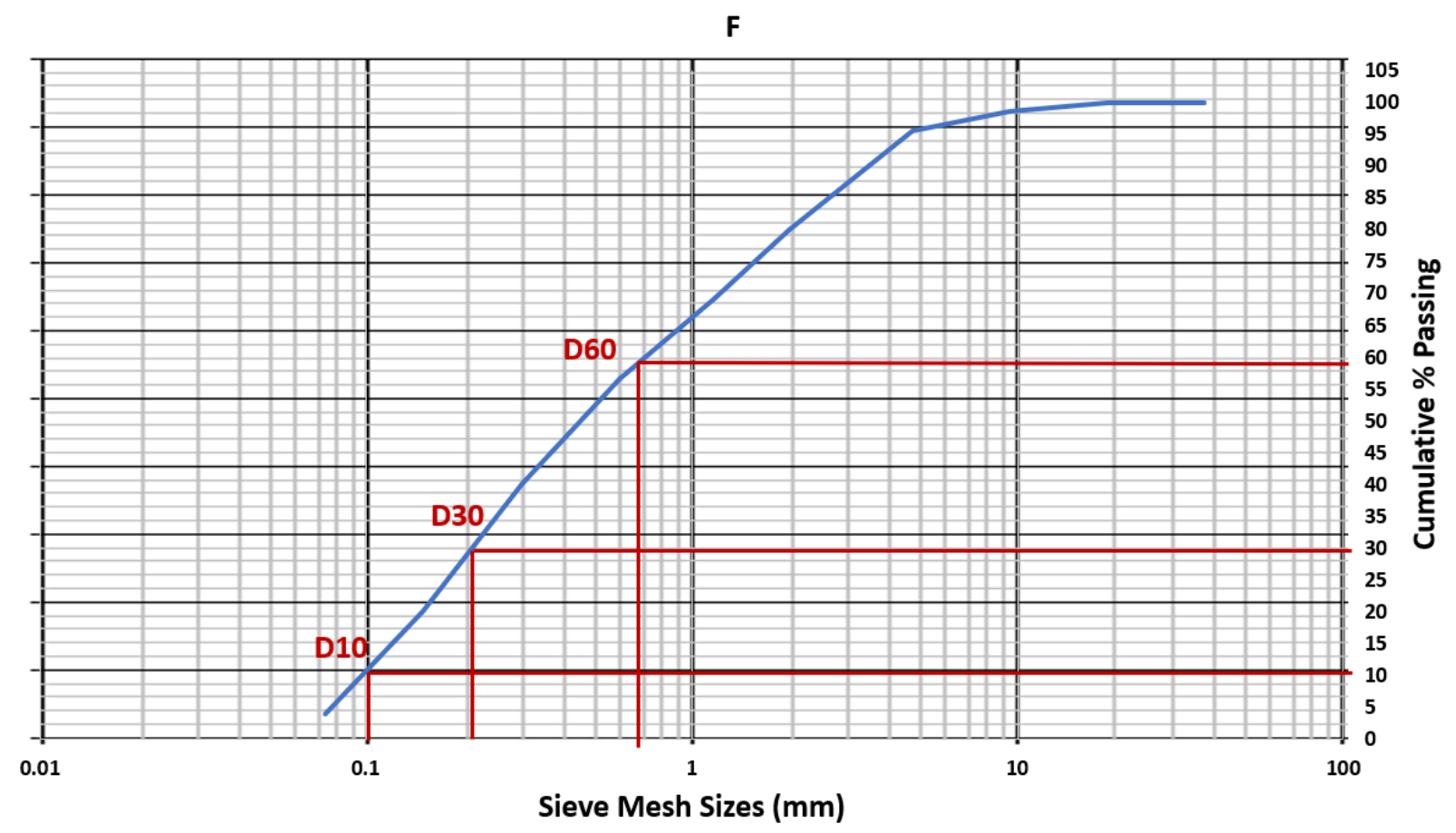

Figure 7-6 Soil particle distribution results in \%-location F 


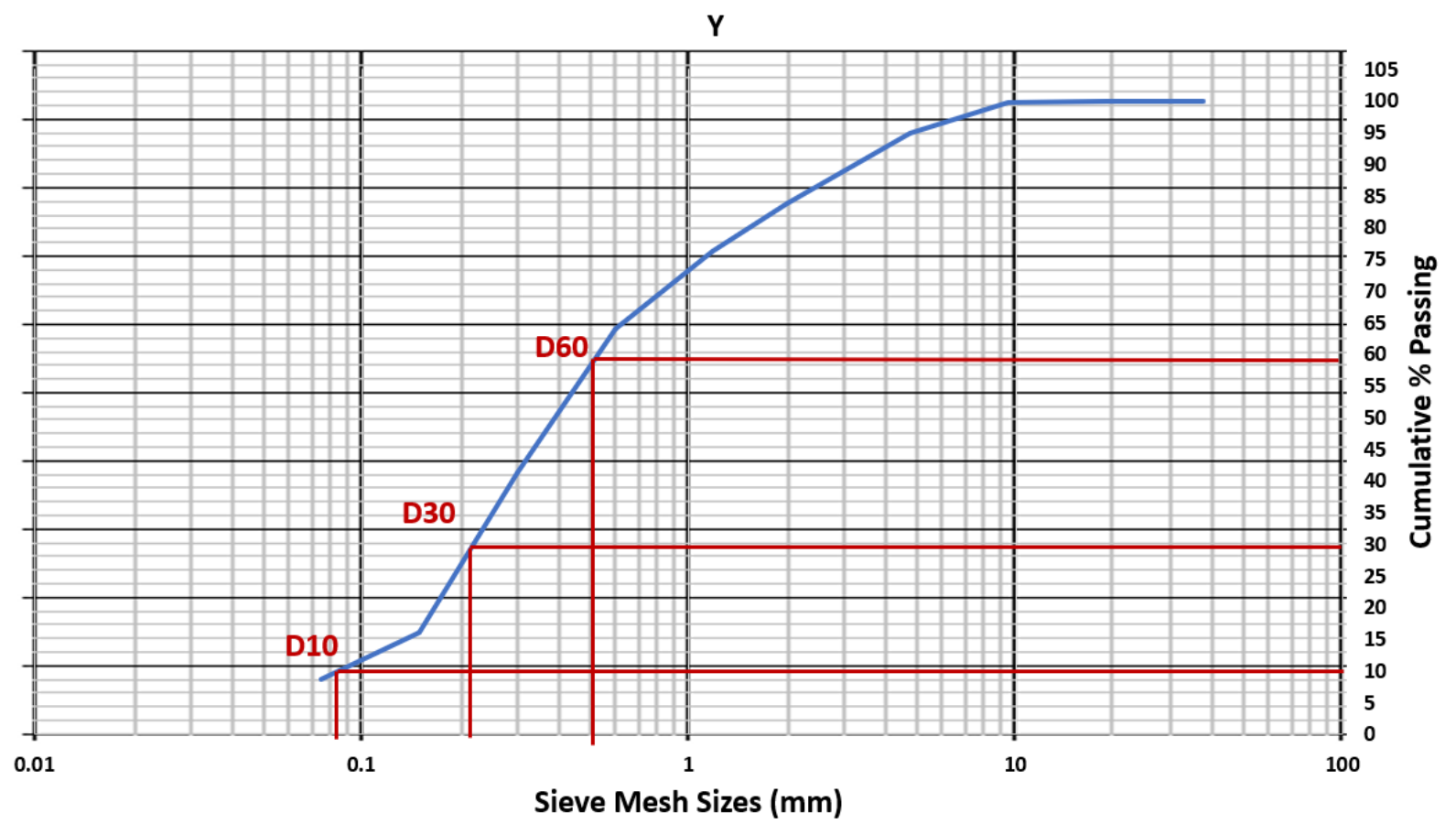

Figure 7-7 Soil particle distribution results in \% - location $Y$

0

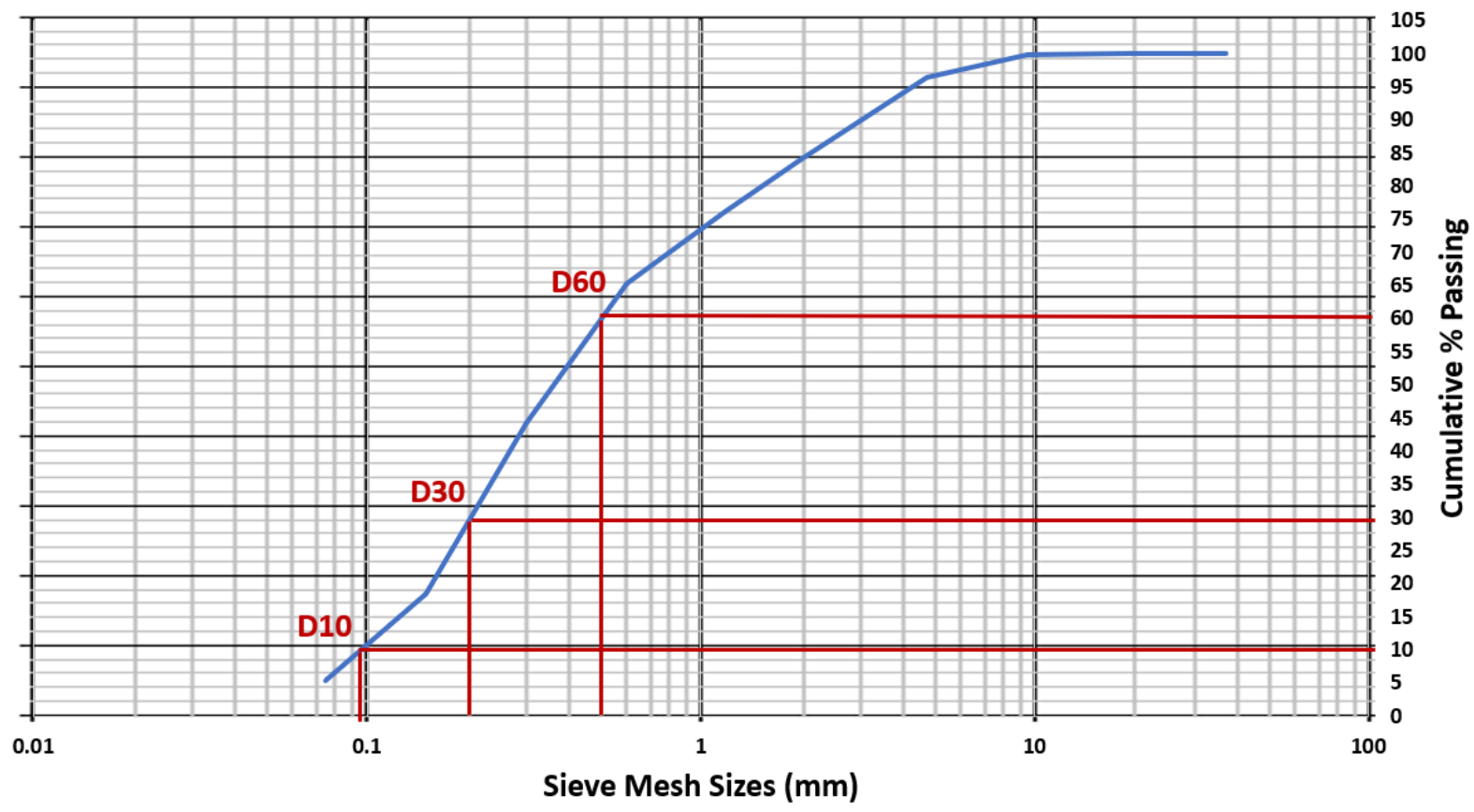

Figure 7-8 Soil particle distribution results in \% - location $O$ 


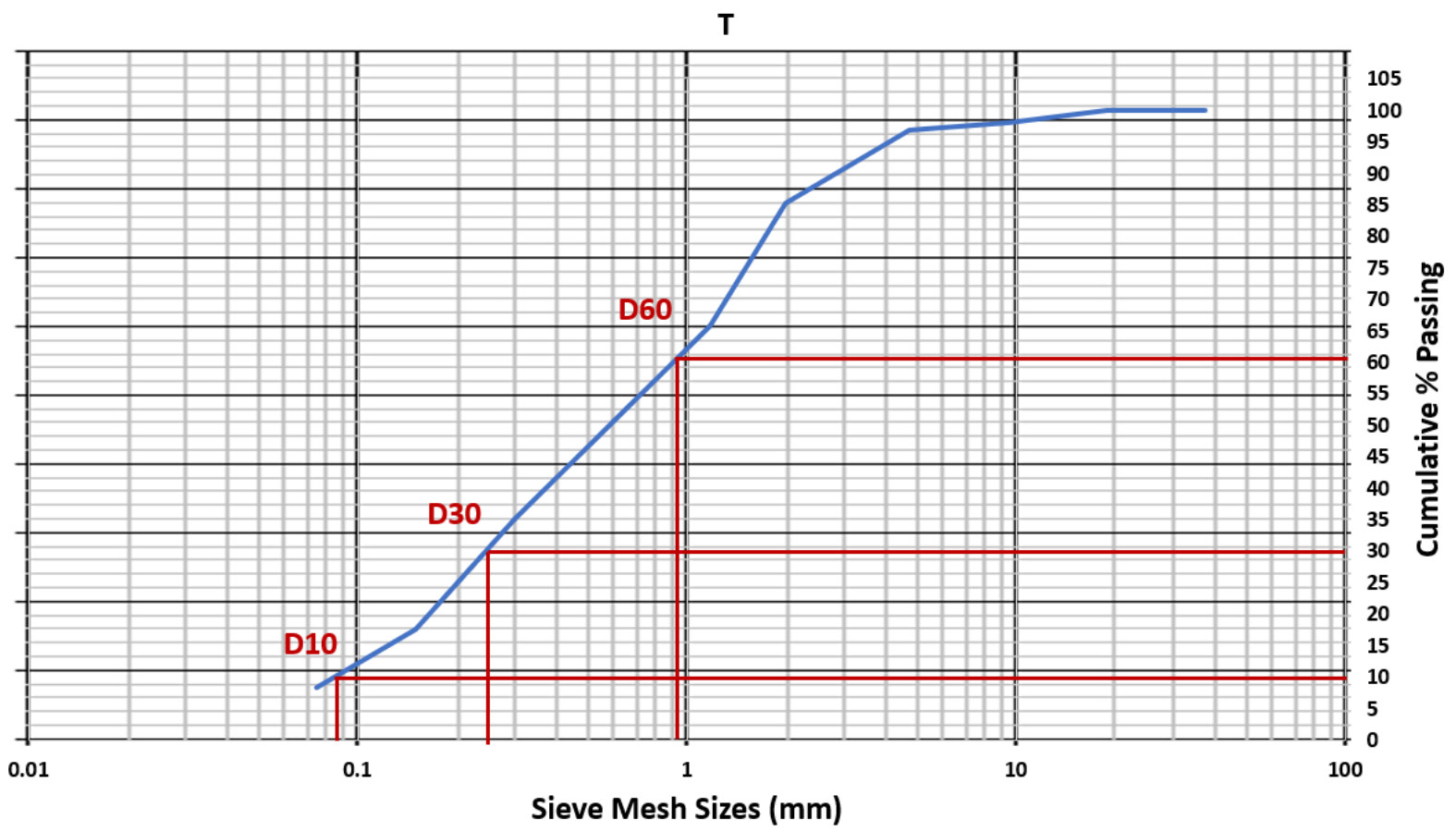

Figure 7-9 Soil particle distribution results in \% - location T

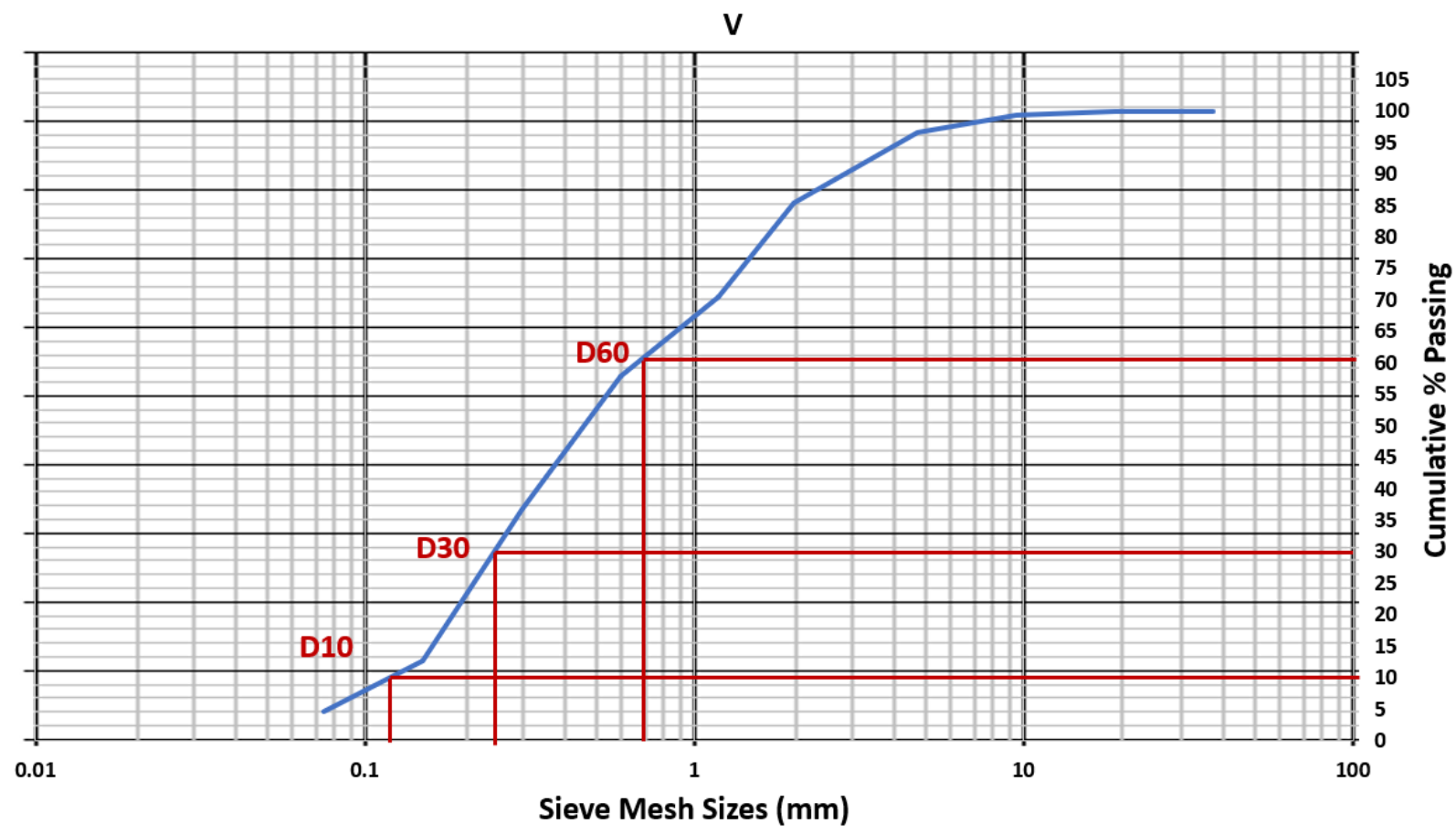

Figure 7-10 Soil particle distribution results in \% - location $V$ 
R

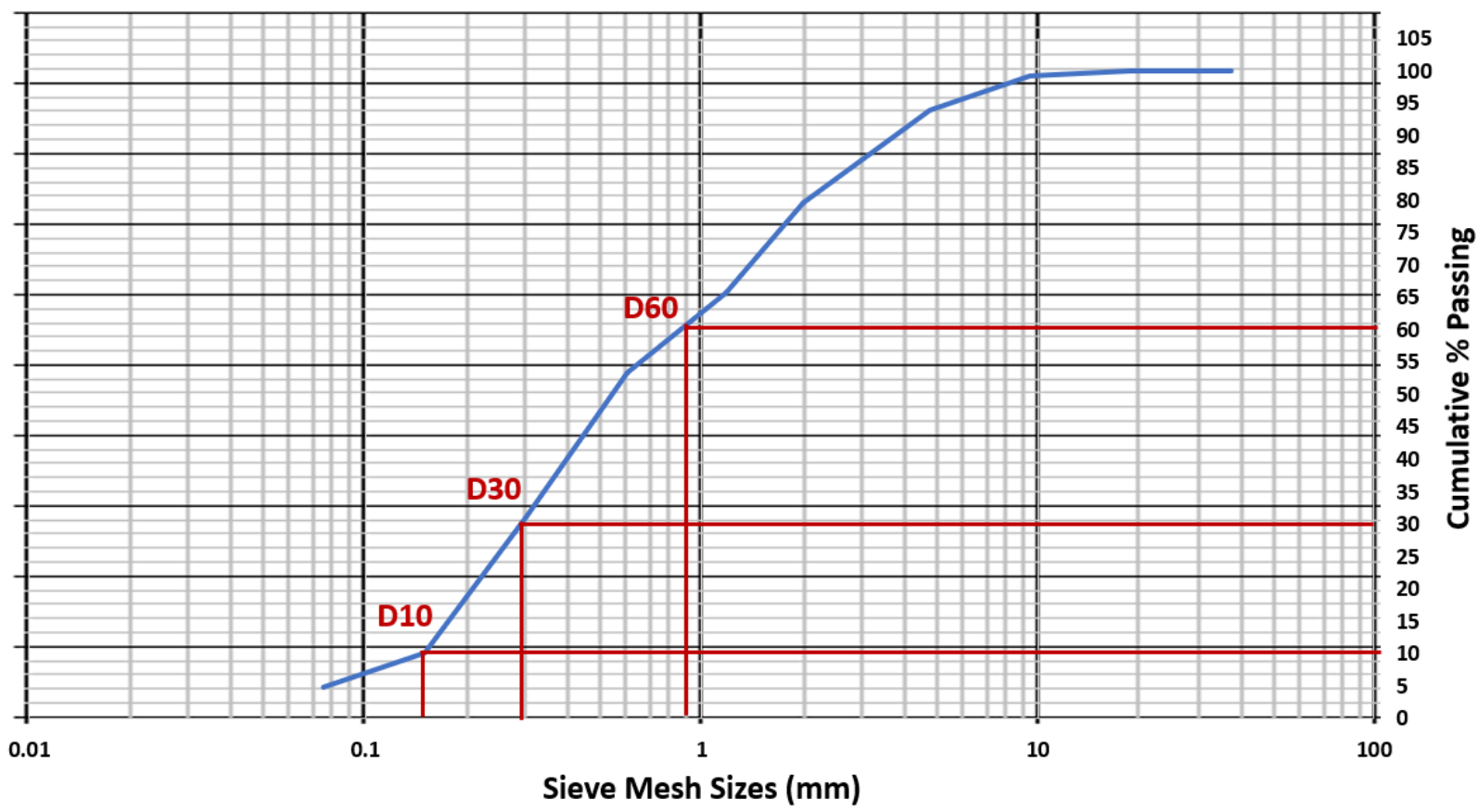

Figure 7-11 Soil particle distribution results in $\%$ - location $R$

C1

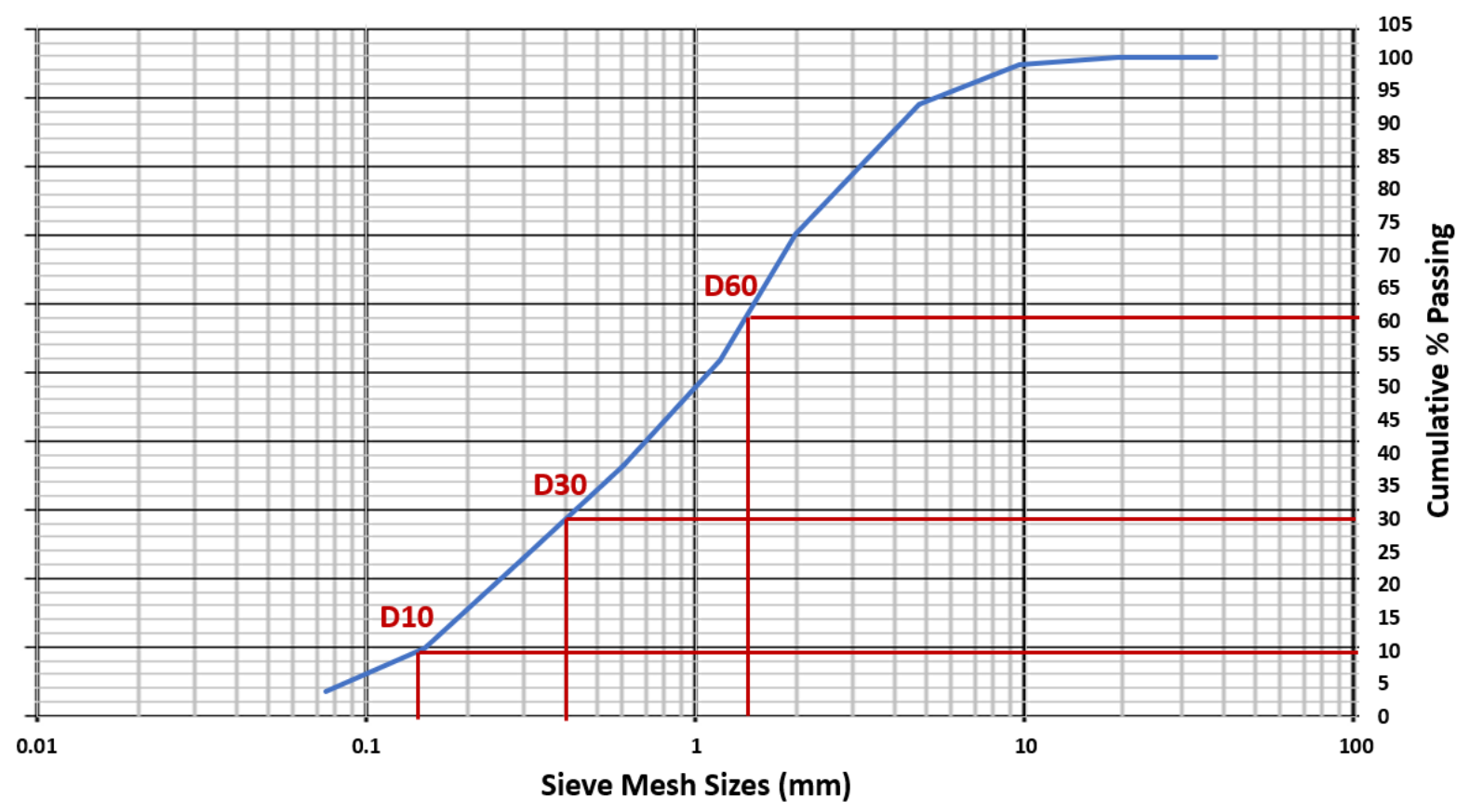

Figure 7-12 Soil particle distribution results in \%-location C1 
$\mathbf{N}$

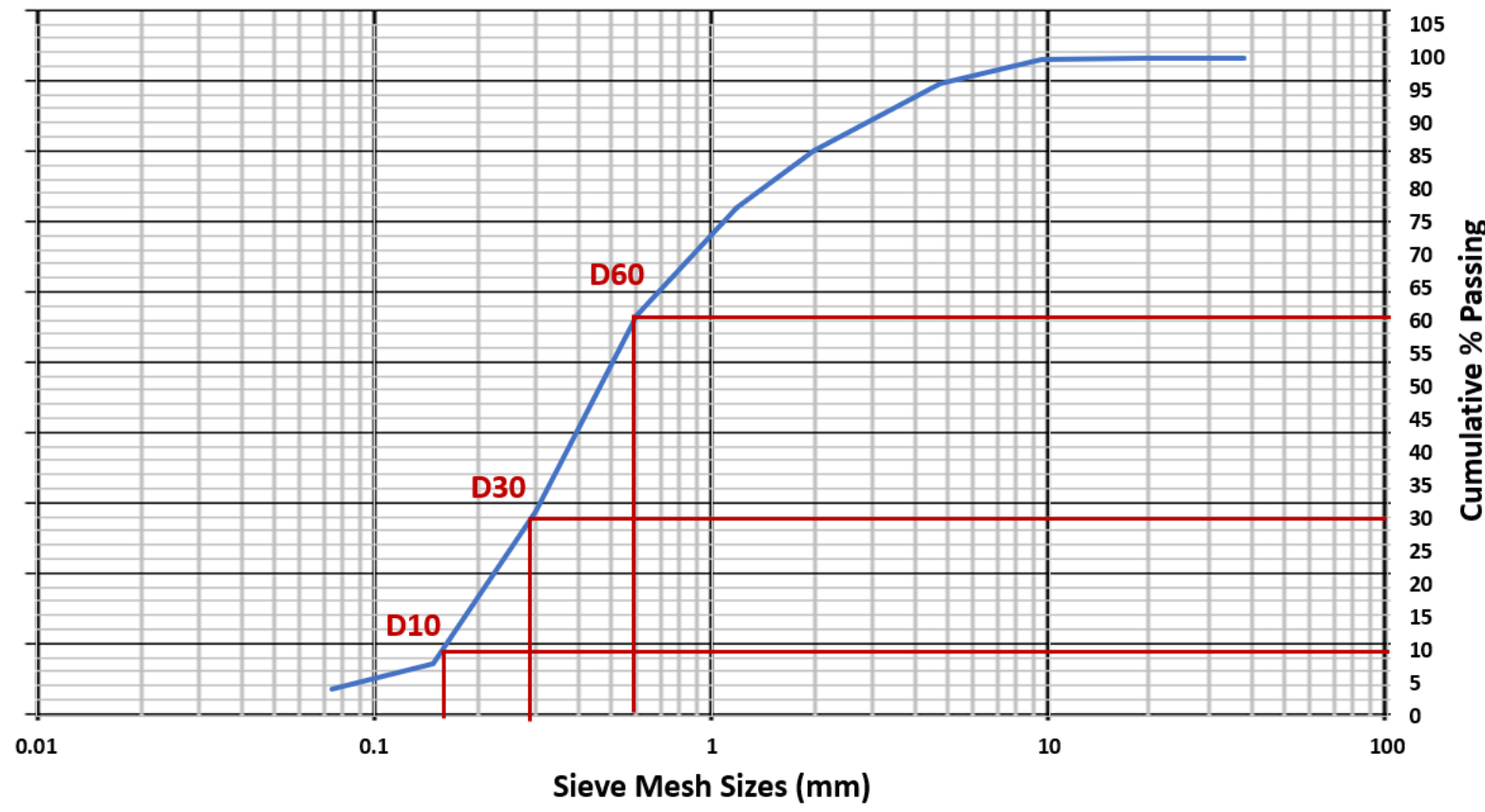

Figure 7-13 Soil particle distribution results in $\%$ - location $N$

I

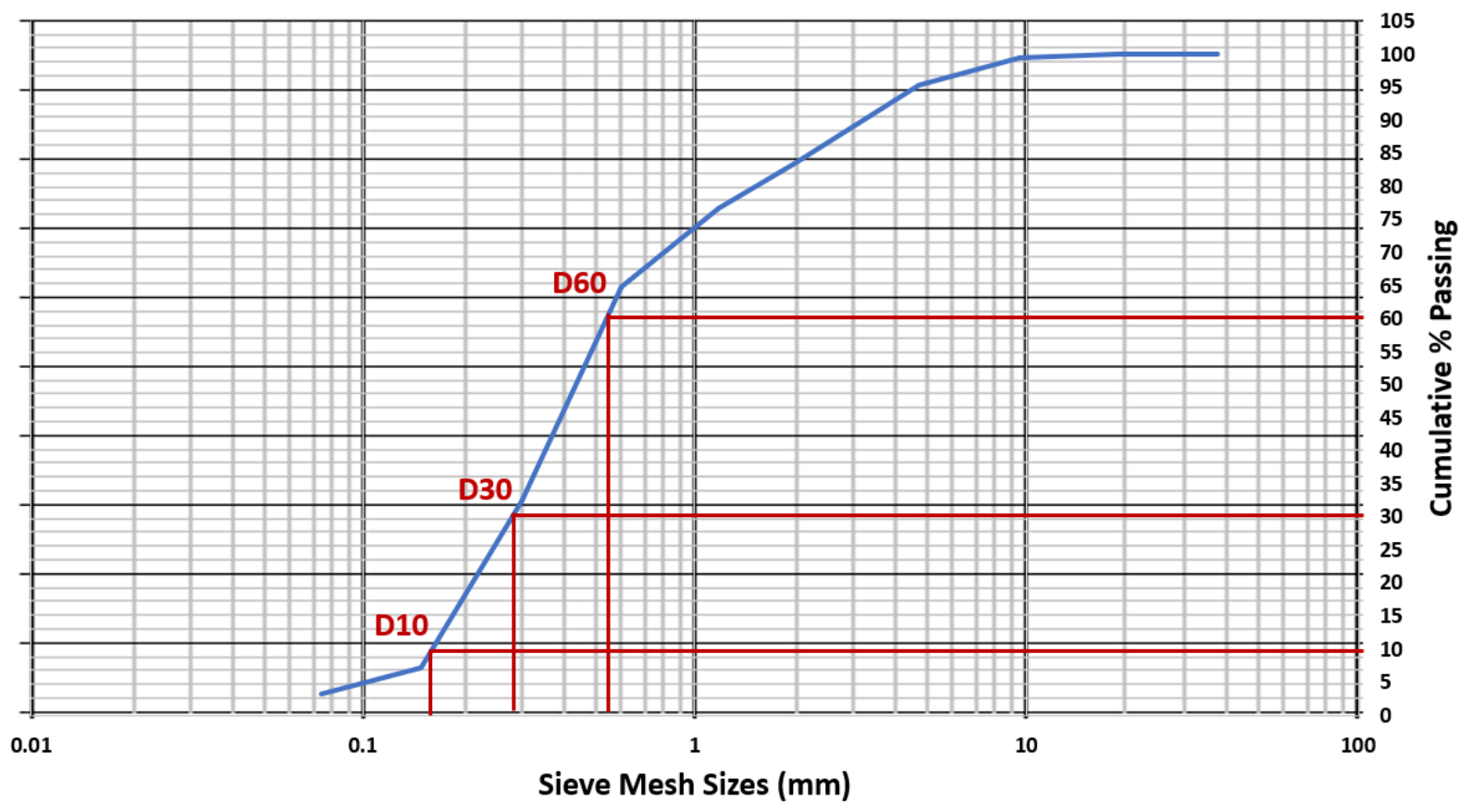

Figure 7-14: Soil particle distribution results in \%-location I 
E

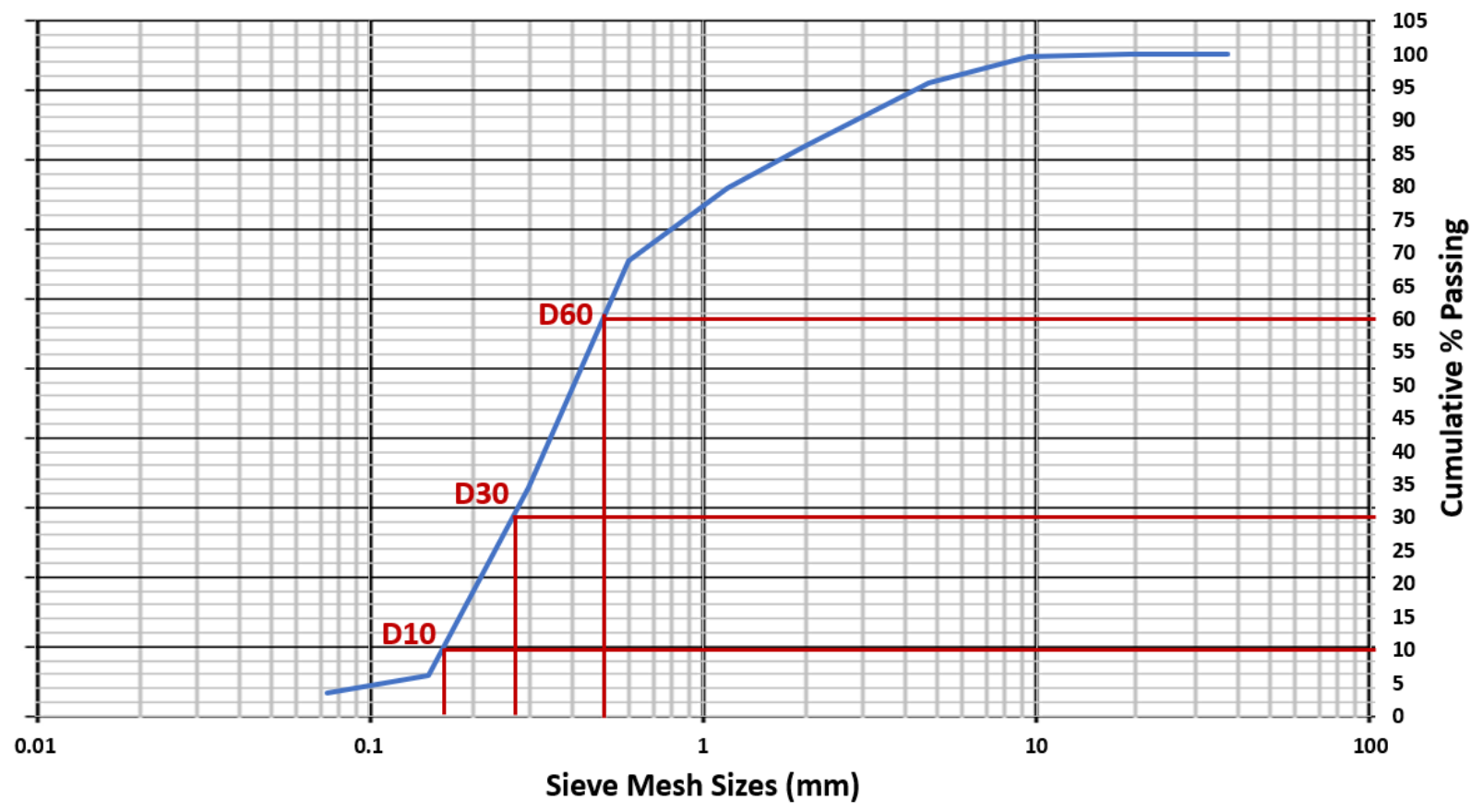

Figure 7-15: Soil particle distribution results in \% - location E

Q

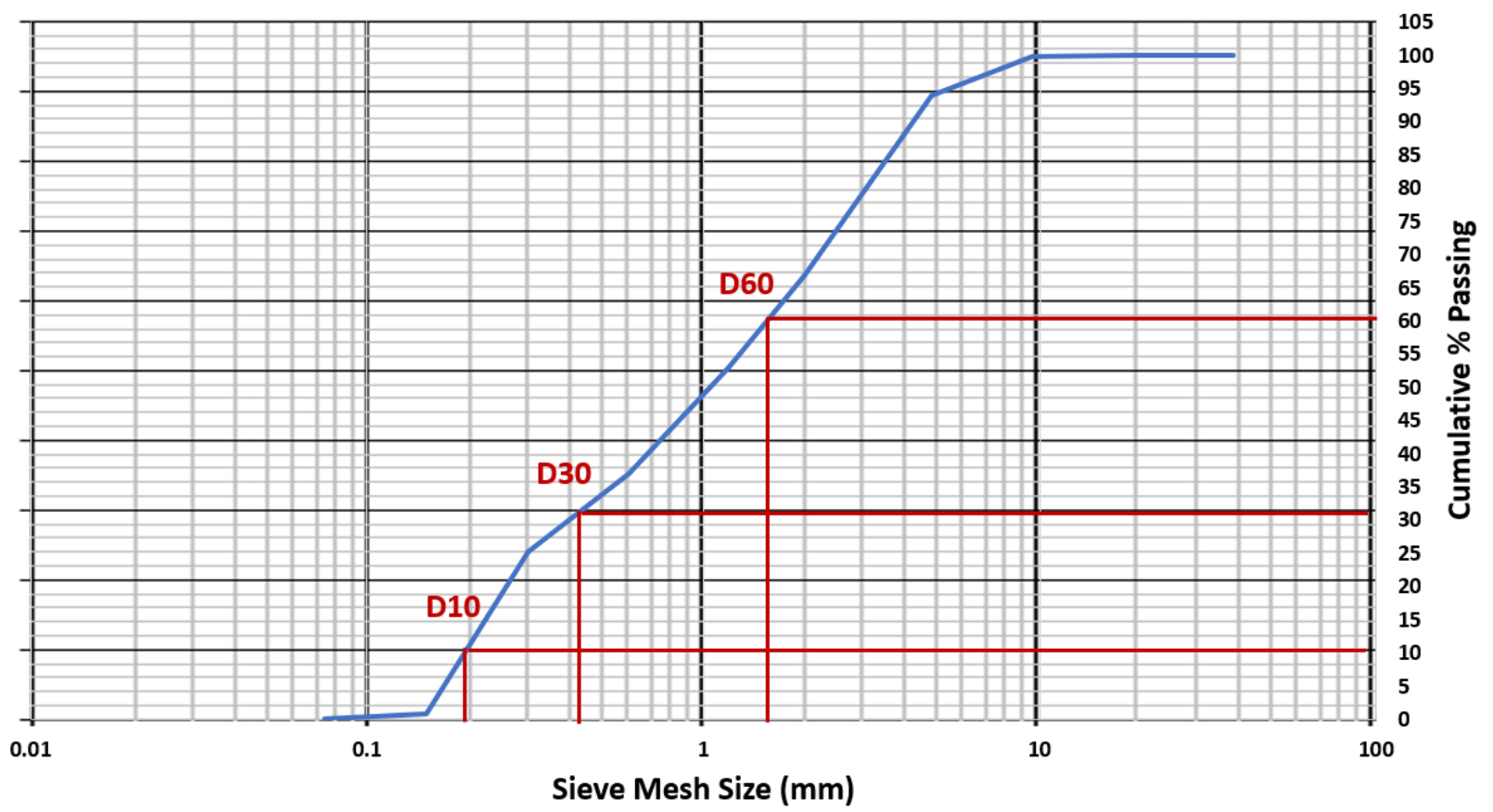

Figure 7-16: Soil particle distribution results in $\%$-location $Q$ 
B

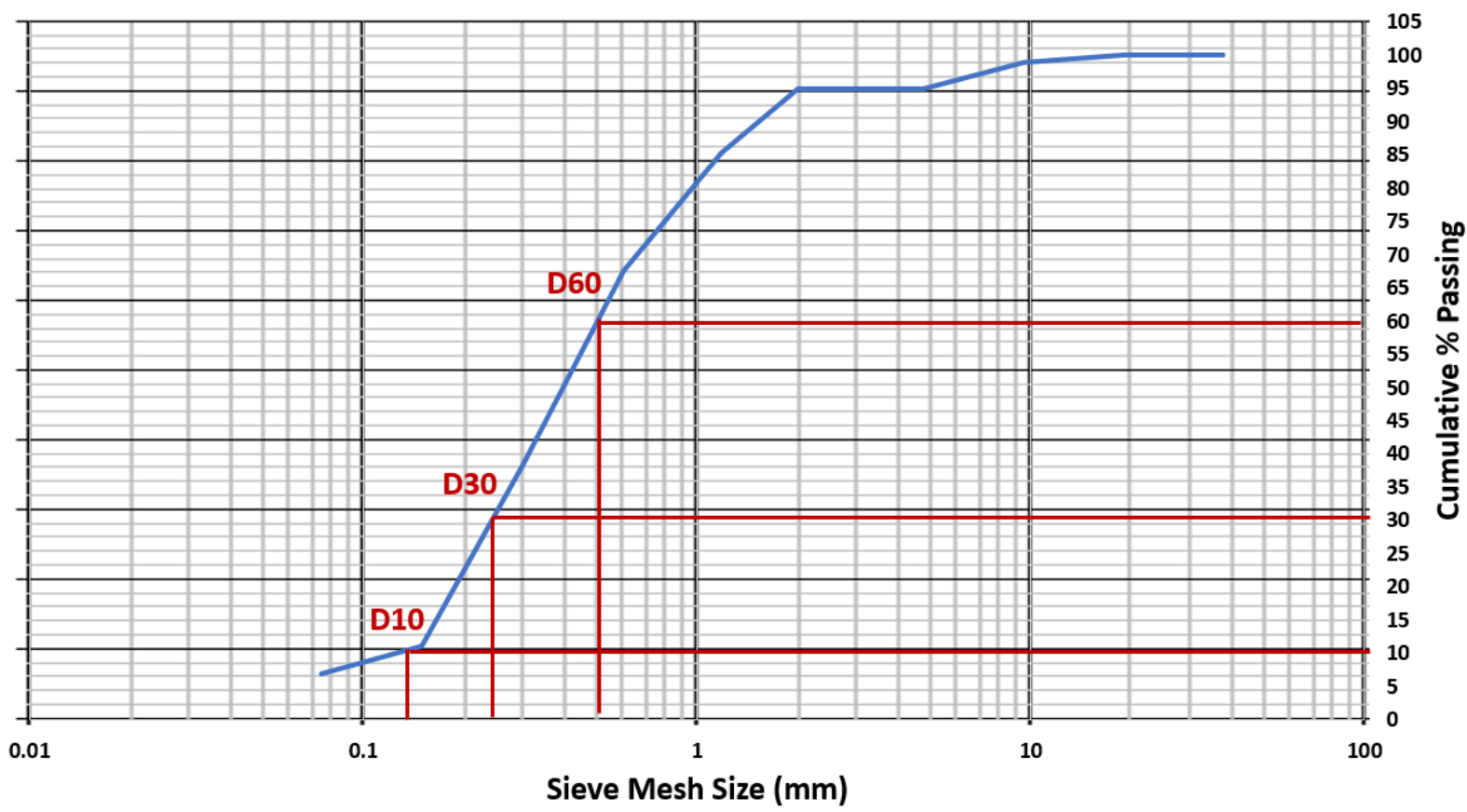

Figure 7-17: Soil particle distribution results in \% - location B

A

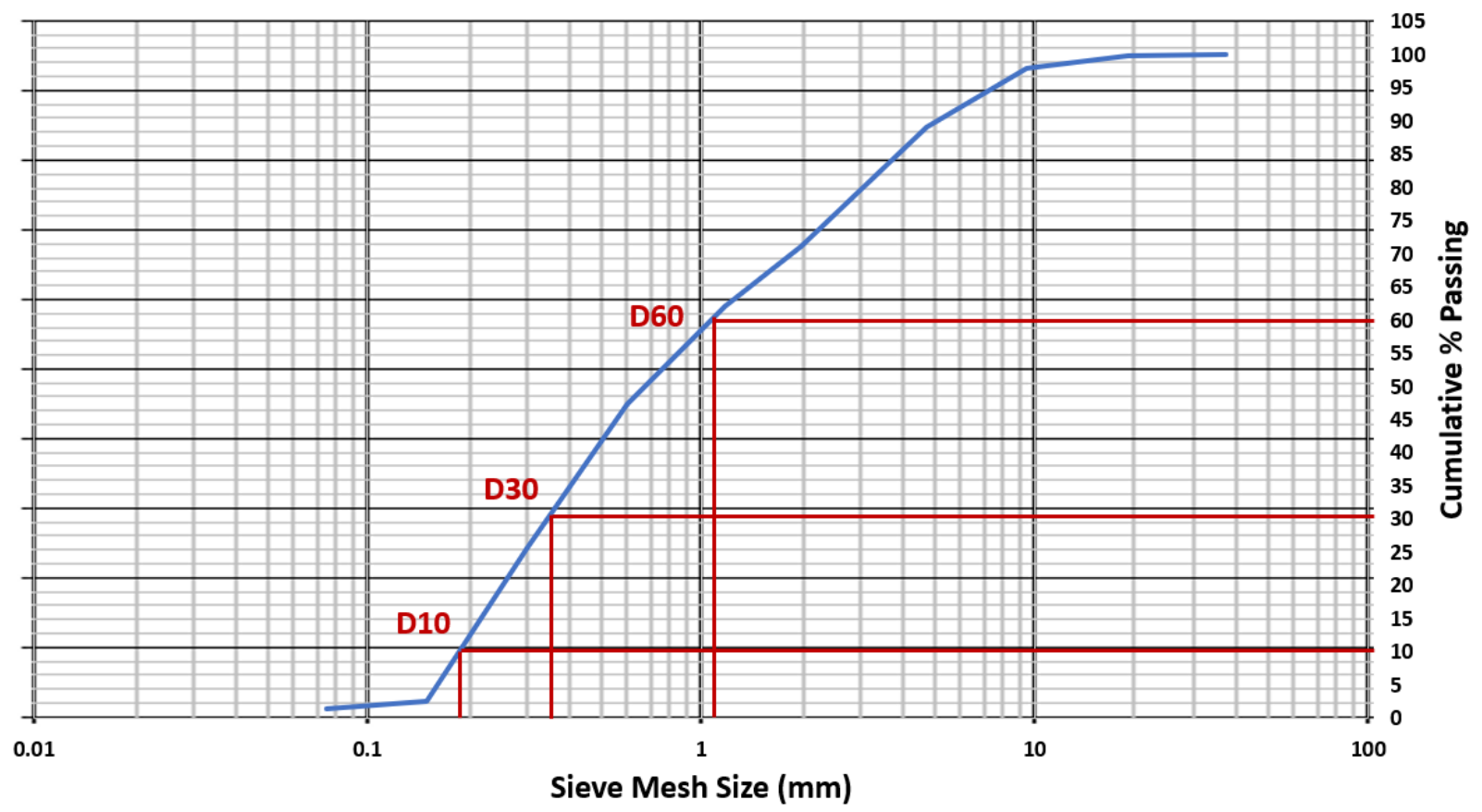

Figure 7-18: Soil particle distribution results in \%-location A 


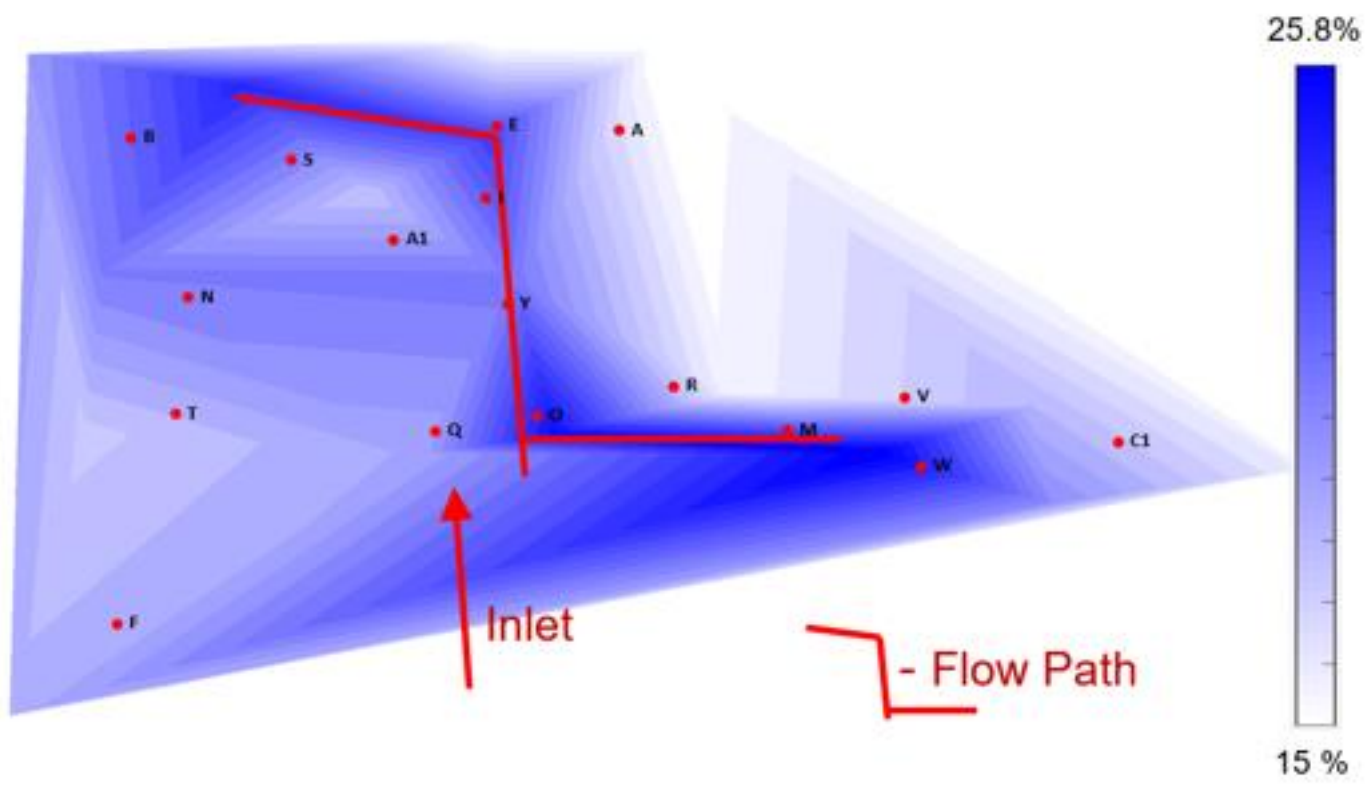

Figure 7-19: Moisture Content Spatial map - All locations

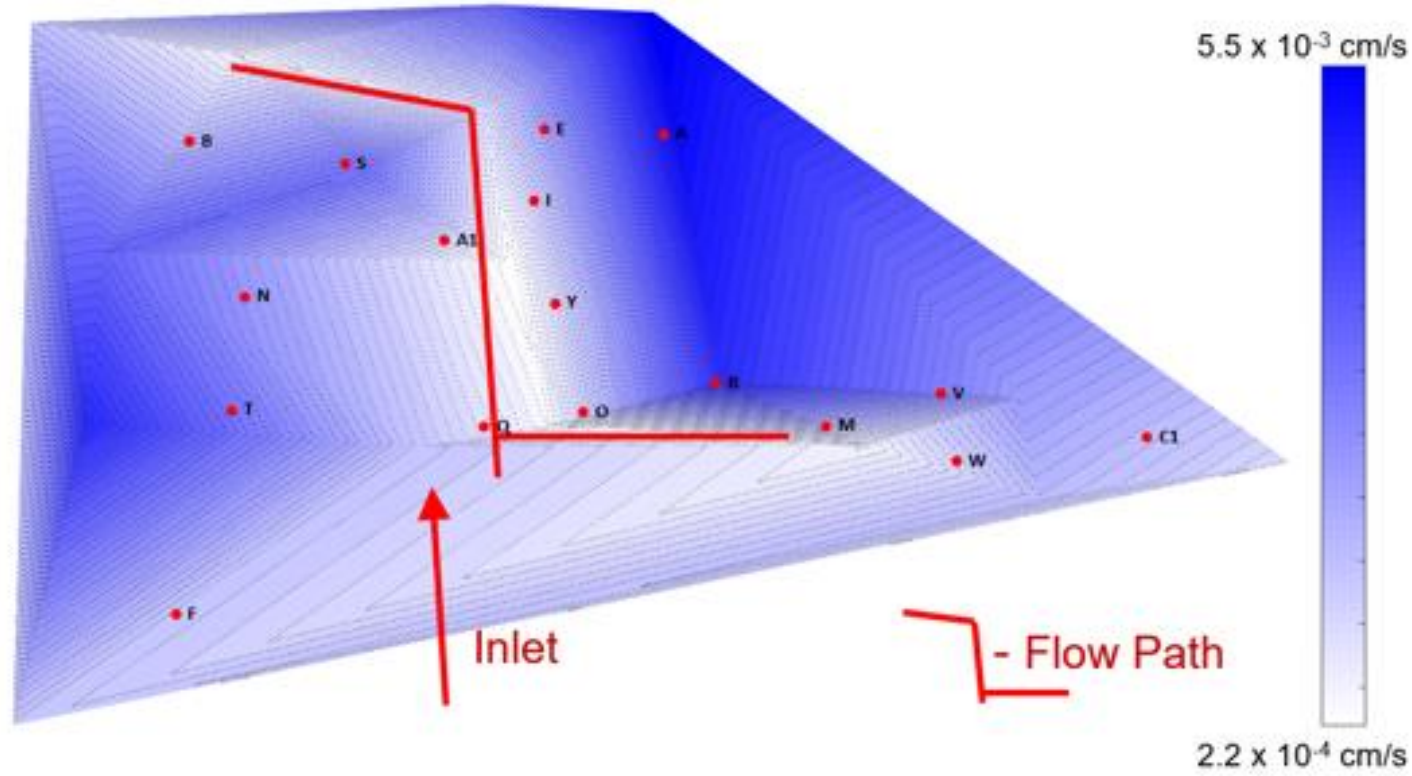

Figure 7-20: Ksat - Radcliffe Method Spatial map - All locations 


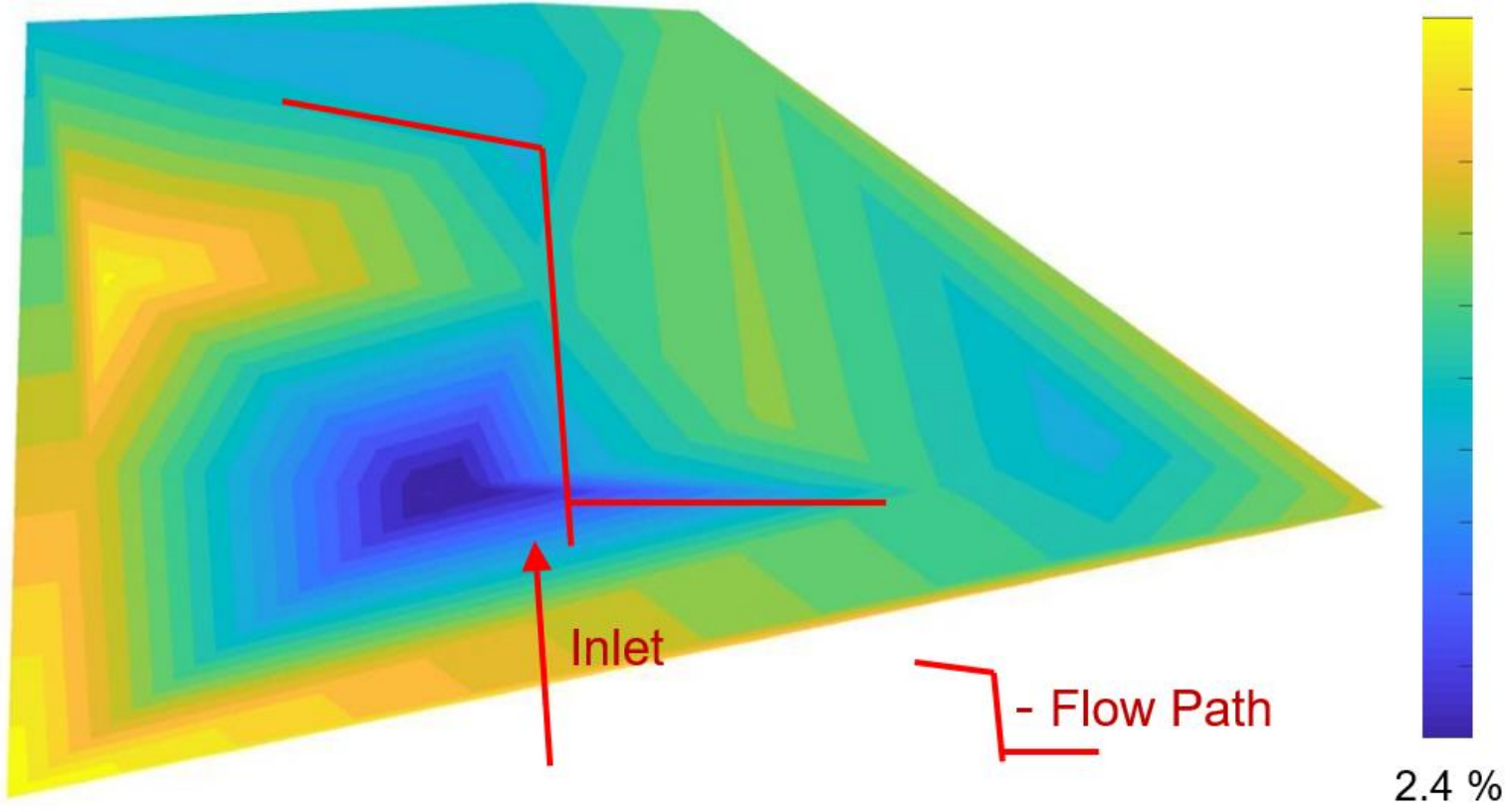

Figure 7-21: Organic Content spatial map - All locations

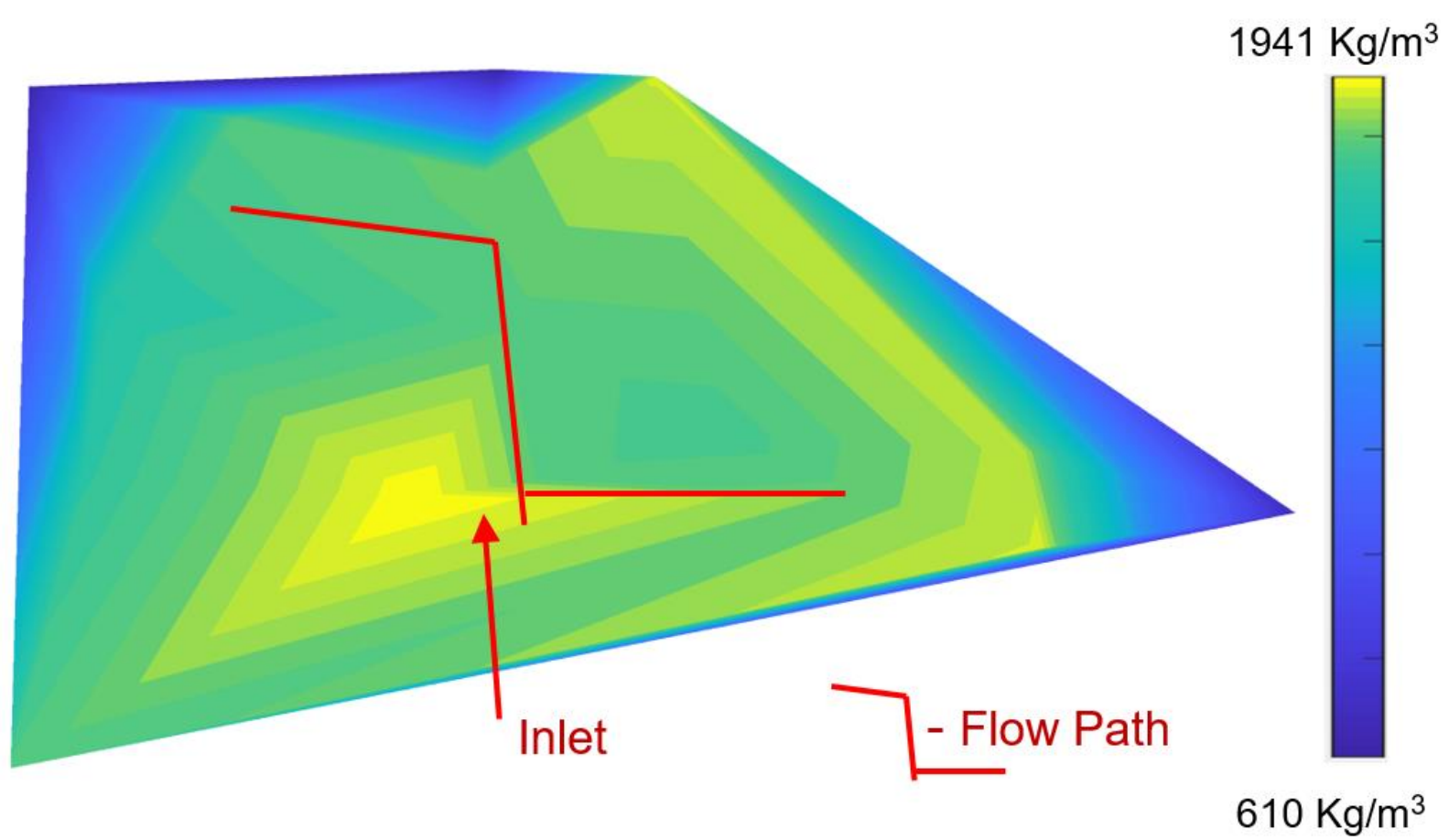

Figure 7-22: Bulk Density spatial map - All locations 


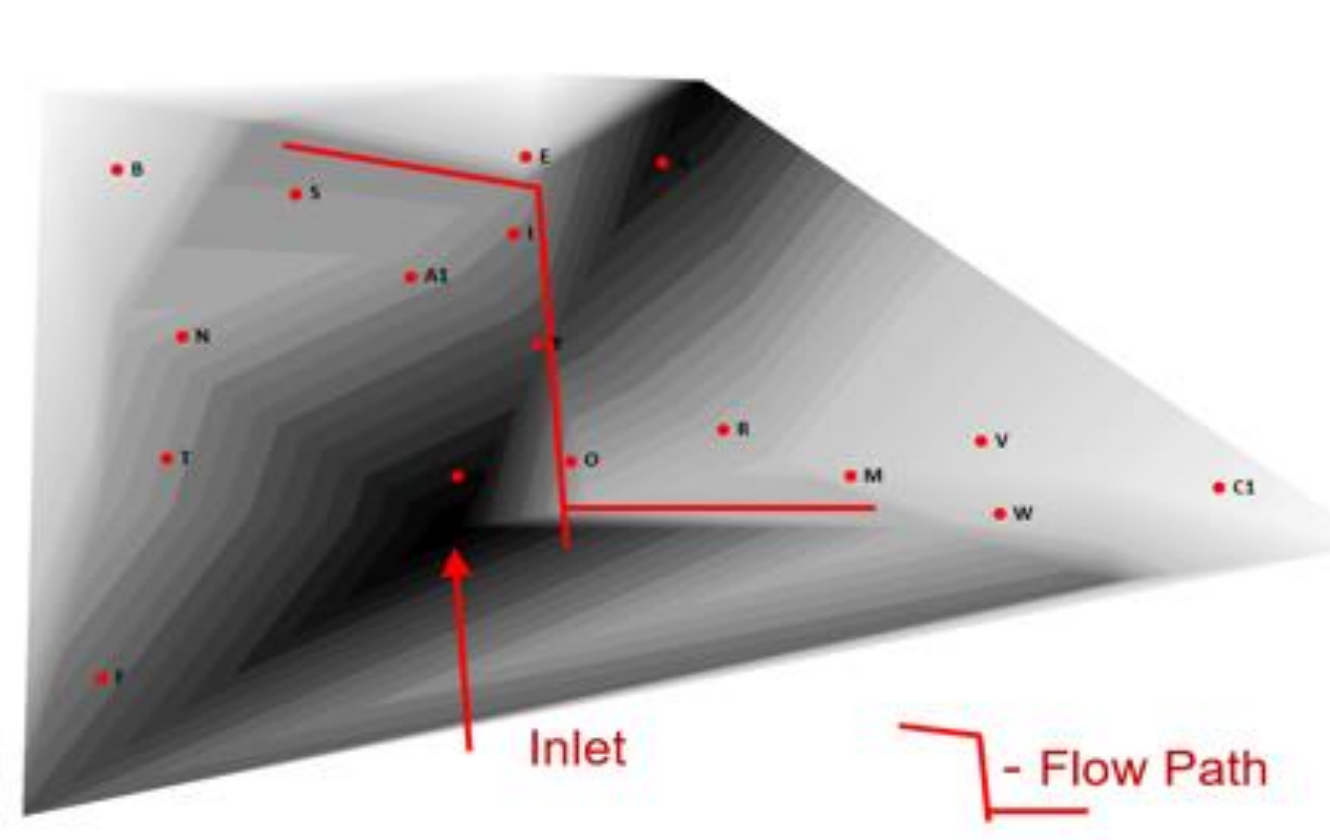

$80 \%$

Figure 7-23: Porosity Spatial map - All locations

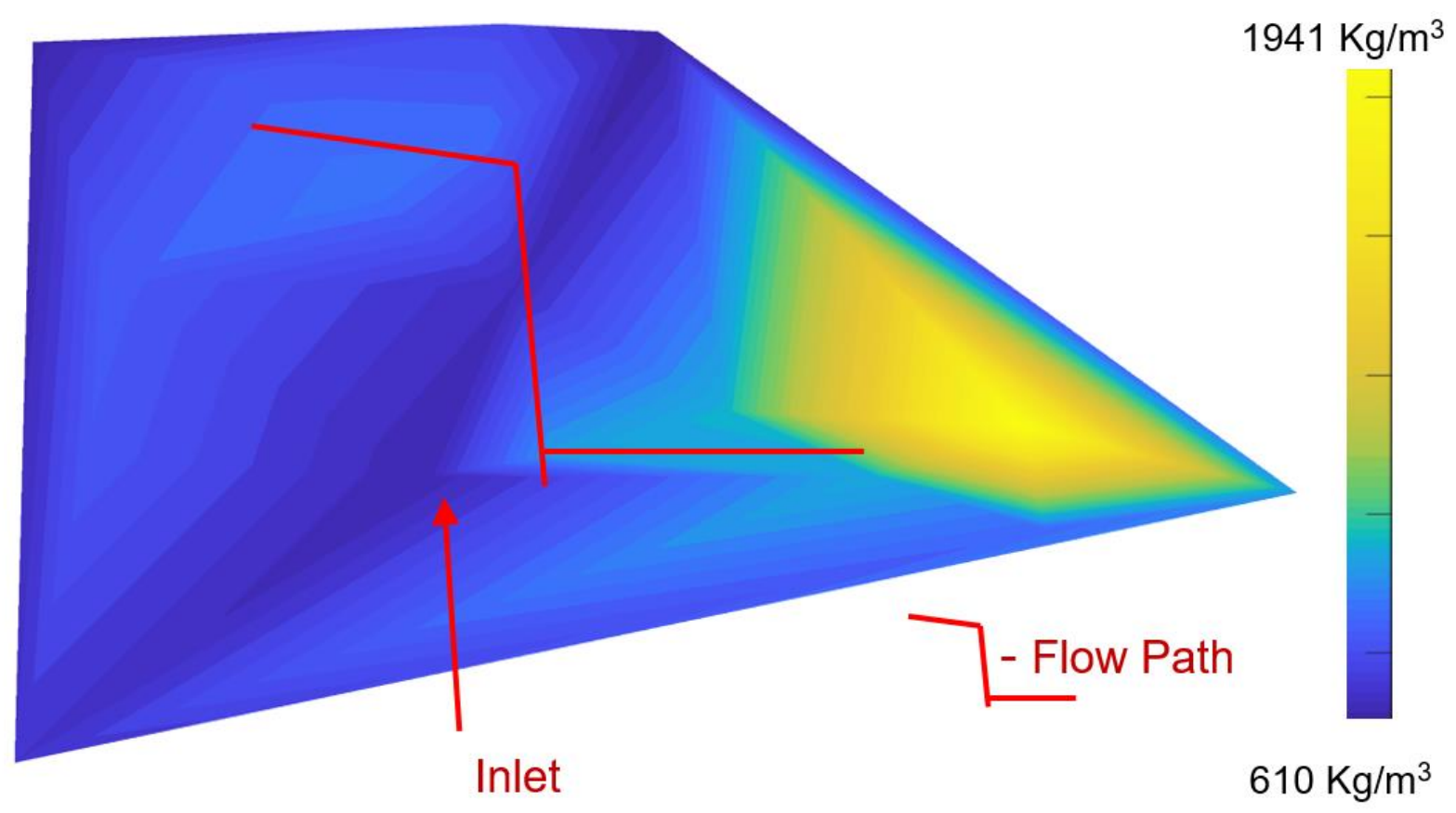

Figure 7-24: Particle Density spatial map - All locations 


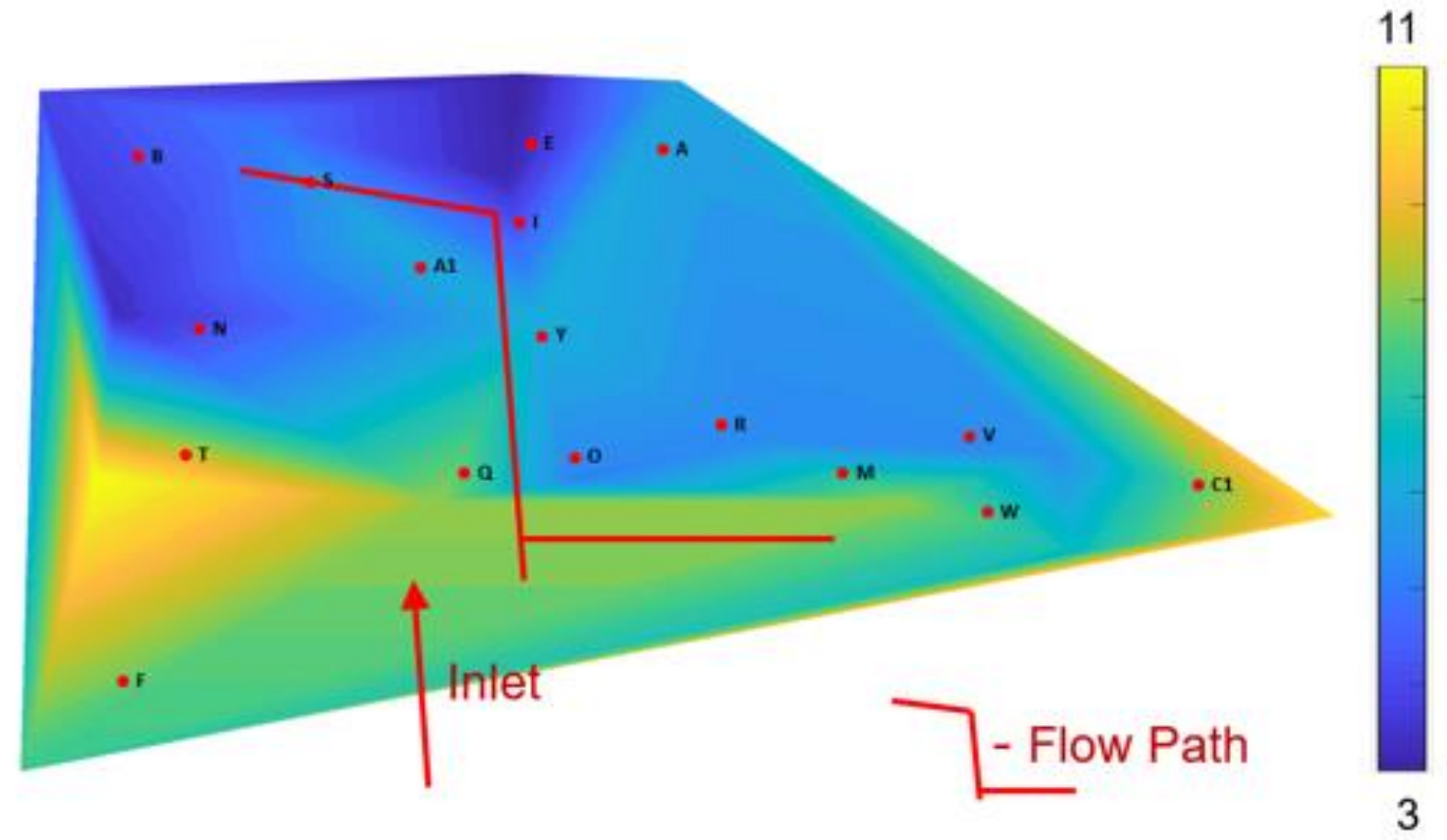

Figure 7-25: Cu spatial map - All locations

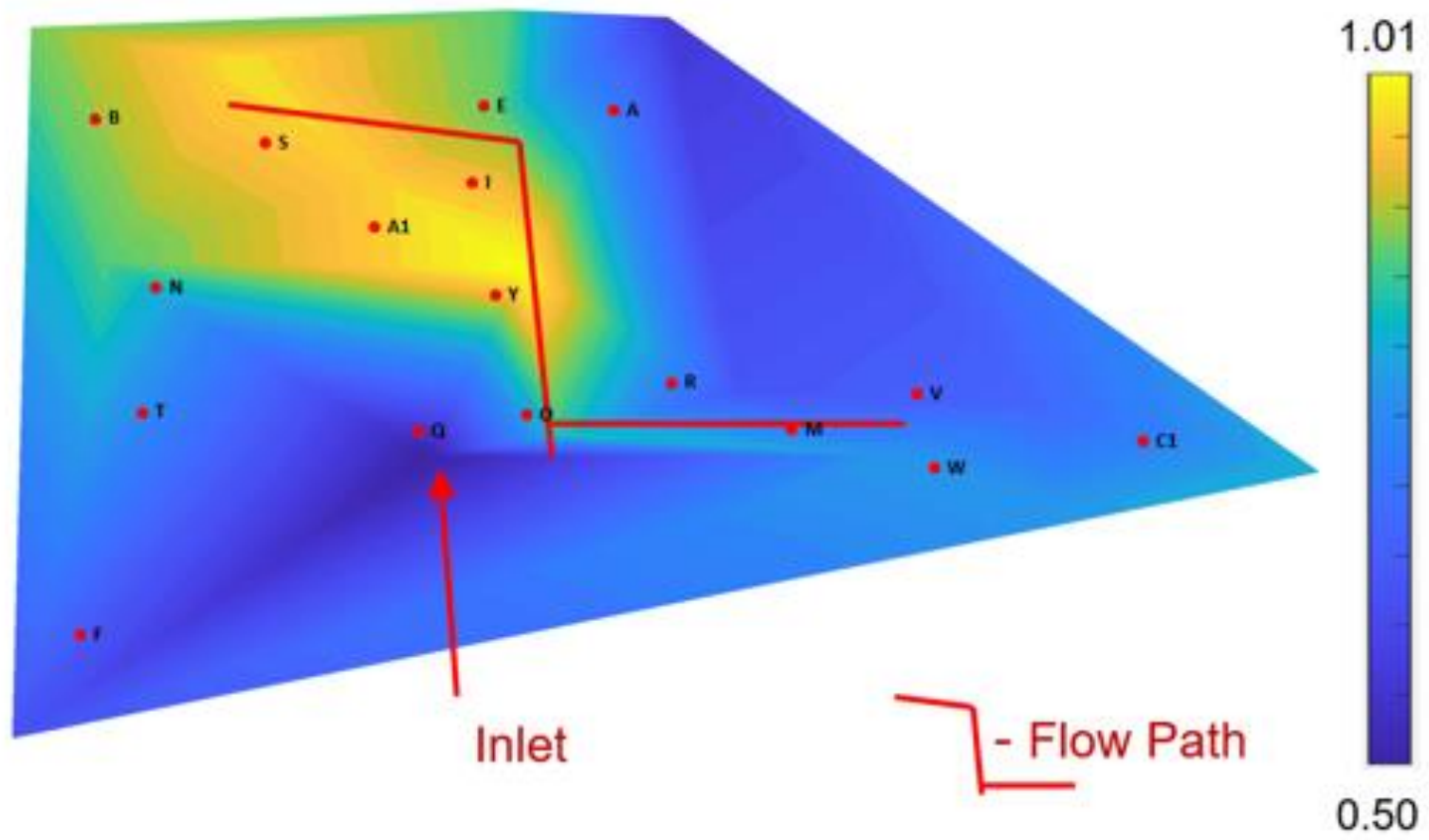

Figure 7-26: Cc Spatial Map - All locations 


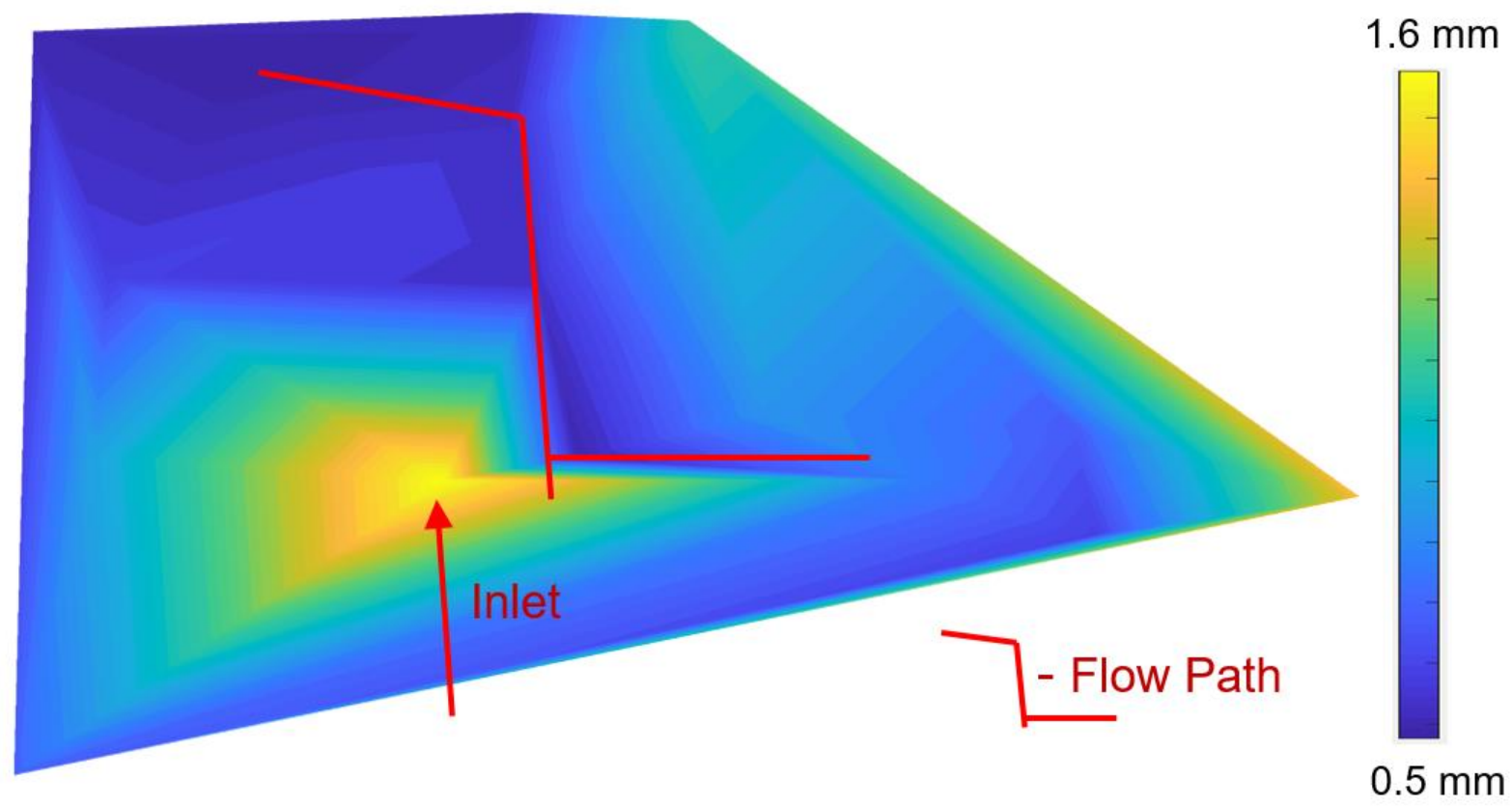

Figure 7-27: Doo Spatial Map - All locations

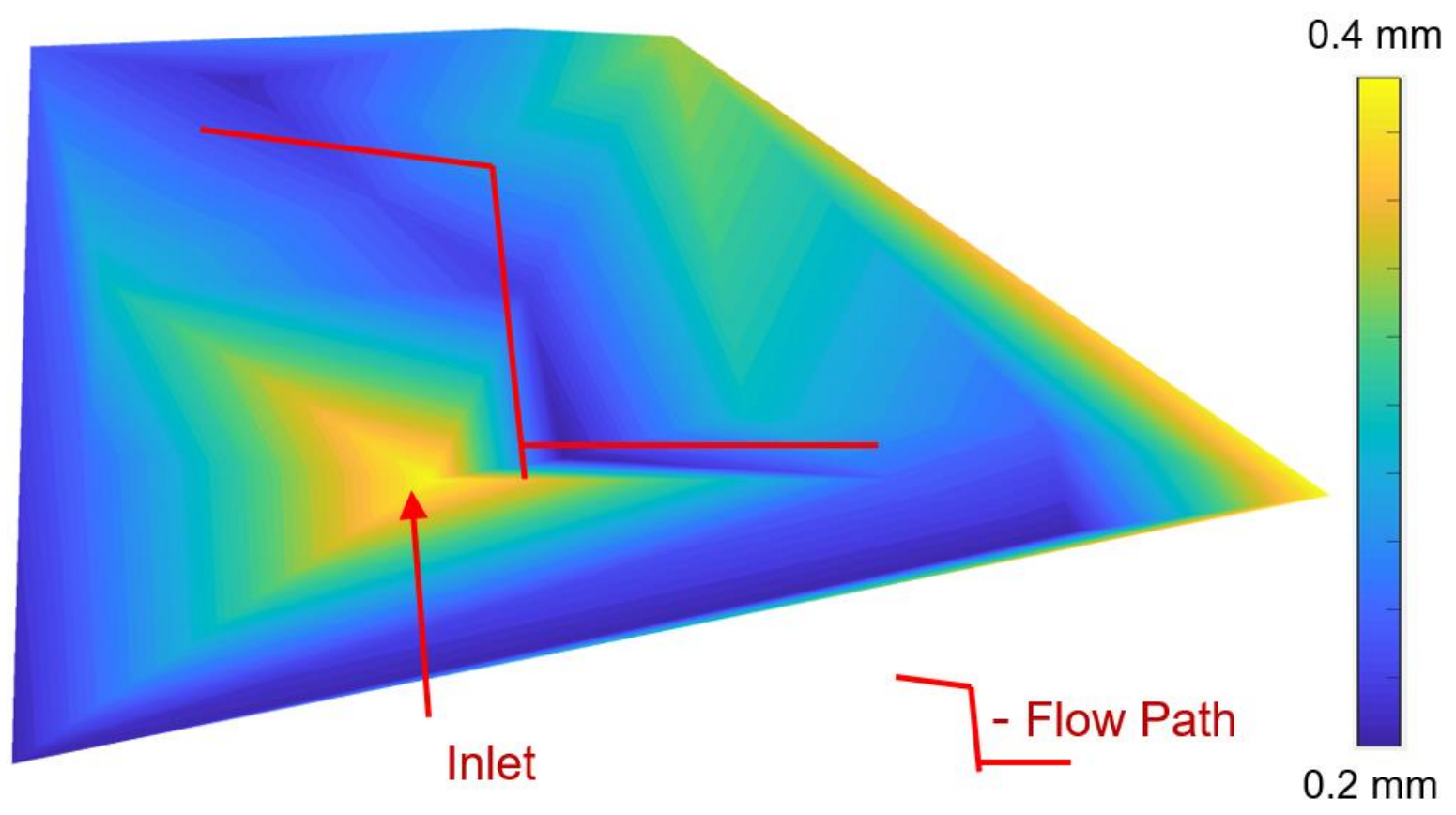

Figure 7-28: D30 Spatial Map - All locations 


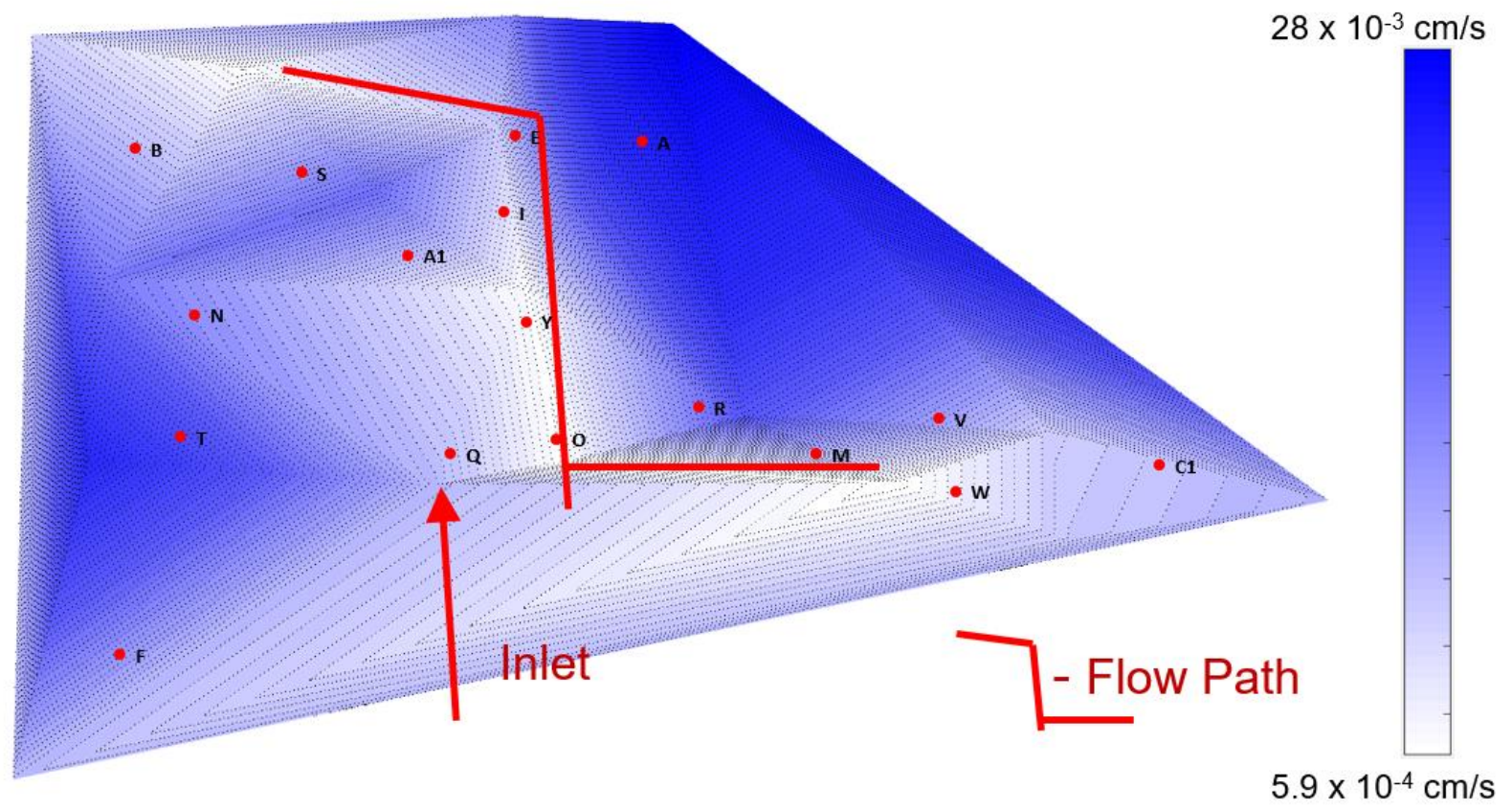

Figure 7-29: Ksat Elrick and Reynolds method average

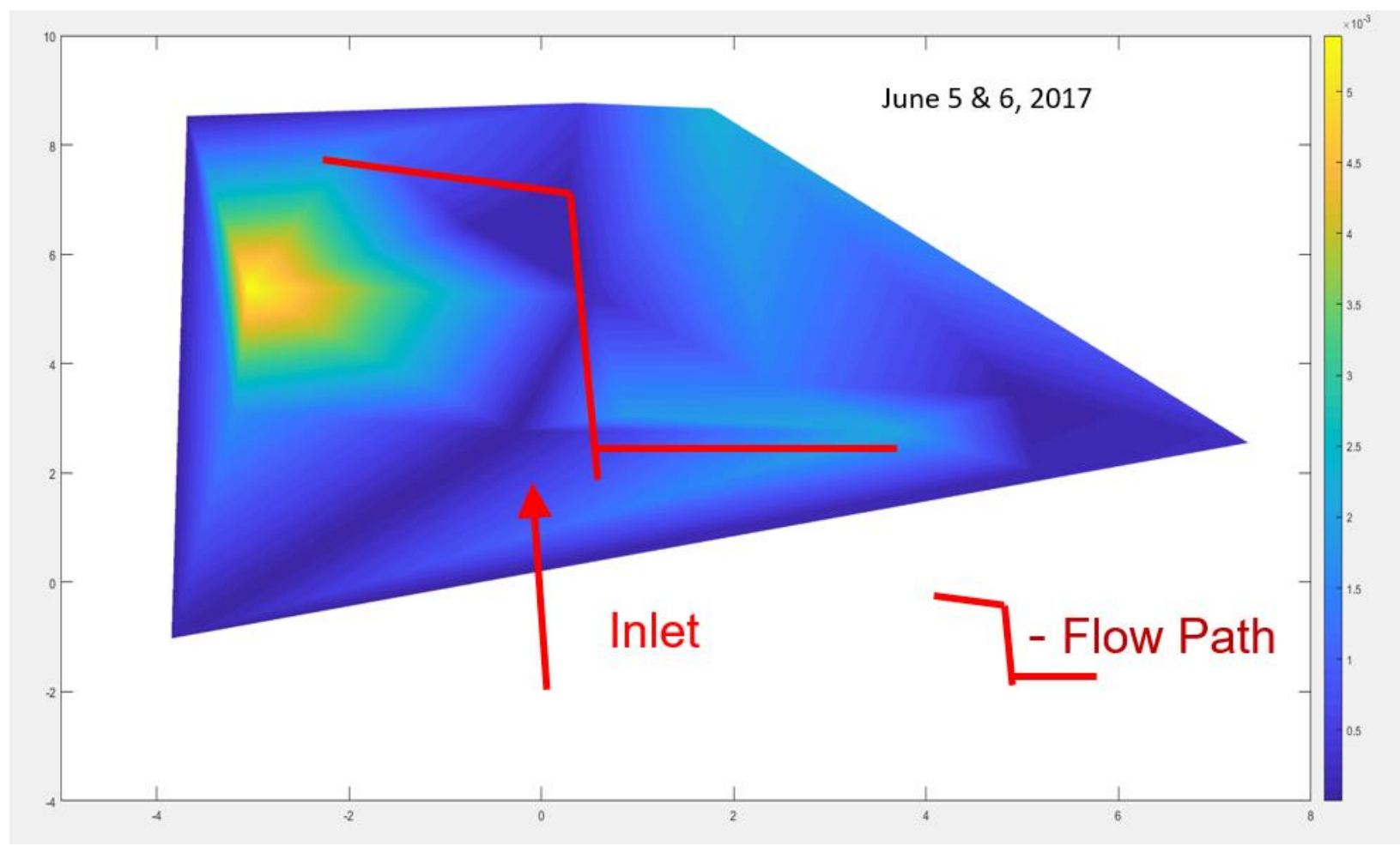

Figure 7-30: June 5 \& 6, 2017 - Ksat Radcliffe method 


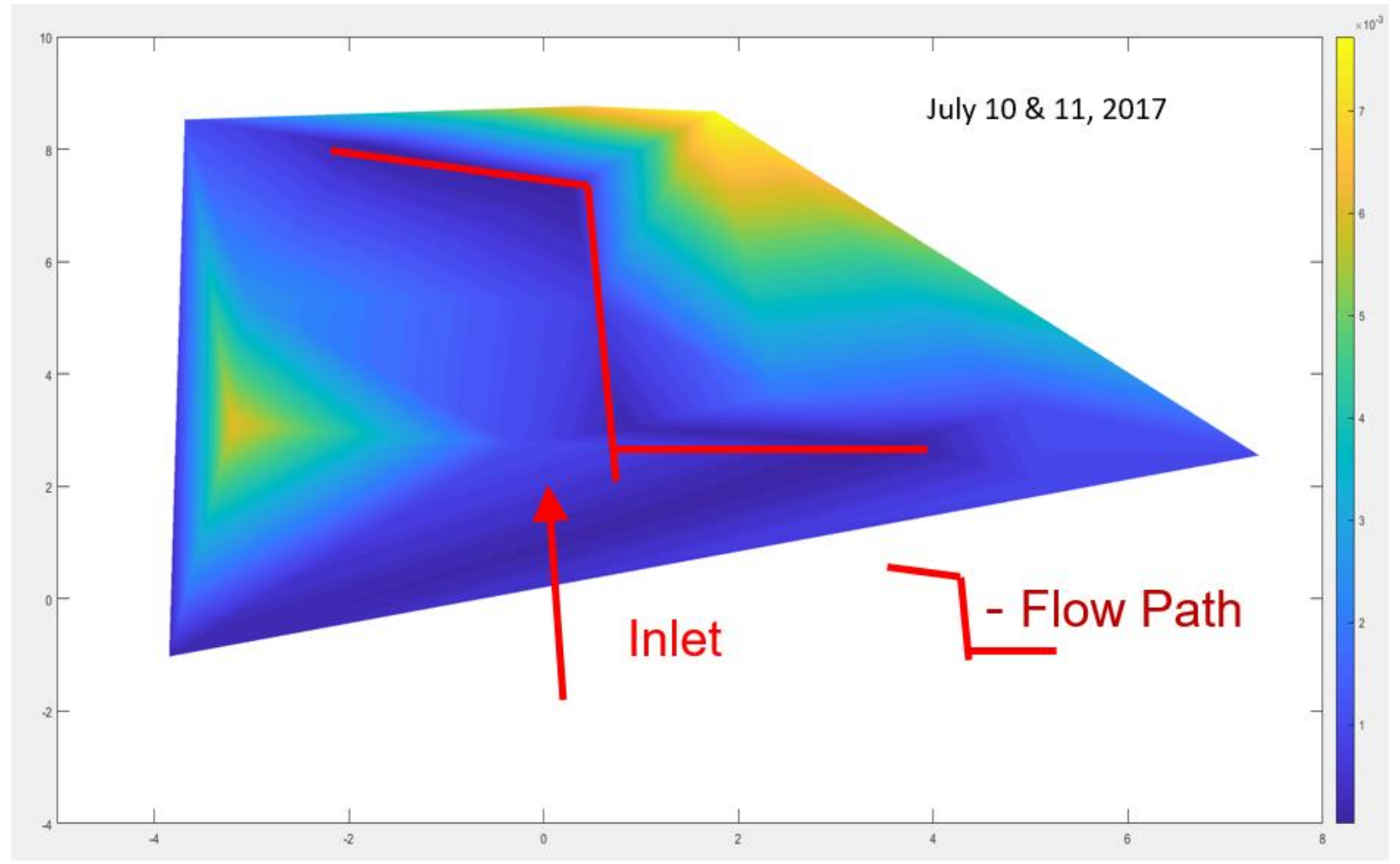

Figure 7-31: July 10 \& 11, 2017 - Ksat Radcliffe method

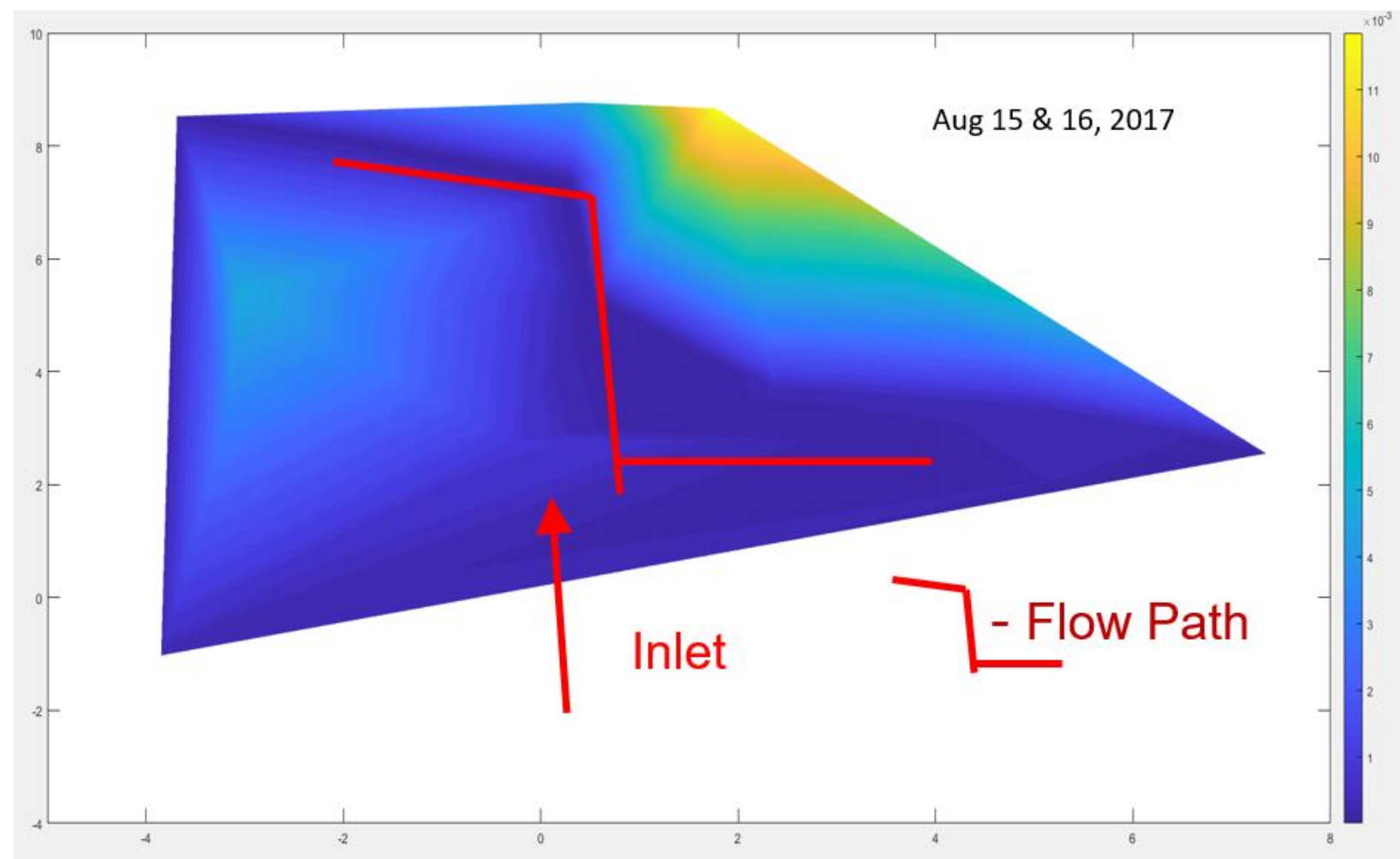

Figure 7-32: August 15 \& 16, 2017 - Ksat Radcliffe method 


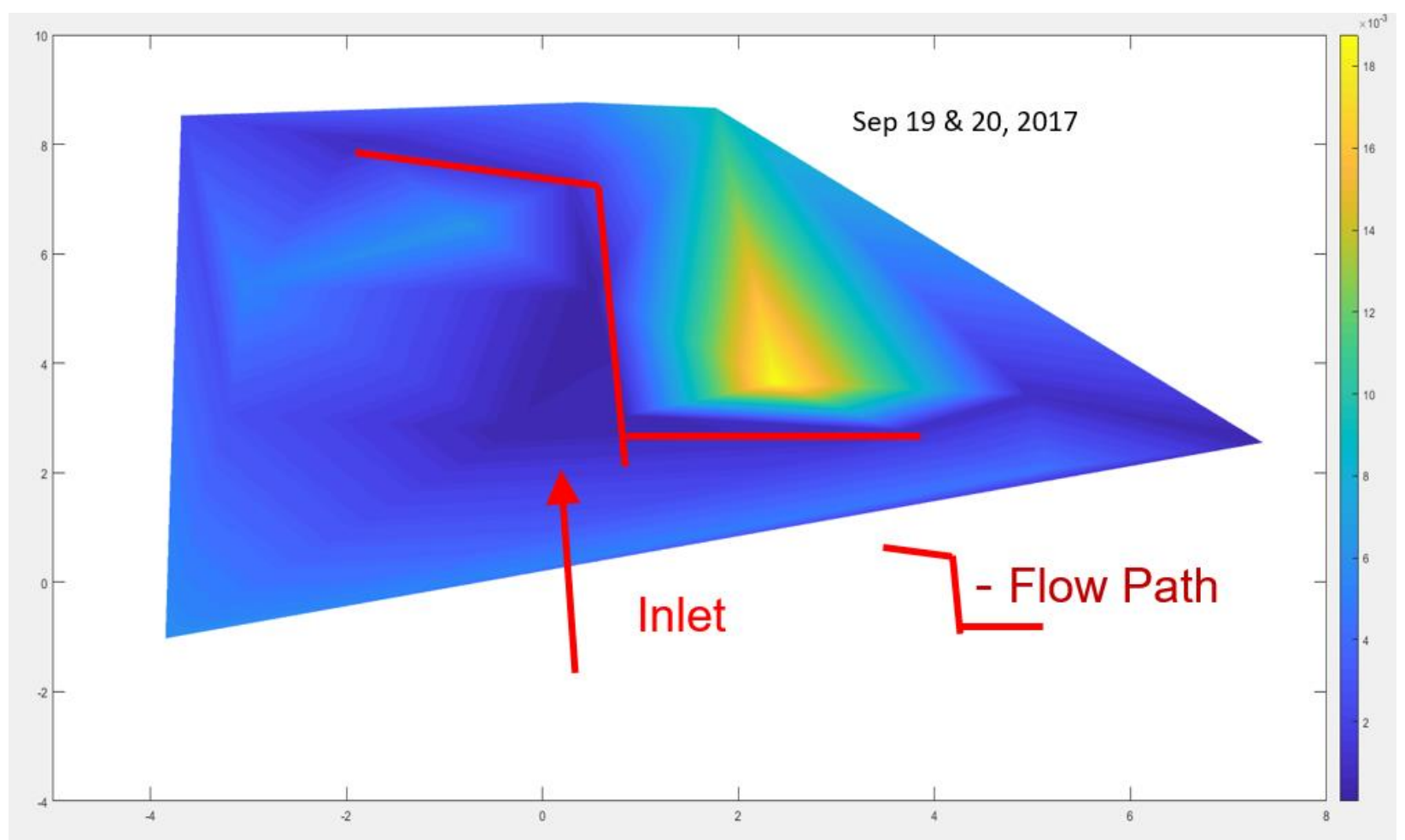

Figure 7-33: September 19 \& 20, 2017 - Ksat Radcliffe method

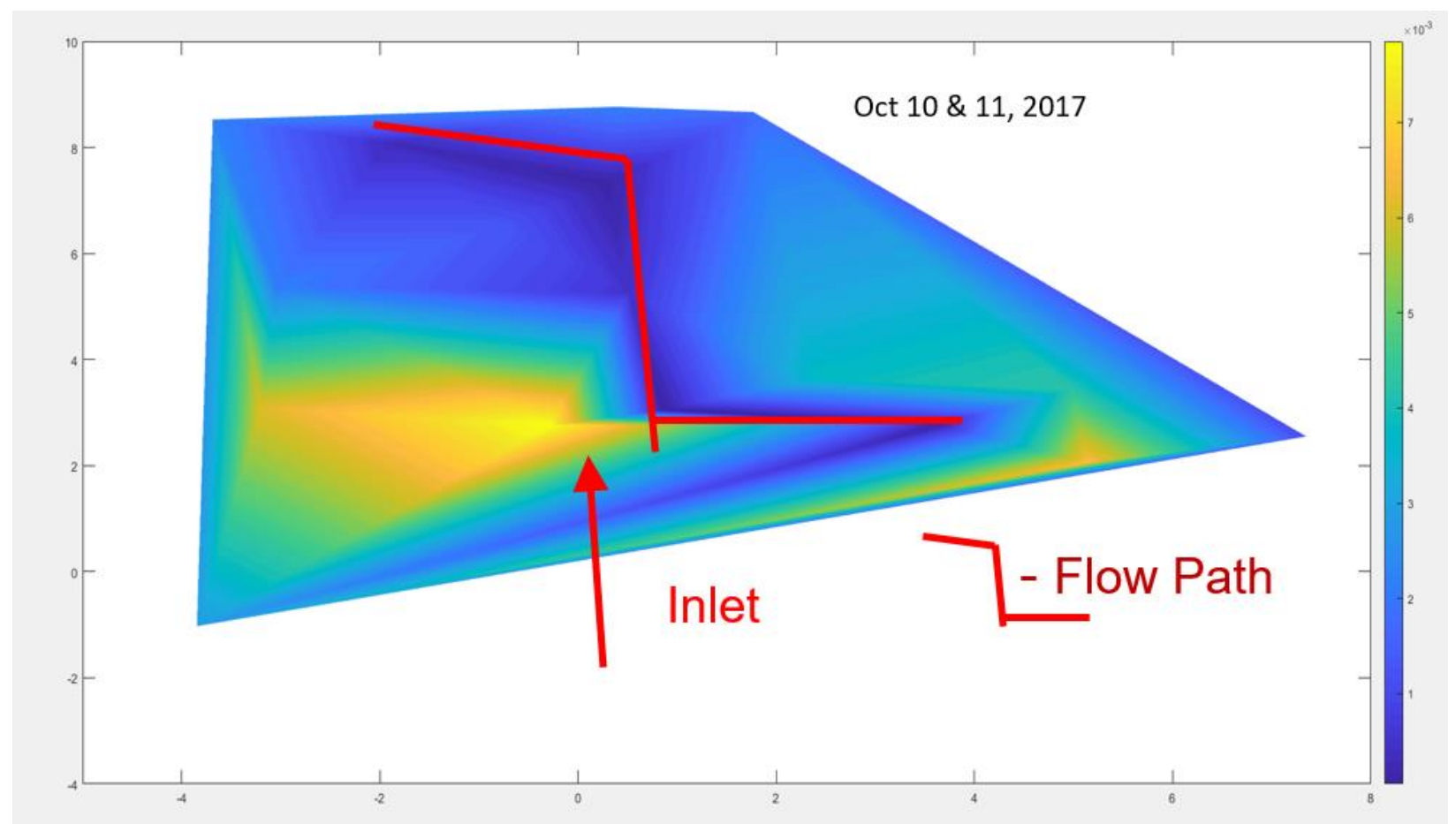

Figure 7-34: Oct $10 \&$ 11, 2017 - Ksat Radcliffe method 


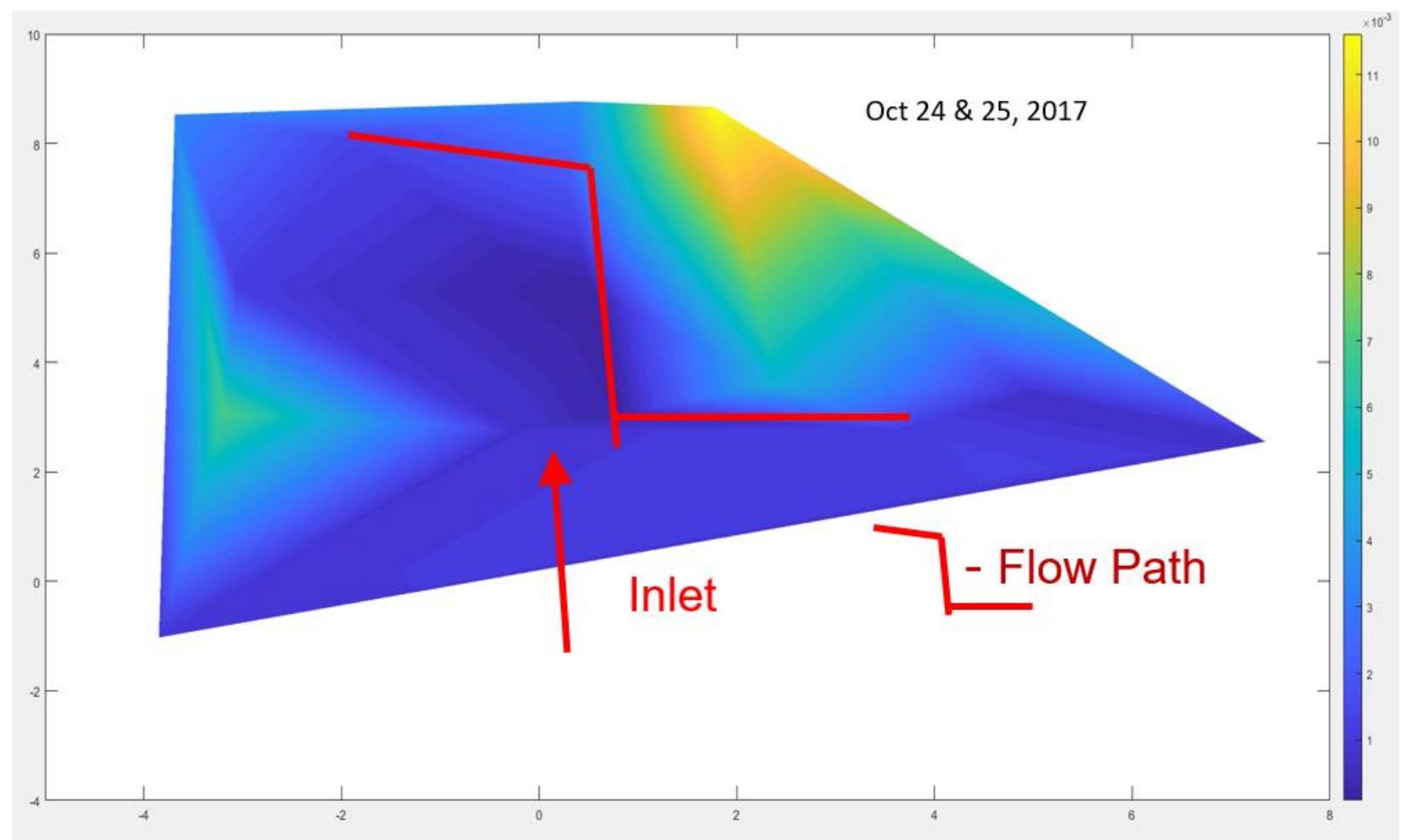

Figure 7-35: Oct 24 \& 25, 2017 - Ksat Radcliffe method

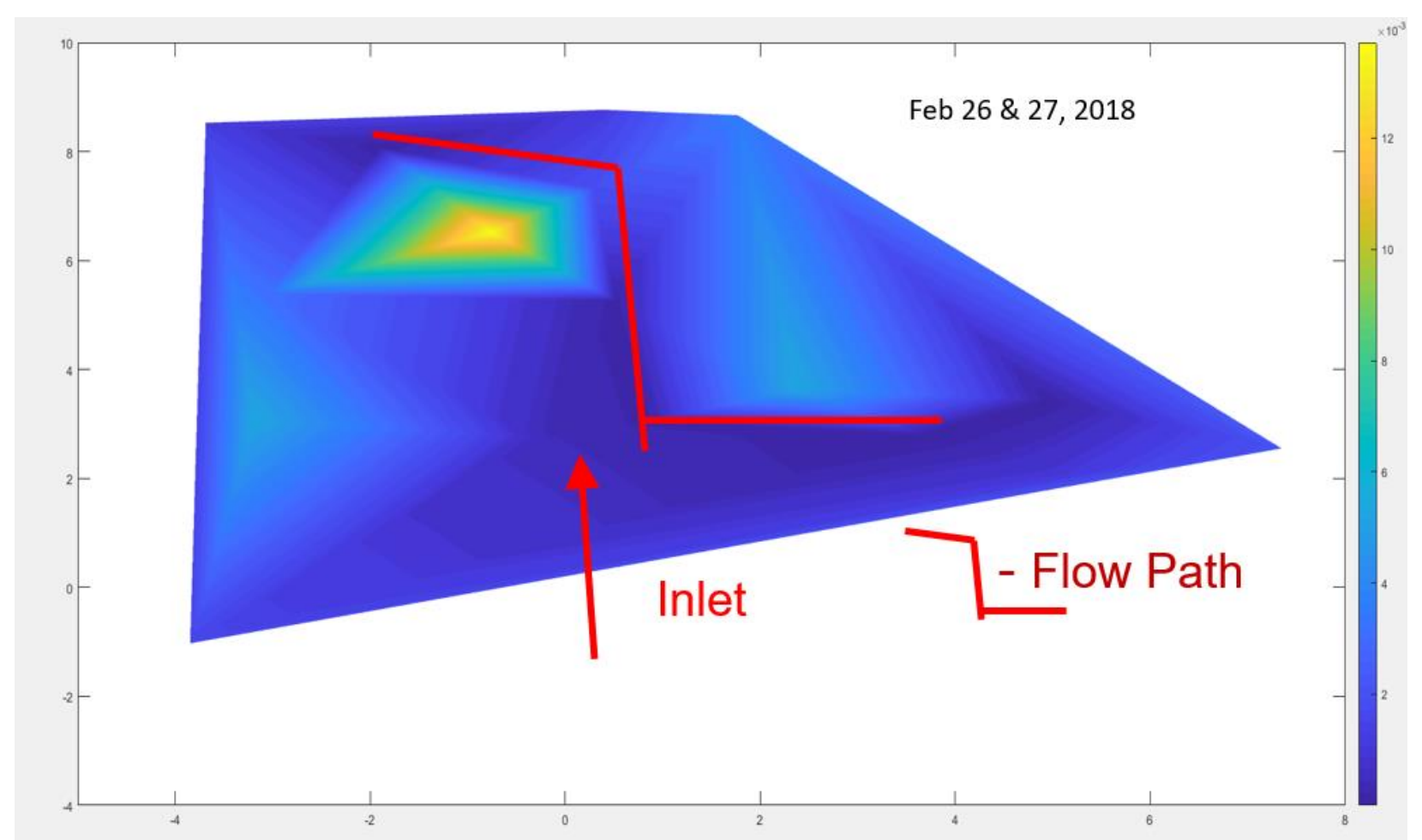

Figure 7-36: February 26 \& 27, 2018 - Ksat Radcliffe method 


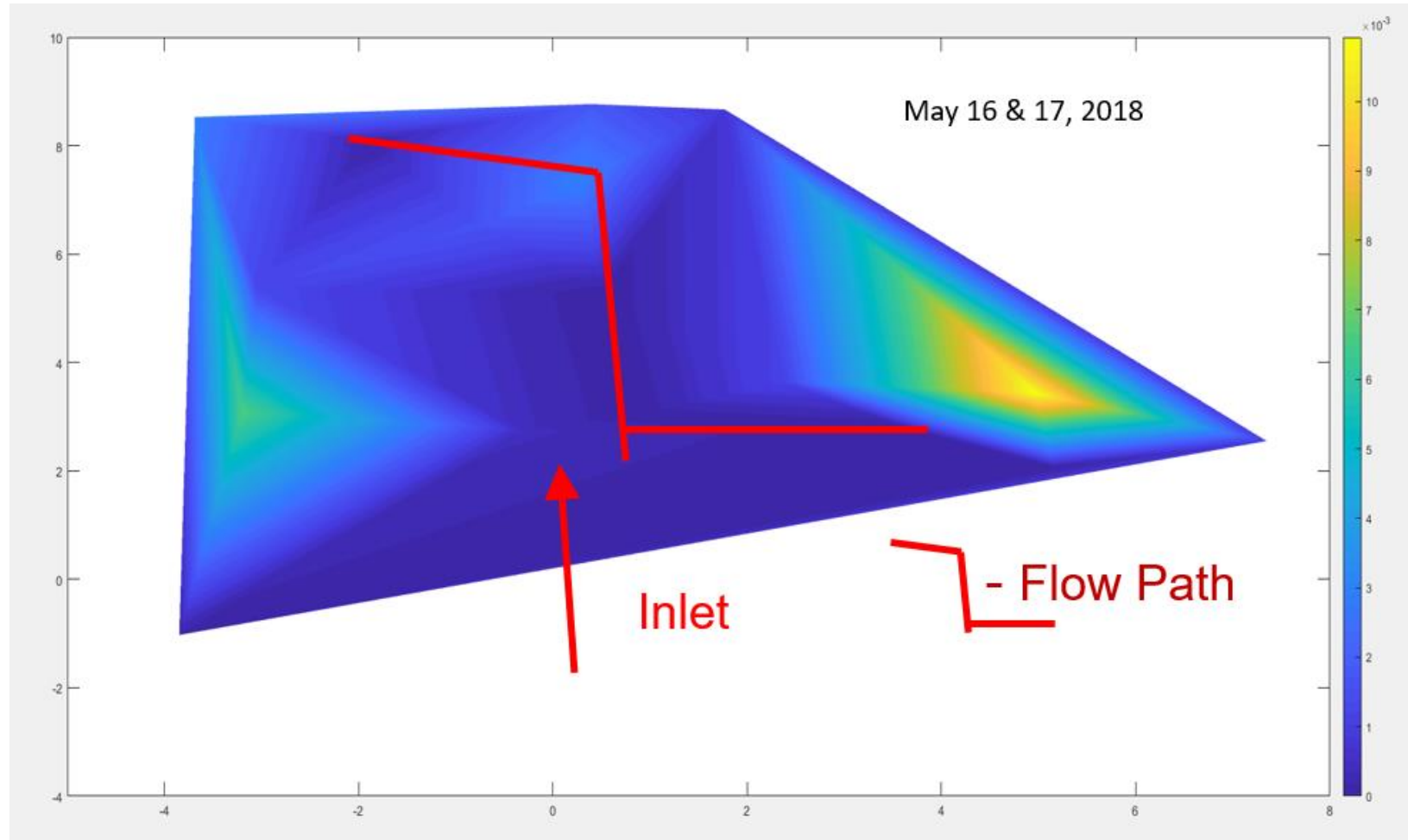

Figure 7-37: May 16 \& 17, 2018 - Ksat Radcliffe method

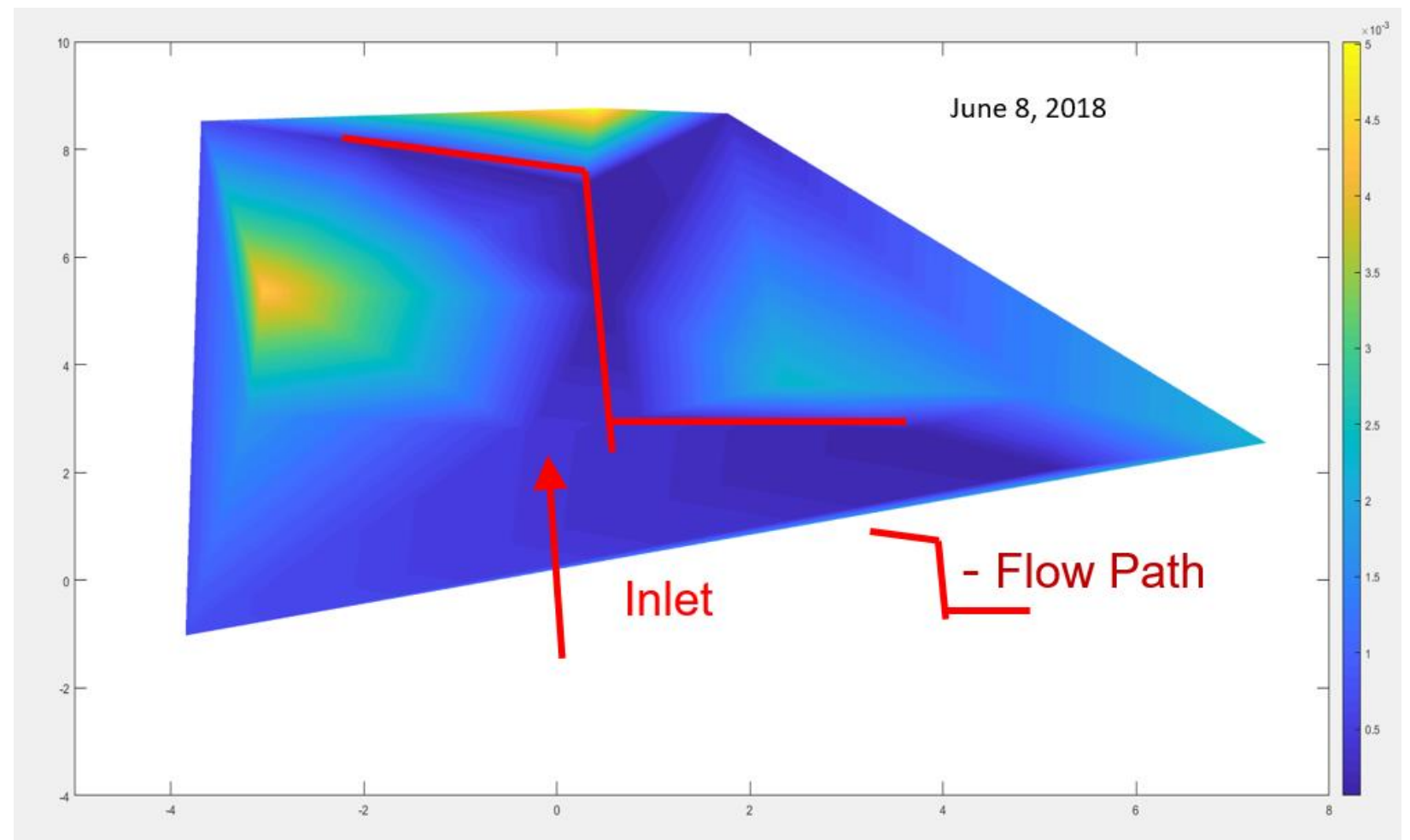

Figure 7-38: June 8, 2018 - Ksat Radcliffe method 


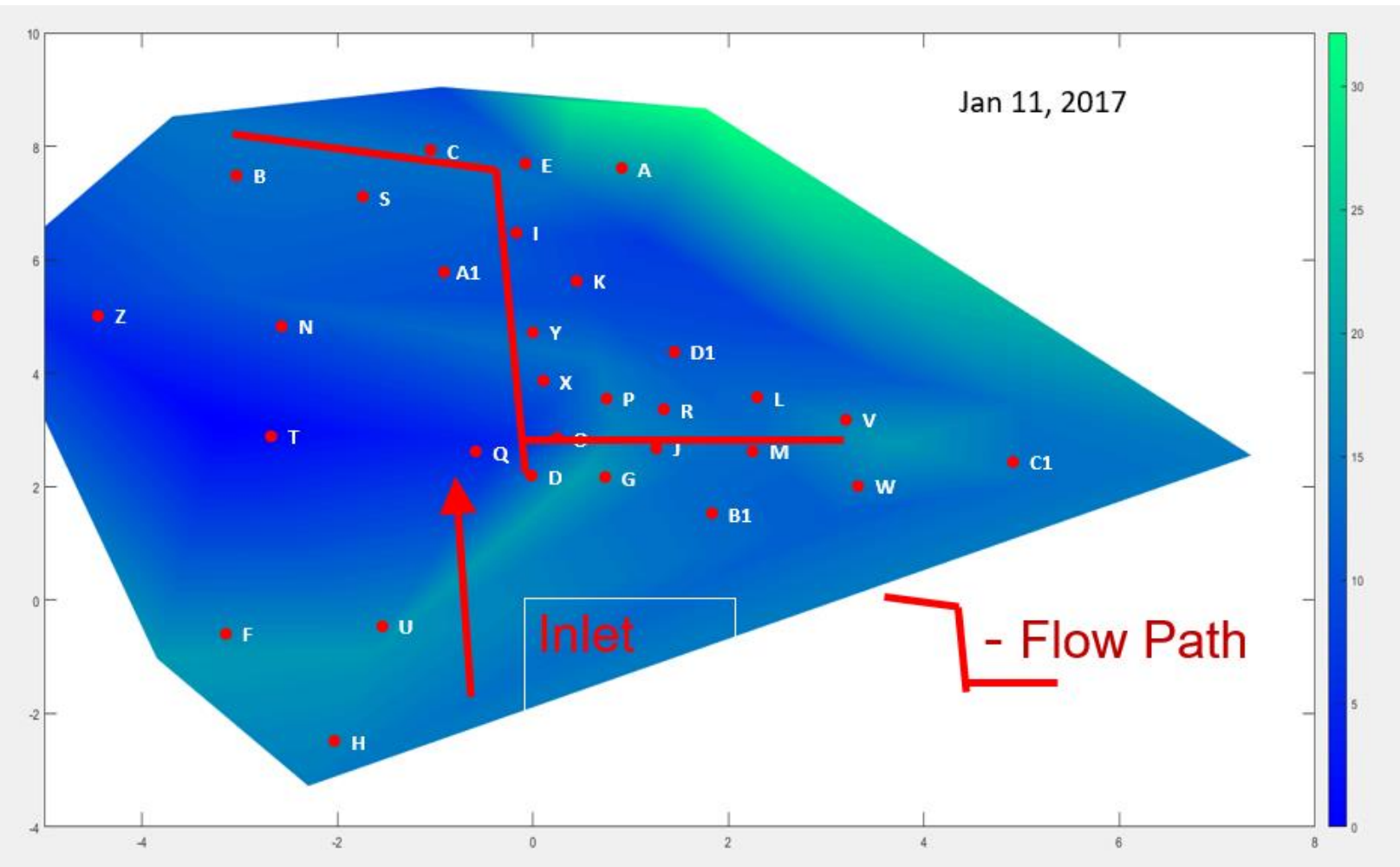

Figure 7-39: January 11, 2017 - Snow Depth

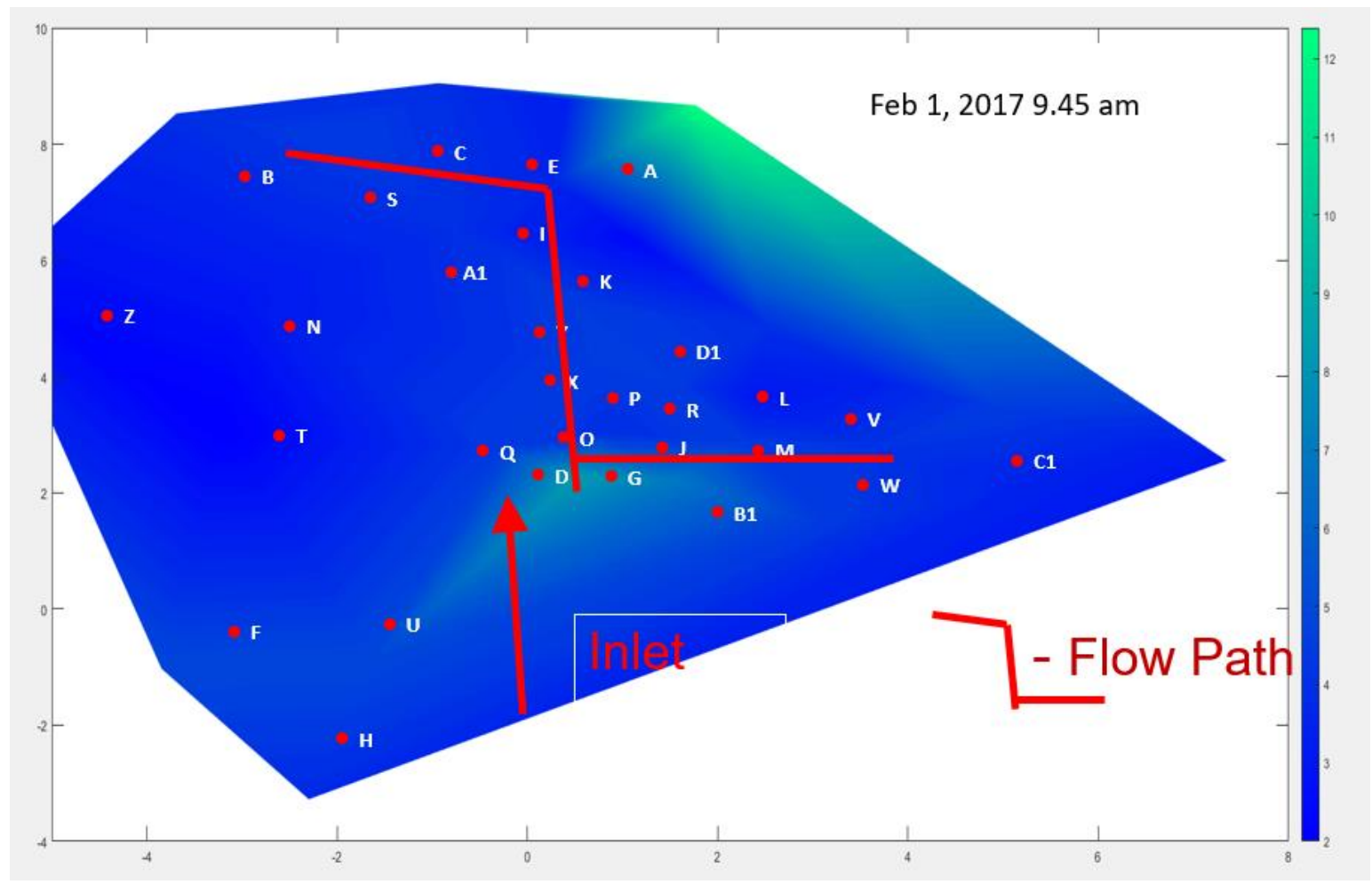

Figure 7-40: February 1, 2017 - Snow Depth 


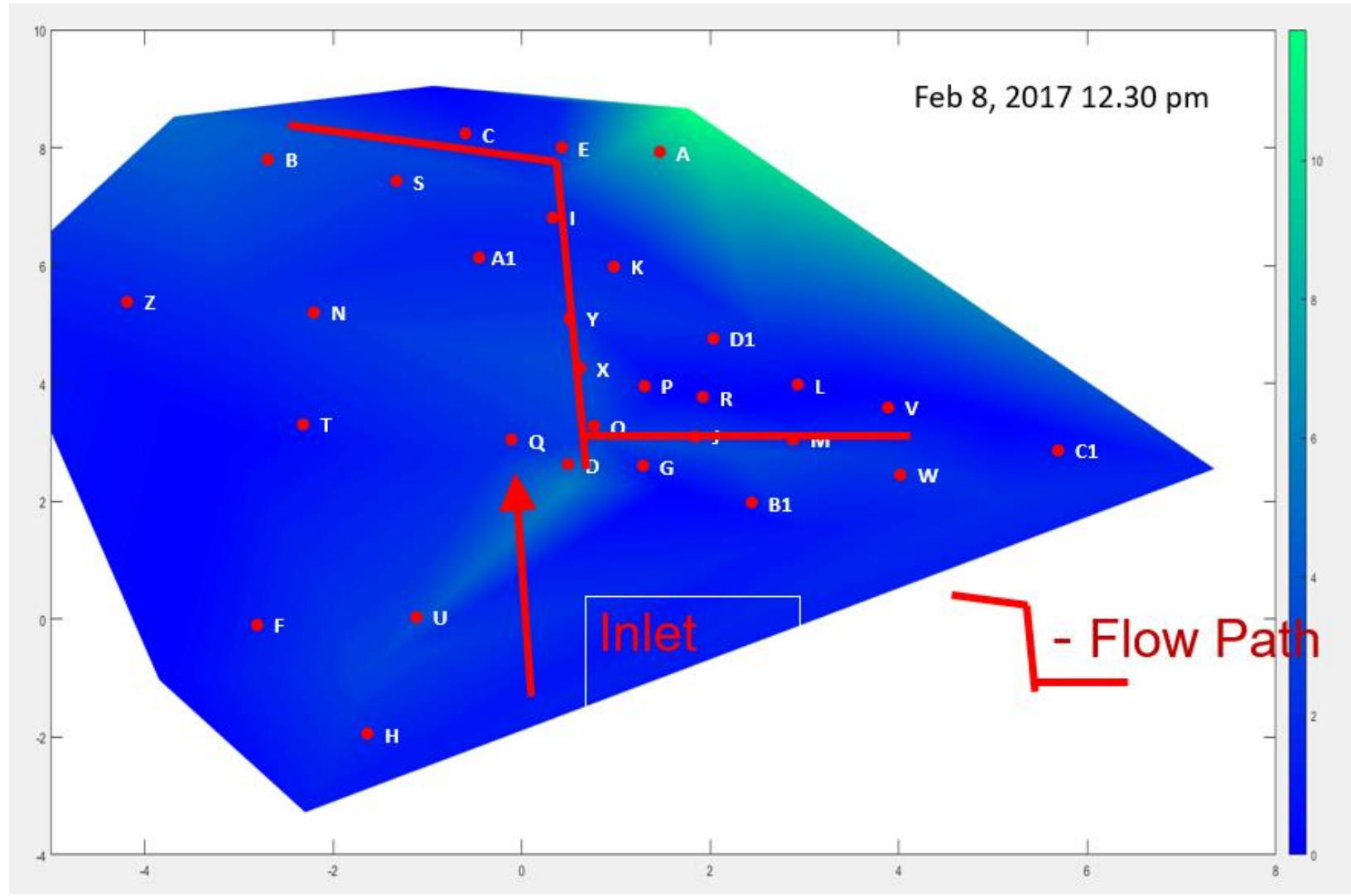

Figure 7-41: February 8, 2017 - Snow Depth

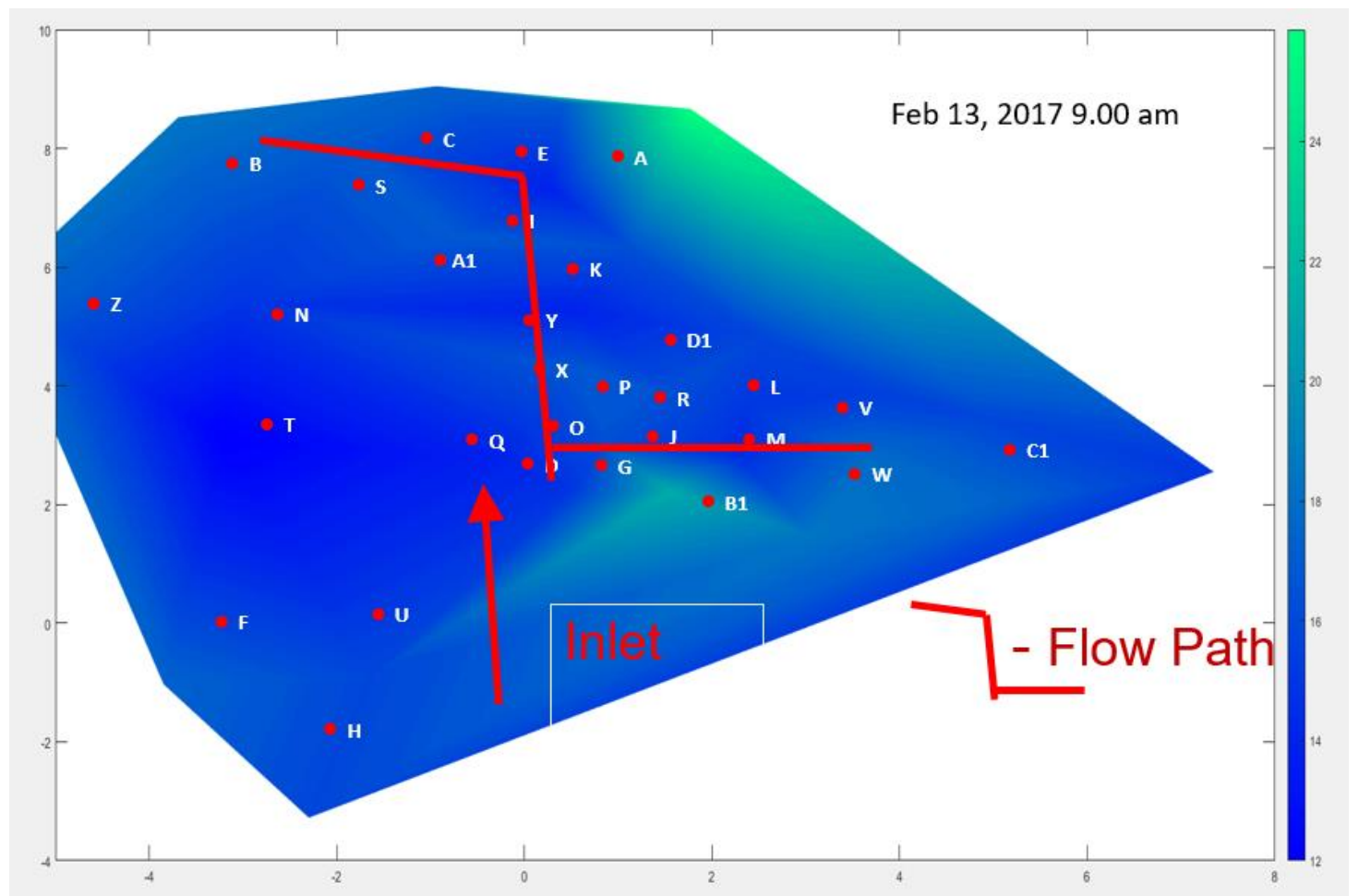

Figure 7-42: February 13, 2017 - Snow Depth 


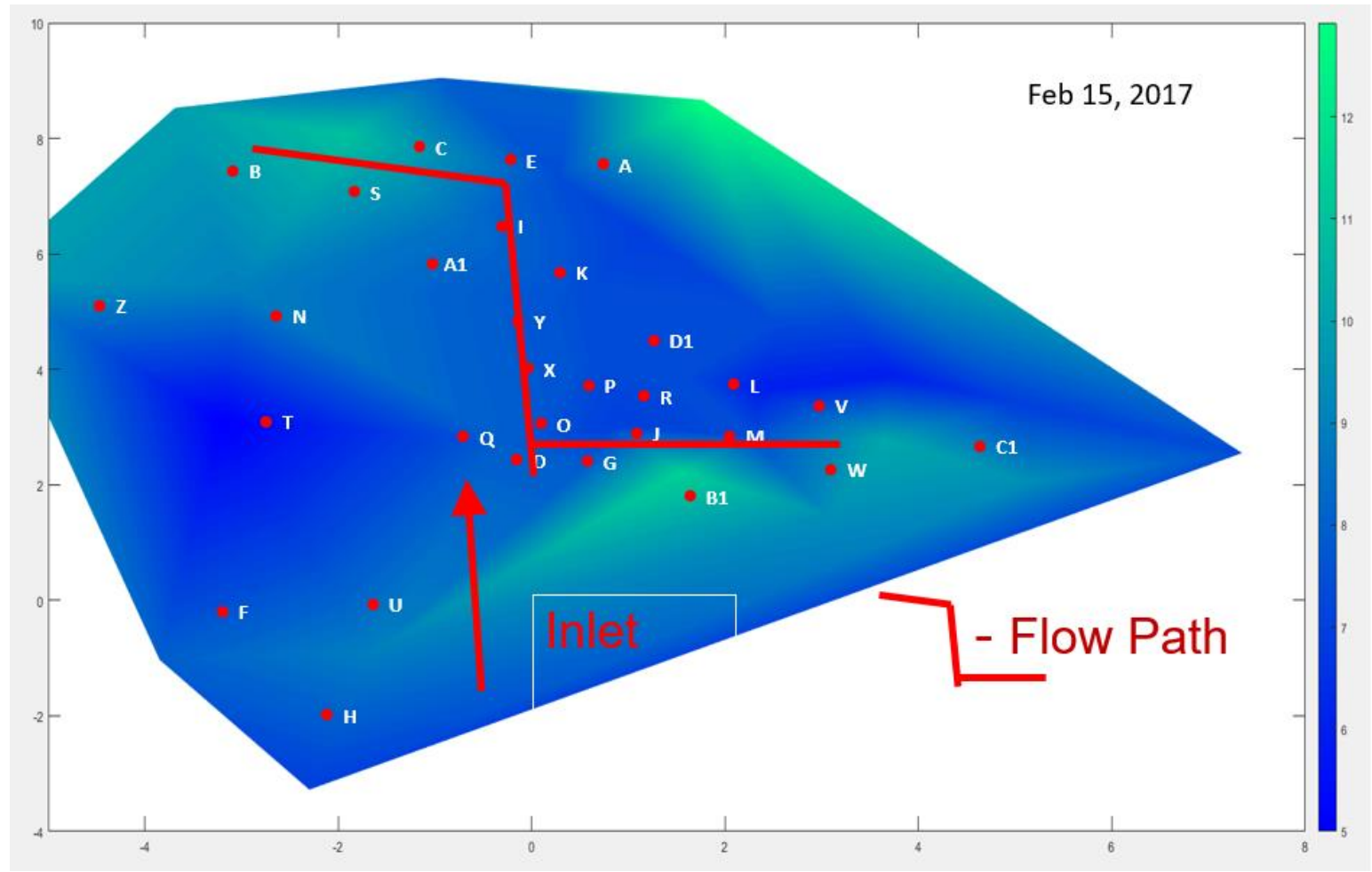

Figure 7-43: February 15, 2017 - Snow Depth

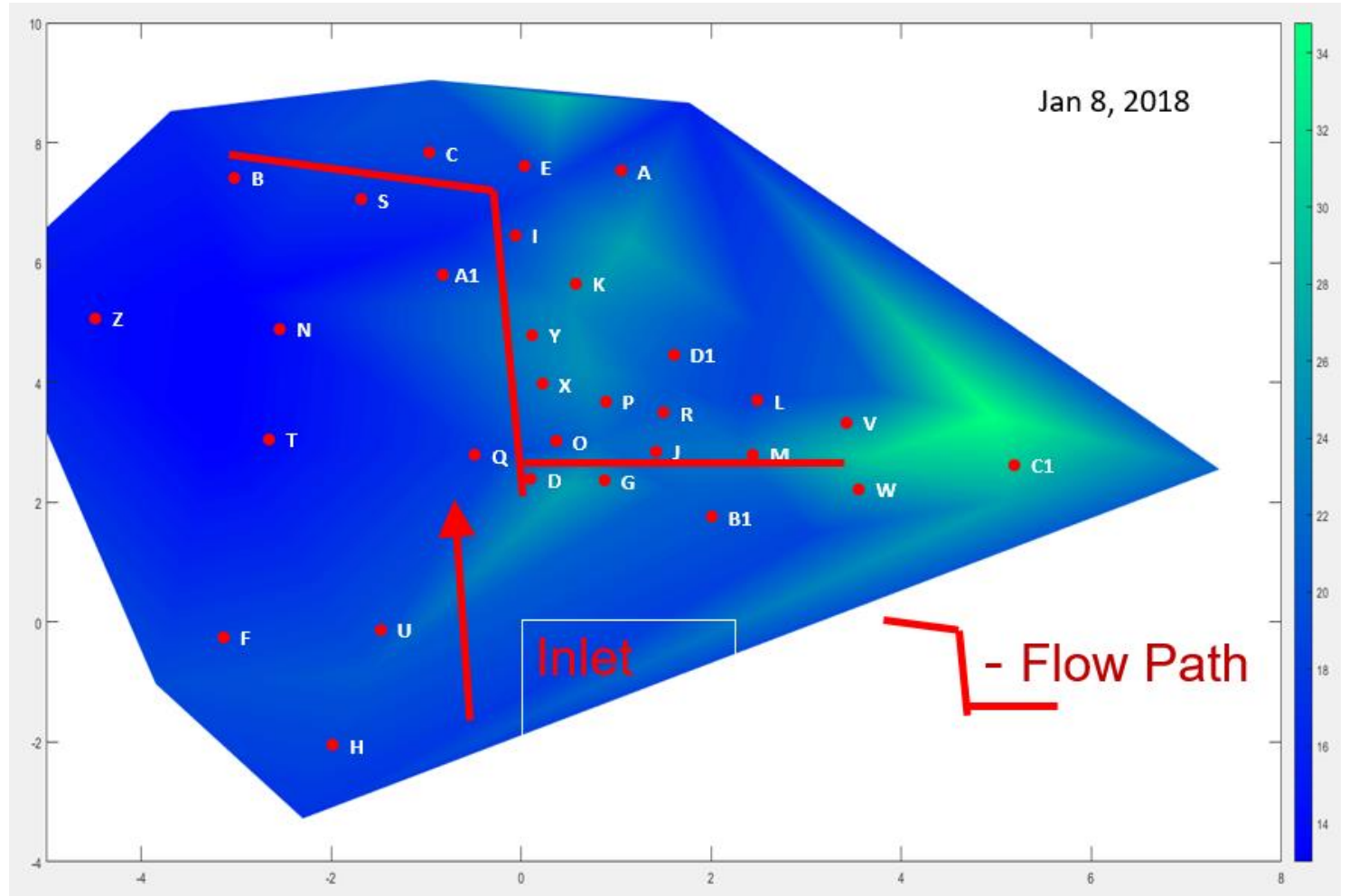

Figure 7-44: January 8, 2018 - Snow Depth 


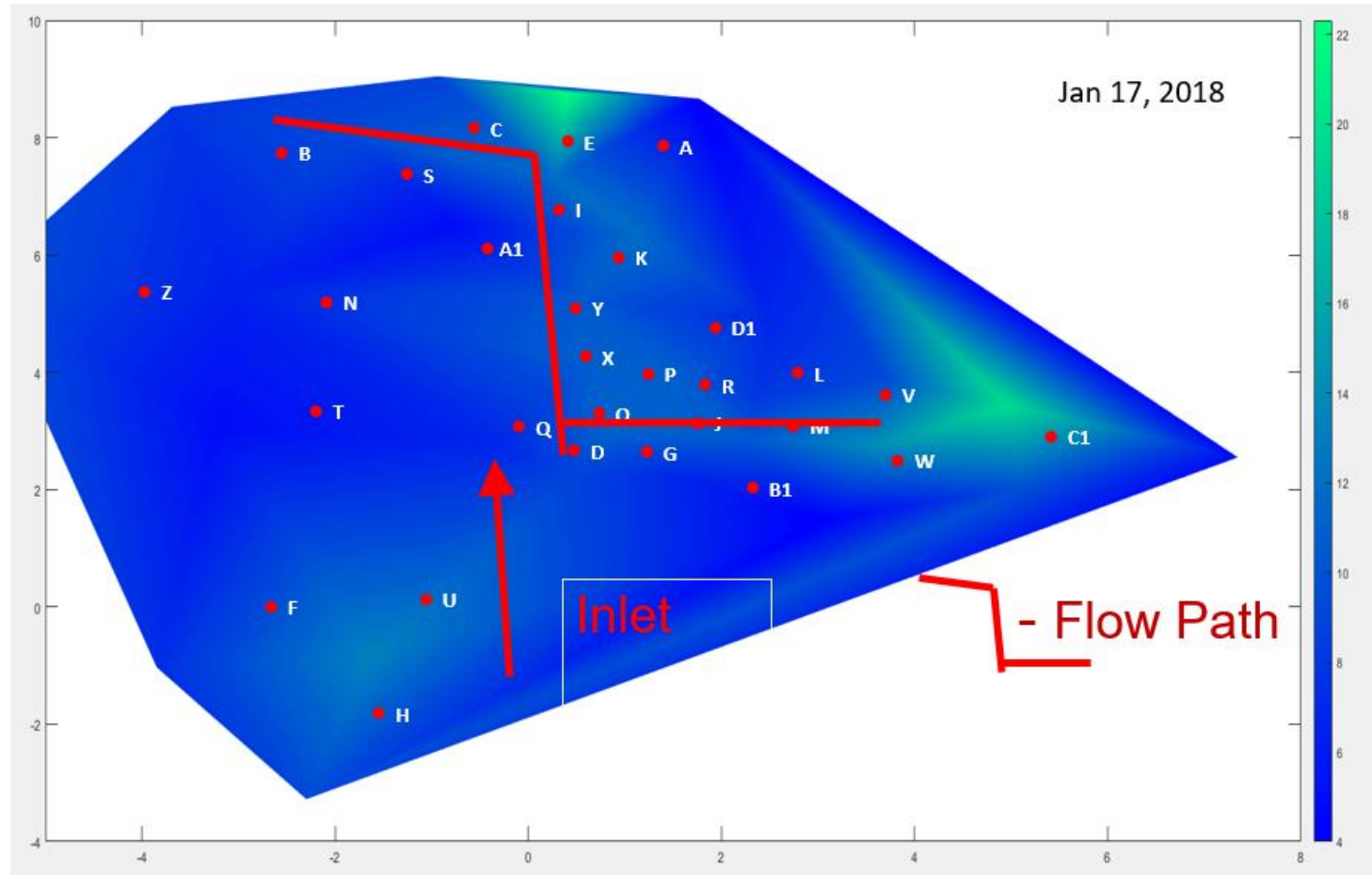

Figure 7-45: January 17, 2018 - Snow Depth

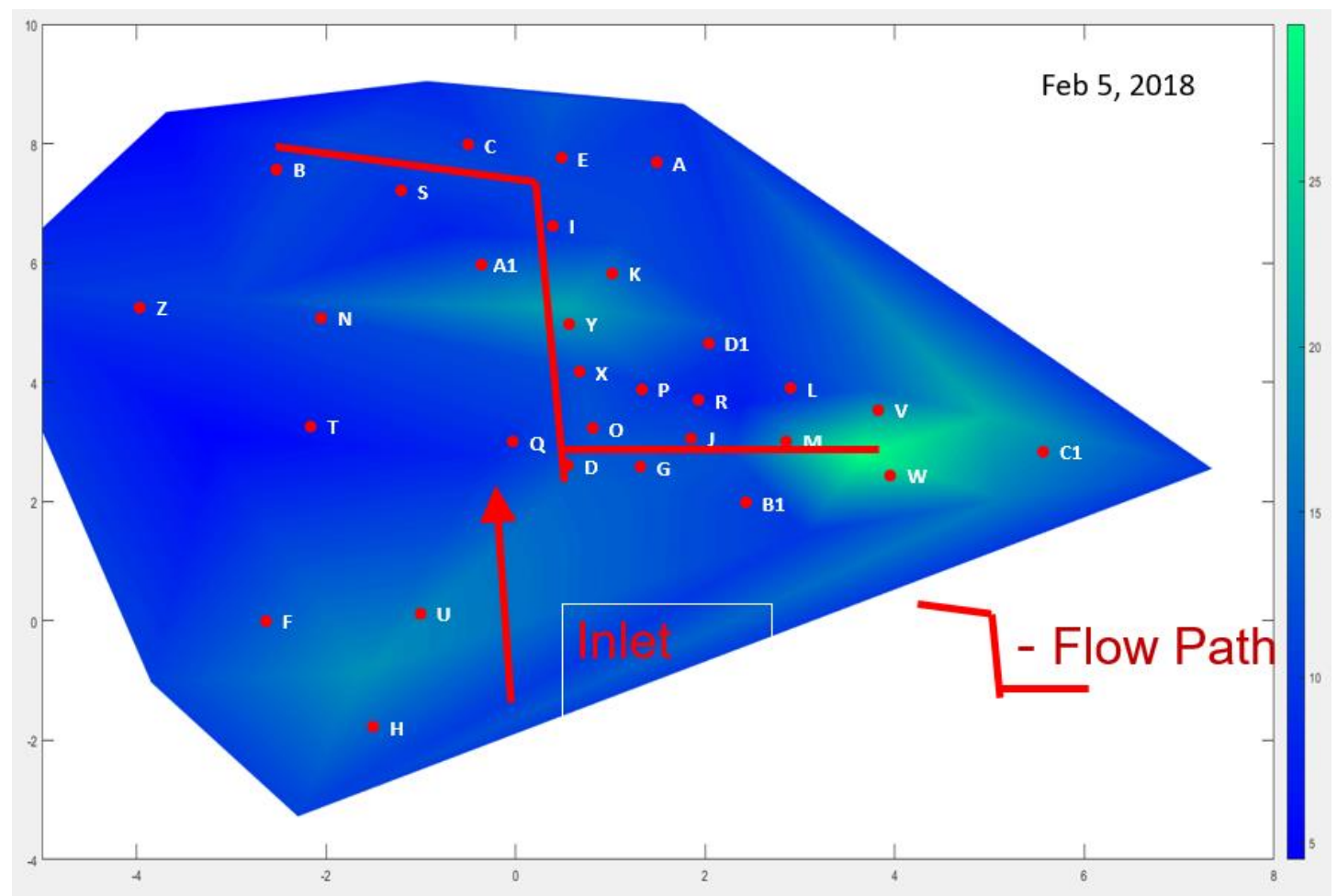

Figure 7-46: February 5, 2018 - Snow Depth 


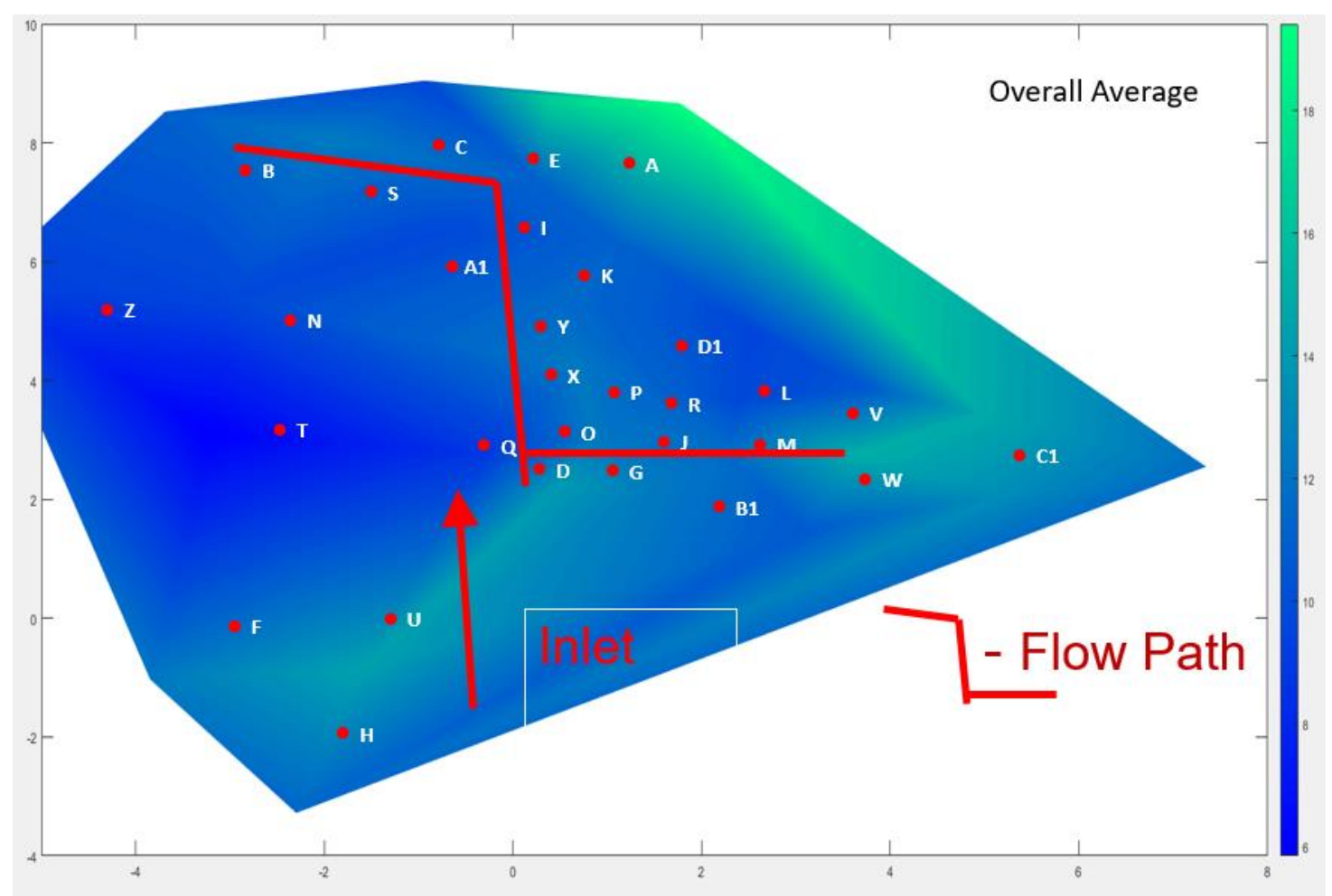

Figure 7-47: Overall Average - Snow Depth 